September 1999 • NREL/TP-540-25818

\title{
Light-Duty Alternative Fuel Vehicles: Federal Test Procedure Emissions Results
}

K. Kelly, L. Eudy, and T. Coburn

\section{ANREI \\ National Renewable Energy Laboratory}

1617 Cole Boulevard

Golden, Colorado 80401-3393

NREL is a U.S. Department of Energy Laboratory

Operated by Midwest Research Institute $\bullet$ Battelle $\bullet$ Bechtel

Contract No. DE-AC36-98-G010337 


\title{
Light-Duty Alternative Fuel Vehicles: Federal Test Procedure Emissions Results
}

\author{
K. Kelly, L. Eudy, and T. Coburn
}

Prepared under Task No. FU905010

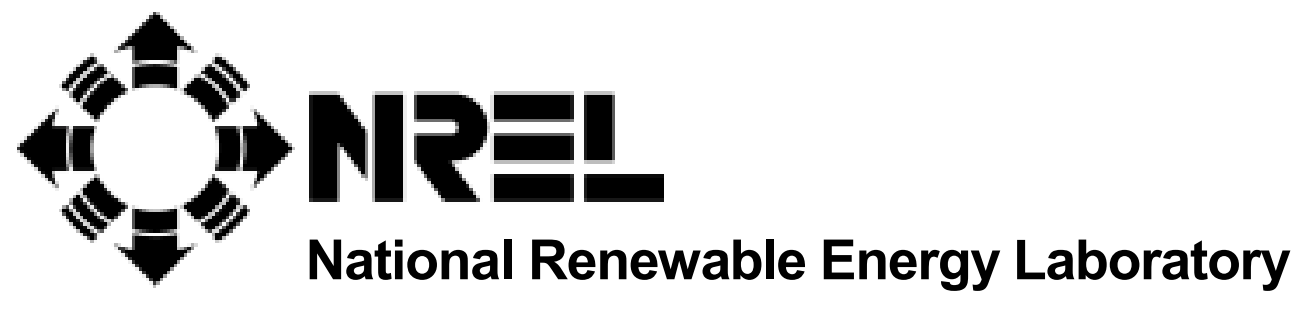

1617 Cole Boulevard

Golden, Colorado 80401-3393

NREL is a U.S. Department of Energy Laboratory

Operated by Midwest Research Institute • Battelle • Bechtel

Contract No. DE-AC36-98-G010337 


\section{ACKNOWLEDGMENTS}

This work was sponsored by the Office of Technology Utilization, which is part of the U.S. Department of Energy's (DOE) Office of Transportation Technologies in Washington, D.C. Mr. Dana O'Hara is DOE's program manager for the light-duty vehicle evaluation projects at the National Renewable Energy Laboratory. Appreciation is expressed to the three emissions laboratories that performed the testing: Environmental Research and Development, in Gaithersburg, Maryland; Automotive Testing Laboratory, in East Liberty, Ohio; and ManTech Environmental, in Denver, Colorado. We also thank Phillips Chemical Company and Compressed Gas Technologies for supplying the test fuels for this project.

\section{NOTICE}

This report was prepared as an account of work sponsored by an agency of the United States government. Neither the United States government nor any agency thereof, nor any of their employees, makes any warranty, express or implied, or assumes any legal liability or responsibility for the accuracy, completeness, or usefulness of any information, apparatus, product, or process disclosed, or represents that its use would not infringe privately owned rights. Reference herein to any specific commercial product, process, or service by trade name, trademark, manufacturer, or otherwise does not necessarily constitute or imply its endorsement, recommendation, or favoring by the United States government or any agency thereof. The views and opinions of authors expressed herein do not necessarily state or reflect those of the United States government or any agency thereof.

Available to DOE and DOE contractors from:

Office of Scientific and Technical Information (OSTI)

P.O. Box 62

Oak Ridge, TN 37831

Prices available by calling (423) 576-8401

Available to the public from:

National Technical Information Service (NTIS)

U.S. Department of Commerce

5285 Port Royal Road

Springfield, VA 22161

(703) 605-6000 or (800)-553-6847

or

DOE Information Bridge

http://www.doe.gov/bridge/home.html 


\section{CONTENTS}

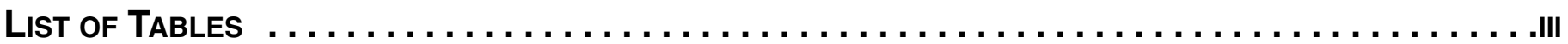

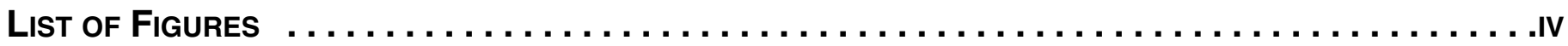

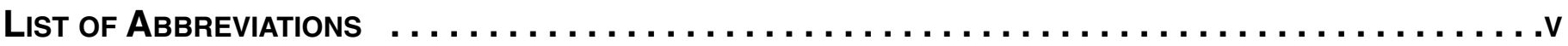

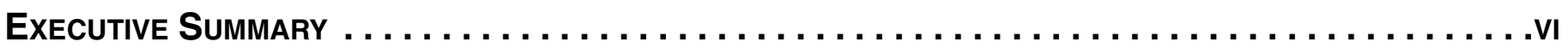

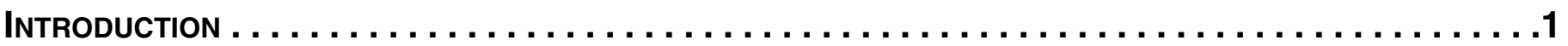

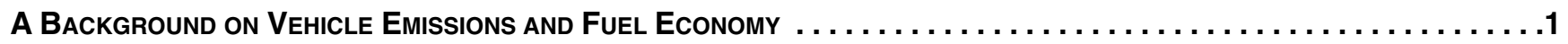

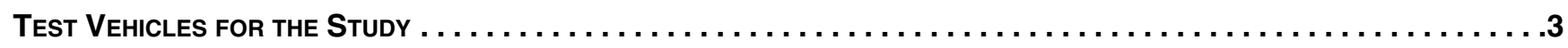

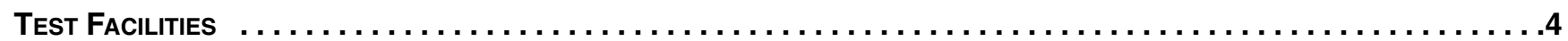

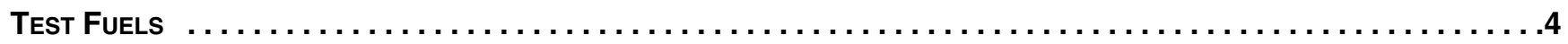

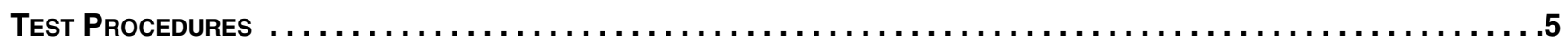

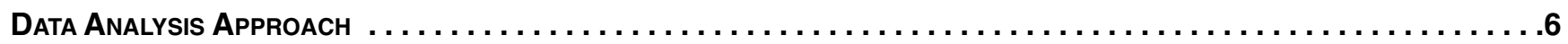

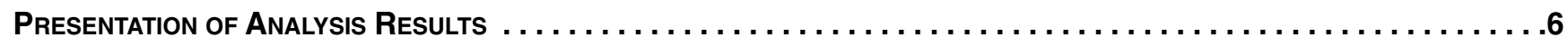

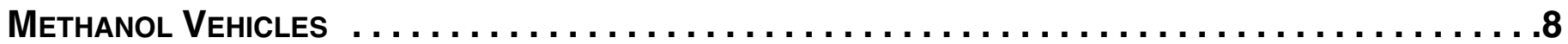

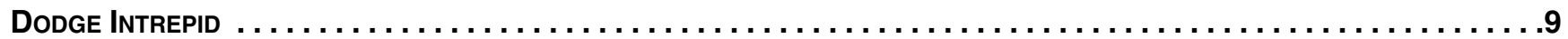

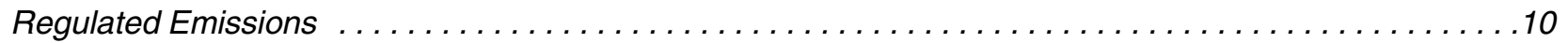

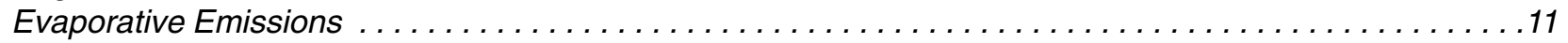

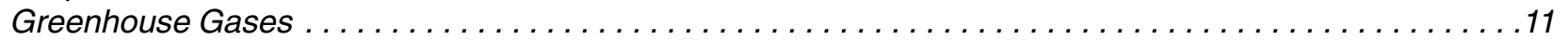

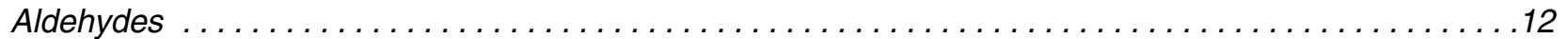

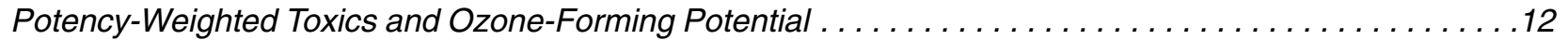

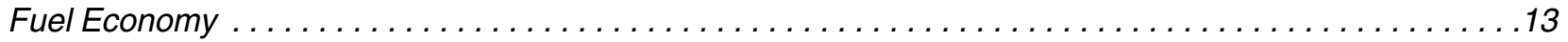

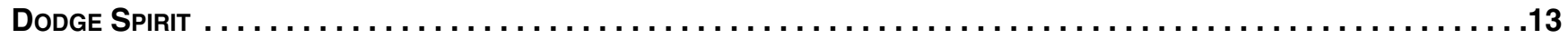

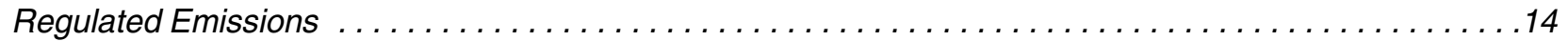

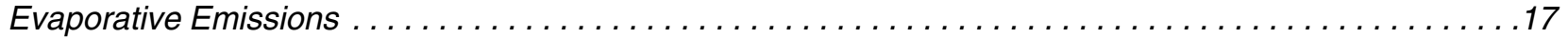

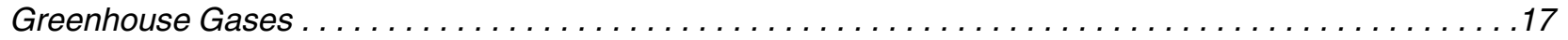

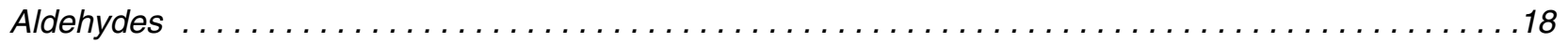

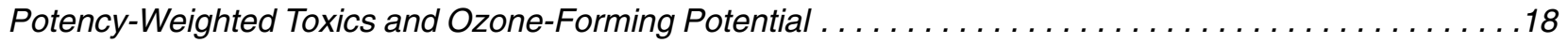

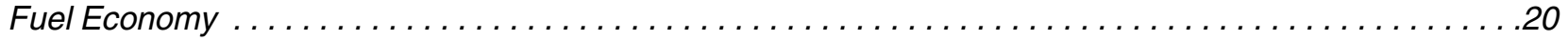

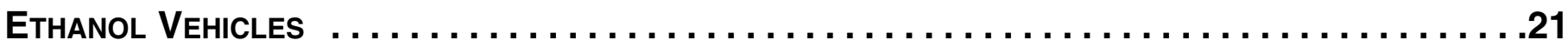

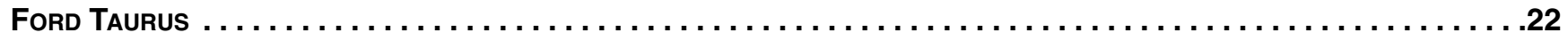

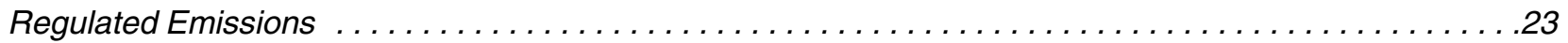

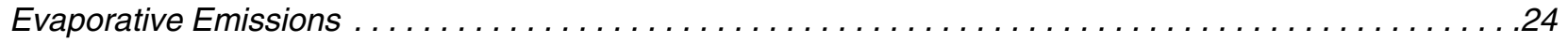

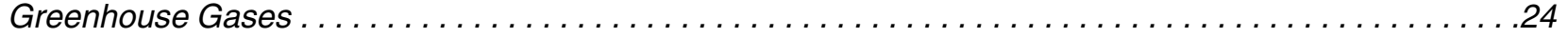

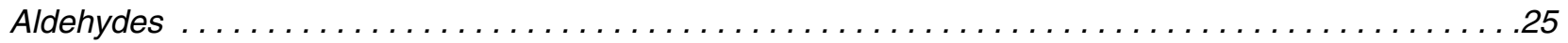

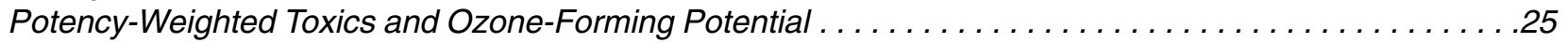

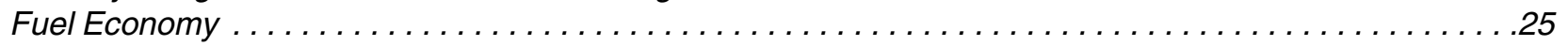

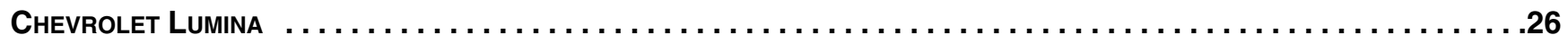

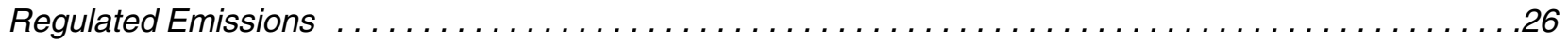

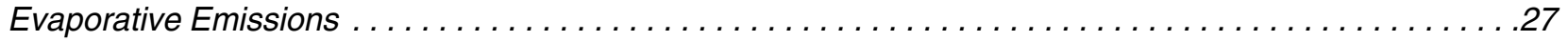

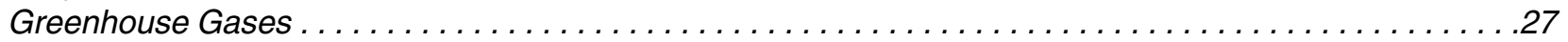

Aldehydes . . . . . . . . . . . . . . .

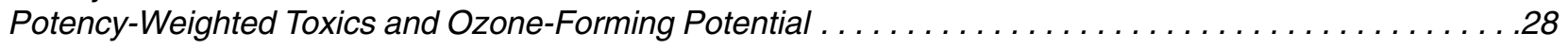




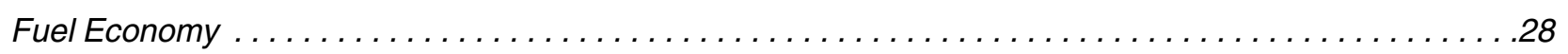

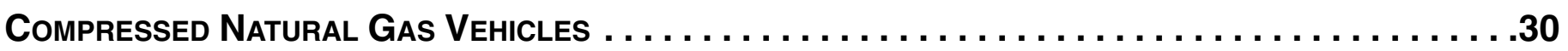

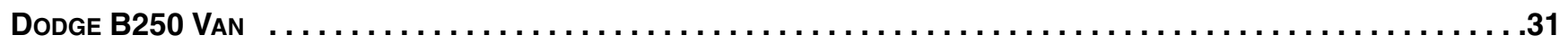

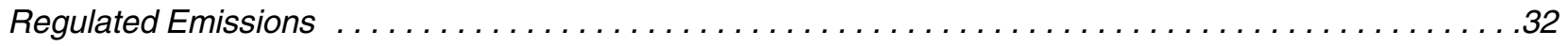

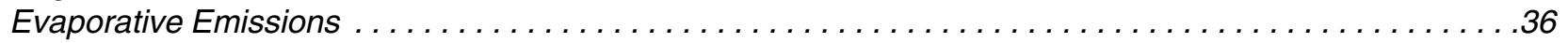

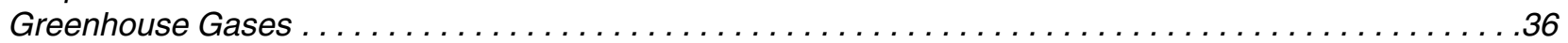

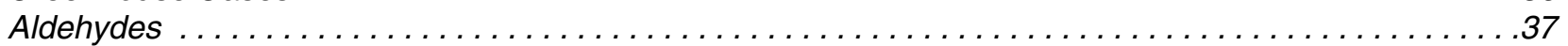

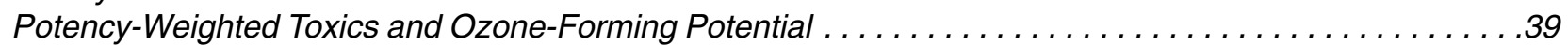

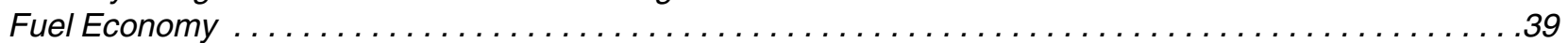

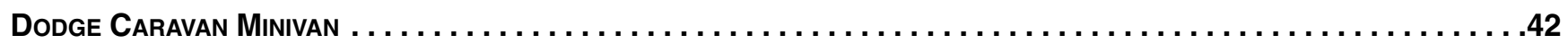

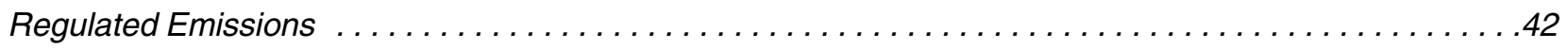

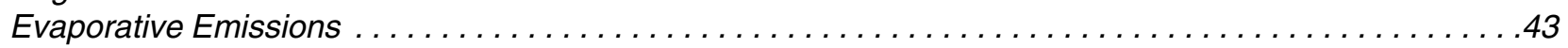

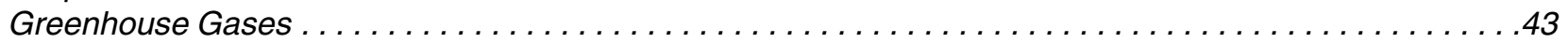

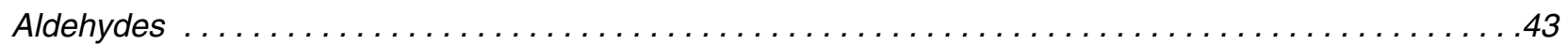

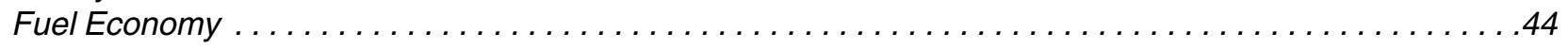

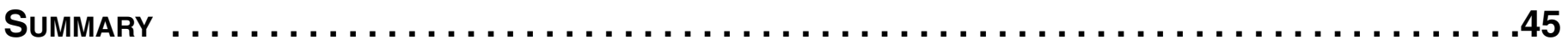

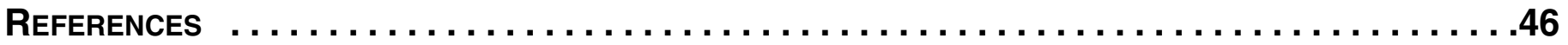

\section{ApPendices}

Appendix A - Emissions Data Sets

Appendix B - Speciated Compounds

Appendix C - Speciated Data Sets

Appendix D - Emissions Data Compilation, Editing, and Reduction and the Analysis of Variance Approach to Statistical Treatment 


\section{LIST OF TABLES}

Table 1. Intermediate Useful Life (5 years, 50,000 miles) Standards for Light-Duty Vehicles $(\mathrm{g} / \mathrm{mi}) \ldots \ldots \ldots \ldots \ldots$

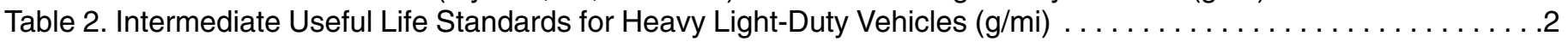

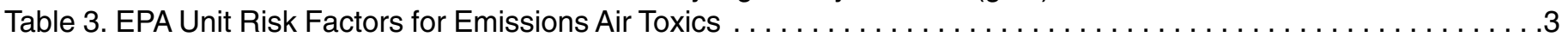

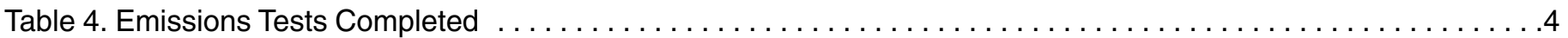

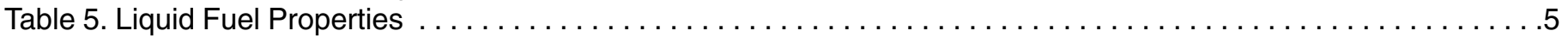

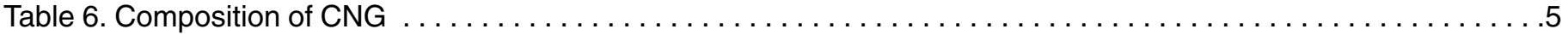

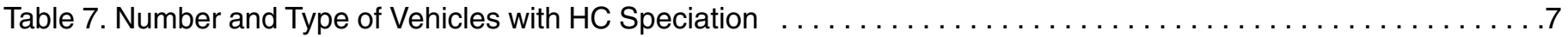
Table 8. Summary Comparison of Average Emission Results from M85 versus RFG $\ldots \ldots \ldots \ldots \ldots \ldots \ldots \ldots$ Table 9. Summary Comparison of Average Speciated Hydrocarbon Results from M85 versus RFG . . . . . . . . .9

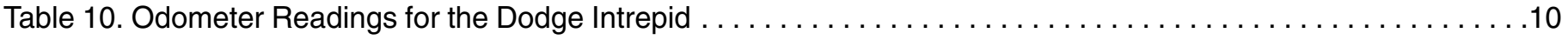

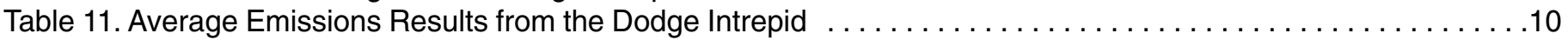

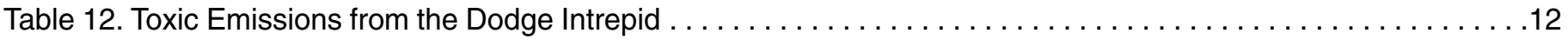

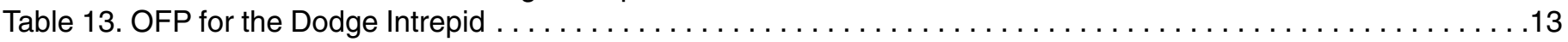

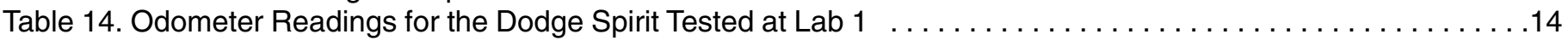

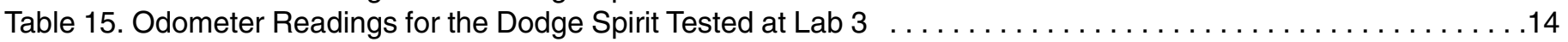
Table 16. Average Emissions Results from the Dodge Spirit Tested at Lab $1 \ldots \ldots \ldots \ldots \ldots \ldots \ldots \ldots \ldots \ldots \ldots$

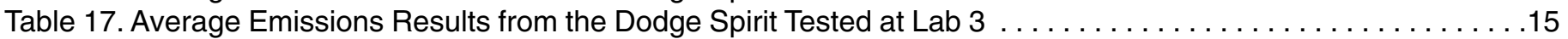

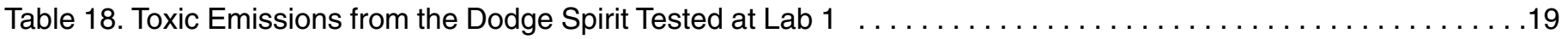

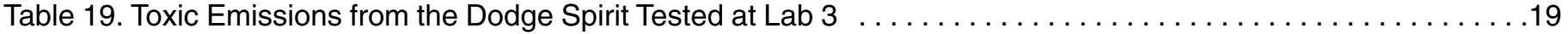

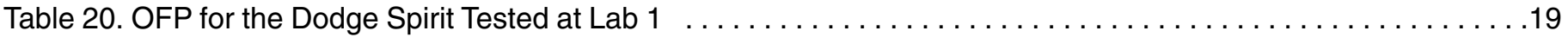

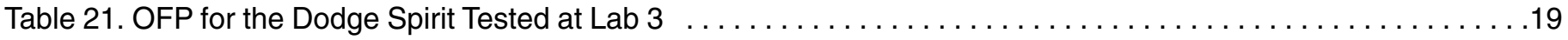
Table 22. Summary Comparison of Average Emission Results from E85 versus RFG $\ldots \ldots \ldots \ldots \ldots \ldots \ldots \ldots 21$ Table 23. Summary Comparison of Average Speciated Hydrocarbon Results from E85 versus RFG $\ldots \ldots \ldots \ldots .21$

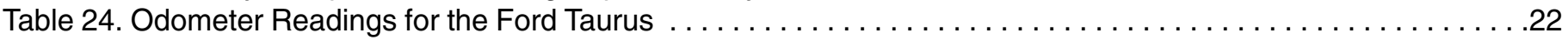

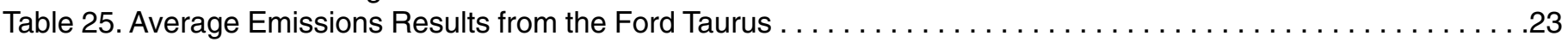

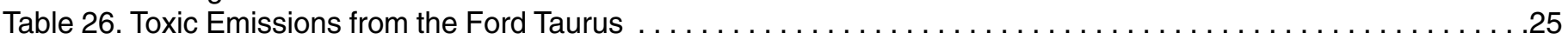

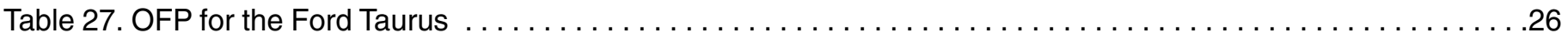

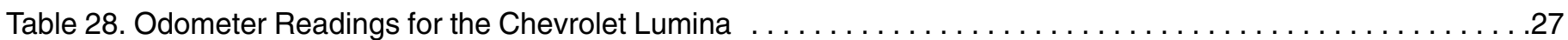
Table 29. Average Emissions Results from the Chevrolet Lumina $\ldots \ldots \ldots \ldots \ldots \ldots \ldots \ldots \ldots \ldots \ldots \ldots \ldots \ldots \ldots$

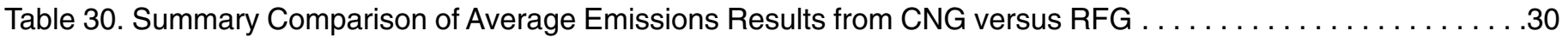
Table 31. Summary Comparison of Average Speciated Hydrocarbon Results from CNG versus RFG $\ldots \ldots \ldots \ldots 31$

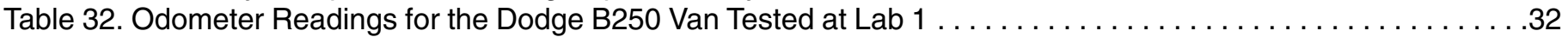

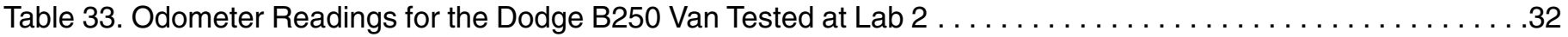

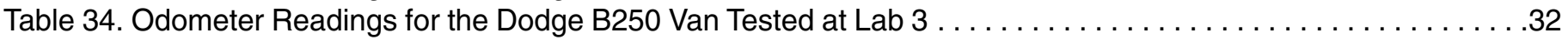
Table 35. Average Emissions Results from the Dodge B250 Van Tested at Lab $1 \ldots \ldots \ldots \ldots \ldots \ldots \ldots \ldots \ldots$

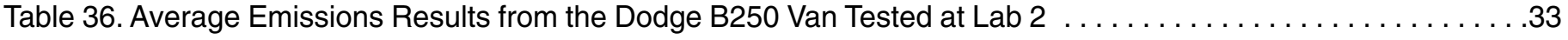
Table 37. Average Emissions Results from the Dodge B250 Van Tested at Lab $3 \ldots \ldots \ldots \ldots \ldots \ldots \ldots \ldots \ldots \ldots$

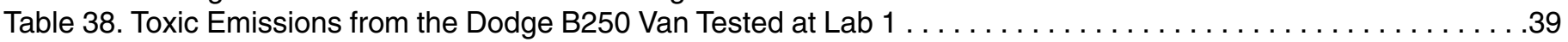

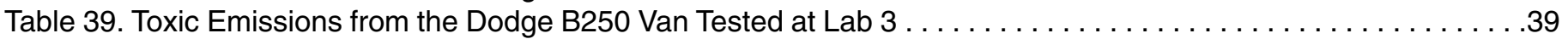

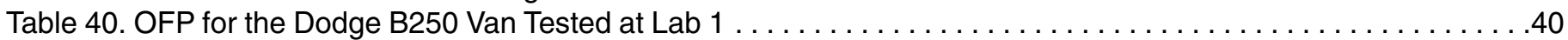

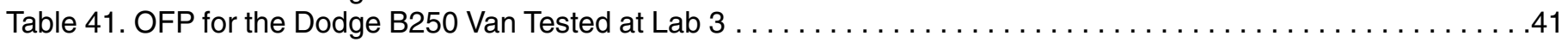

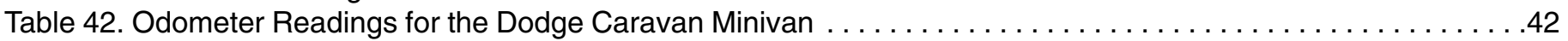
Table 43. Average Emissions Results from the Dodge Caravan Minivan $\ldots \ldots \ldots \ldots \ldots \ldots \ldots \ldots \ldots \ldots \ldots$ 


\section{LIST OF FIGURES}

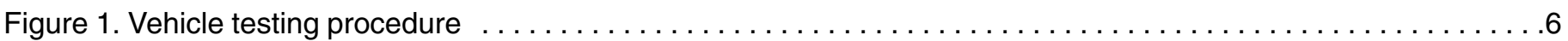

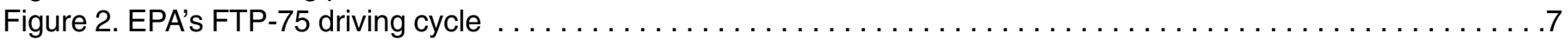

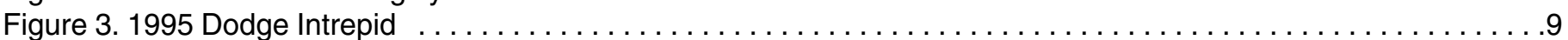

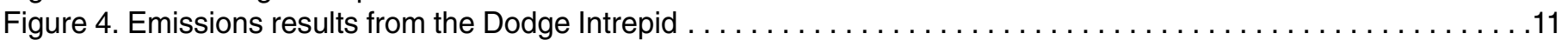

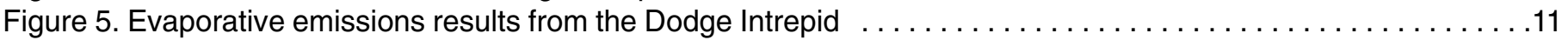

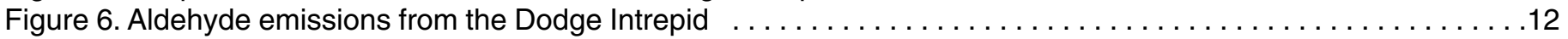

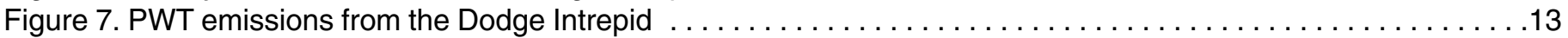

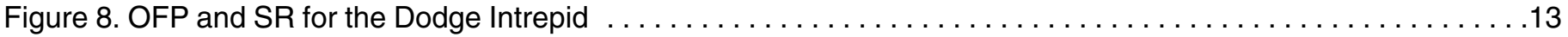

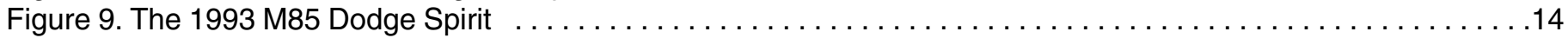

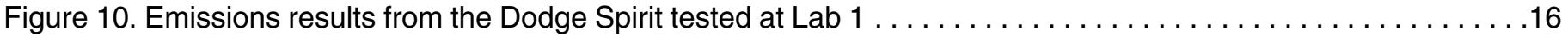

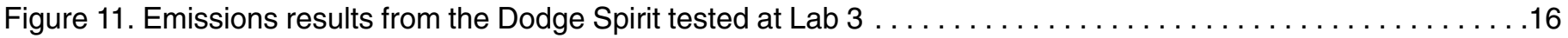

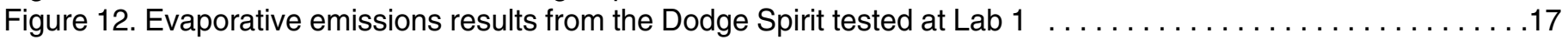

Figure 13. Evaporative emissions results from the Dodge Spirit tested at Lab $3 \ldots \ldots \ldots \ldots \ldots \ldots \ldots \ldots \ldots \ldots$

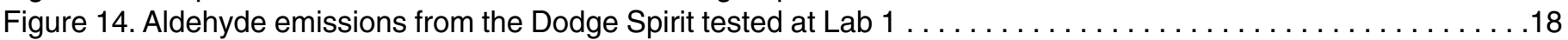

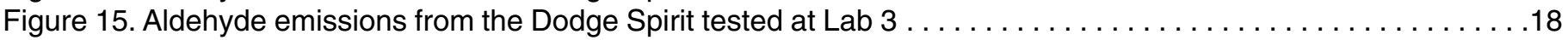

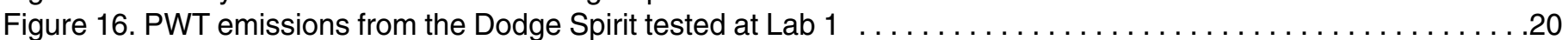

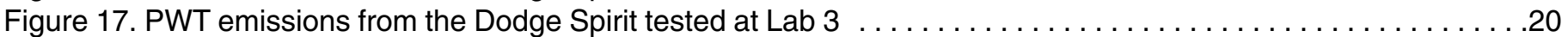

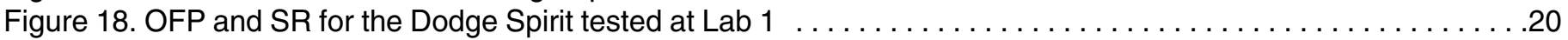

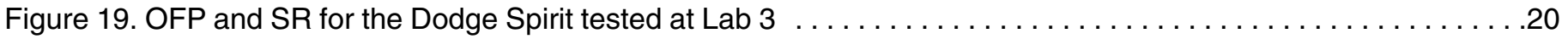

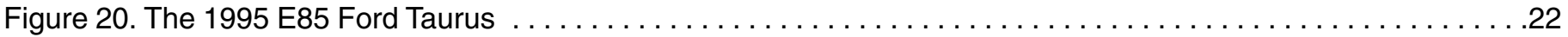

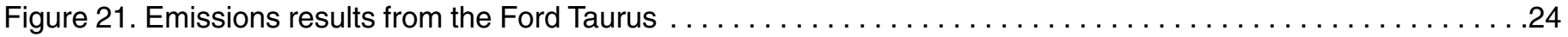

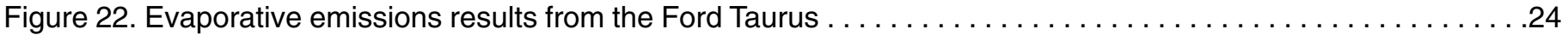

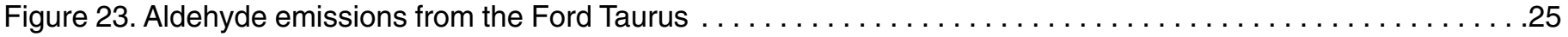

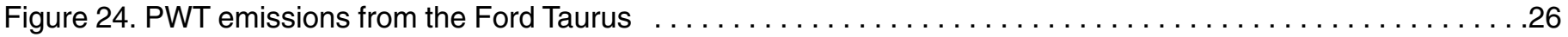

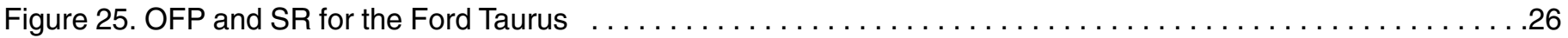

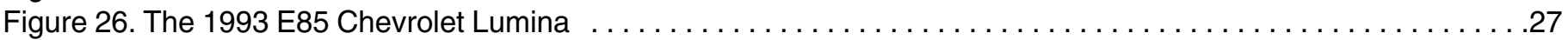

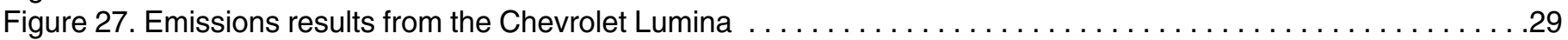

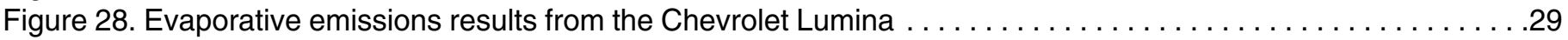

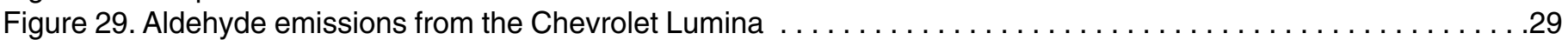

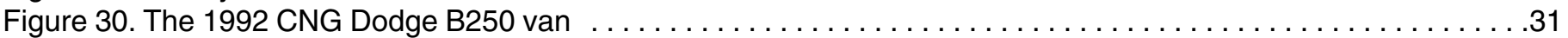

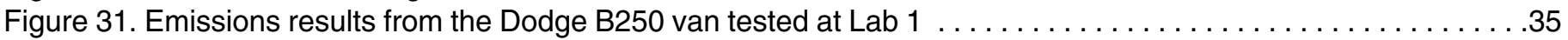

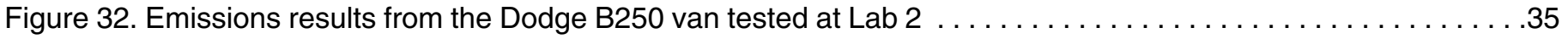

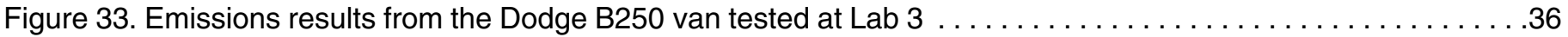

Figure 34. Evaporative emissions results from the Dodge B250 van tested at $\mathrm{Lab} 1 \ldots \ldots \ldots \ldots \ldots \ldots \ldots \ldots$

Figure 35. Evaporative emissions results from the Dodge B250 van tested at $\mathrm{Lab} 2 \ldots \ldots \ldots \ldots \ldots \ldots \ldots \ldots$

Figure 36. Evaporative emissions results from the Dodge B250 van tested at $\mathrm{Lab} 3 \ldots \ldots \ldots \ldots \ldots \ldots \ldots \ldots \ldots$

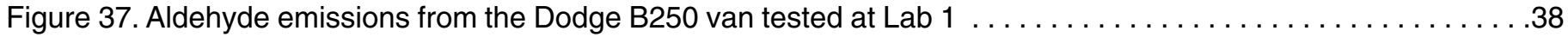

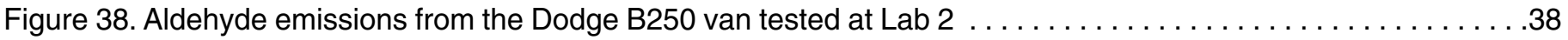

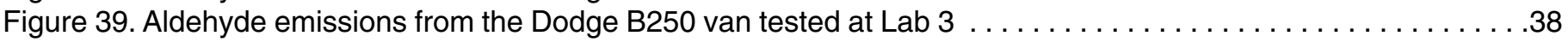

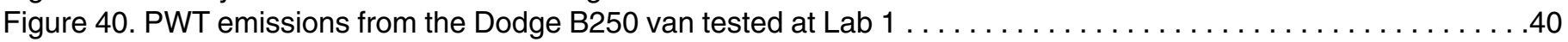

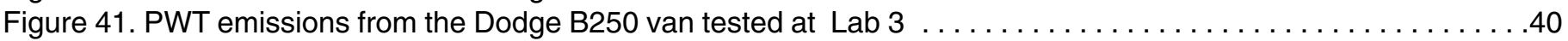

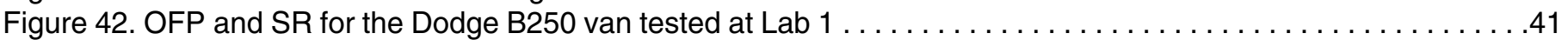

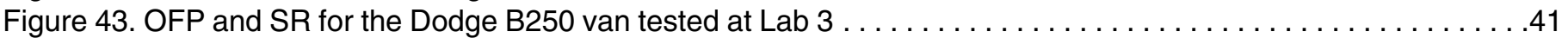

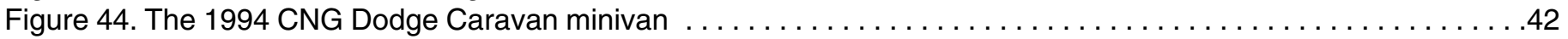

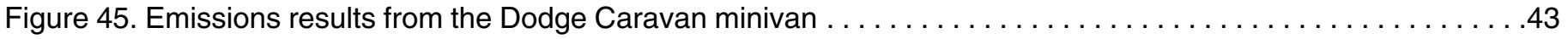

Figure 46. Evaporative emissions results from the Dodge Caravan minivan $\ldots \ldots \ldots \ldots \ldots \ldots \ldots \ldots \ldots \ldots \ldots$

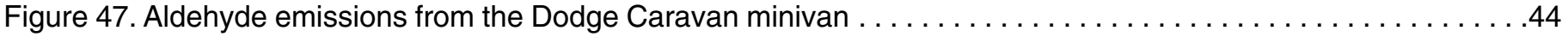




\section{List of AbBreviations}

\begin{tabular}{|c|c|}
\hline AFDC & Alternative Fuels Data Center \\
\hline AFV & alternative fuel vehicle \\
\hline AMFA & Alternative Motor Fuels Act of 1988 \\
\hline ANOVA & analysis of variance \\
\hline AQIRP & Air Quality Improvement Research Program \\
\hline Btu & British thermal unit \\
\hline $\mathrm{C}_{4} \mathrm{H}_{6}$ & chemical formula for 1,3-butadiene \\
\hline $\mathrm{C}_{6} \mathrm{H}_{6}$ & chemical formula for benzene \\
\hline $\mathrm{CH}_{3} \mathrm{CHO}$ & chemical formula for acetaldehyde \\
\hline $\mathrm{CH}_{4}$ & chemical formula for methane \\
\hline $\mathrm{CNG}$ & compressed natural gas \\
\hline $\mathrm{CO}$ & carbon monoxide \\
\hline $\mathrm{CO}_{2}$ & carbon dioxide \\
\hline DOE & Department of Energy \\
\hline E85 & ethanol fuel ( $85 \%$ ethanol, $15 \%$ gasoline) \\
\hline EPA & Environmental Protection Agency \\
\hline EPAct & Energy Policy Act of 1992 \\
\hline FFV & flexible-fuel vehicle \\
\hline FTP & Federal Test Procedure \\
\hline gge & gallon gasoline equivalent \\
\hline GSA & General Services Administration \\
\hline $\mathrm{HC}$ & hydrocarbons \\
\hline $\mathrm{HCHO}$ & chemical formula for formaldehyde \\
\hline LEV & low-emission vehicle \\
\hline M85 & methanol fuel ( $85 \%$ methanol, $15 \%$ gasoline) \\
\hline MIR & maximum incremental reactivity \\
\hline mpeg & miles per equivalent gallon \\
\hline NMHC & non-methane hydrocarbons \\
\hline NMHCE & non-methane hydrocarbon equivalent \\
\hline NMOG & non-methane organic gases \\
\hline $\mathrm{NO}_{\mathrm{x}}$ & oxides of nitrogen \\
\hline NREL & National Renewable Energy Laboratory \\
\hline OEM & original equipment manufacturer \\
\hline OFP & ozone-forming potential \\
\hline PWT & potency-weighted toxics \\
\hline RFG & California Phase II reformulated gasoline \\
\hline $\operatorname{scf}$ & standard cubic foot \\
\hline SR & specific reactivity \\
\hline THC & total hydrocarbons \\
\hline TLEV & transitional low-emission vehicle \\
\hline ULEV & ultra-low emission vehicle \\
\hline
\end{tabular}




\section{EXeCUtIVE SummarY}

In 1988, the federal government enacted the Alternative Motor Fuels Act (AMFA) to encourage the development and use of methanol, ethanol, and natural gas as transportation fuels for consumers. This was followed by the Clean Air Act Amendments (CAAA) in 1990 and the Energy Policy Act (EPAct) in 1992. As part of AMFA and EPAct, the Department of Energy (DOE) is required to promote the use of alternative fuels to address environmental concerns and energy security. As a result of these federal actions and the lack of conclusive information on in-use emissions from alternative fuel vehicles (AFVs), DOE, through the National Renewable Energy Laboratory (NREL), conducted an extensive series of emissions tests on AFVs being used in the federal government fleet.

The goal of the NREL emissions testing program was to provide a high quality, objective assessment of the in-use emissions from commercially available AFVs. This report summarizes the results from 1,280 emissions tests performed on 413 vehicles between 1994 and 1997, including tests on methanol and ethanol flexiblefuel vehicles (FFVs), dedicated compressed natural gas (CNG) vehicles, and matching standard gasoline vehicles. Many vehicles were tested several times at approximately 1-year intervals. The data sets for each year are referred to as test "rounds." All tests followed the U.S. Environmental Protection Agency's (EPA) existing Federal Test Procedures (FTP-75) for emissions certification. Measurement of regulated emissions included nonmethane hydrocarbons (NMHC), carbon monoxide $(\mathrm{CO})$, oxides of nitrogen $\left(\mathrm{NO}_{\mathrm{x}}\right)$, and evaporative hydrocarbons. Measurements of non-regulated emissions included formaldehyde (HCHO), acetaldehyde $\left(\mathrm{CH}_{3} \mathrm{CHO}\right)$, carbon dioxide $\left(\mathrm{CO}_{2}\right)$, and methane $\left(\mathrm{CH}_{4}\right)$. The vehicles tested were original equipment manufacturer (OEM) models taken from the pool of vehicles used in the General Service Administration's (GSA) federal fleet. The testing was performed at private emissions laboratories in Ohio, Colorado, and Maryland. Each laboratory used the EPA's FTP-75 for exhaust emissions and evaporative emissions with test fuels that were blended specifically for this program. The gasoline fuel that was used for comparison was California Phase II reformulated gasoline (RFG). This fuel was chosen in order to make a comparison between alternative fuel emissions and a "best case" scenario for gasoline. One might expect that the comparison of emissions between alternative fuels and an industry average gasoline would be slightly more favorable for alternative fuels than the comparison in this report because RFG is a cleaner burning fuel than the industry average gasoline. Several vehicles were randomly selected for more extensive tests that included detailed analysis of the hydrocarbon emissions. The test results were used to assess differences in the composition of hydrocarbon emissions in terms of their relative toxicity and reactivity or propensity to form ozone in the atmosphere.
In general, this study found that fuel is an important factor in vehicle emissions. However, the study also shows that vehicle-to-vehicle variability is significant, and that engine and emissions controls system design and calibration are also critical factors. In other words, the fuel is important, but individual vehicle differences (resulting from, for example, manufacturing tolerances, vehicle service history, or duty cycle) and vehicle model design differences also play a major role in the measured emissions reductions.

A comparison of the regulated emissions from the FFVs tested on alcohol fuels and RFG tended to fall into one of two categories:

(1) Compared to RFG, the alcohol emissions showed a decrease for one or two of the regulated emissions constituents coupled with an increase in the other constituents, or

(2) There was no significant difference in the emissions from the two test fuels.

In both cases, the average results tended to be well within the applicable emissions standards. The lack of a clear benefit in regulated emissions for the alcohol tests may be a result of FFV design. FFVs are designed to meet customer performance and emissions certification requirements on any blend of alcohol and gasoline from $85 \%$ alcohol with $15 \%$ gasoline up to $100 \%$ gasoline. This design strategy allowed FFVs to be placed in the market with only a limited 
alcohol refueling infrastructure, but it required compromises to be made in engine design and calibration. For example, FFVs cannot take advantage of the higher octane rating of alcohol fuel because they must be designed to accommodate the lowest octane rating of all possible fuel blends (i.e., $100 \%$ gasoline). Other studies have shown that more substantial emissions benefits can be achieved from a vehicle that has been optimized to run on a single blend of alcohol fuel ${ }^{1}$.

Two areas where the alcohol fuel emissions did show clear advantages over RFG were in reducing the toxicity and the ozone-forming potential (OFP) of the hydrocarbon emissions. It could be expected that these benefits would be even more pronounced if a comparison were made to industry average gasoline, because RFG has been shown to reduce emissions of toxic constituents and be less reactive in forming ozone ${ }^{2}$. Tests on the alcohol fuels also showed a small but consistent reduction in $\mathrm{CO}_{2}$ emissions compared to RFG tests.

Comparison of the average results from the CNG vehicles tended to be more straightforward. The dedicated CNG vehicles tested in this program exhibited significantly lower regulated emissions compared to similar gasoline vehicles tested on RFG. The toxicity and reactivity of the hydrocarbon emissions from $\mathrm{CNG}$ vehicles were also significantly lower.

The rapid development of emissions control technology continues, pushed by tougher regulations designed to help meet the National Ambient Air Quality Standards of the CAAA. The results presented here are representative of the alternative fuel technologies that were available during the study (1992 to 1995). More recent developments include both alternative fuel and gasoline vehicle designs that have been shown to meet more stringent emissions standards such as the state of California's ultra lowemission vehicle (ULEV) requirements. Dedicated CNG vehicles have recently been produced that advertise super-ULEV (or 1/10 below ULEV) capabilities. At the same time, auto manufacturers are producing bi-fuel $\mathrm{CNG}$ /gasoline vehicles that may run into similar design constraints as the FFVs (i.e., compromises are required to allow an engine to run on different fuels). Emissions certification tests have also evolved to address issues such as cold temperature emissions, emissions resulting from real-world or more aggressive driving behaviors, extended and running loss evaporative emissions, and emissions during operation of the vehicle's air conditioner. These changes may affect the comparison of emissions from alternative fuel to gasoline vehicles. The ability for AFVs to maintain emissions benefits at high mileage is also a question. Most of the AFVs in the federal fleet do not accumulate high mileage levels. Some of these issues are being addressed in other parts of this DOE/NREL program, and will be covered separately.

\section{SummaRY OF RESULTS}

\section{Methanol}

One-hundred and one M85 FFVs, including 1995 Dodge Intrepids and 1993 Dodge Spirits, were tested along with similar numbers of standard gasoline control vehicles. Most of the results from these vehicles were very consistent across vehicle models, test laboratories and test rounds. Non-methane hydrocarbon equivalent (NMHCE), $\mathrm{CH}_{4}$, and $\mathrm{CO}_{2}$ were significantly lower for the M85 tests than for the tests on RFG.

Results for $\mathrm{NO}_{\mathrm{x}}, \mathrm{CO}$, and evaporative emissions were not as consistent. Although CO emissions were slightly higher for one vehicle model and were lower for the other model tested, these results tended to be not statistically significant. $\mathrm{NO}_{\mathrm{x}}$ results tended to be higher for the FFVs tested on M85 than when those same vehicles were tested on RFG. The evaporative emissions results for one vehicle model were consistently higher for the M85 tests; results for the other model were varied. Fuel economy for the M85 tests was significantly lower than the gasoline tests because of the lower energy content of the fuel, but was slightly higher when compared on an energy equivalent basis. Results for the more detailed tests show that both vehicle models tested on M85 emit significantly less potencyweighted toxics (PWT), and the OFP and specific reactivity is lower.

There are several possible reasons for finding mixed results and fuel effects that are not statistically significant for FFVs. One is that these vehicles are not optimized for either alcohol fuel or gasoline, but are designed to perform acceptably on a wide range of fuel blends. Another reason for varying results is calibration and hardware differences between vehicle models.

\section{Ethanol}

Forty-nine E85 FFVs, including the 1995 Ford Taurus and the 1993 Chevrolet Lumina, were tested along with similar numbers of standard gasoline control vehicles. The regulated emissions results for the two ethanol FFV models were not as consistent as the methanol results. In general, the regulated emissions from the FFV Taurus tested on E85 were not significantly different from emissions from the same vehicles tested on RFG. For the FFV Lumina, the $\mathrm{NO}_{\mathrm{x}}$ emissions were significantly lower on E85, the $\mathrm{CO}$ emissions were significantly higher, and the hydrocarbon emissions were mixed 
from round to round (total hydrocarbon and NMHCE). Non-regulated emissions for both vehicle models tested tended to be consistent, and the differences tended to be statistically significant. Average $\mathrm{CO}_{2}$ was consistently lower when tested on E85 compared to RFG. Average aldehydes were consistently higher from the E85 test compared to the RFG tests.

When comparing the FFVs tested on E85 to the same vehicles tested on RFG, results of the detailed hydrocarbon analysis showed that average aldehyde emissions and OFP tended to be higher, while average 1,3-butadiene, benzene, total PWT, and specific reactivity tended to be significantly lower.

As with the methanol vehicles, the ethanol vehicles are flexible-fuel designs that are not optimized for either gasoline or ethanol. The differences in results between vehicle models and the lack of clear differences in regulated emission results may be due, in part, to engine hardware choices and calibrations that must be flexible to accommodate a wide range of fuel blends.

\section{Compressed Natural Gas}

In all, 67 dedicated CNG vehicles (1992/94 Dodge B250 vans and 1994 Dodge Caravans) were tested along with 69 similar gasoline control vehicles. Results for the CNG vehicles show that there tend to be statistically significant differences between the average emissions from the $\mathrm{CNG}$ and RFG tests, and that these results tend to be fairly consistent for both vehicle models from lab to lab and from round to round. The average NMHC, $\mathrm{CO}, \mathrm{CO}_{2}$, and acetaldehyde results were significantly lower from the CNG tests than from the RFG tests. Average $\mathrm{CH}_{4}$ emissions were consistently higher from $\mathrm{CNG}$ than from
RFG. $\mathrm{NO}_{\mathrm{x}}$ and "evaporative" hydrocarbons tended to be lower from the CNG tests, but in some cases the differences were not significant. A modified "evaporative" emissions test was performed to measure the hydrocarbons emanating from the vehicles during two 1-hour soaks in a sealed enclosure with the engine off. Dedicated gaseous fuel vehicles typically do not have evaporative control systems because the fuel system is said to be "sealed" under pressure. Nevertheless, hydrocarbons (mostly methane) were found emanating from gaseous fuel vehicles. In all cases, the average total hydrocarbons measured during the $\mathrm{CNG}$ evaporative tests were lower than those from the RFG tests, but in a few cases the difference was not statistically significant. The fuel economy results for the $\mathrm{CNG}$ vehicles were lower than those of the gasoline vehicles. This was consistent for both models.

Results from the detailed analysis of hydrocarbon emissions were very consistent for the two labs where this analysis was performed. At both labs, the CNG emissions had lower average values of the four toxic emissions that were quantified, had lower PWT, lower average OFP and lower average specific reactivity. These differences were all deemed statistically significant at the $95 \%$ confidence level. 


\section{INTRODUCTION}

For the past few years, the National

Renewable Energy Laboratory

(NREL) has managed a series of

light-duty vehicle chassis dynamo-

meter emissions tests on alternative fuel vehicles (AFVs) for the U.S.

Department of Energy (DOE). These tests are part of a larger program to demonstrate the use of AFVs that was mandated by the Alternative Motor Fuels Act of 1988 (AMFA) and the Energy Policy Act of 1992 (EPAct). One of the major objectives of these legislative actions is to promote the use of alternative transportation fuels in order to address energy security and environmental issues. As part of the AMFA program, vehicle performance, operational costs, maintenance, and fuel economy data are also being collected by NREL's Alternative Fuels Utilization Program and disseminated through the Alternative Fuels Data Center (AFDC). This report is designed to present a detailed evaluation of the emissions test results collected in this program.

The principal phase of the AMFA test program was initiated in 1994. Its purpose was to determine relative emissions from AFVs compared to otherwise identical gasoline vehicles taken from actual service. Approximately 25 each of several AFV models from several locations (including high altitude) around the country were randomly selected for participation in this program. All vehicles were selected from those available in the U.S. federal fleet. Test vehicles were scheduled for emissions testing once per year. The test matrix of vehicles, locations, and mileage levels was statistically designed to optimize reliability of the data and to control variability in the emissions results.

In addition to testing all vehicles for regulated exhaust and evaporative emissions, we conducted a detailed speciation of the hydrocarbon (HC) emissions on a subset of the test vehicles. Speciation of the HC emissions allows for an evaluation of the relative level of air toxic emissions and the reactivity or ozone forming potential (OFP) of the HC. Additionally, we also tested a small number of vehicles using new or proposed chassis dynamometer driving cycles. These "off-cycle" emissions tests are still in progress and the results will be discussed in a later report.

\section{A Background on Vehicle EMISSIONS AND FUEL ECONOMY}

As a result of fuel combustion, automobiles emit various compounds into the atmosphere in the form of exhaust. The U.S. Environmental Protection Agency (EPA) regulates some of these compounds; the amounts of the compounds that are emitted by vehicles cannot exceed certain levels. Other compounds, although not officially regulated, are important contributors to adverse atmospheric conditions such as ambient ozone and global climate change.

The emissions compounds regulated by the EPA include carbon monoxide $(\mathrm{CO})$, oxides of nitrogen $\left(\mathrm{NO}_{\mathrm{x}}\right), \mathrm{HC}$, and non-methane hydrocarbons (NMHC). Methane $\left(\mathrm{CH}_{4}\right)$ is not currently regulated because it is considered to be relatively non-reactive in forming ozone in the atmosphere. Exhaust from alcohol fuel vehicles also includes unburned alcohol and aldehydes, which are partial combustion products. For alcohol fuels, such as the ones investigated in this study, these compounds are regulated along with non-methane hydrocarbons as non-methane hydrocarbon equivalent (NMHCE). NMHCE is calculated by modifying the measured NMHC fraction to account for the alcohol and aldehyde emissions that are prevalent in emissions from alcohol fuels. More recent standards use nonmethane organic gases (NMOG) as the regulated compound. NMOG is the sum of non-oxygenated and oxygenated $\mathrm{HC}$ in a gas sample. This includes all oxygenated organic gases with 5 or less carbon atoms (such as aldehydes, ketones, and alcohols) and all known alkanes, alkynes, alkenes, and aromatics with 12 or less carbon atoms. ${ }^{3}$ The EPA's emissions standards applicable to the light-duty vehicles tested in this program are given in Table 1 . Table 2 shows the EPA standards applicable to the heavy light-duty vehicles that were tested. EPA defines heavy lightduty vehicles as those with gross vehicular weight ratings between 6,000 and 8,500 lb.

Hydrocarbons can also escape from a vehicle through evaporation of the liquid fuel. Such evaporation occurs in several ways. Diurnal evaporative losses are emissions that occur during the day as the temperature rises. 
Table 1. Intermediate Useful Life (5 years, 50,000 miles) Standards for Light-Duty Vehicles (g/mi) ${ }^{4}$

\begin{tabular}{|l|c|l|l|l|l|l|l|l|}
\hline Fuel & Standard & THC & NMHC & NMOG & HCE & NMHCE & CO & NOx \\
\hline Gasoline & Tier 0 & 0.41 & & & & & 3.4 & 1.0 \\
\hline Gasoline & Tier 1 & 0.41 & 0.25 & & & & 3.4 & 0.4 \\
\hline Alcohol & Tier 0 & & & & 0.41 & & 3.4 & 1.0 \\
\hline Alcohol & Tier 1 & & & & 0.41 & 0.25 & 3.4 & 0.4 \\
\hline & TLEV & & & 0.125 & & & 3.4 & 0.4 \\
\hline
\end{tabular}

Table 2. Intermediate Useful Life Standards for Heavy Light-Duty Vehicles (g/mi) ${ }^{4}$

\begin{tabular}{|l|c|c|c|c|}
\hline Standard & THC & NMHC & CO & NOx \\
\hline Tier 0 (120,000 mi full useful life) & 0.80 & 0.67 & 10 & 1.7 \\
\hline Tier 1 (5-yr or 50,000 mi intermediate useful life) & & 0.32 & 4.4 & 0.7 \\
\hline Tier 1 (100,000 mi intermediate useful life) & & 0.4 & 5.5 & 0.97 \\
\hline
\end{tabular}

As the fuel tank temperature increases, fuel evaporation increases and vapors are vented. Hot soak losses occur after the vehicle is turned offthe engine and fuel tank remains hot for a period of time, allowing further fuel evaporation. While the vehicle is running, the hot engine and exhaust system cause additional fuel to be vaporized. These emissions are called running loss emissions. Finally, during refueling, fuel vapors present in the tank are forced out as the tank is filled, resulting in refueling losses. ${ }^{5}$ Since this test program began, the EPA has expanded its Federal Test Procedures for evaporative emissions to include procedures for each of the evaporative sources listed above. However, all the evaporative emissions results discussed in this report are from the previous EPA test procedures that were limited to two (one diurnal and one hot soak) 1-hour evaporative emissions tests.

Modern light-duty vehicles include evaporative control systems that contain and redirect much of the vaporized fuel back into the engine. One notable exception is compressed natural gas $(\mathrm{CNG})$ vehicles. For vehicles designed to operate exclusively on $\mathrm{CNG}$, the fuel remains in a gaseous state, and the entire fuel system is sealed under pressure. Therefore, a separate evaporative control system is not necessary for these vehicle types.

The non-regulated emissions evaluated in this study include carbon dioxide $\left(\mathrm{CO}_{2}\right), \mathrm{CH}_{4}$, and air toxics. $\mathrm{CO}_{2}$ and $\mathrm{CH}_{4}$ are greenhouse gases that trap the earth's heat and may contribute to global warming. Air toxics are pollutants that EPA classifies as known or probable human carcinogens-in other words, components considered to have adverse affects on human health. The air toxics evaluated in this study include benzene $\left(\mathrm{C}_{6} \mathrm{H}_{6}\right)$, formaldehyde ( $\mathrm{HCHO}$ ), acetaldehyde $\left(\mathrm{CH}_{3} \mathrm{CHO}\right)$, and 1,3butadiene $\left(\mathrm{C}_{4} \mathrm{H}_{6}\right)$. Benzene is a known carcinogen, and the latter three compounds are probable carcinogens.

Hydrocarbon emissions from vehicles may be made up of hundreds of individual hydrocarbon compounds or species. A gas chromatograph can be used to quantify the amounts of the individual $\mathrm{HC}$ species in a process known as detailed $\mathrm{HC}$ speciation. In this report, the speciation of hydrocarbon emissions is used to gain additional insight into $\mathrm{HC}$ emissions. Air toxics emissions are reported directly and as potencyweighted toxics (PWT). Potency weighting gives an indication of the relative level of risk for each of the toxic compounds emitted. The EPA has calculated an inhalation unit risk factor for each of the hazardous compounds. The weighting factor for each compound is determined by dividing its individual unit risk factor by the unit risk factor that is the highest of the four (in this case, 1,3-butadiene). The resulting number is multiplied by the mass emissions for the respective compound to calculate the PWT value. For example, acetaldehyde has a risk factor that is 127 times lower than 1,3-butadiene. The total PWT is the sum of the individual potency weighted values. These EPA risk factors are listed in Table 3.6

Results from the $\mathrm{HC}$ speciation are also used to evaluate the tendency for $\mathrm{HC}$ emissions to react in the atmosphere and form ozone. These results are reported here as OFP and specific reactivity (SR). Regulations in California assign a maximum incremental reactivity (MIR) value to individual compounds emitted in automobile exhaust. The MIR value is the predicted contribution of the compound to ozone formation in certain urban atmospheres, and is expressed in units of milligrams of 
ozone formed per milligram of the compound emitted. The MIR value is determined in a laboratory experiment in which a small increment of the compound is added to a simulated urban background mixture and the net increase in ozone is measured. Taking into account the MIR values for all measured exhaust compounds, an OFP for the fuel in question may be calculated. Specific reactivity for a given fuel may also be calculated by combining the respective mass of compound emissions per mile with the OFP, which results in units of milligrams of ozone per milligram of total organic emissions. In California, SR is based on NMOG emissions. Specific reactivity is usually constant for a given fuel and engine technology. To clarify the difference between them, OFP gives an estimate of the amount of ozone formed per mile traveled; SR gives an estimate of the amount of ozone formed per gram of NMOG emitted. OFP and SR are relative numbers associated with particular atmospheric conditions.

Fuel economy is also calculated from the results of the emissions testing procedures. For vehicles tested on gasoline, fuel economy is reported in miles per gallon (mpg). For vehicles tested on alcohol fuels, fuel economy is expressed both as miles per gallon and miles per equivalent gallon (mpeg). The mpeg measurement gives an estimate of how far the vehicle can travel on an amount of fuel that has the same energy as a gallon of gasoline. Both are reported for alcohol tests because alcohol fuels have a lower volumetric energy content than gasoline. The energy content of the methanol test fuel (M85) is approximately 58\% of gasoline; the energy content of the ethanol test fuel (E85) is approximately $73 \%$ of gasoline (M85 and E85 are further described below). For vehicles tested on $\mathrm{CNG}$, fuel economy is reported only in miles per equivalent gallons.

Table 3. EPA Unit Risk Factors for Emissions Air Toxics

\begin{tabular}{|l|c|c|}
\hline \multicolumn{1}{|c|}{ Compound } & \multicolumn{1}{|c|}{$\begin{array}{c}\text { EPA Risk } \\
(\mu \mathrm{g} / \mathrm{m} 3)^{-1}\end{array}$} & $\begin{array}{c}\text { EPA Factor } \\
\text { (Normalized) }\end{array}$ \\
\hline 1,3-butadiene & $2.8 \times 10^{-4}$ & 1.000 \\
\hline Benzene & $8.3 \times 10^{-6}$ & 0.030 \\
\hline Formaldehyde & $1.3 \times 10^{-5}$ & 0.046 \\
\hline Acetaldehyde & $2.2 \times 10^{-6}$ & 0.008 \\
\hline
\end{tabular}

This is used for CNG tests because $\mathrm{CNG}$ is stored in a compressed gaseous state, which is not typically measured in gallons. For transportation applications, $\mathrm{CNG}$ is often dispensed and priced per gasoline gallon equivalent.

\section{Test VehicLes for the STUDY}

This report presents emissions test results on a number of different vehicle models. Table 4 lists these vehicle models, along with the numbers of vehicles of each model that were tested, and the total numbers of tests that were performed on all vehicles of each model. For every AFV model tested, an equivalent number of vehicles of the corresponding standard gasoline model (controls) were also tested. Because many vehicles were tested more than once over the course of the program (at increased mileage levels) more tests than vehicles are reported in Table 4. Replicate tests were also conducted on some vehicles. All the vehicles discussed here are original equipment manufacturer (OEM) vehicles. The test vehicles include four passenger car models, one full-size passenger van, and one minivan.

In order to provide information on emissions deterioration over time, the vehicles were scheduled for testing approximately once per year. The first set of tests on a particular vehicle model was designated as "Round 1," the second set as "Round 2," and so forth.
Both alcohol-fueled and CNG-fueled AFVs were included in the testing program. The principal alcohol fuels of interest were M85 (a blend of 85\% methanol and $15 \%$ gasoline) and E85 (a blend of $85 \%$ ethanol and $15 \%$ gasoline). The alcohol-fueled vehicles are flexible-fuel vehicles (FFVs), which means that they are capable of operating on unleaded gasoline, or any blend of the alcohol and gasoline up to $85 \%$ alcohol and $15 \%$ gasoline. All the CNG models included in this report are dedicated $\mathrm{CNG}$ vehicles, which means they are designed to operate on CNG only.

As noted above, all test vehicles included in this program were part of the federal vehicle pool leased to various government fleets by the General Services Administration (GSA). A relatively large number of vehicles were selected for testing to account for the high variability observed in emissions from vehicles pulled directly from fleet service. These differences may be caused by physical differences inherent in any manufacturing process, or because vehicle usage and care vary from driver to driver and fleet manager to fleet manager. For instance, vehicle service applications may vary from short delivery routes to highway driving, and the degree to which the preventive maintenance schedule is followed depends, to a certain extent, on the diligence of the fleet manager. For these and other reasons, vehicleto-vehicle variability in emissions levels was expected to be fairly high, even at the outset of the testing program. 
Table 4. Emissions Tests Completed

\begin{tabular}{|c|c|c|c|c|}
\hline $\begin{array}{l}\text { Vehicle } \\
\text { Model }\end{array}$ & $\begin{array}{l}\text { Model } \\
\text { Year }\end{array}$ & Vehicle Type & $\begin{array}{c}\text { Number of } \\
\text { Vehicles Tested }\end{array}$ & $\begin{array}{l}\text { Number } \\
\text { of Tests }\end{array}$ \\
\hline \multicolumn{5}{|c|}{ Methanol } \\
\hline \multirow{2}{*}{$\begin{array}{l}\text { Dodge } \\
\text { Intrepid }\end{array}$} & \multirow{2}{*}{1995} & M85 FFV & 24 & 89 \\
\hline & & Standard & 25 & 47 \\
\hline \multirow{2}{*}{$\begin{array}{l}\text { Dodge } \\
\text { Spirit }\end{array}$} & \multirow{2}{*}{1993} & M85 FFV & 77 & 373 \\
\hline & & Standard & 72 & 145 \\
\hline \multicolumn{5}{|c|}{ Ethanol } \\
\hline \multirow{2}{*}{$\begin{array}{l}\text { Ford } \\
\text { Taurus }\end{array}$} & $1994 / 95$ & E85 FV & 24 & 88 \\
\hline & 1995 & Standard & 24 & 45 \\
\hline \multirow{2}{*}{$\begin{array}{l}\text { Chevrolet } \\
\text { Lumina }\end{array}$} & $1992 / 93$ & E85 FFV & 25 & 144 \\
\hline & 1993 & Standard & 16 & 45 \\
\hline \multicolumn{5}{|c|}{ Compressed Natural Gas } \\
\hline \multirow{2}{*}{$\begin{array}{l}\text { Dodge } \\
\text { B-250 }\end{array}$} & \multirow{2}{*}{$1992 / 94$} & Dedicated CNG & 54 & 144 \\
\hline & & Standard & 53 & 138 \\
\hline \multirow{2}{*}{$\begin{array}{l}\text { Dodge } \\
\text { Caravan }\end{array}$} & \multirow{2}{*}{1994} & Dedicated CNG & 13 & 16 \\
\hline & & Standard & 6 & 6 \\
\hline \multicolumn{3}{|l|}{ Total } & 413 & 1,280 \\
\hline
\end{tabular}

\section{Test Facilities}

All testing was performed at private commercial laboratories with chassis dynamometer exhaust and evaporative emission test equipment that is capable of performing EPA emissions certification test procedures. A detailed description of the type of test procedures and equipment used can be found on the AFDC Web site (http://www.afdc. doe.gov). The laboratories were selected on the basis of a federal government competitive bidding process in which experience with performing the Federal Test Procedures (FTP) - in particular, FTP testing of alcohol and natural gas vehicles - was stressed. Three organizations were awarded emissions testing subcontracts: Automotive Testing Laboratories (ATL) in East Liberty, Ohio, which tested vehicles from Ohio, Michigan, and Illinois; Environmental Research and Development (ERD), which tested vehicles in the Washington D.C. and
New York City regions; and ManTech Environmental Technology, Inc. (ManTech), which tested vehicles from Colorado (at a high altitude of approximately 5,300 feet). For the remainder of the report, these labs are referred to as Lab 1, Lab 2, and Lab 3, respectively. Before any testing began, a coordination meeting was held between all the participating laboratories and NREL to ensure consistency in the test procedures. NREL and EPA employees subsequently conducted laboratory site visits.

\section{Test Fuels}

Table 5 summarizes the physical properties of the liquid test fuels used in this study. The baseline gasoline used was California Phase 2 reformulated gasoline, or RFG. This fuel was chosen because it represents a "best case" scenario for gasoline emissions. If alternative fuels are to compete, they must be compared to the best gasoline available. RFG has a lower sulfur, olefin, and aromatic content than standard unleaded gasoline. The Auto/Oil Air Quality Improvement Research Program (AQIRP) conducted extensive testing that compared emissions from vehicles tested on various fuel blends, including certification test fuel, industry-average gasoline, and $\mathrm{RFG}^{2}$. In general, the AQIRP study found that vehicles tested on RFG tended to show reduced regulated emissions. Therefore, one might expect that the comparison between alternative fuels and an industry-average gasoline would be slightly more favorable for alternative fuels than the results discussed here. The alcohol blends were prepared using $85 \%$ alcohol (methanol or ethanol) and $15 \%$ RFG. Phillips Petroleum Company blended and supplied the alcohol and gasoline fuels. Compressed Gas Technologies, Inc., supplied the CNG fuel that was designed to represent a national industry-average fuel composition. 
Table 5. Liquid Fuel Properties

\begin{tabular}{|l|c|c|c|}
\hline & M85 & E85 & RFG \\
\hline Fuel Blend & $\begin{array}{c}\text { 85\% Methanol } \\
\text { 15\% RFG }\end{array}$ & $\begin{array}{c}\text { 85\% Ethanol } \\
\text { 15\% RFG }\end{array}$ & 100\% RFG \\
\hline Specific Gravity & 0.787 & 0.784 & 0.741 \\
\hline Carbon (wt \%) & 44.1 & 56.7 & 84.4 \\
\hline Hydrogen (wt \%) & 12.7 & 13.2 & 13.6 \\
\hline Oxygen (wt \%) & 43.1 & 30.1 & 2.0 \\
\hline Net Heat of Combustion (Btu/gal) & 64,600 & 81,825 & 111,960 \\
\hline Reid Vapor Pressure & 7.5 & 6.15 & 6.9 \\
\hline
\end{tabular}

Table 6 lists the specifications and a sample analysis of the CNG fuel used throughout the study.

\section{Test Procedures}

This program used the EPA's emissions certification test procedure, known as the FTP-75. The FTP-75 includes measurement of exhaust emissions on a chassis dynamometer and two 1-hour evaporative emissions tests. Details of the test procedures are described in the Code of Federal Regulations ${ }^{4}$. Once a vehicle was identified for testing, the laboratory notified the fleet representative and scheduled a convenient test date. The lab also verified that the vehicle had received all scheduled maintenance and was operating properly. On arrival at the test laboratory, the vehicle was inspected for any problems. Once the vehicle was approved for testing, it was subjected to an extensive procedure designed to minimize residual effects from resident fuels. Figure 1 outlines the complete procedure for testing a vehicle, including the fuel changeover procedure. The fuel changeover procedure was performed before every test, including the first test in the sequence. This process follows the AQIRP's vehicle testing procedures. ${ }^{7}$ The main elements of the fuel changeover procedure are a 60-minute purge of the vehicle's evaporative canister, several fuel tank drain and fill sequences, a

Table 6. Composition of CNG

\begin{tabular}{|l|c|c|}
\hline & \multicolumn{2}{|c|}{ \% Volume } \\
\hline Component & Specification & Analysis \\
\hline Methane & 93.05 & 93.15 \\
\hline Ethane & 3.47 & 3.52 \\
\hline Nitrogen & 1.67 & 1.47 \\
\hline Carbon Dioxide & 0.81 & 0.82 \\
\hline Propane & 0.66 & 0.68 \\
\hline N-Butane & 0.12 & 0.13 \\
\hline I-Butane & 0.08 & 0.07 \\
\hline N-Hexane & 0.06 & 0.06 \\
\hline I-Pentane & 0.04 & 0.06 \\
\hline N-Pentane & 0.03 & 0.04 \\
\hline Oxygen & 0.00 & 0.00 \\
\hline
\end{tabular}

chassis dynamometer driving cycle using the test fuel, and several engine start-up and idle sequences. Another part of the vehicle preconditioning procedure is the Urban Dynamometer Driving Schedule (UDDS), also called the LA4. The UDDS was derived from an actual driving route through LA that was selected to represent a typical city driving pattern.

Once the fuel changeover procedure was complete, the vehicle was tested following the FTP-75 for light-duty vehicle chassis dynamometer testing (including evaporative testing). Figure 2 shows the FTP-75 driving cycle. Alcohol fuel vehicles were tested on both alcohol fuel (M85 or
E85) and RFG. The corresponding control vehicles were tested on RFG. All CNG vehicles were tested only on CNG fuel, and their corresponding gasoline controls were tested on RFG.

The emissions samples collected during the FTP were analyzed for HC, $\mathrm{CH}_{4}, \mathrm{NO}_{\mathrm{x}}, \mathrm{CO}$, and $\mathrm{CO}_{2}$. Alcohols (ethanol and methanol) in the emissions were collected using primary and secondary impingers. Gas chromatography was used to analyze the alcohols. Aldehydes were collected on dinitrophenylhydrazine (DNPH) coated silica cartridges or impingers filled with an acetonitrile/DNPH solution, and analyzed 


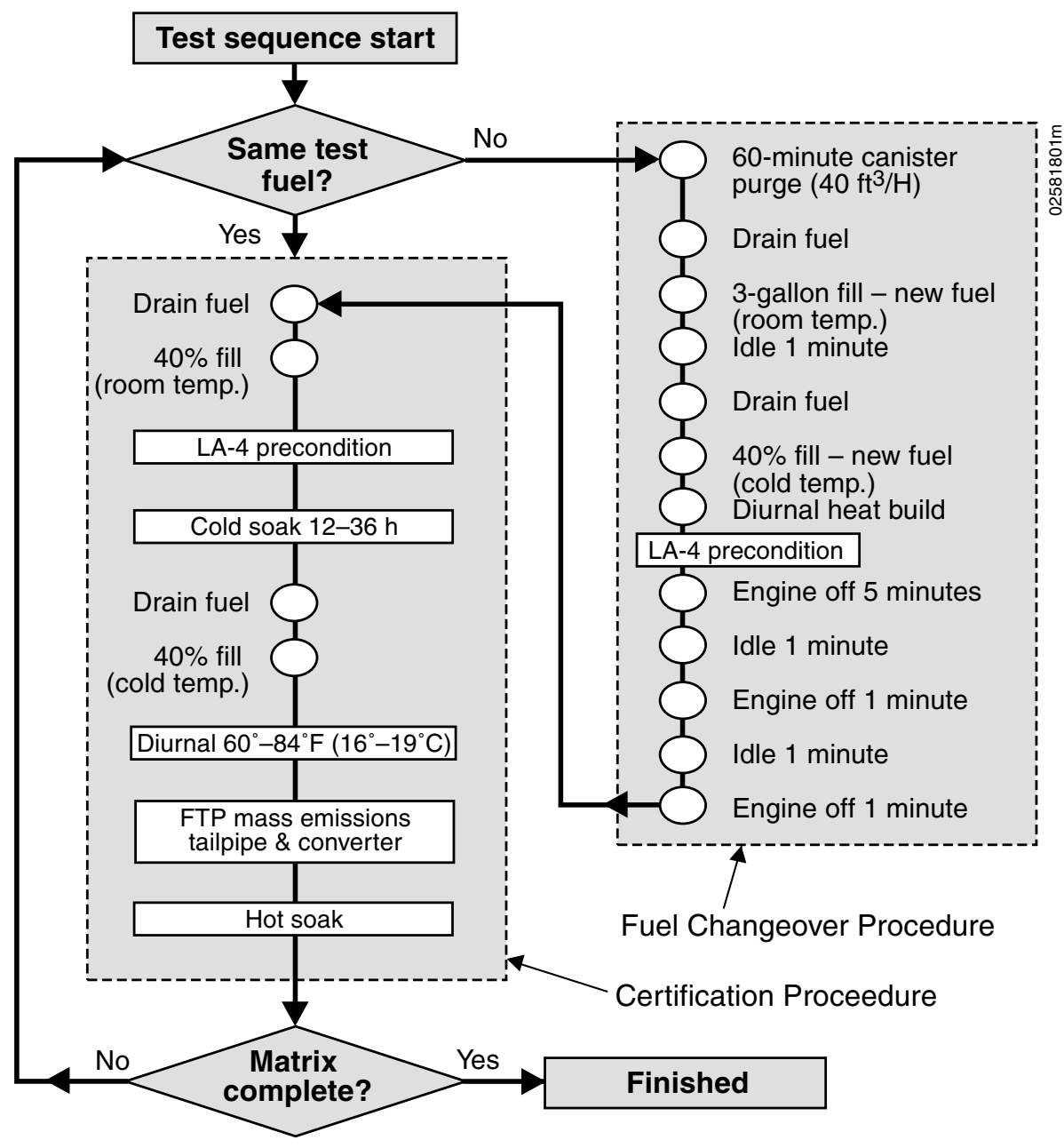

Figure 1. Vehicle testing procedure

using high-performance liquid chromatography. Appendix A contains the entire FTP data set.

The emissions from a subset of test vehicles were subjected to full hydrocarbon speciation. Speciation is the quantification of individual $\mathrm{HC}$ components using gas chromatography. Table 7 lists the numbers and types of vehicles for which hydrocarbon emissions were speciated. Up to $288 \mathrm{HC}$ constituents in the emissions samples were identified; a complete list is given in Appendix B. Appendix C contains the speciated $\mathrm{HC}$ data set.

\section{Data Analysis Approach}

Raw data files of the emissions tests from each laboratory were electronically submitted and loaded into the AFDC at NREL. Before conducting any analyses of the data, a number of checks and edits were undertaken to ensure data quality. The data sets were sorted by vehicle model, test fuel, and test round. Repeat tests were reviewed for problems or outliers. In most cases, these duplicate tests were averaged and returned to the data set. Each data set was then analyzed for outliers, which were removed. Outliers were defined as any value that was $+/-3$ standard deviations from the mean. An exception was made with the evaporative emissions results. Because of the high variability of evaporative data, no outliers were removed from the data sets.

After all checks and edits were applied, the data were imported into the JMP ${ }^{\circledR}$ software, which is a comprehensive PC-based statistical data analysis package developed by SAS Institute. Using this software, a multi-variable analysis of variance (ANOVA) was performed to determine the statistical significance of various factors on emissions. The primary effects of interest include fuel, vehicle, and test round. Secondary effects include the fuel by vehicle, fuel by test round, and vehicle by test round interactions. All data were analyzed at the $95 \%$ confidence level. Appendix D gives a detailed explanation of the data compilation and the ANOVA statistical approach.

\section{Presentation of Analysis Results}

The following sections contain discussions of the results from each of the individual vehicle models tested. Sections on each alternative fuel begin with an overview comparing the fuel with RFG, followed by details on each model. The discussions on each vehicle model are subdivided into sections on regulated emissions, evaporative emissions, greenhouse gases, and aldehydes. Separate tables and graphs cover the air toxics, OFP, and SR. Each of these sections concentrates on the comparison between the emissions and the EPA standard, fuel differences, and round-to-round differences.

The results are presented in tables that include regulated and non-regulated emissions constituents for each vehicle model. These tables contain descriptive statistics for emissions results obtained for each fuel on which the vehicle model was tested. Average emissions are reported as grams per mile. Of particular interest is the percent difference between the emissions from the alternative fuel and the RFG tests (e.g., M85 versus RFG). 


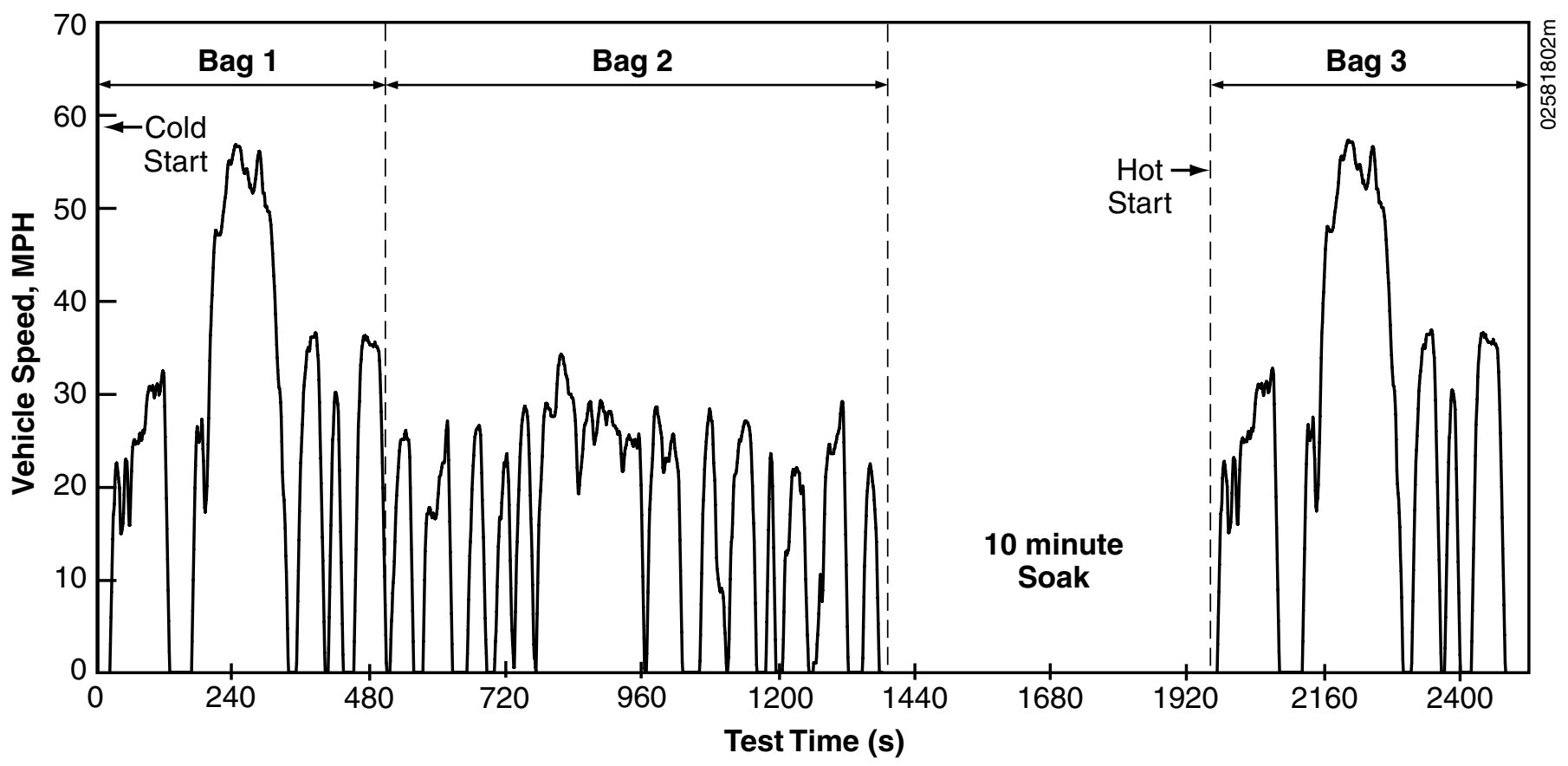

Figure 2. EPA's FTP-75 driving cycle

For each vehicle model tested, a summary table of results shows the average results, percent differences between the averages, and an indication of which differences in average values are statistically significant at the $95 \%$ confidence level. Percent difference was calculated using the following formula:

$$
\frac{\overline{U_{\text {AlternateFuel }}}-\overline{U_{\text {Gasoline }}}}{\overline{U_{\text {Gasoline }}}} \times 100,
$$

where $\bar{U}$ is the average of emissions test results obtained on the fuel in question. Statistical significance was determined through ANOVA procedures, applying the appropriate data model for each particular case. An example ANOVA table is shown in Appendix D.

In addition to the tables, each section contains a series of graphs depicting the average emissions results (by fuel, lab, and/or round) for the

Table 7. Number and Type of Vehicles with HC Speciation

\begin{tabular}{|c|c|c|c|c|}
\hline Model & Fuel & Type & $\begin{array}{l}\text { Number of } \\
\text { Vehicles }\end{array}$ & $\begin{array}{c}\text { Number of } \\
\text { Tests }\end{array}$ \\
\hline \multirow{2}{*}{$\begin{array}{l}\text { Dodge } \\
\text { Intrepid }\end{array}$} & M85 & FFV & 6 & 16 \\
\hline & RFG & Standard & 4 & 7 \\
\hline \multirow{2}{*}{$\begin{array}{l}\text { Dodge } \\
\text { Spirit }\end{array}$} & M85 & FFV & 10 & 28 \\
\hline & RFG & Standard & 9 & 14 \\
\hline \multirow{2}{*}{$\begin{array}{l}\text { Ford } \\
\text { Taurus }\end{array}$} & E85 & FFV & 6 & 16 \\
\hline & RFG & Standard & 5 & 8 \\
\hline \multirow{2}{*}{$\begin{array}{l}\text { Dodge } \\
\text { B250 }\end{array}$} & CNG & Dedicated CNG & 8 & 17 \\
\hline & RFG & Standard & 8 & 16 \\
\hline \multicolumn{3}{|l|}{ Total } & 56 & 122 \\
\hline
\end{tabular}




\section{Methanol Vehicles}

For this study, three different M85 FFV models were tested: the Dodge Spirit, the Dodge Intrepid, and the Ford Econoline van. Because the results for the Ford van were reported in a previous publication, ${ }^{8}$ they are not included in this report.

Table 8 provides a summary comparison of the emissions from the FFVs tested on M85 to the same vehicles tested on RFG. In the table, the highlighted blocks indicate that there was a $95 \%$ statistically significant difference (based on the ANOVA) in emissions from the two fuels tested. A plus sign in the block means that the emissions from the M85 test were higher than those from the RFG test, and a minus sign means that the M85 emissions were lower. These results are shown for all of the measured emissions from the Dodge Spirit and the Intrepid at the respective test laboratories. For instance, during the first round (Round 1) of testing, the $\mathrm{CO}$ emissions from the Dodge Intrepid were higher for M85 than RFG (plus sign), but the difference was not statistically significant at the 95\% confidence level (not highlighted). A more detailed and quantitative discussion of the specific results for each vehicle is presented in the following sections, but it may also be useful to consider a more qualitative view of the general trends for the methanol tests.

Some of the results (such as HC, greenhouse gases, aldehydes, and the fuel economy calculation) were very consistent across vehicle models, test laboratories and test rounds, others
$\left(\mathrm{CO}, \mathrm{NO}_{\mathrm{x}}\right.$, and evaporative $\left.\mathrm{HC}\right)$ were more mixed. Although both vehicle models are FFVs produced by Dodge, the two models may employ different engine calibrations in order to meet differing performance and emissions expectations.

In general, both vehicles tended to have significantly (evaluated at 95\%) lower NMHCE, total hydrocarbon (THC), $\mathrm{CO}_{2}, \mathrm{CH}_{4}$, and $\mathrm{CH}_{3} \mathrm{CHO}$ emissions, as well as lower fuel economy, when tested on M85. On the other hand, both vehicles tended to have significantly higher $\mathrm{HCHO}$ emissions and energy equivalent fuel economy (mpeg) when tested on M85. There appeared to be very little difference (not statistically significant at $95 \%$ ) in $\mathrm{CO}$ and evaporative $\mathrm{HC}$ emissions between the two fuels. The $\mathrm{NO}_{\mathrm{x}}$ emissions tended to be higher

\section{Table 8. Summary Comparison of Average Emission Results from M85 versus RFG}

\begin{tabular}{|c|c|c|c|c|c|c|}
\hline & \multirow{2}{*}{\multicolumn{2}{|c|}{$\begin{array}{l}\text { Dodge Intrepid } \\
\text { Lab } 1\end{array}$}} & \multicolumn{4}{|c|}{ Dodge Spirit } \\
\hline & & & \multicolumn{2}{|c|}{ Lab 1} & \multicolumn{2}{|c|}{ Lab 3} \\
\hline & Round 1 & Round 2 & Round 1 & Round 2 & Round 1 & Round 2 \\
\hline \multicolumn{7}{|c|}{ Regulated Emissions } \\
\hline NMHCE & - & - & - & - & - & - \\
\hline THC & - & - & - & - & - & - \\
\hline $\mathrm{CO}$ & + & + & - & - & - & - \\
\hline $\mathrm{NO}_{\mathrm{x}}$ & + & + & + & - & + & + \\
\hline \multicolumn{7}{|c|}{ Evaporative Emissions } \\
\hline THC & + & + & - & - & - & + \\
\hline \multicolumn{7}{|c|}{ Greenhouse Gases } \\
\hline $\mathrm{CO}_{2}$ & - & - & - & - & - & - \\
\hline $\mathrm{CH}_{4}$ & - & - & - & - & - & - \\
\hline \multicolumn{7}{|l|}{ Aldehydes } \\
\hline $\mathrm{HCHO}$ & + & + & + & + & + & + \\
\hline $\mathrm{CH}_{3} \mathrm{CHO}$ & - & - & - & - & - & - \\
\hline \multicolumn{7}{|c|}{ Fuel Economy } \\
\hline $\mathrm{mpg}$ & - & - & - & - & - & - \\
\hline mpeg & + & + & + & + & - & + \\
\hline
\end{tabular}

"+" Indicates results from M85 tests were higher than RFG tests

"-" Indicates results from M85 tests were lower than RFG tests

Highlighted blocks indicate a significant statistical difference. 
from M85, but this result was not consistent across all test categories.

One possible reason for finding mixed results and fuel effects that are not statistically significant is that a FFV is not optimized for either fuel, but is instead designed to perform acceptably on a wide range of fuel blends. An inherent benefit of the flexible fuel design is the capability for convenient fueling on gasoline or methanol where it is available. An inherent drawback to this design is that the vehicle cannot be optimized to take advantage of some of the beneficial properties of methanol. One obvious example of this is that these vehicles are designed with a compression ratio that is suitable for gasoline. A vehicle optimized for methanol could be designed with an increased compression ratio that would take advantage of methanol's higher octane rating and provide increased power and efficiency.

A similar evaluation of the general trends from the more limited set of $\mathrm{HC}$ speciation tests (shown in Table 9 ) is very consistent across vehicles and labs. These results give an indication of how the chemical composition of the hydrocarbon emissions differ between the two fuels. With regard to the four air toxic HC covered here,

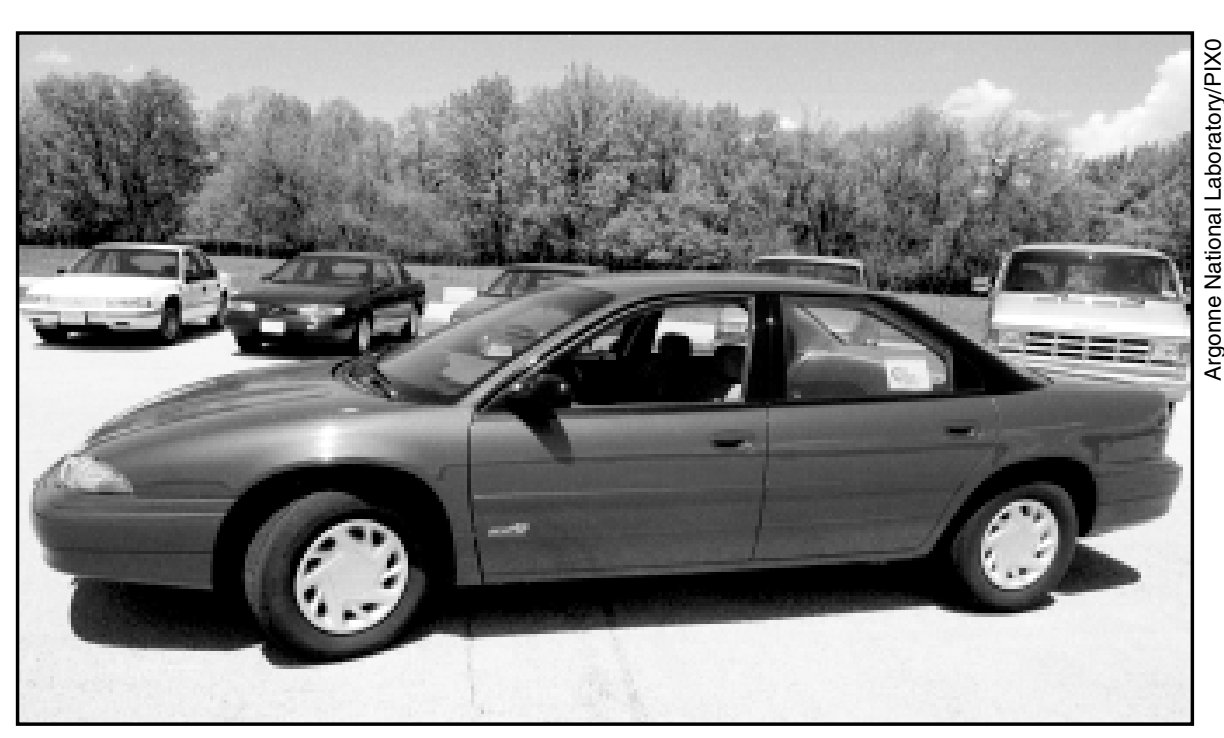

Figure 3. 1995 Dodge Intrepid

the vehicles tested on M85 tended to emit much higher levels of $\mathrm{HCHO}$, and significantly lower levels of $\mathrm{CH}_{3} \mathrm{CHO}, 1,3$-butadiene, and benzene compared to the same vehicles tested on RFG. When the potency weighting factors are applied to these emissions levels and totaled as the total PWT emissions, the M85 results were significantly lower than the RFG results.

The detailed speciation of the $\mathrm{HC}$ was also used to compare the tendency for $\mathrm{HC}$ emissions to react and

Table 9. Summary Comparison of Average Speciated Hydrocarbon Results from M85 versus RFG

\begin{tabular}{|l|c|c|c|}
\hline & Intrepid & \multicolumn{2}{|c|}{ Spirit } \\
\hline Air Toxics & Lab 1 & Lab 1 & Lab 3 \\
\hline $\mathrm{HCHO}$ & + & + & + \\
\hline $\mathrm{CH}_{3} \mathrm{CHO}$ & - & - & - \\
\hline 1,3-butadiene & - & - & - \\
\hline Benzene & - & - & - \\
\hline Total PWT & - & - & - \\
\hline Ozone Reactivity & & & \\
\hline OFP & - & - & - \\
\hline SR & - & - & \\
\hline
\end{tabular}

"+" Indicates results from M85 tests were higher than RFG tests

"-" Indicates results from M85 tests were lower than RFG tests Highlighted blocks indicate a significant statistical difference.

form ozone. The OFP and the SR of the HC emissions from the M85 tests were significantly lower than those from the same vehicles tested on RFG. The detailed evaluation of hydrocarbon emissions from M85 and RFG was consistent for both the toxic emissions and the parameters related to ozone formation for both vehicle models at the two laboratories that performed hydrocarbon speciation.

\section{DODGE INTREPID}

The 1995 Dodge Intrepid (shown in Figure 3) is a passenger car equipped with a 3.3 L V6 engine. This vehicle model employs electronically controlled multi-point fuel injection and is equipped with a three-way catalyst for exhaust emissions control. The flexible-fuel version was certified to the EPA federal Tier 0 emissions standard and the standard gasoline version was certified to federal Tier 1 levels (refer to Table 1, page 2). We performed two rounds of tests on the Dodge Intrepids at Lab 1. There were 17 standard gasoline Intrepids and $16 \mathrm{FFVs}$ tested in both rounds. Mileage ranges and average 
Table 10. Odometer Readings for the Dodge Intrepid

\begin{tabular}{|l|c|c|c|c|}
\hline & \multicolumn{2}{|c|}{ FFV } & \multicolumn{2}{c|}{ Gasoline } \\
\hline Round & 1 & 2 & 1 & 2 \\
\hline No. vehicles tested & 16 & 16 & 17 & 17 \\
\hline \multicolumn{5}{|c|}{ Odometer (miles) } \\
\hline Average & 5,128 & 14,332 & 5,661 & 17,231 \\
\hline Maximum & 9,558 & 26,084 & 18,783 & 42,738 \\
\hline Minimum & 3,047 & 9,653 & 3,336 & 5,929 \\
\hline
\end{tabular}

odometer readings for the Intrepids are shown in Table 10. The complete listing of the vehicles tested and the detailed emissions test results are included in Appendix A.

\section{Regulated Emissions}

Table 11 shows the average emissions results for the Dodge Intrepid. The values shown include the averages for the FFV model tested on M85 and
RFG and the percent difference between the averages. An indication is also given on whether the difference between the average results is statistically significant as determined by the ANOVA. All average regulated emissions shown here were well below the Tier 1 emissions standards. Figure 4 shows the regulated and $\mathrm{CO}_{2}$ emissions for the Intrepid along with the Tier 1 50,000-mile certification standard. In general, when comparing the M85 and RFG regulated emissions for the FFV Dodge Intrepid, NMHCE emissions from the M85 tests were lower, there was very little difference in $\mathrm{CO}$ emissions, and the $\mathrm{NO}_{\mathrm{x}}$ emissions from the M85 tests were substantially higher.

More specifically, the FFV Intrepid showed a statistically significant decrease in $\mathrm{HC}$ emissions when tested on M85. In Round 1, the average emissions from the M85 tests were $16 \%$ lower; in Round 2, they were $19.6 \%$ lower than those from the same vehicles tested on RFG. When comparing the FFV tested on RFG to the standard Intrepid, the FFV had higher NMHCE emissions in both test rounds. For the FFVs, there tended to be a small, but statistically significant increase in NMHCE emissions from Round 1 to Round 2.

Table 11. Average Emissions Results from the Dodge Intrepid

\begin{tabular}{|c|c|c|c|c|c|c|c|c|}
\hline & \multicolumn{4}{|c|}{ Round 1} & \multicolumn{4}{|c|}{ Round 2} \\
\hline & $\begin{array}{l}\text { FFV- } \\
\text { M85 }\end{array}$ & $\begin{array}{l}\text { FFV- } \\
\text { RFG }\end{array}$ & $\begin{array}{c}\text { Percent } \\
\text { Difference }\end{array}$ & $\begin{array}{l}\text { Sig. Fuel } \\
\text { Effect? }\end{array}$ & $\begin{array}{l}\text { FFV- } \\
\text { M85 }\end{array}$ & $\begin{array}{l}\text { FFV- } \\
\text { RFG }\end{array}$ & $\begin{array}{c}\text { Percent } \\
\text { Difference }\end{array}$ & $\begin{array}{l}\text { Sig. Fue } \\
\text { Effect? }\end{array}$ \\
\hline \multicolumn{9}{|c|}{ Regulated Emissions (g/mi) } \\
\hline NMHCE & 0.107 & 0.127 & $-15.7 \%$ & $\mathrm{y}$ & 0.127 & 0.158 & $-19.62 \%$ & $\mathrm{y}$ \\
\hline THC & 0.112 & 0.149 & $-24.7 \%$ & $\mathrm{y}$ & 0.132 & 0.182 & $-27.6 \%$ & $\mathrm{y}$ \\
\hline $\mathrm{CO}$ & 1.01 & 0.99 & $2.0 \%$ & $\mathrm{n}$ & 1.16 & 1.12 & $3.9 \%$ & $\mathrm{n}$ \\
\hline $\mathrm{NO}_{\mathrm{x}}$ & 0.328 & 0.245 & $33.9 \%$ & $\mathrm{y}$ & 0.283 & 0.239 & $18.2 \%$ & $\mathrm{y}$ \\
\hline \multicolumn{9}{|c|}{ Evaporative Emissions (g/Test) } \\
\hline Total Evaporative & 0.876 & 0.669 & $30.9 \%$ & $\mathrm{y}$ & 0.816 & 0.712 & $14.6 \%$ & $\mathrm{n}$ \\
\hline \multicolumn{9}{|c|}{ Greenhouse Gases (g/mi) } \\
\hline $\mathrm{CO}_{2}$ & 413.9 & 452.3 & $-8.5 \%$ & $\mathrm{y}$ & 395.0 & 431.2 & $-8.4 \%$ & $\mathrm{y}$ \\
\hline $\mathrm{CH}_{4}$ & 0.016 & 0.028 & $-42.7 \%$ & $\mathrm{y}$ & 0.017 & 0.031 & $-43.6 \%$ & $\mathrm{y}$ \\
\hline \multicolumn{9}{|c|}{ Aldehydes (mg/mi) } \\
\hline $\mathrm{HCHO}$ & 16.0 & 1.9 & $742.1 \%$ & $\mathrm{y}$ & 17.62 & 2.52 & $604.8 \%$ & $\mathrm{y}$ \\
\hline $\mathrm{CH}_{3} \mathrm{CHO}$ & 0.17 & 0.45 & $-62.0 \%$ & $\mathrm{y}$ & 0.23 & 0.59 & $-60.9 \%$ & $\mathrm{y}$ \\
\hline \multicolumn{9}{|l|}{ Fuel Economy } \\
\hline $\mathrm{mpg}$ & 11.66 & 19.19 & $-39.2 \%$ & $\mathrm{y}$ & 12.16 & 20.13 & $-39.6 \%$ & $\mathrm{y}$ \\
\hline mpeg & 20.21 & 19.19 & $5.3 \%$ & $\mathrm{y}$ & 21.07 & 20.13 & $4.7 \%$ & $y$ \\
\hline
\end{tabular}




\section{4a: Non-Methane Hydrocarbon Equivalent}

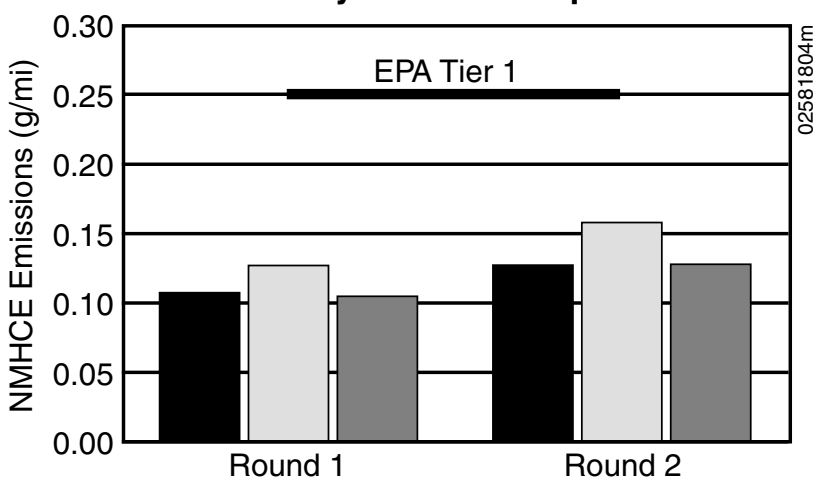

4b: Carbon Monoxide

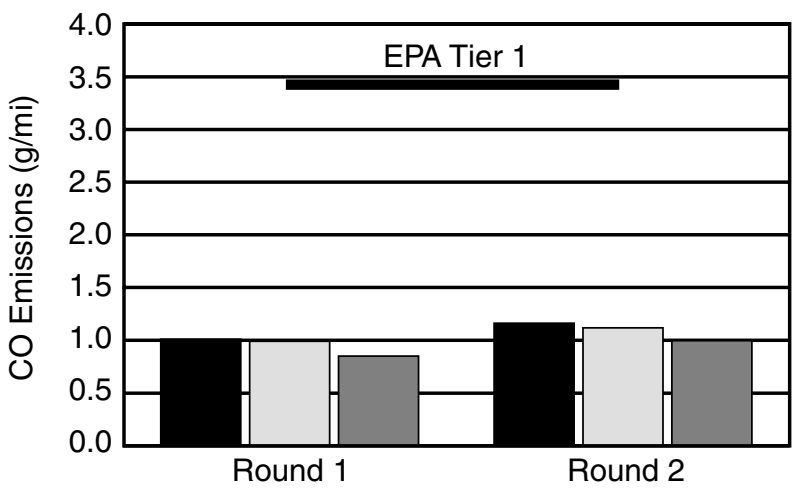

4c: Oxides of Nitrogen

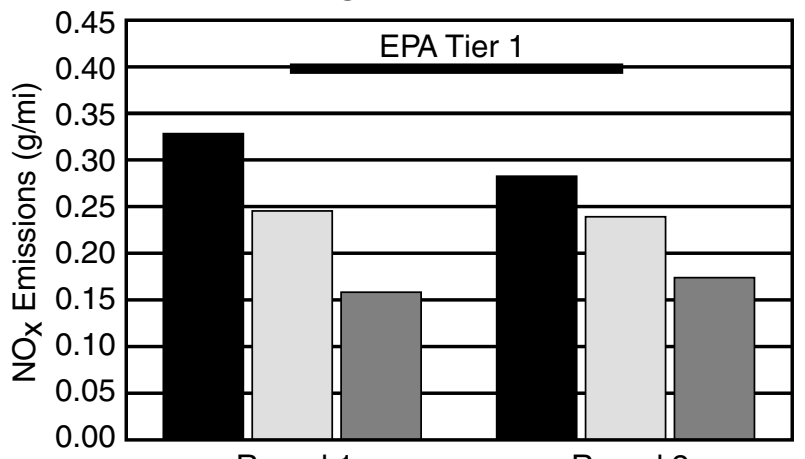

Round 1

Round 2

\section{4d: Carbon Dioxide}

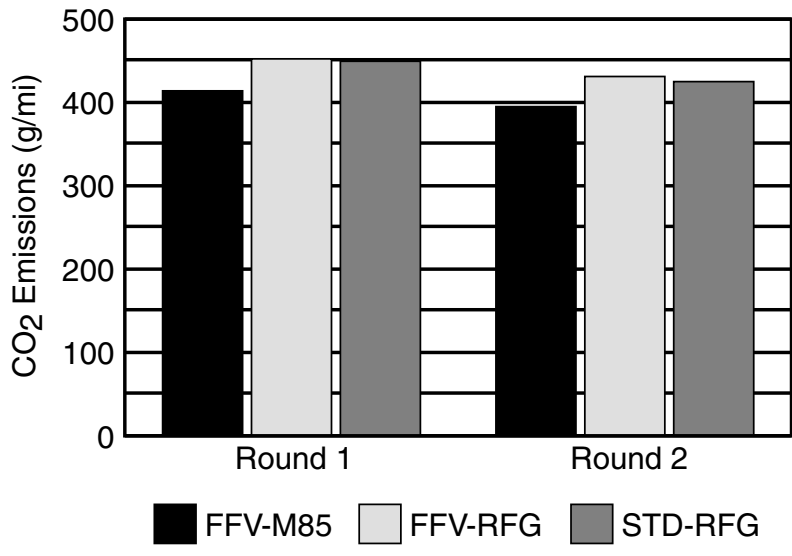

Figure 4. Emissions results from the Dodge Intrepid
The $\mathrm{CO}$ and $\mathrm{NO}_{\mathrm{x}}$ emissions do not show the same trend as NMHCE. The CO emissions from the FFVs tested on M85 were not statistically different from the results of the FFVs tested on RFG and there was little difference between rounds. There was a statistically significant increase in $\mathrm{NO}_{\mathrm{x}}$ emissions for the FFV tested on M85. In Round 1, the $\mathrm{NO}_{\mathrm{x}}$ emissions from the M85 tests were 33.9\% higher; in Round 2, they were $18.2 \%$ higher than those from the RFG tests on the same vehicles. The $\mathrm{NO}_{\mathrm{x}}$ emissions for the FFV Intrepid show a decrease in the second round that was significant for M85, but was not statistically significant for RFG. $\mathrm{NO}_{\mathrm{x}}$ emissions from the standard gasoline vehicles tested on RFG were substantially lower than those from the FFVs tested on the same fuel.

\section{Evaporative Emissions}

The average evaporative emissions for the FFV Intrepid are listed in Table 11 and shown graphically in Figure 5. The average evaporative $\mathrm{HC}$ were well below the 2 -g standard for the FFVs and the gasoline vehicles. When comparing evaporative emissions results for the FFV Intrepid tested on M85 to the same vehicles tested on RFG, the M85 evaporative emissions were $30 \%$ higher in Round 1, and $14.6 \%$ higher in Round 2. The higher evaporative emissions for the FFV tested on M85 is expected, because the Reid vapor pressure (RVP) of the methanol fuel is higher than that of RFG (see Table 5). The difference in evaporative emissions was statistically significant in Round 1, but was not in Round 2. The average evaporative emissions for the conventional Intrepids were lower than the averages for the FFV on both fuels. There was no significant difference between Round 1 and 2 for the FFV on either fuel.

\section{Greenhouse Gases}

The average $\mathrm{CO}_{2}$ emissions for the Intrepids are listed in Table 11 and shown in Figure 4d. Results from Rounds 1 and 2

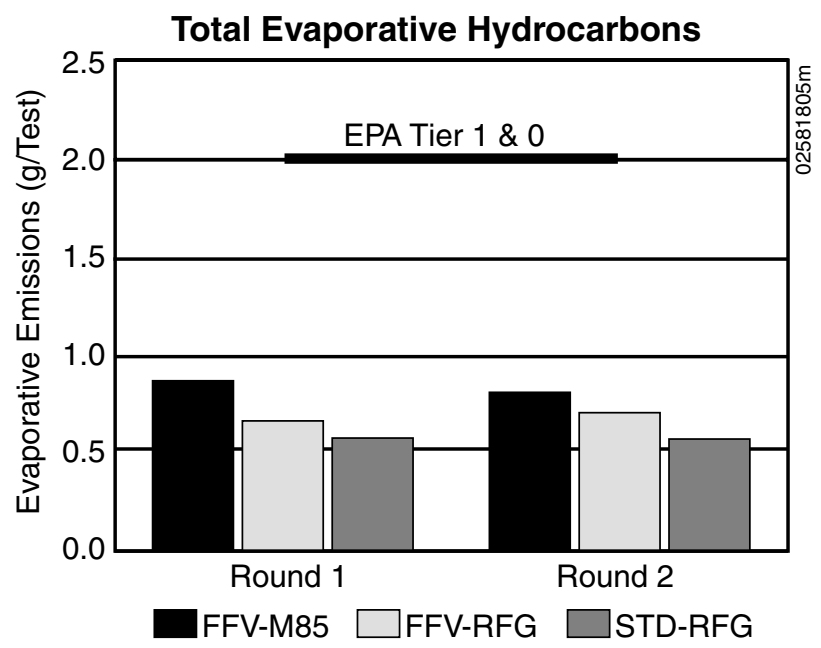

Figure 5. Evaporative emissions results from the Dodge Intrepid 
followed the same trend between the fuels and vehicle types, with very little difference between the rounds. The $\mathrm{CO}_{2}$ emissions from the FFV tested on M85 were approximately $8.5 \%$ lower than those from the same vehicles tested on RFG. The results for the standard model were similar to the FFV on RFG. Average $\mathrm{CH}_{4}$ emissions were very low (less than $0.05 \mathrm{~g} / \mathrm{mi}$ ). For the FFV tested on $\mathrm{M} 85$, the $\mathrm{CH}_{4}$ emissions were approximately $43 \%$ lower than those from the FFV tested on RFG in both rounds.

\section{Aldehydes}

Figure 6 shows the comparison of aldehyde emissions for the Dodge Intrepid. This graph shows that the formaldehyde emissions were much higher from the FFV when tested on M85. Formaldehyde is a primary decomposition product from methanol combustion; therefore, the higher numbers are expected. For Round 1, average formaldehyde emissions were $742 \%$ higher in the M85 tests, and for Round 2, the M85 results were $605 \%$ higher than the RFG results. Acetaldehyde emission levels for the FFV tested on M85 were approximately $61 \%$ lower than the results for the same vehicles tested on RFG, but the levels of acetaldehyde emissions were very low (less than $0.6 \mathrm{mg} / \mathrm{mi}$ ).

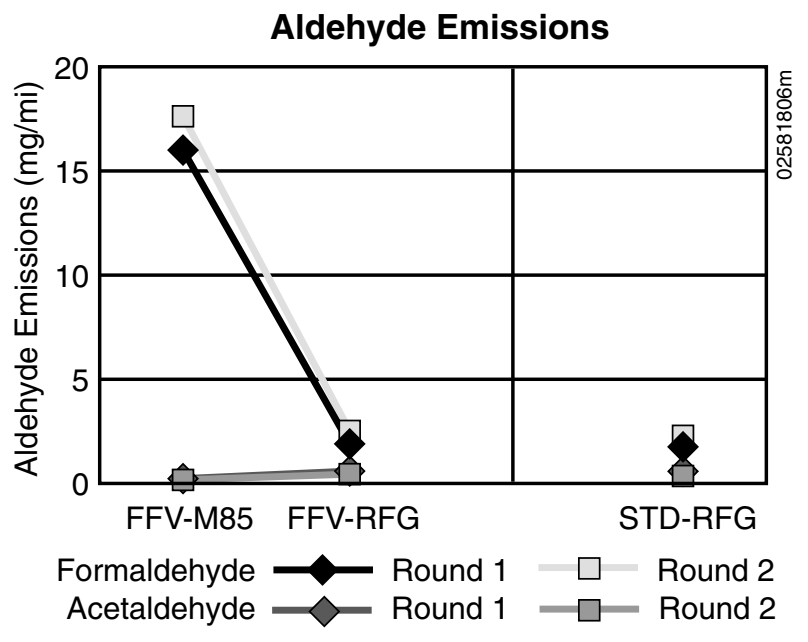

Figure 6. Aldehyde emissions from the Dodge Intrepid

\section{Potency-Weighted Toxics and Ozone-Forming Potential}

Over the two rounds of emissions tests performed, full $\mathrm{HC}$ speciation was performed on a total of six FFV Intrepids and four standard gasoline vehicles. Table 12 lists the average measured toxic emissions and the PWT values and percent difference for the four air toxic compounds. The potency weighting is discussed on page 2 and the factors are shown in Table 3 . The aldehyde values listed are the averages for the speciated vehicles only. Figure 7 shows the comparison of these compounds and the total PWT for the Dodge Intrepids. When comparing PWT for the FFV Dodge Intrepids tested on M85 compared to the same vehicles tested on RFG, the HCHO emissions were significantly higher, but $\mathrm{CH}_{3} \mathrm{CHO}, 1,3$-butadiene, and ben- zene were significantly lower when tested on M85. Total PWT emissions for the FFVs tested on M85 were $16.2 \%$ lower than those from the same vehicles tested on RFG.

Table 13 lists the average OFP and SR for the FFV Intrepid. Figure 8 illustrates an important consideration when comparing $\mathrm{HC}$ emissions for the two test fuels. Both OFP and SR were significantly lower for the FFV when tested on M85. Although the average NMOG emissions from the M85 tests were $85 \%$ higher than the RFG tests, the OFP was $33.7 \%$ lower and the SR was $65.2 \%$ lower for the M85 tests. In other words, although the NMOG emissions from this subset of vehicles were higher, the potential to form ozone based on the exhaust composition is significantly lower. The exhaust from M85 is less reactive in forming ozone in the

Table 12. Toxic Emissions from the Dodge Intrepid

\begin{tabular}{|l|c|c|c|c|c|c|}
\hline & \multicolumn{2}{|c|}{ FFV-M85 } & \multicolumn{2}{c|}{ FFV-RFG } & \multirow{2}{*}{$\begin{array}{c}\text { Percent } \\
\text { Difference }\end{array}$} & $\begin{array}{c}\text { Sig. Fuel } \\
\text { Effect? }\end{array}$ \\
\cline { 2 - 5 } & $\begin{array}{c}\text { Measured } \\
\text { Value (mg/mi) }\end{array}$ & PWT & $\begin{array}{c}\text { Measured } \\
\text { Value (mg/mi) }\end{array}$ & PWT & P. & \\
\hline $\mathrm{HCHO}$ & 15.65 & 0.72 & 2.00 & 0.092 & $682.5 \%$ & $\mathrm{y}$ \\
\hline $\mathrm{CH}_{3} \mathrm{CHO}$ & 0.20 & 0.0016 & 0.488 & 0.0039 & $-59.0 \%$ & $\mathrm{y}$ \\
\hline $1,3-$-butadiene & 0.113 & 0.113 & 0.813 & 0.813 & $-86.2 \%$ & $\mathrm{y}$ \\
\hline Benzene & 0.919 & 0.028 & 3.956 & 0.119 & $-76.8 \%$ & $\mathrm{y}$ \\
\hline Total & 16.882 & 0.861 & 7.257 & 1.027 & $-16.2 \%$ & $\mathrm{y}$ \\
\hline
\end{tabular}




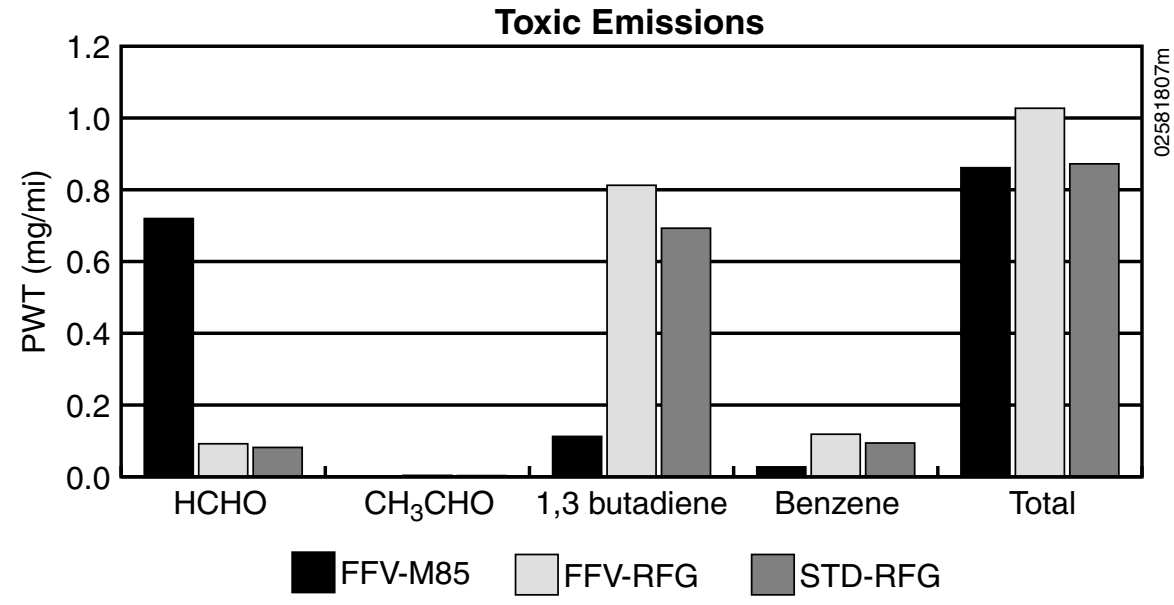

Figure 7. PWT emissions from the Dodge Intrepid

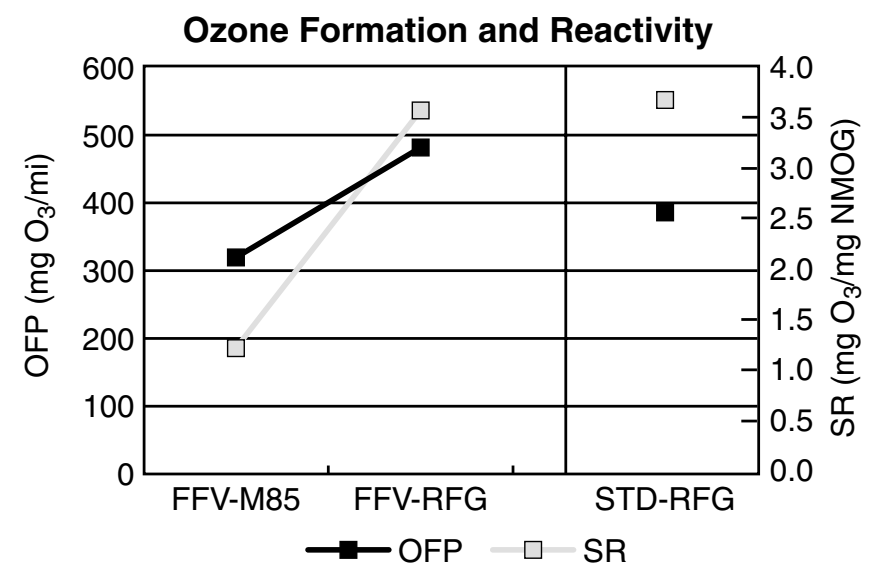

Figure 8. OFP and SR for the Dodge Intrepid

Table 13. OFP for the Dodge Intrepid

\begin{tabular}{|l|c|c|c|c|}
\hline & $\begin{array}{c}\text { FFV- } \\
\text { M85 }\end{array}$ & $\begin{array}{c}\text { FFV- } \\
\text { RFG }\end{array}$ & $\begin{array}{c}\text { Percent } \\
\text { Difference }\end{array}$ & $\begin{array}{c}\text { Sig. Fuel } \\
\text { Effect? }\end{array}$ \\
\hline NMOG $(\mathrm{mg} / \mathrm{mi})$ & 257.94 & 139.76 & 84.6 & $\mathrm{y}$ \\
\hline OFP $\left(\mathrm{mg} \mathrm{O}_{3} / \mathrm{mi}\right)$ & 319.5 & 481.69 & $-33.7 \%$ & $\mathrm{y}$ \\
\hline $\mathrm{SR}(\mathrm{mg} \mathrm{O} / \mathrm{mg} \mathrm{NMOG})$ & 1.248 & 3.587 & $-65.2 \%$ & $\mathrm{y}$ \\
\hline
\end{tabular}

atmosphere. The OFP and the $\mathrm{SR}$ for the gasoline model tested on RFG were similar to those of the FFV tested on RFG.

\section{Fuel Economy}

The fuel economy for the FFV Intrepid was approximately $12 \mathrm{mpg}$ when operating on M85 and $20 \mathrm{mpg}$ on gasoline. This is a decrease of approximately $39 \%$ for the FFV tested on M85 for both rounds. This is expected because methanol has a lower volumetric energy content than gasoline. The energy content of the M85 $(64,600 \mathrm{Btu} / \mathrm{gal})$ is $58 \%$ of the RFG (111,960 Btu/gal). In other words, it takes approximately 1.7 gallons of M85 to travel the same distance as 1 gallon of gasoline. When the values are adjusted to account for this difference, the average fuel economy for the FFV Intrepid on M85 is 20 mpeg in Round 1 and 21 mpeg in
Round 2. In other words, the M85 tests showed a 5\% improvement in energy equivalent fuel economy over RFG for Round 1 and a 4.7\% improvement for Round 2. The FFV on gasoline had similar fuel economy numbers to the conventional model. An important consideration for most drivers is the range of the vehicle. Because of the difference in energy content of the fuels, the FFV operating on M85 will not travel as far as when using gasoline. For this reason, many manufacturers increase the size of the tank to help offset this difference. The FFV Intrepid and the gasoline control Intrepid tested here, however, both had 18-gallon fuel tanks. Based on the fuel economy for the FTP-75, the gasoline control vehicle has an approximate range of 356 miles; the FFV has a range of 214 miles on M85 and 354 miles on gasoline.

\section{Dodge SPIRIT}

The 1993 Dodge Spirit (shown in Figure 9) is a passenger car equipped with a $2.5 \mathrm{~L}$, I6 engine with multipoint fuel injection. Although both the FFV and gasoline Spirits were certified to federal Tier 0 emissions standards, the majority of the emissions results are below the more stringent Tier 1 levels. This report covers the two rounds of testing performed on the Dodge Spirits at Labs 1 and 3. Lab 2 tested the Dodge Spirit in only 1 round and the results can be found in a previous publication. ${ }^{8}$ At Lab 1 , 21 FFV Spirits and 24 gasoline controls were tested in both rounds. At Lab 3, the FFV Spirits totaled 22 and the gasoline controls 20 in both rounds. Mileage ranges and average odometer readings for each vehicle type and round are listed in Tables 14 and 15 . The complete data set can be found in Appendix A. 


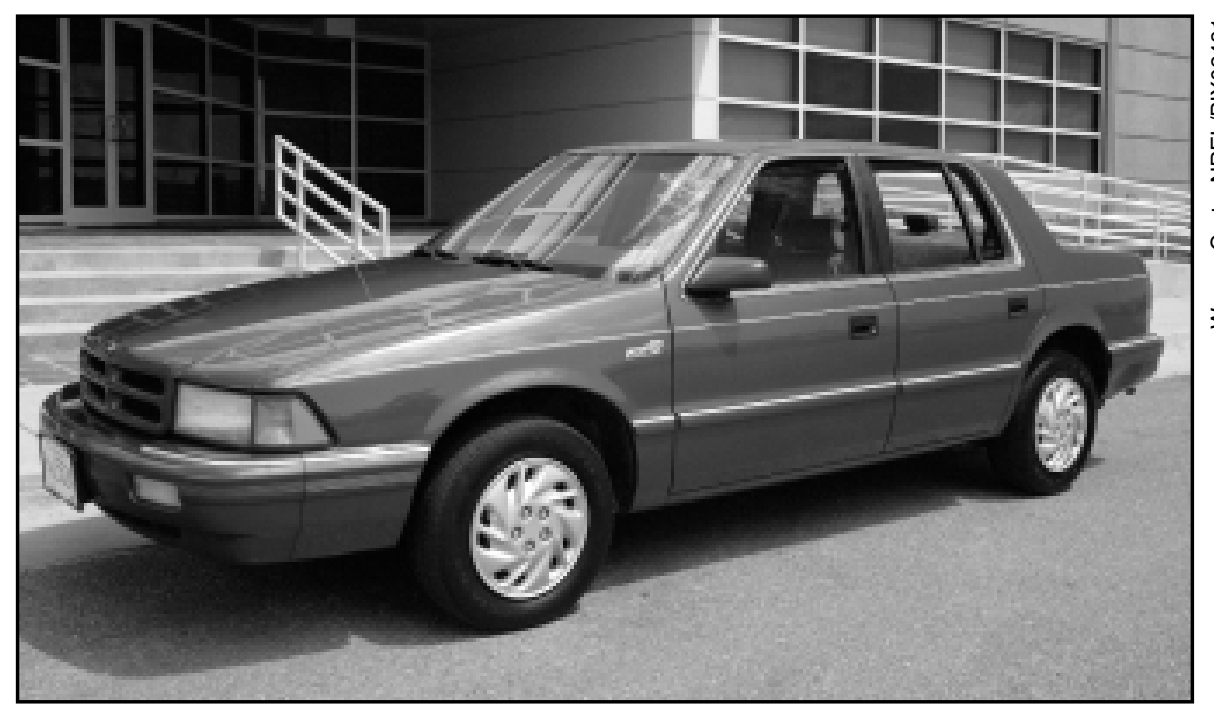

Figure 9. The 1993 M85 Dodge Spirit

Table 14. Odometer Readings for the Dodge Spirit Tested at Lab 1

\begin{tabular}{|l|c|c|c|c|}
\hline & \multicolumn{2}{|c|}{ FFV } & \multicolumn{2}{c|}{ Gasoline } \\
\hline Round & 1 & 2 & 1 & 2 \\
\hline No. vehicles tested & 21 & 21 & 24 & 24 \\
\hline \multicolumn{5}{|c|}{ Odometer (miles) } \\
\hline Average & 8,803 & 17,073 & 12,208 & 27,834 \\
\hline Maximum & 18,203 & 29,679 & 35,757 & 61,638 \\
\hline Minimum & 3,704 & 7,683 & 4,339 & 10,036 \\
\hline
\end{tabular}

Table 15. Odometer Readings for the Dodge Spirit Tested at Lab 3

\begin{tabular}{|l|c|c|c|c|}
\hline & \multicolumn{2}{|c|}{ FFV } & \multicolumn{2}{c|}{ Gasoline } \\
\hline Round & 1 & 2 & 1 & 2 \\
\hline No. vehicles tested & 22 & 22 & 20 & 20 \\
\hline \multicolumn{5}{|c|}{ Odometer (miles) } \\
\hline Average & 14,030 & 24,240 & 16,063 & 28,035 \\
\hline Maximum & 26,058 & 38,506 & 28,005 & 47,989 \\
\hline Minimum & 4,080 & 8,746 & 5,743 & 9,467 \\
\hline
\end{tabular}

\section{Regulated Emissions}

Tables 16 and 17 list the average emissions results for the FFV Dodge Spirits tested at Lab 1 and Lab 3. Included in the tables are the averages for the FFV tested on M85 and RFG, along with the percent difference between the averages. The statistical significance of the fuel effect was determined using the ANOVA analysis. All average regulated emissions for the Spirits tested at both labs were well below the Tier 0 emission standard and in most cases, also below the more stringent Tier 1 levels. (The EPA emissions certification standards are shown in Table 1 on page 2.)

Figures 10 and 11 show the regulated and $\mathrm{CO}_{2}$ emissions for the Spirits tested at Labs 1 and 3. In general, when comparing the regulated emissions for M85 and RFG tests for the Dodge Spirit, NMHCE emissions from the M85 tests were lower, CO emissions from the M85 tests were slightly lower, and $\mathrm{NO}_{\mathrm{x}}$ emissions for the M85 tests tended to be higher.

Average $\mathrm{HC}$ emissions showed similar patterns on the vehicles tested at both labs. The NMHCE emissions for the FFV operating on M85 were significantly less than those from the same vehicles tested on gasoline (Figures 10a and 11a). For Lab 1, the difference was $17 \%$ during Round 1 and $27 \%$ in Round 2. For Lab 3, the difference between the fuels was even larger, approximately $30.5 \%$ in both rounds. NMHCE emissions for the conventional Spirits tested at both labs were lower than the levels of the FFV operating on either fuel. The difference in NMHCE emissions from Round 1 to Round 2 tended to be not significant at the $95 \%$ confidence level.

The $\mathrm{CO}$ emissions from both labs are shown in Figures $10 \mathrm{~b}$ and $11 \mathrm{~b}$. The average values at Lab 3 were higher than the averages at Lab 1, but they follow the same pattern. At both labs the standard gasoline model had lower $\mathrm{CO}$ emissions than the FFV on either fuel. The FFV had lower CO emissions when tested on M85, but the difference between the two fuels was only significant for Round 2 at Lab 1. At Lab 1, the FFV on M85 was $1 \%$ lower in Round 1 and approximately $11 \%$ lower in Round 2 . The FFVs tested at Lab 3 showed a difference of approximately $10 \%$ lower on M85 for both rounds. Average CO emissions showed increases from Round 1 to Round 2 that were statistically significant for both fuels at both labs. All CO emissions averages were well below the Tier 0 and Tier 1 standard of $3.4 \mathrm{~g} / \mathrm{mi}$. 
Table 16. Average Emissions Results from the Dodge Spirit Tested at Lab 1

\begin{tabular}{|c|c|c|c|c|c|c|c|c|}
\hline & \multicolumn{4}{|c|}{ Round 1} & \multicolumn{4}{|c|}{ Round 2} \\
\hline & $\begin{array}{l}\text { FFV- } \\
\text { M85 }\end{array}$ & $\begin{array}{l}\text { FFV- } \\
\text { RFG }\end{array}$ & $\begin{array}{c}\text { Percent } \\
\text { Difference }\end{array}$ & $\begin{array}{c}\text { Sig. Fuel } \\
\text { Effect? }\end{array}$ & $\begin{array}{l}\text { FFV- } \\
\text { M85 }\end{array}$ & $\begin{array}{l}\text { FFV- } \\
\text { RFG }\end{array}$ & $\begin{array}{c}\text { Percent } \\
\text { Difference }\end{array}$ & $\begin{array}{l}\text { Sig. Fuel } \\
\text { Effect? }\end{array}$ \\
\hline \multicolumn{9}{|c|}{ Regulated Emissions (g/mi) } \\
\hline NMHCE & 0.108 & 0.130 & $-16.9 \%$ & $\mathrm{y}$ & 0.104 & 0.142 & $-26.9 \%$ & $\mathrm{y}$ \\
\hline $\mathrm{THC}$ & 0.112 & 0.151 & $-25.8 \%$ & $\mathrm{y}$ & 0.111 & 0.168 & $-33.8 \%$ & $\mathrm{y}$ \\
\hline $\mathrm{CO}$ & 1.43 & 1.45 & $-1.2 \%$ & $\mathrm{n}$ & 1.61 & 1.81 & $-10.9 \%$ & $y$ \\
\hline $\mathrm{NO}_{\mathrm{x}}$ & 0.212 & 0.151 & $40.4 \%$ & $\mathrm{y}$ & 0.182 & 0.219 & $-16.9 \%$ & $\mathrm{y}$ \\
\hline \multicolumn{9}{|c|}{ Evaporative Emissions (g/Test) } \\
\hline Total Evaporative & 0.708 & 0.724 & $-2.21 \%$ & $\mathrm{n}$ & 0.78 & 0.887 & $-12.1 \%$ & $\mathrm{n}$ \\
\hline \multicolumn{9}{|c|}{ Greenhouse Gases (g/mi) } \\
\hline $\mathrm{CO}_{2}$ & 350.3 & 379.5 & $-7.7 \%$ & $\mathrm{y}$ & 348.6 & 376.8 & $-7.5 \%$ & $y$ \\
\hline $\mathrm{CH}_{4}$ & 0.015 & 0.026 & $-43.1 \%$ & $\mathrm{y}$ & 0.016 & 0.031 & $-49.8 \%$ & $\mathrm{y}$ \\
\hline \multicolumn{9}{|c|}{ Aldehydes (mg/mi) } \\
\hline $\mathrm{HCHO}$ & 12.7 & 1.47 & $763.9 \%$ & $\mathrm{y}$ & 12.4 & 1.42 & $771.8 \%$ & $\mathrm{y}$ \\
\hline $\mathrm{CH}_{3} \mathrm{CHO}$ & 0.31 & 0.50 & $-37.8 \%$ & $y$ & 0.19 & 0.39 & -50.9 & $y$ \\
\hline \multicolumn{9}{|l|}{ Fuel Economy } \\
\hline $\mathrm{mpg}$ & 13.56 & 22.82 & $-40.6 \%$ & $\mathrm{y}$ & 13.8 & 23.02 & $-40.1 \%$ & $\mathrm{y}$ \\
\hline mpeg & 23.5 & 22.82 & $3.0 \%$ & $y$ & 23.92 & 23.02 & $3.9 \%$ & $y$ \\
\hline
\end{tabular}

Table 17. Average Emissions Results from the Dodge Spirit Tested at Lab 3

\begin{tabular}{|c|c|c|c|c|c|c|c|c|}
\hline & \multicolumn{4}{|c|}{ Round 1} & \multicolumn{4}{|c|}{ Round 2} \\
\hline & $\begin{array}{l}\text { FFV- } \\
\text { M85 }\end{array}$ & $\begin{array}{l}\text { FFV- } \\
\text { RFG }\end{array}$ & $\begin{array}{c}\text { Percent } \\
\text { Difference }\end{array}$ & $\begin{array}{l}\text { Sig. Fuel } \\
\text { Effect? }\end{array}$ & $\begin{array}{l}\text { FFV- } \\
\text { M85 }\end{array}$ & $\begin{array}{l}\text { FFV- } \\
\text { RFG }\end{array}$ & $\begin{array}{c}\text { Percent } \\
\text { Difference }\end{array}$ & $\begin{array}{c}\text { Sig. Fuel } \\
\text { Effect? }\end{array}$ \\
\hline NMHCE & 0.113 & 0.162 & $-30.6 \%$ & $\mathrm{y}$ & 0.128 & 0.184 & $-30.4 \%$ & $\mathrm{y}$ \\
\hline THC & 0.061 & 0.188 & $-67.5 \%$ & $\mathrm{y}$ & 0.061 & 0.220 & $-72.5 \%$ & $\mathrm{y}$ \\
\hline $\mathrm{CO}$ & 1.63 & 1.80 & $-9.6 \%$ & $n$ & 1.98 & 2.11 & $-10.5 \%$ & $\mathrm{n}$ \\
\hline $\mathrm{NO}_{\mathrm{x}}$ & 0.207 & 0.166 & $24.7 \%$ & $\mathrm{y}$ & 0.251 & 0.236 & $6.4 \%$ & $\mathrm{n}$ \\
\hline \multicolumn{9}{|c|}{ Evaporative Emissions (g/Test) } \\
\hline Total Evaporative & 0.371 & 0.48 & $-22.7 \%$ & $\mathrm{n}$ & 1.207 & 1.067 & $13.1 \%$ & $\mathrm{n}$ \\
\hline \multicolumn{9}{|c|}{ Greenhouse Gases (g/mi) } \\
\hline $\mathrm{CO}_{2}$ & 331.3 & 357.2 & $-7.3 \%$ & $\mathrm{y}$ & 331.5 & 357.9 & $-7.4 \%$ & $y$ \\
\hline $\mathrm{CH}_{4}$ & 0.014 & 0.028 & $-48.5 \%$ & $\mathrm{y}$ & 0.015 & 0.031 & $-52.0 \%$ & $\mathrm{y}$ \\
\hline \multicolumn{9}{|c|}{ Aldehydes (mg/mi) } \\
\hline $\mathrm{HCHO}$ & 9.15 & 1.16 & $688.8 \%$ & $\mathrm{y}$ & 10.4 & 1.63 & $538.0 \%$ & $\mathrm{y}$ \\
\hline $\mathrm{CH}_{3} \mathrm{CHO}$ & 0.19 & 0.35 & $-45.7 \%$ & $y$ & 0.29 & 0.47 & $-38.3 \%$ & $y$ \\
\hline \multicolumn{9}{|l|}{ Fuel Economy } \\
\hline $\mathrm{mpg}$ & 12.78 & 24.07 & $-46.9 \%$ & $\mathrm{y}$ & 14.46 & 24.0 & $-39.8 \%$ & $\mathrm{y}$ \\
\hline mpeg & 22.15 & 24.07 & $-8.0 \%$ & $y$ & 25.06 & 24.0 & $4.4 \%$ & $y$ \\
\hline
\end{tabular}


10a: Non-Methane Hydrocarbon Equivalent

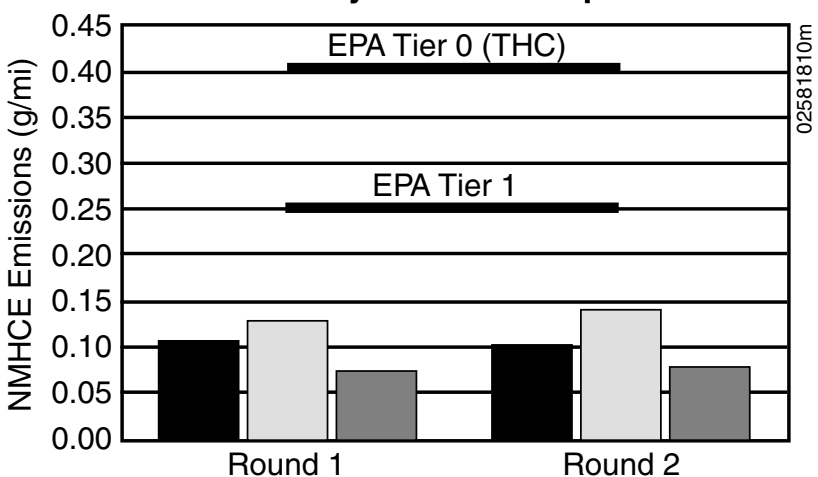

10b: Carbon Monoxide

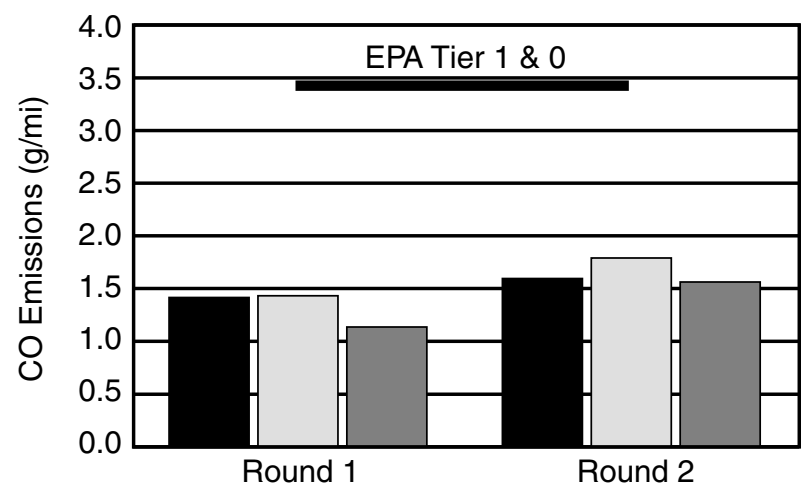

10c: Oxides of Nitrogen

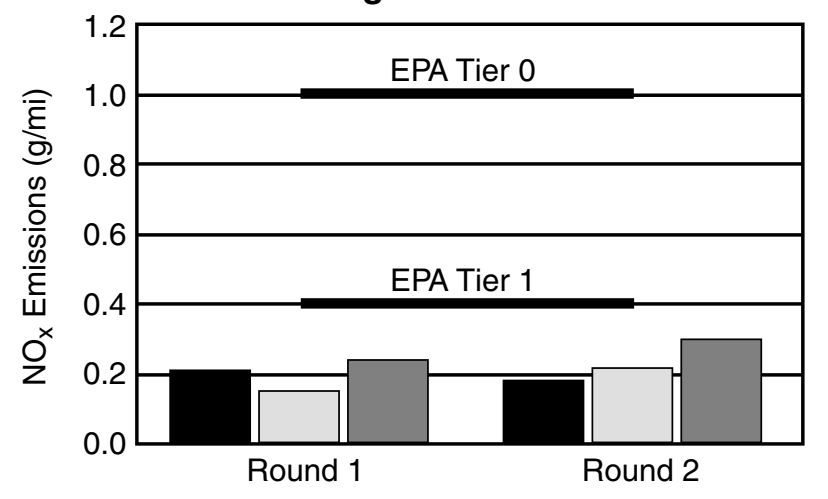

10d: Carbon Dioxide

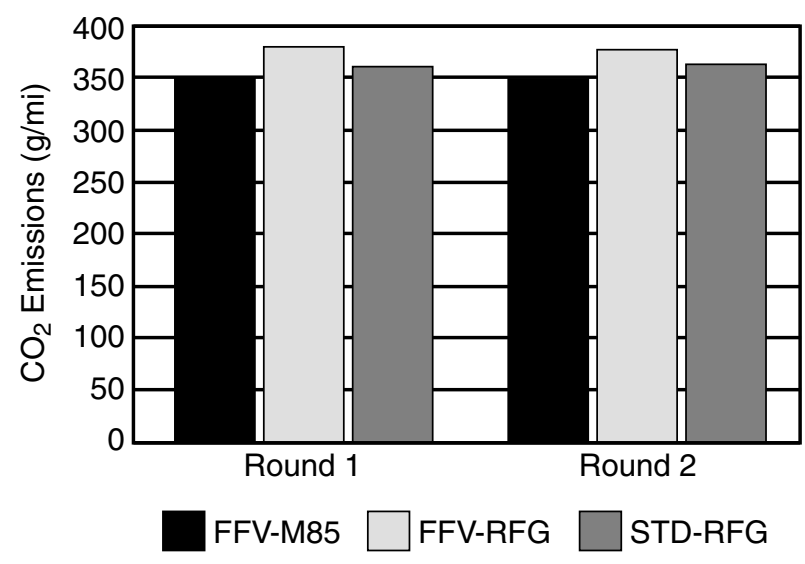

Figure 10. Emissions results from the Dodge Spirit tested at Lab 1 11a: Non-Methane Hydrocarbon Equivalent

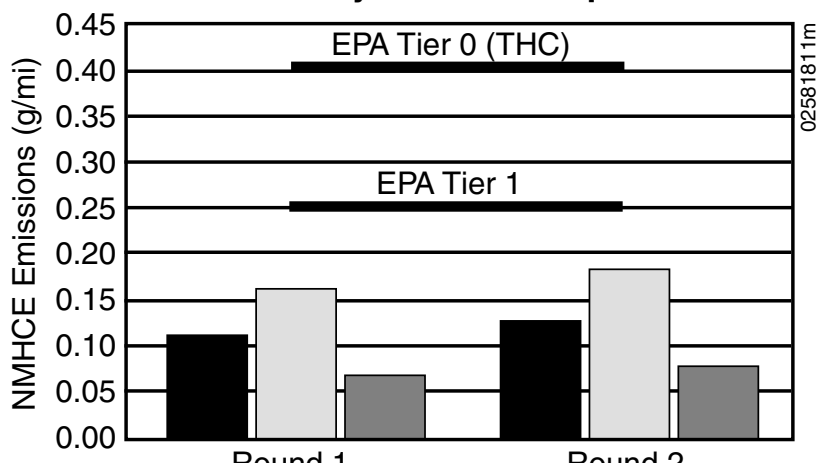

Round 1

Round 2

11b: Carbon Monoxide

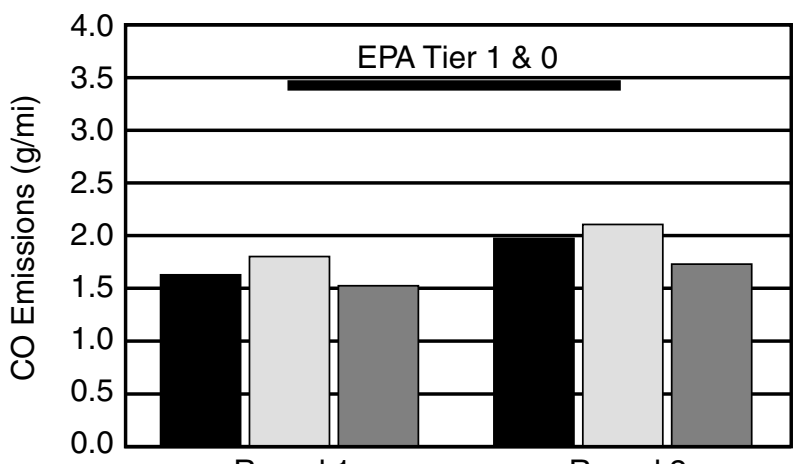

Round 1

Round 2

11c: Oxides of Nitrogen

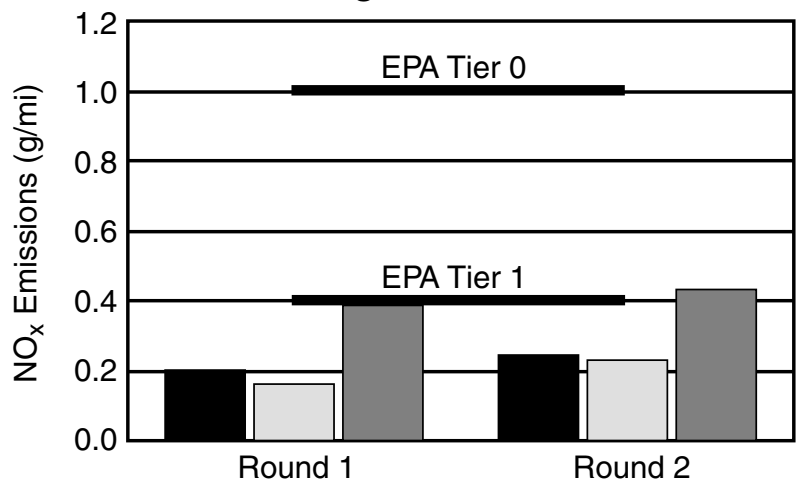

11d: Carbon Dioxide

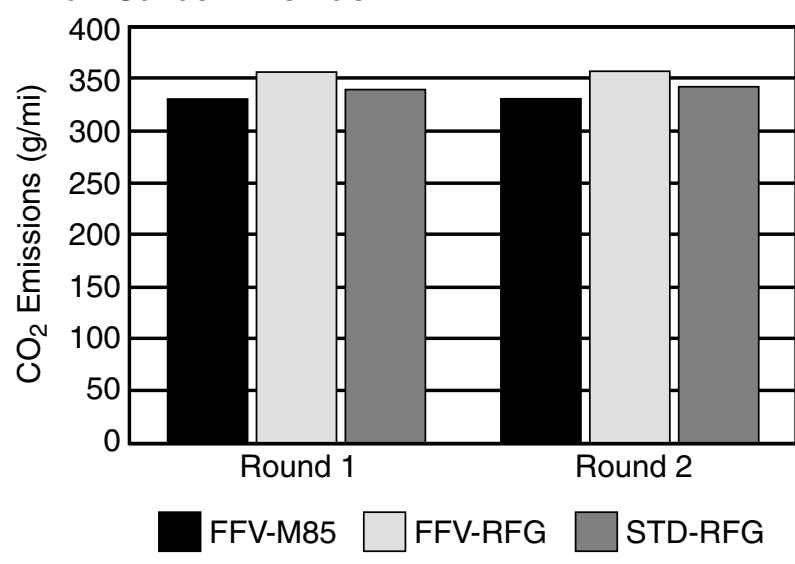

Figure 11. Emissions results from the Dodge Spirit tested at Lab 3 
The $\mathrm{NO}_{\mathrm{x}}$ emissions for the Spirits tested at Lab 1 showed different patterns in the two rounds. During Round 1, the $\mathrm{NO}_{\mathrm{x}}$ emissions from the FFV operating on M85 were $40 \%$ higher than those from the same vehicles tested on RFG. The standard model tested on RFG had an even higher $\mathrm{NO}_{\mathrm{x}}$ average. In Round 2, the average $\mathrm{NO}_{\mathrm{x}}$ emissions for the FFV tested on M85 were $17 \%$ lower than the average when tested on RFG. The standard model again tested higher than the FFV on both fuels. The Spirits tested at Lab 3 showed similar trends. In Round 1, the FFV Spirits tested on M85 had 25\% higher $\mathrm{NO}_{\mathrm{x}}$ emissions than when they were tested on RFG. In Round 2, the average for M85 was only $6 \%$ higher than the average for RFG. The values for the standard model Spirits were much higher than the FFV Spirits in both rounds. All $\mathrm{NO}_{\mathrm{x}}$ values were well below the Tier 0 levels.

\section{Evaporative Emissions}

Average evaporative emissions for the Dodge Spirits are listed in Tables 16 and 17. Figures 12 and 13 graphically illustrate these values. The average evaporative $\mathrm{HC}$ for the FFV and standard gasoline Spirits were well below the standard of $2 \mathrm{~g}$ per test. When comparing the FFV Spirits tested on M85 to the same vehicles tested on RFG, both labs showed no significant difference between the two fuels. The conventional Spirits tested lower than the FFV Spirits on either fuel with one exception. At Lab 3 during Round 1 , the conventional Spirits had higher evaporative emissions than the FFV. There was an increase in evaporative emissions between Rounds 1 and 2 for the FFV tested on both fuels at Lab 1, but the difference was not significant at the 95\% confidence level. At Lab 3, the FFV on both fuels showed statistically significant increases in Round 2.

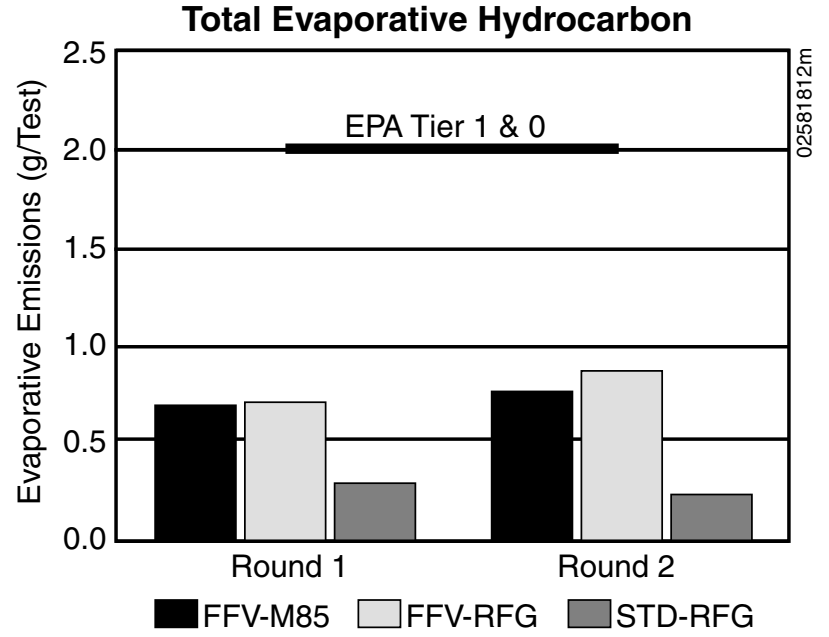

Figure 12. Evaporative emissions results from the Dodge Spirit tested at Lab 1

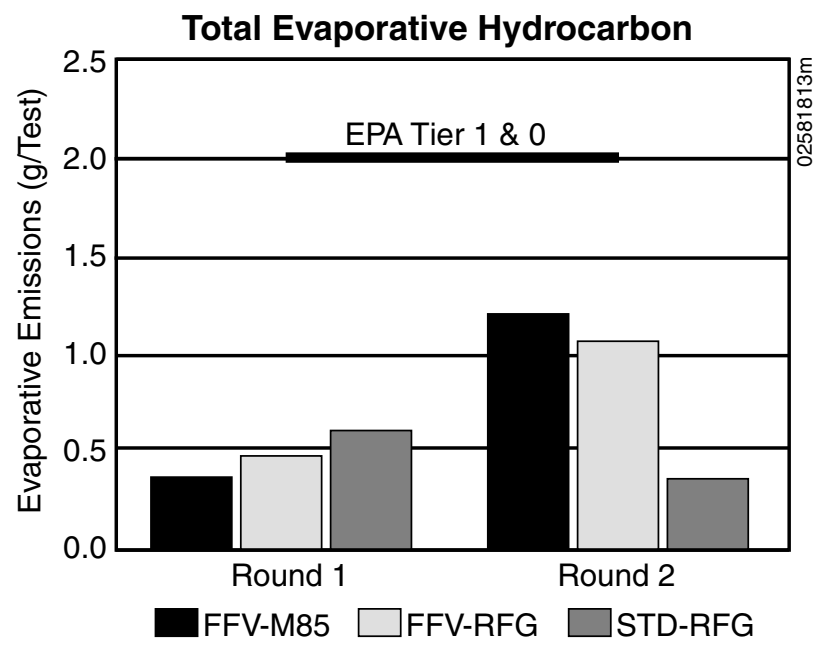

Figure 13. Evaporative emissions results From the Dodge Spirit tested at Lab 3

Because of the high variability of evaporative results, outliers were not deleted from the data sets. Round 2 evaporative results for the FFV Spirits tested at Lab 3 increased significantly over Round 1 for both fuels. This was not consistent with the results from Lab 1, and warranted a closer look. The evaporative results for the FFV Spirits tested at Lab 1 showed only 2 outliers, which had little effect on the final averages. The evaporative results from the Spirits tested at Lab 3, however, revealed several apparent outliers. Most of those data points were well above the EPA limit of $2 \mathrm{~g}$ per test; the highest was $6.9 \mathrm{~g}$ total. When those outliers were removed from the data set, the results were more consistent from lab to lab and round to round.

\section{Greenhouse Gases}

The average $\mathrm{CO}_{2}$ emissions are shown in Figures 10d and 11d. Both labs showed the same patterns, with the FFV on M85 having the lowest $\mathrm{CO}_{2}$ emissions and the FFV on RFG the highest. The percent difference between the FFV on M85 and on RFG was approximately $7 \%$ for both labs during both rounds. These were statistically significant differences at the $95 \%$ confidence level. Average 


\section{Aldehyde Emissions}

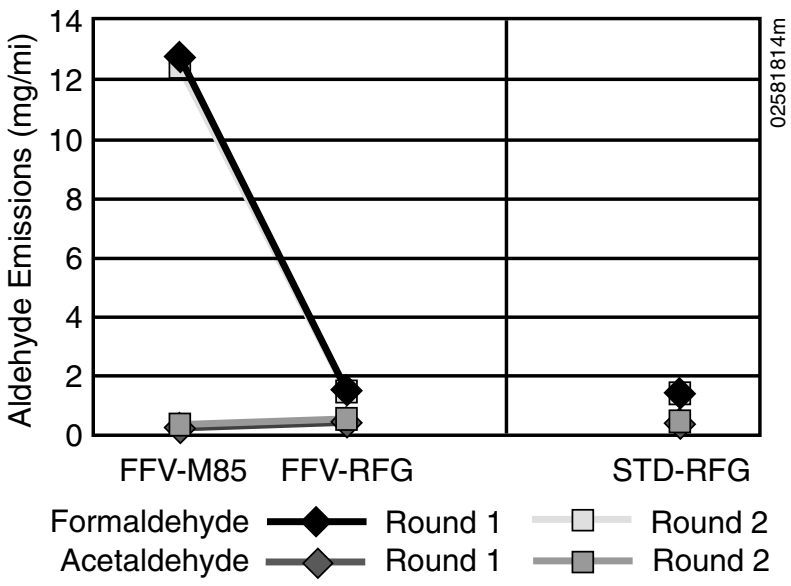

Figure 14. Aldehyde emissions from the Dodge Spirit tested at Lab 1

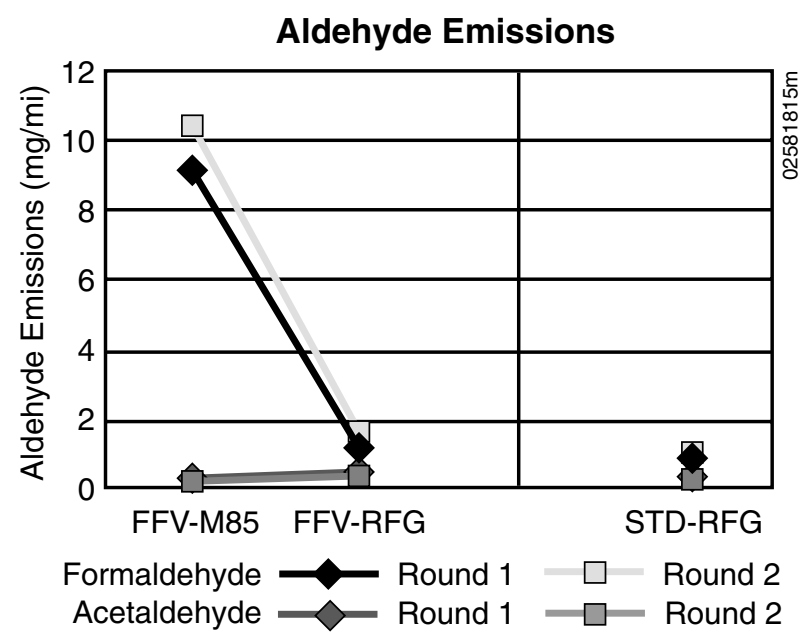

Figure 15. Aldehyde emissions from the Dodge Spirit tested at Lab 3

$\mathrm{CO}_{2}$ emissions at Lab 1 showed a decrease between Round 1 and Round 2 that was not significant for M85, but was significant for RFG. Average $\mathrm{CO}_{2}$ emissions at Lab 3 showed an increase from Round 1 to Round 2 for both fuels that was not statistically significant at the $95 \%$ confidence level.

Although the differences in $\mathrm{CH}_{4}$ emissions between fuels were statistically significant for both rounds at both labs, the measured amounts were all below $0.04 \mathrm{~g} / \mathrm{mi}$. The average $\mathrm{CH}_{4}$ values for the FFV tested on M85 were $43 \%$ to $52 \%$ less than those from the same vehicles tested on RFG. Both labs show increases in $\mathrm{CH}_{4}$ during Round 2 for M85 and RFG. These differences between rounds were not significant for M85, but they were significant for RFG at Lab 1.

\section{Aldehydes}

The average aldehyde emissions for the Dodge Spirits are shown in

Figures 14 and 15. For both labs, the formaldehyde emissions were six to eight times higher in the FFVs tested on M85. As with the Intrepid, this is expected, because formaldehyde is a primary decomposition product from methanol combustion. At Lab 1, the percent increase for the M85 tests was $764 \%$ and $772 \%$ for Rounds 1 and 2, respectively. At Lab 3, the increase was $689 \%$ and $538 \%$ for the two rounds. The average formaldehyde emissions for the FFV and the standard model (both tested on RFG) were similar.

Acetaldehyde emissions from the M85 and RFG tests were quite low (all below $0.005 \mathrm{~g} / \mathrm{mi}$ ). The acetaldehyde emissions were lowest on the FFV tested on M85 for both labs. At Lab 1, the FFV tested on M85 in Round 1 showed a decrease in acetaldehyde emissions of $38 \%$ and in Round 2, the decrease was $51 \%$ when compared to the FFV tested on RFG. Lab 3 showed similar decreases for M85 compared to RFG of $46 \%$ and $38 \%$ in Rounds 1 and 2, respectively. The average acetaldehyde emissions for the standard models was higher than the FFV tested on M85, but lower than those from the FFV tested on RFG for both labs.

\section{Potency-Weighted Toxics and Ozone-Forming Potential}

During this study, full speciation was performed on 10 FFV Spirits and 9 standard gasoline Spirits. Tables 18 and 19 list the average measured toxic emissions and the average PWT for the FFV Dodge Spirits tested at Labs 1 and 3. Aldehyde values are the average of the speciated vehicles only. Figures 16 and 17 illustrate the differences graphically. When comparing the FFV tested on M85 to the same vehicles tested on RFG, there was a significant increase in formaldehyde emissions, and significant decreases in acetaldehyde, 1,3-butadiene, and benzene. Total PWT for Lab 1 FFV Spirits tested on M85 was 23\% lower than the total PWT for the RFG tests. At Lab 3, the difference was $46 \%$ lower for the M85 tests. All of these differences between fuels were statistically significant at the 95\% confidence level. The total PWT for the gasoline control Spirits was substantially lower than the PWT for 
Table 18. Toxic Emissions from the Dodge Spirit Tested at Lab 1

\begin{tabular}{|c|c|c|c|c|c|c|}
\hline & \multicolumn{2}{|c|}{ FFV-M85 } & \multicolumn{2}{|c|}{ FFV-RFG } & \multirow{2}{*}{$\begin{array}{l}\text { Percent } \\
\text { Difference }\end{array}$} & \multirow{2}{*}{$\begin{array}{r}\text { Sig. Fue } \\
\text { Effect? }\end{array}$} \\
\hline & $\begin{array}{c}\text { Measured } \\
\text { Value }(\mathrm{mg} / \mathrm{mi})\end{array}$ & PWT & $\begin{array}{c}\text { Measured } \\
\text { Value }(\mathrm{mg} / \mathrm{mi})\end{array}$ & PWT & & \\
\hline $\mathrm{HCHO}$ & 14.035 & 0.646 & 1.687 & 0.078 & $731.0 \%$ & $\mathrm{y}$ \\
\hline $\mathrm{CH}_{3} \mathrm{CHO}$ & 0.252 & 0.002 & 0.488 & 0.004 & $-50.0 \%$ & $y$ \\
\hline 1,3-butadiene & 0.10 & 0.10 & 0.80 & 0.80 & $-87.5 \%$ & $\mathrm{y}$ \\
\hline Benzene & 1.042 & 0.031 & 4.40 & 0.132 & $-90.2 \%$ & $\mathrm{y}$ \\
\hline Total & 15.429 & 0.779 & 7.375 & 1.013 & $-23.1 \%$ & $y$ \\
\hline
\end{tabular}

Table 19. Toxic Emissions from the Dodge Spirit Tested at Lab 3

\begin{tabular}{|c|c|c|c|c|c|c|}
\hline & \multicolumn{2}{|c|}{ FFV-M85 } & \multicolumn{2}{|c|}{ FFV-RFG } & \multirow{2}{*}{$\begin{array}{l}\text { Percent } \\
\text { Difference }\end{array}$} & \multirow{2}{*}{$\begin{array}{l}\text { Sig. Fuel } \\
\text { Effect? }\end{array}$} \\
\hline & \begin{tabular}{|c|} 
Measured \\
Value $(\mathrm{mg} / \mathrm{mi})$ \\
\end{tabular} & PWT & $\begin{array}{c}\text { Measured } \\
\text { Value }(\mathrm{mg} / \mathrm{mi}) \\
\end{array}$ & PWT & & \\
\hline $\mathrm{HCHO}$ & 9.725 & 0.447 & 1.538 & 0.071 & $532.3 \%$ & $y$ \\
\hline $\mathrm{CH}_{3} \mathrm{CHO}$ & 0.275 & 0.0022 & 0.475 & 0.0038 & $-42.1 \%$ & $\mathrm{y}$ \\
\hline 1,3-butadiene & 0.174 & 0.174 & 0.997 & 0.997 & $-82.6 \%$ & $y$ \\
\hline Benzene & 1.695 & 0.051 & 6.023 & 0.181 & $-71.9 \%$ & $\mathrm{y}$ \\
\hline Total & 11.869 & 0.674 & 9.033 & 1.252 & $-46.2 \%$ & $y$ \\
\hline
\end{tabular}

Table 20. OFP for the Dodge Spirit Tested at Lab 1

\begin{tabular}{|l|c|c|c|c|}
\hline & $\begin{array}{c}\text { FFV- } \\
\text { M85 }\end{array}$ & $\begin{array}{c}\text { FFV- } \\
\text { RFG }\end{array}$ & $\begin{array}{c}\text { Percent } \\
\text { Difference }\end{array}$ & $\begin{array}{c}\text { Sig. Fuel } \\
\text { Effect? }\end{array}$ \\
\hline $\mathrm{NMOG}(\mathrm{mg} / \mathrm{mi})$ & 191.70 & 151.80 & $26.3 \%$ & $\mathrm{y}$ \\
\hline $\mathrm{OFP}\left(\mathrm{mg} \mathrm{O}_{3} / \mathrm{mi}\right)$ & 263.74 & 380.63 & $-30.7 \%$ & $\mathrm{y}$ \\
\hline $\mathrm{SR}\left(\mathrm{mg} \mathrm{O}_{3} / \mathrm{mg} \mathrm{NMOG}\right)$ & 1.385 & 2.908 & $-52.4 \%$ & $\mathrm{y}$ \\
\hline
\end{tabular}

Table 21. OFP for the Dodge Spirit Tested at Lab 3

\begin{tabular}{|l|c|c|c|c|}
\hline & $\begin{array}{c}\text { FFV- } \\
\text { M85 }\end{array}$ & $\begin{array}{c}\text { FFV- } \\
\text { RFG }\end{array}$ & $\begin{array}{c}\text { Percent } \\
\text { Difference }\end{array}$ & $\begin{array}{c}\text { Sig. Fuel } \\
\text { Effect? }\end{array}$ \\
\hline $\mathrm{NMOG}(\mathrm{mg} / \mathrm{mi})$ & 242.56 & 219.18 & $10.7 \%$ & $\mathrm{n}$ \\
\hline $\mathrm{OFP}\left(\mathrm{mg} \mathrm{O}_{3} / \mathrm{mi}\right)$ & 332.66 & 749.19 & $-55.6 \%$ & $\mathrm{y}$ \\
\hline $\mathrm{SR}\left(\mathrm{mg} \mathrm{O}_{3} / \mathrm{mg} \mathrm{NMOG}\right)$ & 1.387 & 3.581 & $-61.9 \%$ & $\mathrm{y}$ \\
\hline
\end{tabular}

the FFV Spirit tested on either fuel. This trend was consistent among labs. The decrease in PWT appears to be a direct result of the decrease in NMHCE for the gasoline Spirits compared to the FFV Spirit tested on RFG. The decrease in HC may result from the differences in calibration of the vehicle models.

Tables 20 and 21 list the NMOG, OFP, and SR for the Spirits at both labs. Figures 18 and 19 graphically illustrate these averages. The NMOG emissions from the M85 tests were higher than those from the RFG tests on this vehicle subset, but the OFP and SR were lower. As with the Intrepids, although the NMOG emissions were higher, the ozone formed from these emissions would tend to be less than that formed from the RFG emissions. The OFP and SR were significantly lower for the FFV when tested on M85. The FFV Spirits 


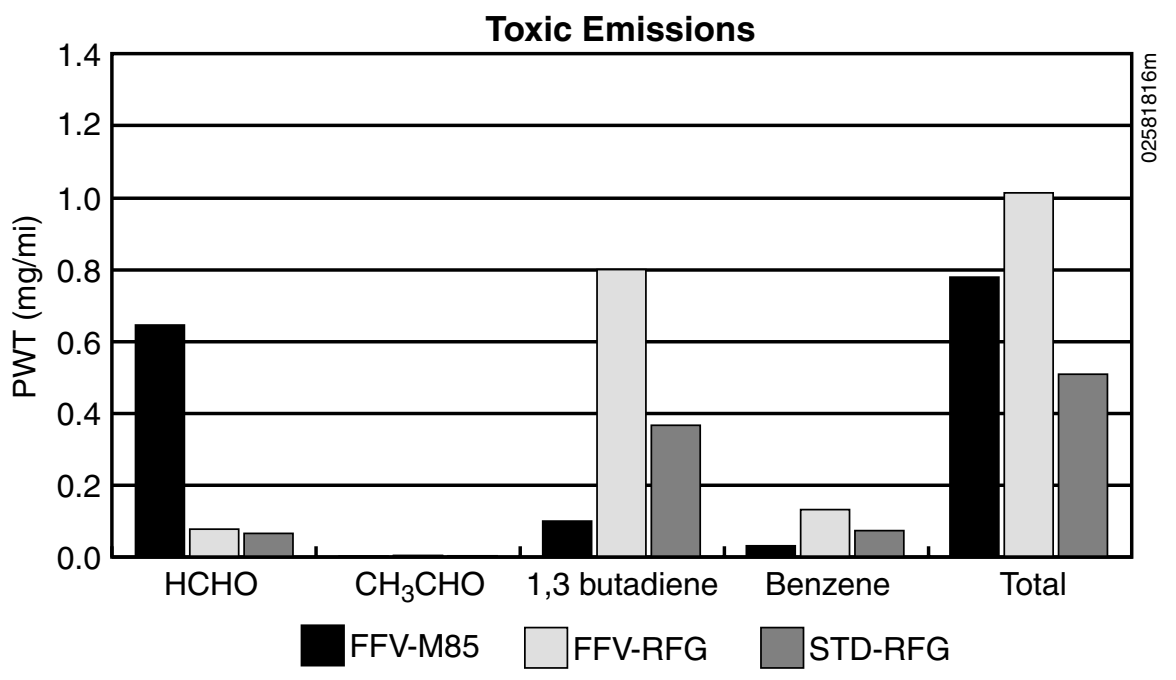

Figure 16. PWT emissions from the Dodge Spirit tested at Lab 1

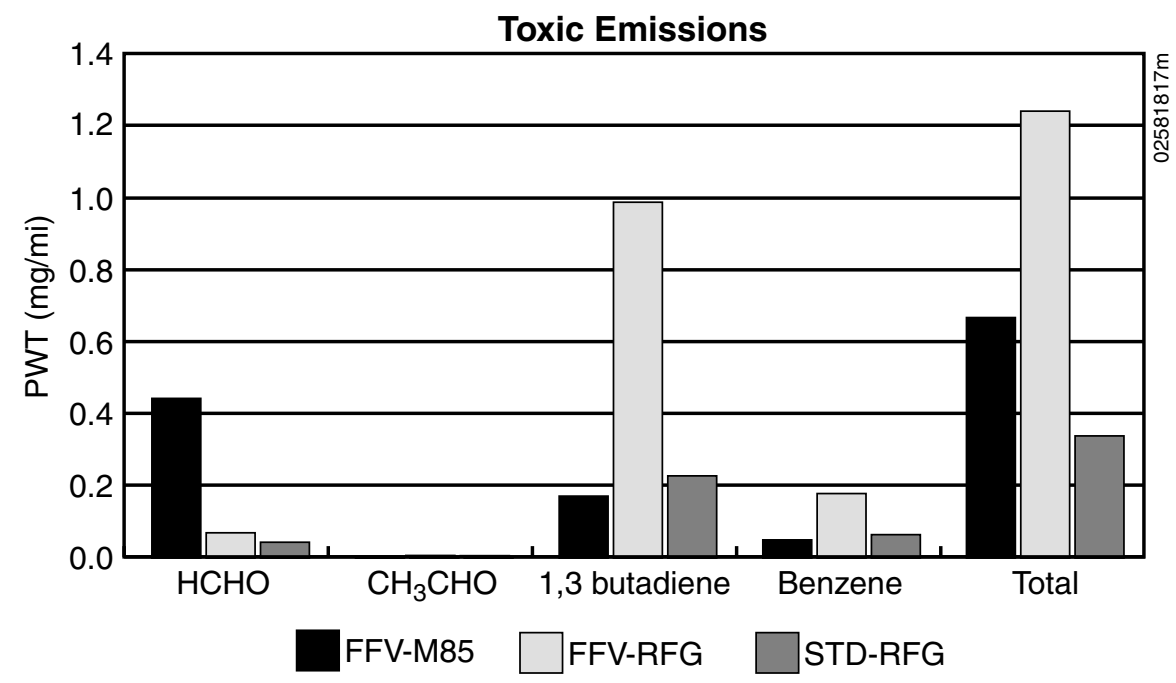

Figure 17. PWT emissions from the Dodge Spirit tested at Lab 3 tested at Lab 1 on M85 showed a $31 \%$ reduction in OFP and a $52.4 \%$ reduction in SR. Lab 3 values showed a similar finding; OFP was 55.6\% lower in the M85 tests and SR was $61.8 \%$ lower.

\section{Fuel Economy}

When tested on M85, the fuel economy on the Dodge Spirits was significantly less than when the same vehicles were tested on gasoline. For Lab 1, there was a decrease of about $40 \%$ for both rounds. The Dodge Spirits tested at Lab 3 averaged $47 \%$ lower in Round 1 and 40\% lower in Round 2 when tested on M85. As with the Intrepids, the energy equivalent fuel economy for the Spirits on M85 was much higher. On an energy equivalent basis, the FFV tested on M85 was 3\% to 4\% more energy efficient than when it was tested on RFG at Lab 1. The Spirits tested at Lab 3 during Round 1 were approximately $8 \%$ less energy efficient in Round 1 , but were $4.4 \%$ more energy efficient in Round 2. Unlike the Intrepid, Dodge increased the tank size of the FFV Spirit to help offset the difference in energy content of the fuels. The tank on the gasoline control holds 16 gallons for a range of approximately 390 miles. The FFV tank holds 18 gallons for a range of approximately 245 miles on M85 and 420 miles on gasoline.

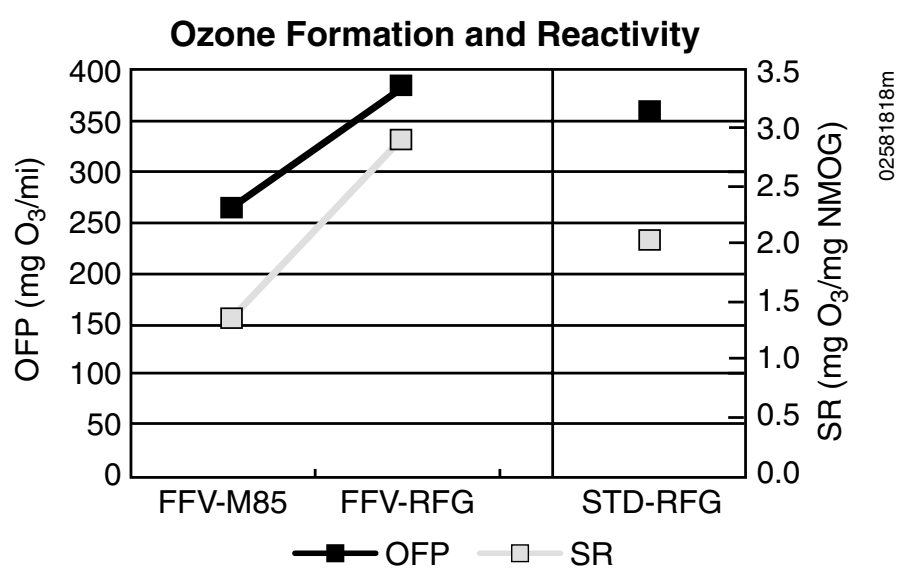

Figure 18. OFP and SP for the Dodge Spirit tested at Lab 1

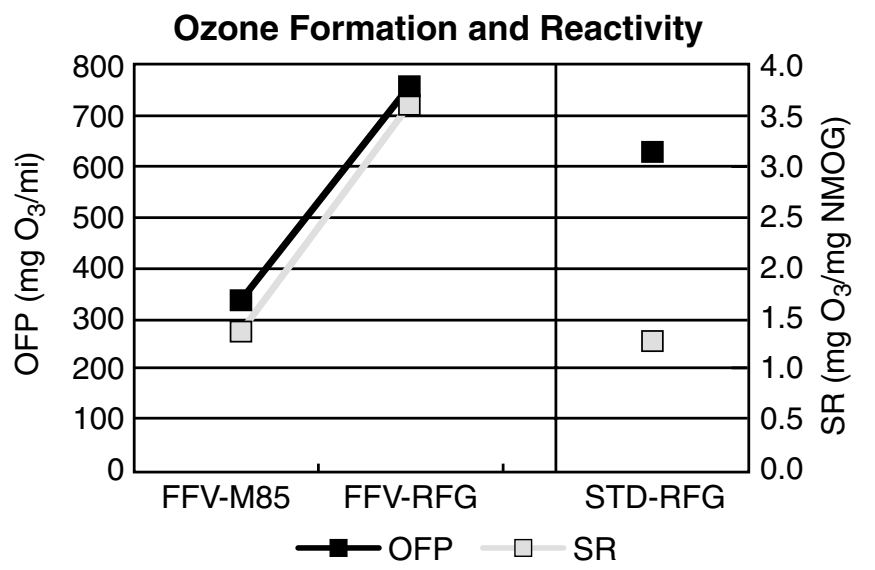

Figure 19. OFP and SR for the Dodge Spirit tested at Lab 3 


\section{Ethanol Vehicles}

Two vehicle models were tested on ethanol during this study: the FFV Ford Taurus and the FFV Chevrolet Lumina. The Taurus was tested at Lab 1 over two rounds and the Lumina was tested at Lab 2 over three rounds. Full hydrocarbon speciation was not performed on the Lumina emissions. The following sections of this report provide a detailed discussion of the results for both vehicles. A brief overview with a more qualitative discussion of the results is presented in this section.

Table 22 and Table 23 provide a summary comparison of the average mass emissions and the hydrocarbon speciation, respectively, from E85 compared to RFG tests. As in the previous section on methanol, the shaded blocks represent a statistically significant difference (at the 95\% confidence level) between average

\section{Table 22. Summary Comparison of Average Emission Results} from E85 versus RFG

\begin{tabular}{|c|c|c|c|c|c|}
\hline & \multicolumn{2}{|c|}{$\begin{array}{l}\text { Ford Taurus } \\
\text { Lab } 1\end{array}$} & \multicolumn{3}{|c|}{$\begin{array}{c}\text { Chevrolet Lumina } \\
\text { Lab } 2\end{array}$} \\
\hline & Round 1 & Round 2 & Round 1 & Round 2 & Round 3 \\
\hline \multicolumn{6}{|c|}{ Regulated Emissions } \\
\hline NMHCE & - & + & - & - & + \\
\hline $\mathrm{THC}$ & + & + & - & + & - \\
\hline $\mathrm{CO}$ & + & + & + & + & + \\
\hline $\mathrm{NO}_{\mathrm{x}}$ & - & + & - & - & - \\
\hline \multicolumn{6}{|c|}{ Evaporative Emissions } \\
\hline $\mathrm{THC}$ & - & + & - & - & - \\
\hline \multicolumn{6}{|c|}{ Greenhouse Gases } \\
\hline $\mathrm{CO}_{2}$ & - & - & - & - & - \\
\hline $\mathrm{CH}_{4}$ & + & + & + & + & + \\
\hline \multicolumn{6}{|l|}{ Aldehydes } \\
\hline $\mathrm{HCHO}$ & + & + & + & + & + \\
\hline $\mathrm{CH}_{3} \mathrm{CHO}$ & + & + & + & + & + \\
\hline \multicolumn{6}{|c|}{ Fuel Economy } \\
\hline mpg & - & - & - & - & - \\
\hline mpeg & + & + & + & + & + \\
\hline
\end{tabular}

"+" Indicates results from E85 tests were higher than RFG tests

"-" Indicates results from E85 tests were lower than RFG tests Highlighted blocks indicate a significant statistical difference.

Table 23. Summary Comparison of Average Speciated Hydrocarbon Results for E85 versus RFG

\begin{tabular}{|l|c|}
\hline & $\begin{array}{c}\text { Ford } \\
\text { Taurus }\end{array}$ \\
\hline Air Toxics & Lab 1 \\
\hline $\mathrm{HCHO}$ & + \\
\hline $\mathrm{CH}_{3} \mathrm{CHO}$ & + \\
\hline 1,3-butadiene & - \\
\hline Benzene & - \\
\hline Total PWT & - \\
\hline Ozone Reactivity & \\
\hline OFP & + \\
\hline SR & - \\
\hline
\end{tabular}

results from the two fuels. A plus sign indicates that the average E85 results were higher, and a minus sign indicates that the average E85 results were lower than the RFG results.

The most obvious trend displayed in Table 22 is that the comparison of non-regulated emissions (greenhouse gases, aldehydes, and fuel economy) tended to be consistent across test rounds and vehicle types, and the differences tended to be statistically significant. Average $\mathrm{CO}_{2}$ and mpg were consistently lower when tested on E85 compared to RFG. Average aldehydes ( $\mathrm{HCHO}$ and $\mathrm{CH}_{3} \mathrm{CHO}$ ) and gasoline equivalent fuel economy (mpeg) were consistently higher from the E85 tests compared to the RFG tests. On the other hand, the comparison of average regulated emissions results tended to be less consistent. 
Results from the FFV Taurus tended to show higher regulated emissions from E85, but the differences were not statistically significant. For the Lumina, some of the regulated emissions were significantly lower on E85 $\left(\mathrm{NO}_{\mathrm{x}}\right)$, some tended to be significantly higher (CO), and others were mixed from round to round (THC and NMHCE).

Similar to the methanol vehicles, the ethanol vehicles are flexible-fuel designs that are not fully optimized for either gasoline or ethanol. The differences in results between vehicle models and the lack of clear regulated emissions differences may result, in part, from engine hardware choices and calibrations that must be flexible to accommodate a wide range of fuel blends.

The results from the detailed speciation of hydrocarbon emissions on the Taurus are summarized in Table 23. This table combines the results from the two rounds because the difference between the two rounds was not significant. The general trends that are evident in Table 23 include:

- Average aldehyde emissions ( $\mathrm{HCHO}$ and $\mathrm{CH}_{3} \mathrm{CHO}$ ) tended to be higher from the E85 tests compared to the RFG tests

- Average 1,3-butadiene, benzene, and total PWT emissions tended to be significantly lower from the E85 tests compared to the RFG tests

- Average OFP tended to be higher, but SR tended to be significantly lower from the E85 tests compared to the RFG tests.

This last point was a bit surprising and deserves additional explanation. Although the OFP (expressed in milligrams of ozone per mile) was higher for the ethanol tests, the SR (expressed in terms of milligrams of ozone per milligram of non-methane organic gases) was lower. This was the case because, although the hydrocarbon emissions from the E85 tests were significantly less reactive, the total hydrocarbons from this subset of test vehicles were significantly higher when tested on E85 compared to the same vehicles tested on RFG. However, this was not the case for the larger sample of test vehicles. As was mentioned earlier, for all the Ford Taurus test vehicles, there was not a statistically significant difference between the average NMHCE emissions from E85 compared to the same vehicles tested on RFG.

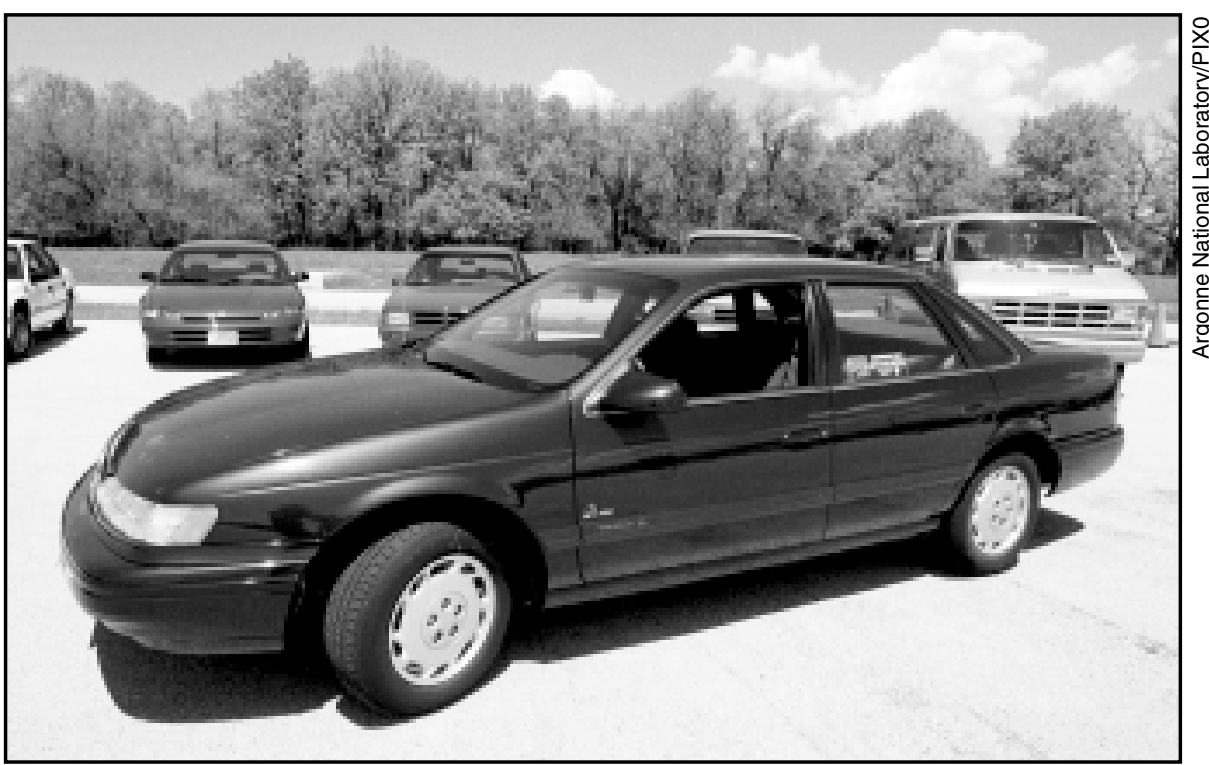

Figure 20. The 1995 E85 Ford Taurus

Table 24. Odometer Readings for the Ford Taurus

\begin{tabular}{|l|c|c|c|c|}
\hline & \multicolumn{2}{|c|}{ FFV } & \multicolumn{2}{c|}{ Gasoline } \\
\hline Round & 1 & 2 & 1 & 2 \\
\hline No. vehicles tested & 14 & 14 & 16 & 16 \\
\hline \hline \multicolumn{5}{|c|}{ Odometer (miles) } \\
\hline Average & 5,069 & 16,095 & 4,859 & 14,201 \\
\hline Maximum & 10,253 & 29,184 & 12,822 & 31,503 \\
\hline Minimum & 3,067 & 8,158 & 3,027 & 8,055 \\
\hline
\end{tabular}


readings for the Taurus are listed in Table 24. The complete data set for the Taurus is found in Appendix A.

\section{Regulated Emissions}

Table 25 shows the average emissions results for the FFV Ford Taurus.

Figure 21 illustrates the average regulated emissions and $\mathrm{CO}_{2}$ values. In general, when comparing the regulated emissions from the FFV Taurus tested on E85 to the same vehicles tested on RFG, there was no significant difference between fuels. In Round 1, the emissions levels from the FFV on E85 and RFG were similar to the conventional Taurus tested on RFG. In Round 2, the FFV on E85 had slightly higher values for all three regulated compounds.

When comparing the NMHCE emissions for the Taurus (Figure 21a), there was not a significant difference between the FFV on either fuel and the conventional model for Round 1 . In Round 2, the NMHCE emissions for the FFV on E85 were $12.5 \%$ higher than on RFG, but this difference was not significant at the $95 \%$ confidence level. The average for the standard model in Round 2 was lower than the FFV on both fuels. All these values were below the Tier 1 limit of $0.25 \mathrm{~g} / \mathrm{mi}$. The FFV Taurus is certified to the TLEV emissions standard, which is written in terms of NMOG (see explanation on page 1). Although NMOG was not evaluated for the entire set of vehicles, it appears that the FFV in Round 2 exceeded the TLEV standard.

When comparing the average $\mathrm{CO}$ emissions for the Taurus (Figure 21b), the FFV on E85 had slightly higher values than the same vehicles tested on RFG in both rounds, but the difference was not statistically significant at the $95 \%$ confidence level.

In Round 1, the increase for the FFV tested on E85 was 8\% higher and in Round 2 the average was approximately $2 \%$ higher. Once again, all averages were well below the Tier 1 and TLEV limit of $3.4 \mathrm{~g} / \mathrm{mi}$.

$\mathrm{NO}_{\mathrm{x}}$ emissions for the Taurus are shown in Figure 21c. When comparing the FFV on E85 to the same vehicles on RFG, there was a decrease in average $\mathrm{NO}_{\mathrm{x}}$ in Round 1, but an increase in Round 2. Neither of these differences was statistically significant, and all values remained well below the Tier 1 and TLEV limit of $0.4 \mathrm{~g} / \mathrm{mi}$. The averages for all three regulated compounds showed significant increases from Round 1 to Round 2, but all were below the Tier 1 certification limit.

Table 25. Average Emissions Results from the Ford Taurus

\begin{tabular}{|c|c|c|c|c|c|c|c|c|}
\hline & \multicolumn{4}{|c|}{ Round 1} & \multicolumn{4}{|c|}{ Round 2} \\
\hline & $\begin{array}{l}\text { FFV- } \\
\text { E85 }\end{array}$ & $\begin{array}{l}\text { FFV- } \\
\text { RFG }\end{array}$ & $\begin{array}{c}\text { Percent } \\
\text { Difference }\end{array}$ & $\begin{array}{l}\text { Sig. Fuel } \\
\text { Effect? }\end{array}$ & $\begin{array}{l}\text { FFV- } \\
\text { E85 }\end{array}$ & $\begin{array}{l}\text { FFV- } \\
\text { RFG }\end{array}$ & $\begin{array}{c}\text { Percent } \\
\text { Difference }\end{array}$ & $\begin{array}{l}\text { Sig. Fuel } \\
\text { Effect? }\end{array}$ \\
\hline \multicolumn{9}{|c|}{ Regulated Emissions (g/mi) } \\
\hline NMHCE & 0.089 & 0.091 & $-2.2 \%$ & $\mathrm{n}$ & 0.163 & 0.144 & $12.5 \%$ & $\mathrm{n}$ \\
\hline THC & 0.103 & 0.101 & $2.4 \%$ & $\mathrm{n}$ & 0.184 & 0.156 & $17.9 \%$ & $\mathrm{y}$ \\
\hline $\mathrm{CO}$ & 1.162 & 1.075 & $8.1 \%$ & $\mathrm{n}$ & 1.522 & 1.486 & $2.4 \%$ & $\mathrm{n}$ \\
\hline $\mathrm{NO}_{\mathrm{x}}$ & 0.104 & 0.125 & $-16.8 \%$ & $\mathrm{n}$ & 0.183 & 0.178 & $2.8 \%$ & $\mathrm{n}$ \\
\hline \multicolumn{9}{|c|}{ Evaporative Emissions (g/test) } \\
\hline Total Evaporative & 0.328 & 0.332 & $-1.2 \%$ & $\mathrm{n}$ & 0.362 & 0.319 & $13.5 \%$ & $\mathrm{n}$ \\
\hline \multicolumn{9}{|c|}{ Greenhouse Gases (g/mi) } \\
\hline $\mathrm{CO}_{2}$ & 405.5 & 426.5 & $-4.9 \%$ & $\mathrm{y}$ & 398.5 & 422.9 & $-5.8 \%$ & $\mathrm{y}$ \\
\hline $\mathrm{CH}_{4}$ & 0.025 & 0.012 & $107.4 \%$ & $y$ & 0.035 & 0.016 & $122.9 \%$ & $y$ \\
\hline \multicolumn{9}{|c|}{ Aldehydes (mg/mi) } \\
\hline $\mathrm{HCHO}$ & 2.03 & 1.29 & $57.4 \%$ & $\mathrm{y}$ & 2.96 & 1.54 & $92.2 \%$ & $\mathrm{y}$ \\
\hline $\mathrm{CH}_{3} \mathrm{CHO}$ & 9.0 & 0.37 & $2332.4 \%$ & $y$ & 13.6 & 0.37 & $3575.7 \%$ & $y$ \\
\hline \multicolumn{9}{|l|}{ Fuel Economy } \\
\hline $\mathrm{mpg}$ & 15.22 & 20.4 & $-25.4 \%$ & $y$ & 15.46 & 20.49 & $-24.6 \%$ & $y$ \\
\hline mpeg & 20.82 & 20.4 & $2.1 \%$ & $y$ & 21.15 & 20.49 & $3.2 \%$ & $y$ \\
\hline
\end{tabular}




\section{1a: Non-Methane Hydrocarbon Equivalent}

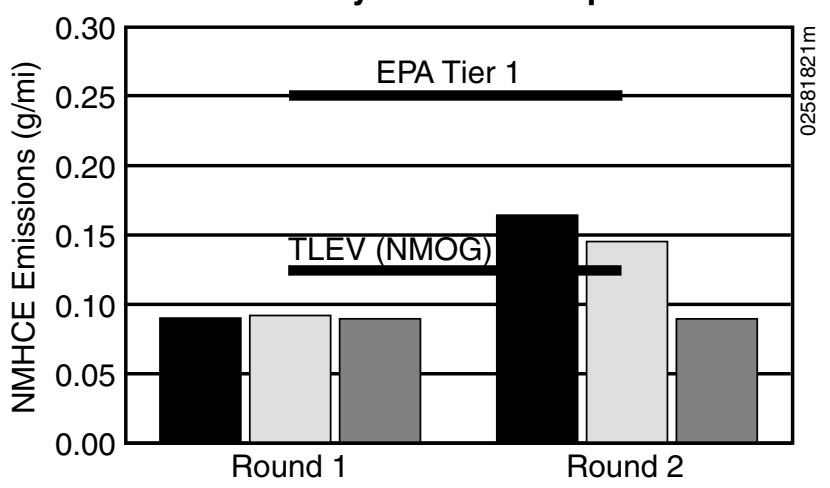

21b: Carbon Monoxide

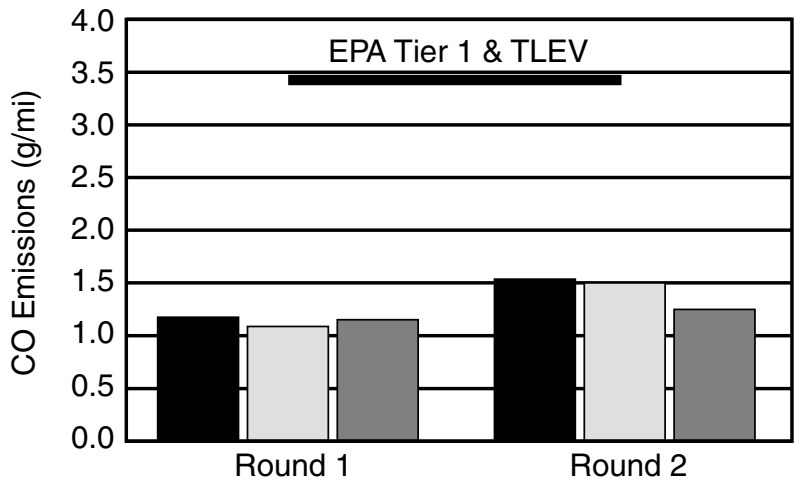

21c: Oxides of Nitrogen

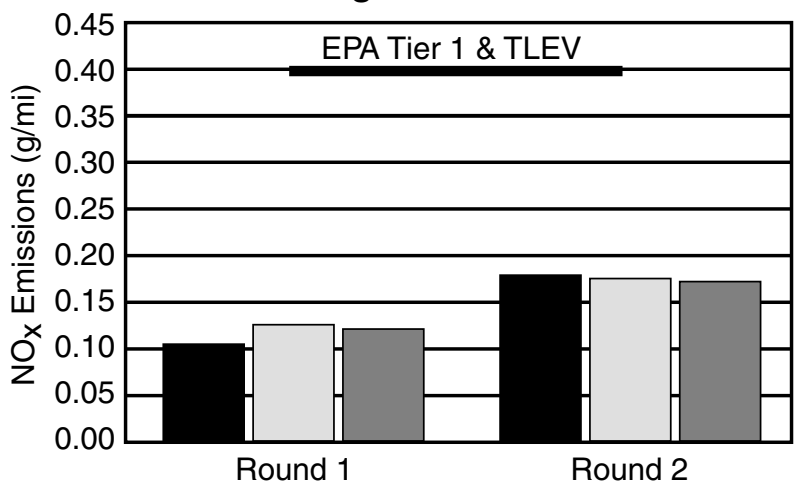

21d: Carbon Dioxide

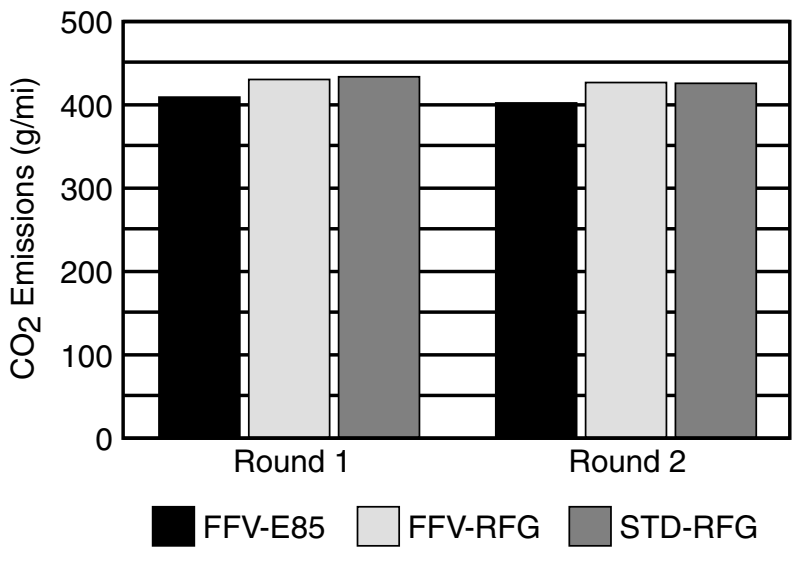

Figure 21. Emissions results from the Ford Taurus

\section{Evaporative Emissions}

Figure 22 shows the comparison of the average evaporative emissions for the Taurus. Evaporative emissions for the FFV on both fuels and the conventional Tauruses were well below the EPA limit of $2 \mathrm{~g}$ of hydrocarbon per test. When comparing the evaporative emissions for the FFV Taurus, there was not a significant difference in the FFV tested on E85 and the same vehicles tested on RFG. The conventional Taurus had lower average evaporative emissions than the FFV on either fuel. The round-to-round comparison for the FFV showed a small increase for the E85 tests, and a small decrease for the RFG tests. Neither of these differences was statistically significant at the $95 \%$ confidence level.

\section{Greenhouse Gases}

Carbon dioxide emissions for the Taurus are shown in Figure 21d. When comparing the FFV on E85 to the same vehicles tested on $\mathrm{RFG}$, the $\mathrm{E} 85 \mathrm{CO}_{2}$ emissions were approximately 5\% lower in both rounds. This difference was statistically significant at the $95 \%$ confidence level. The conventional Taurus tested on RFG showed very similar values to the FFV tested on RFG. There was a small decrease in $\mathrm{CO}_{2}$ emissions for Round 2 that was statistically significant for both fuels.

Methane emissions for the FFV tested on E85 were significantly higher than when the same vehicles were tested on RFG. The average $\mathrm{CH}_{4}$ emissions were $107 \%$ higher in Round 1 and $123 \%$ higher in Round 2. It is important to note, however, that the values for both fuels are very small $(0.012$ to $0.035 \mathrm{~g} / \mathrm{mi}$ ). There was a small increase in $\mathrm{CH}_{4}$ emissions from Round 1 to Round 2 that was significant for both fuels.

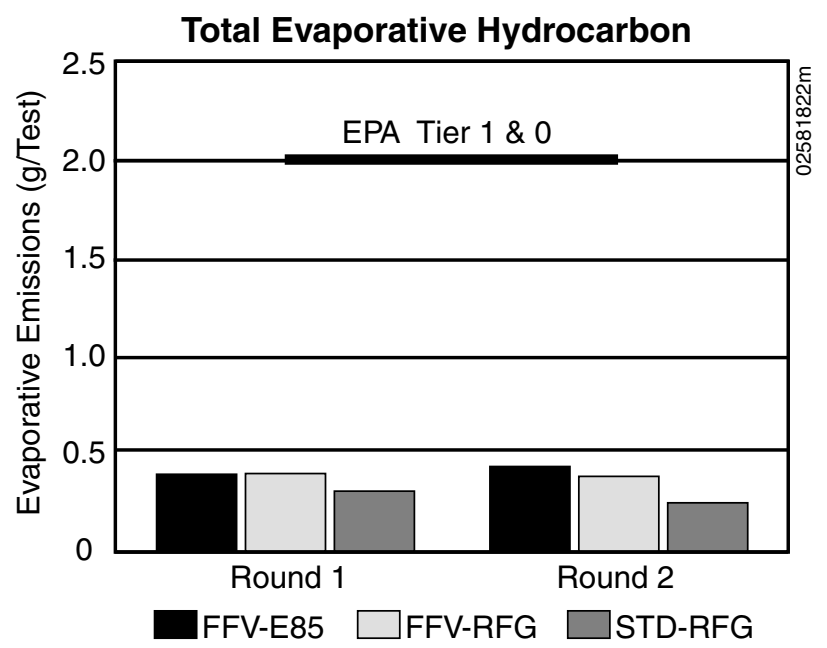

Figure 22. Evaporative emissions results from the Ford Taurus 


\section{Aldehydes}

Aldehyde emissions for the Ford Taurus are shown in Figure 23. Formaldehyde emissions were higher for the FFV tested on E85 in both rounds. The percent difference between the FFV tested on E85 and the same vehicles tested on RFG was $57 \%$ for Round 1 and $92.2 \%$ for Round 2. Acetaldehyde is a primary decomposition product from ethanol combustion; therefore, the much higher values were expected when the vehicle was operating on E85. The percent increase in the FFV acetaldehyde emissions when tested on E85 was 2,332\% for Round 1 and 3,575\% for Round 2. The acetaldehyde levels for RFG were very low-less than $0.5 \mathrm{mg} / \mathrm{mi}$. Although both fuels show increases in aldehyde emissions from Round 1 to Round 2, only the increases for the E85 tests were statistically significant.

\section{Potency-Weighted Toxics and Ozone-Forming Potential}

During this project, full hydrocarbon speciation was performed on six of the FFVs and five of the standard Tauruses. Table 26 summarizes the average measured toxic emissions and the PWT results for the Taurus. When comparing the FFV tested on E85 to the same vehicles tested on RFG, there were significant increases in aldehyde emissions and significant decreases in 1,3-butadiene and

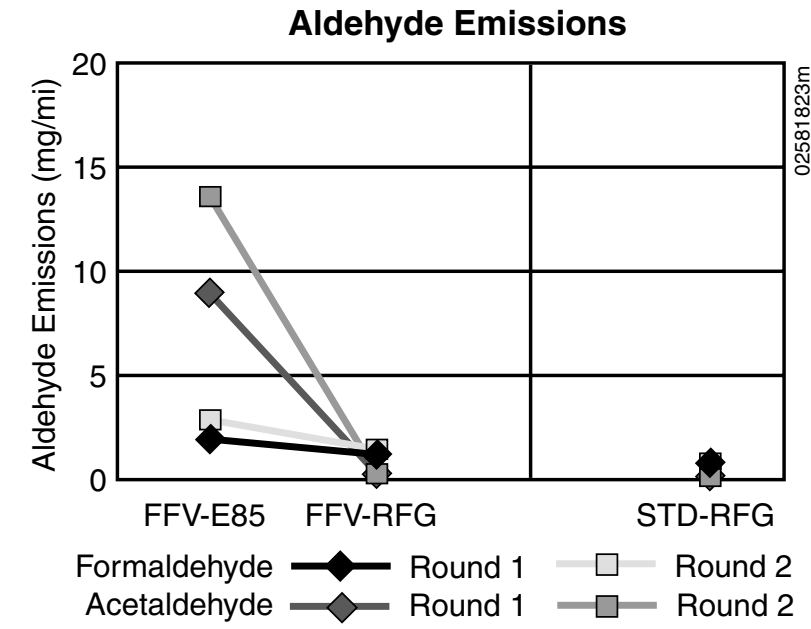

Figure 23. Aldehyde emissions from the Ford Taurus

benzene. Figure 24 shows this difference graphically. Although the total measured toxics were higher, the potency weighted values were significantly lower for the E85 tests. Total PWT for the FFV tested on E85 were $44 \%$ lower than the same vehicles tested on RFG. Although acetaldehyde is the highest measured value for E85 tests, it is the least toxic of the four. The conventional model tested on RFG showed results similar to the FFV tested on RFG.

Table 27 and Figure 25 show the NMOG, OFP, and SR results for the Taurus. The OFP for the FFV tested on E85 was significantly higher $(19 \%)$ than the same vehicles tested on RFG, but the SR was significantly lower (approximately 38\%) for the E85 tests. The OFP for the FFV tested on E85 was higher than the same vehicles tested on RFG because the total HC from this subset of vehicles were substantially higher. The lower SR indicates that the FFV tested on E85 was less reactive per unit mass.

\section{Fuel Economy}

Table 25 gives the actual and equivalent fuel economy for the FFV Ford Taurus. Average fuel economy for the FFV Taurus on E85 was approximately $15 \mathrm{mpg}$. The average when tested on RFG was approximately $25 \%$ higher, at $20 \mathrm{mpg}$. As with methanol, E85 has a lower volumetric energy content than RFG. The volumetric energy content for E85 $(81,825 \mathrm{Btu} / \mathrm{gal})$ is approximately $73 \%$ of RFG (111,960 Btu/gal). This

Table 26. Toxic Emissions from the Ford Taurus

\begin{tabular}{|c|c|c|c|c|c|c|}
\hline & \multicolumn{2}{|c|}{ FFV-E85 } & \multicolumn{2}{|c|}{ FFV-RFG } & \multirow{2}{*}{$\begin{array}{c}\text { Percent } \\
\text { Difference }\end{array}$} & \multirow{2}{*}{$\begin{array}{l}\text { Sig. Fuel } \\
\text { Effect? }\end{array}$} \\
\hline & $\begin{array}{c}\text { Measured } \\
\text { Value }(\mathrm{mg} / \mathrm{mi})\end{array}$ & PWT & $\begin{array}{c}\text { Measured } \\
\text { Value }(\mathrm{mg} / \mathrm{mi}) \\
\end{array}$ & PWT & & \\
\hline $\mathrm{HCHO}$ & 2.223 & 0.102 & 1.30 & 0.06 & $70.9 \%$ & $y$ \\
\hline $\mathrm{CH}_{3} \mathrm{CHO}$ & 9.854 & 0.079 & 0.275 & 0.002 & $3,490.9 \%$ & $y$ \\
\hline 1,3-butadiene & 0.175 & 0.175 & 0.544 & 0.544 & $-67.8 \%$ & $\mathrm{y}$ \\
\hline Benzene & 1.013 & 0.03 & 2.863 & 0.086 & $-65.1 \%$ & $\mathrm{y}$ \\
\hline Total & 13.265 & 0.386 & 4.982 & 0.692 & $-44.2 \%$ & $y$ \\
\hline
\end{tabular}




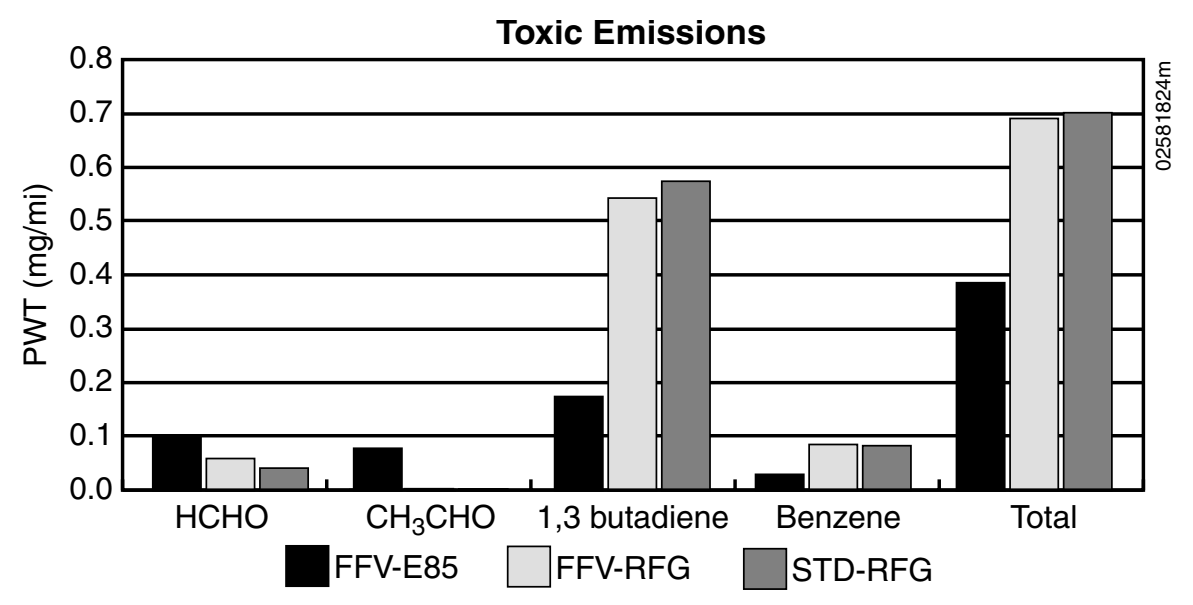

Figure 24. PWT emissions from the Ford Taurus

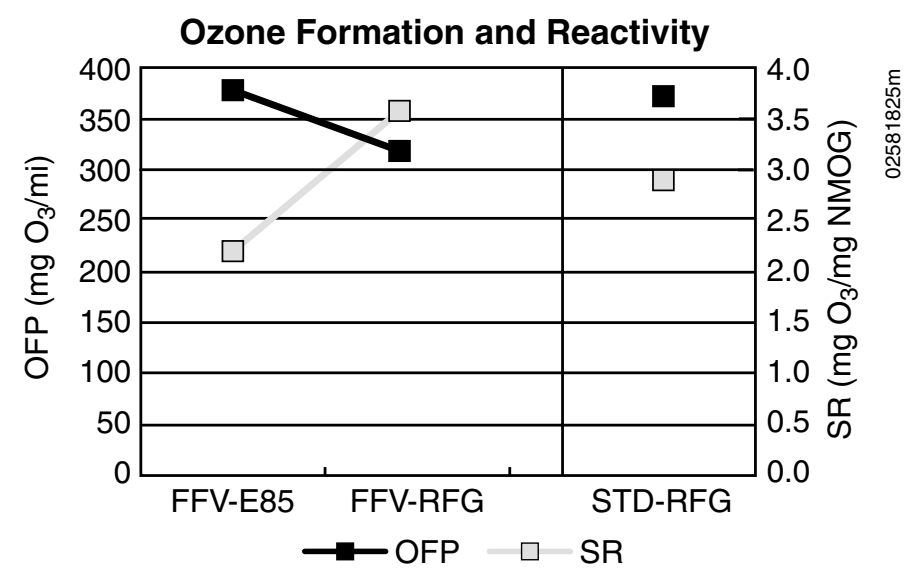

Figure 25. OFP and SR for the Ford Taurus

Table 27. OFP for the Ford Taurus

\begin{tabular}{|l|c|c|c|c|}
\hline & $\begin{array}{c}\text { FFV- } \\
\text { E85 }\end{array}$ & $\begin{array}{c}\text { FFV- } \\
\text { RFG }\end{array}$ & $\begin{array}{c}\text { Percent } \\
\text { Difference }\end{array}$ & $\begin{array}{c}\text { Sig. Fuel } \\
\text { Effect? }\end{array}$ \\
\hline NMOG $(\mathrm{mg} / \mathrm{mi})$ & 171.97 & 92.30 & $86.3 \%$ & $y$ \\
\hline OFP $\left(\mathrm{mg} \mathrm{O}_{3} / \mathrm{mi}\right)$ & 377.58 & 318.06 & $18.7 \%$ & $y$ \\
\hline $\mathrm{SR}\left(\mathrm{mg} \mathrm{O}_{3} / \mathrm{mg} \mathrm{NMOG}\right)$ & 2.215 & 3.57 & $-38.0 \%$ & $y$ \\
\hline
\end{tabular}

means that it takes 1.3 gallons of E85 to travel the same distance as 1 gallon of gasoline. On an energy equivalent basis, the FFV Taurus was $2 \%$ to $3 \%$ more energy efficient when tested on E85. Like the Spirit, the fuel tank of the FFV Taurus was increased to account for the differing energy content of the fuel. The gasoline Taurus has a 16-gallon tank for a range of approximately 326 miles. The FFV has a tank that holds 20.4 gallons for a range of 313 miles on E85 and 417 miles on gasoline.

\section{Chevrolet Lumina}

The 1993 FFV Chevrolet Lumina (shown in Figure 26) is a passenger car equipped with a $3.1 \mathrm{~L} \mathrm{V6}$ engine with multi-point fuel injection. The Lumina was certified to EPA federal Tier 0 emissions levels. This report covers the three rounds of testing completed on the Chevrolet Lumina at Lab 2. Ten FFV Luminas and 11 gasoline controls were tested in all 3 rounds. Mileage ranges and average odometer readings for the Luminas are listed in Table 28. Lab 1 tested a limited number of FFV Luminas during Round 1 only. The results for those tests were reported in another publication and are not included in this paper. ${ }^{9}$ Hydrocarbon speciation was not performed on the vehicles included in this analysis. The entire data set is located in Appendix A.

\section{Regulated Emissions}

The average emissions results for the Lumina are listed in Table 29. The regulated and $\mathrm{CO}_{2}$ emissions for the FFV Lumina are shown in Figure 27. In general, when comparing the FFV tested on E85 to the same vehicles tested on RFG, there tended to be a slight decrease in NMHCE, a larger decrease in $\mathrm{NO}_{\mathrm{x}}$, and an increase in $\mathrm{CO}$ emissions. The average regulated emissions for the FFV Lumina were all well below the Tier 0 standard, as well as the more stringent Tier 1 standard, shown here for reference. The regulated emissions for the gasoline model did not follow the same trend. NMHCE and $\mathrm{NO}_{\mathrm{x}}$ emissions for the gasoline Lumina were below the Tier 0 levels, but $\mathrm{CO}$ emissions were over the limit for all 3 rounds.

Although NMHCE values for the FFV tested on E85 were lower than the RFG tests in Rounds 1 and 2 (see Figure 27a), the difference was not significant in Round 2. There was no significant difference in NMHCE emissions between the two fuels for Round 3. All the values for the FFV Lumina were below the EPA Tier 1 limit of $0.25 \mathrm{~g} / \mathrm{mi}$. Round-to-round comparison for the E85 tests showed an increase in NMHCE over time that was statistically significant. The smaller increase in NMHCE for the RFG tests on the FFV was not statistically significant at the $95 \%$ confidence level. The standard gasoline 
model showed a small but significant increase in each round.

$\mathrm{CO}$ emissions follow a different trend than NMHCE (Figure 27b). In all three rounds, the FFV tested on E85 showed higher $\mathrm{CO}$ emissions than when the same vehicles were tested on RFG. The percent increases were $7.5 \%$ for Round $1,33 \%$ for Round 2, and $22 \%$ for Round 3. This increase was statistically significant for Rounds 2 and 3, but not for Round 1 . The standard gasoline model tested significantly higher than the FFV on either fuel. The average $\mathrm{CO}$ for the FFV tested on E85 and RFG were below the Tier 0 emissions standard, but the gasoline Lumina exceeded the limit for all three rounds. The Round 3 average for the gasoline Luminas was approximately $50 \%$ higher than the $3.4 \mathrm{~g} / \mathrm{mi}$ standard.

$\mathrm{NO}_{\mathrm{x}}$ emissions for the FFV tested on E85 were significantly lower than those from the same vehicles tested on RFG for all 3 rounds. There was a decrease of $40 \%, 37 \%$, and $34 \%$ for Rounds 1, 2, and 3, respectively. As with the $\mathrm{CO}$ emissions, $\mathrm{NO}_{\mathrm{x}}$ averages for the standard model were much higher than the averages for the FFV. Both the FFV tested on E85 and RFG and the standard model tested on RFG had $\mathrm{NO}_{\mathrm{x}}$ levels below the Tier 0 standard of $1 \mathrm{~g} / \mathrm{mi}$. The FFV on each fuel was also below the more stringent Tier 1 level.

\section{Evaporative Emissions}

Evaporative emissions for the FFV Lumina are listed in Table 29 and graphically illustrated in Figure 28. When comparing the average evaporative emissions for the FFV tested on E85 to the averages for the same vehicles tested on RFG, there was a small reduction in evaporative emissions for all three rounds. However, only the reduction for Round 2 was statistically significant. The conventional Lumina tested higher than

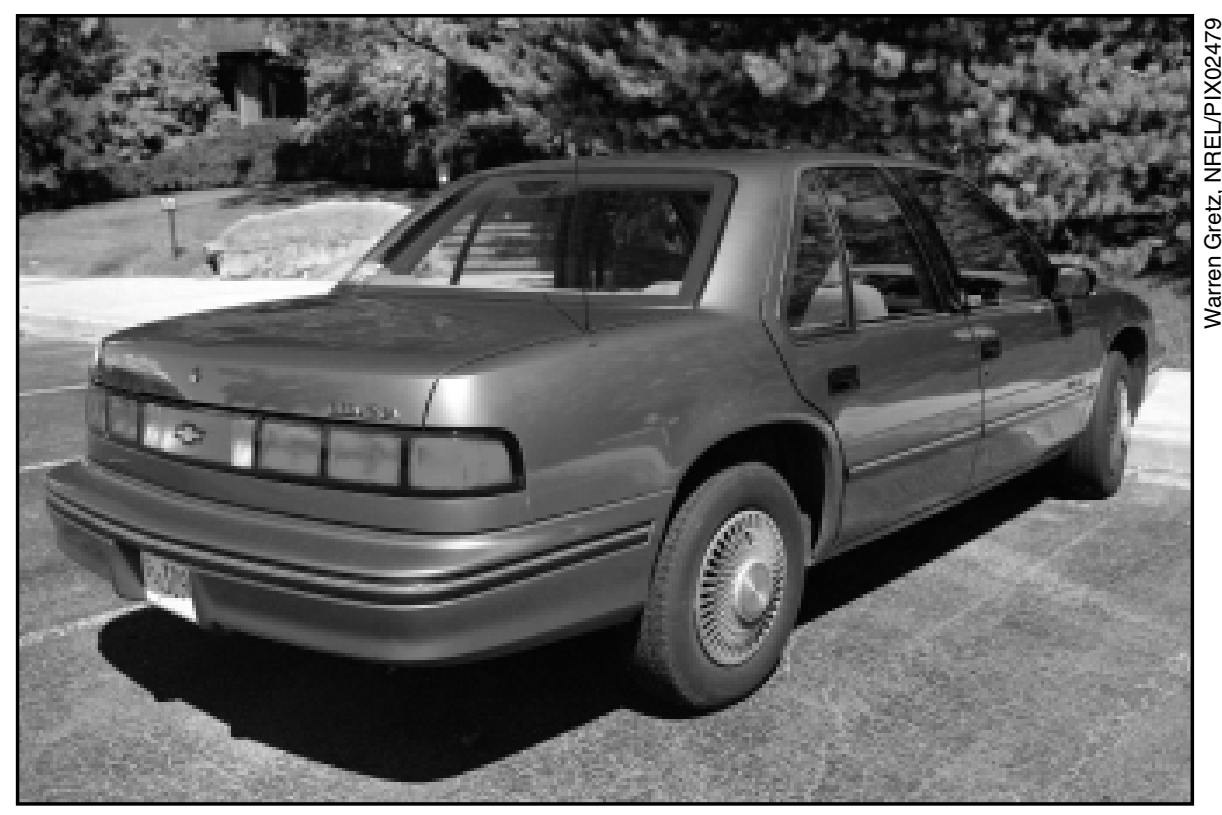

Figure 26. The 1993 E85 Chevrolet Lumina

Table 28. Odometer Readings for the Chevrolet Lumina

\begin{tabular}{|l|c|c|c|c|c|c|}
\hline & \multicolumn{3}{|c|}{ FFV } & \multicolumn{3}{c|}{ Gasoline } \\
\hline Round & 1 & 2 & 3 & 1 & 2 & 3 \\
\hline No. vehicles tested & 10 & 10 & 10 & 11 & 11 & 11 \\
\hline \multicolumn{6}{|c|}{ Odometer (miles) } \\
\hline Average & 10,111 & 22,568 & 30,883 & 6,344 & 12,434 & 19,403 \\
\hline Maximum & 12,409 & 35,842 & 42,538 & 10,713 & 18,970 & 37,902 \\
\hline Minimum & 8,218 & 12,991 & 19,700 & 2,903 & 6,826 & 11,365 \\
\hline
\end{tabular}

the FFV on both fuels. All averages were well below the $2 \mathrm{~g}$ per test standard. Round-to-round differences show small increases over time for the FFV on both fuels. These differences tended not to be significant at the $95 \%$ confidence level.

\section{Greenhouse Gases}

Figure 27d shows the average $\mathrm{CO}_{2}$ emissions levels for the Lumina. The $\mathrm{CO}_{2}$ average for the FFV tested on E85 was approximately $6 \%$ lower than when tested on RFG in all three rounds. These differences were all statistically significant at the $95 \%$ confidence level. $\mathrm{CO}_{2}$ emissions for the standard Lumina tested on RFG were lower than the FFV on RFG. Round-to-round comparisons for the FFV tested on E85 and RFG showed significant decreases in $\mathrm{CO}_{2}$ during Round 2 and significant increases in Round 3. This held true for both the E85 and RFG tests on the FFV Lumina.

Although emissions of $\mathrm{CH}_{4}$ for the FFV are small (less than $0.08 \mathrm{~g} / \mathrm{mi}$ ), the results for the tests on E85 are significantly higher than those from the RFG tests. Round-to-round comparisons of $\mathrm{CH}_{4}$ emissions for the E85 tests show a small but significant increase in Round 2 and a small but significant decrease in Round 3. The FFV tests with RFG show no 
Table 29. Average Emissions Results from the Chevrolet Lumina

\begin{tabular}{|c|c|c|c|c|c|c|c|c|c|c|c|c|}
\hline & $\begin{array}{l}\text { FFV } \\
\text { E85 }\end{array}$ & $\begin{array}{l}\text { FFV } \\
\text { RFG }\end{array}$ & $\begin{array}{r}\text { Percent } \\
\text { Difference }\end{array}$ & $\begin{array}{c}\text { Sig. Fuel } \\
\text { Effect? }\end{array}$ & $\begin{array}{l}\text { FFV } \\
\text { E85 }\end{array}$ & $\begin{array}{l}\text { FFV } \\
\text { RFG }\end{array}$ & $\begin{array}{c}\text { Percent } \\
\text { Difference }\end{array}$ & $\begin{array}{l}\text { Sig. Fuel } \\
\text { Effect? }\end{array}$ & $\begin{array}{l}\text { FFV } \\
\text { E85 }\end{array}$ & $\begin{array}{l}\text { FFV } \\
\text { RFG }\end{array}$ & $\begin{array}{c}\text { Percent } \\
\text { Difference }\end{array}$ & $\begin{array}{l}\text { Sig. Fuel } \\
\text { Effect? }\end{array}$ \\
\hline \multicolumn{13}{|c|}{ Regulated Emissions (g/mi) } \\
\hline NMHCE & 0.087 & 0.102 & $-14.7 \%$ & $y$ & 0.105 & 0.109 & $-3.7 \%$ & $\mathrm{n}$ & 0.118 & 0.117 & $0.8 \%$ & $\mathrm{n}$ \\
\hline $\mathrm{CO}$ & 2.22 & 2.07 & $7.5 \%$ & $\mathrm{n}$ & 3.08 & 2.32 & $32.9 \%$ & $y$ & 2.84 & 2.33 & $21.3 \%$ & $y$ \\
\hline $\mathrm{NO}_{\mathrm{x}}$ & 0.156 & 0.261 & $-40.4 \%$ & y & 0.206 & 0.329 & $-37.4 \%$ & $y$ & 0.233 & 0.352 & $-34.1 \%$ & $y$ \\
\hline \multicolumn{13}{|c|}{ Evaporative Emissions (g/test) } \\
\hline Total Evaporative & 0.153 & 0.162 & $-5.6 \%$ & $\mathrm{n}$ & 0.159 & 0.242 & $-34.3 \%$ & $\mathrm{y}$ & 0.163 & 0.207 & $-21.3 \%$ & $\mathrm{n}$ \\
\hline $\mathrm{CH}_{4}$ & 0.056 & 0.028 & $100 \%$ & $\mathrm{y}$ & 0.074 & 0.031 & $141.6 \%$ & $y$ & 0.066 & 0.031 & $110.6 \%$ & $y$ \\
\hline \multicolumn{13}{|c|}{ Aldehydes (mg/mi) } \\
\hline $\mathrm{HCHO}$ & 6.98 & 4.66 & $49.8 \%$ & $\mathrm{y}$ & 5.56 & 3.92 & $41.8 \%$ & $\mathrm{y}$ & 5.38 & 3.36 & $60.1 \%$ & y \\
\hline $\mathrm{CH}_{3} \mathrm{CHO}$ & 18.08 & 0.73 & $2482.9 \%$ & $\mathrm{y}$ & 17.04 & 0.78 & $2030 \%$ & $y$ & 17.98 & 0.70 & $2468.6 \%$ & $y$ \\
\hline \multicolumn{13}{|l|}{ Fuel Economy } \\
\hline $\mathrm{mpg}$ & 13.57 & 18.09 & $-25.0 \%$ & $y$ & 14.1 & 18.99 & $-25.8 \%$ & $y$ & 13.86 & 18.72 & $-26 \%$ & $y$ \\
\hline mpeg & 18.57 & 18.09 & $2.6 \%$ & $y$ & 19.29 & 18.99 & $1.6 \%$ & $y$ & 18.96 & 18.72 & $1.3 \%$ & $y$ \\
\hline
\end{tabular}

significant difference between rounds. Average $\mathrm{CH}_{4}$ values for the gasoline Lumina also show no significant difference between rounds.

\section{Aldehydes}

Aldehyde emissions for the Lumina are shown in Figure 29. Formaldehyde emissions from the FFV tested on E85 were significantly higher than those from the same vehicles tested on RFG. In Round 1, formaldehyde emissions from the FFV on E85 were $50 \%$ higher than those from RFG, Round 2 results were $42 \%$ higher, and Round 3 results were $60 \%$ higher. Formaldehyde emissions for the standard Lumina were higher than those from the FFV on RFG, but lower than those from the FFV on E85. The average acetaldehyde (a primary decomposition product of ethanol combustion) emissions for the FFV tested on E85 were 2,483\%, $2,030 \%$, and $2,469 \%$ higher than those from the same vehicles tested on RFG, respectively. The differences between rounds were not statistically significant.

\section{Potency-Weighted Toxics and Ozone -Forming Potential}

Because full hydrocarbon speciation was not performed on the Luminas during this project, PWT and OFP were not evaluated.

\section{Fuel Economy}

Table 29 gives actual and equivalent fuel economy for the FFV Lumina. Actual fuel economy for the Lumina tested on E85 over the 3 rounds ranged from 13.5 to $14 \mathrm{mpg}$. This was $25 \%$ to $26 \%$ lower than the same vehicles when tested on RFG. The standard models tested slightly higher than the FFV on RFG. Because of the difference in energy content between E85 and RFG, gasoline energy equivalent fuel economy was calculated for the E85 tests. The energy equivalent fuel economy for the E85 tests ranged from $18.6 \mathrm{mpeg}$ to $19.3 \mathrm{mpeg}$. Taking this into account, the fuel economy for the FFV tested on E85 was 1.3\% to $2.6 \%$ higher than when tested on RFG. The fuel tanks for the gasoline and FFV Lumina are similar in size. The gasoline Lumina has a tank that holds 17.1 gallons for a range of approximately 330 miles. The FFV Lumina has a 16.5-gallon fuel tank for a range of 228 miles on E85 and 306 miles on gasoline. 
27a: Non-Methane Hydrocarbon Equivalent

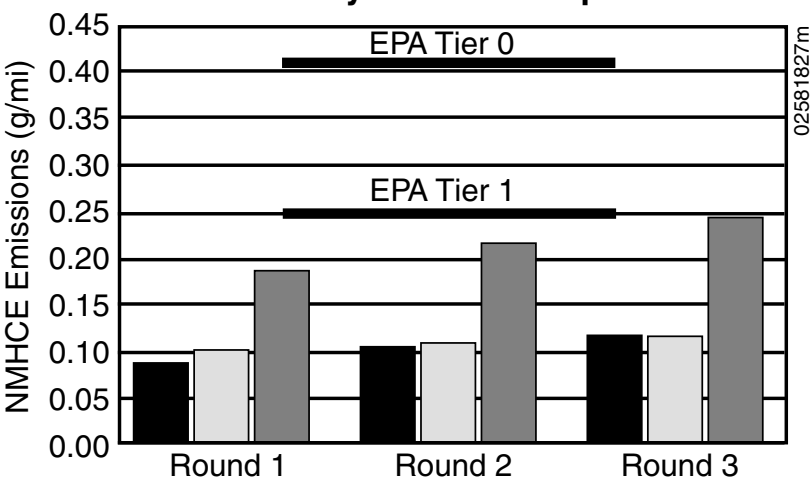

27b: Carbon Monoxide

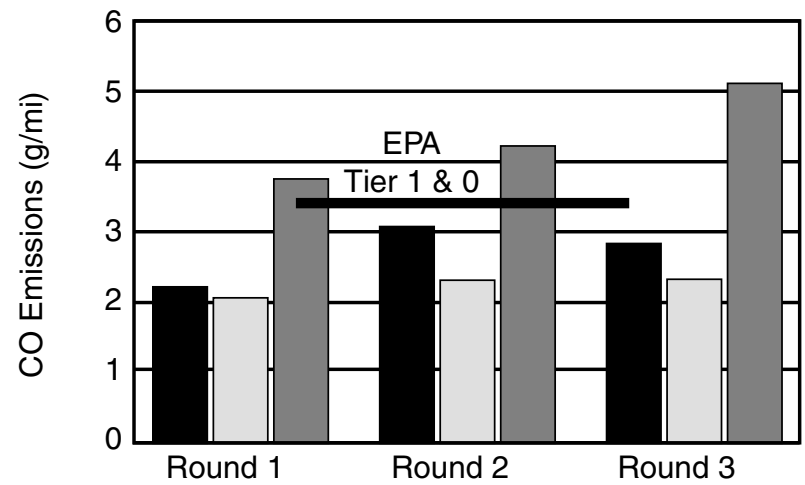

27c: Oxides of Nitrogen

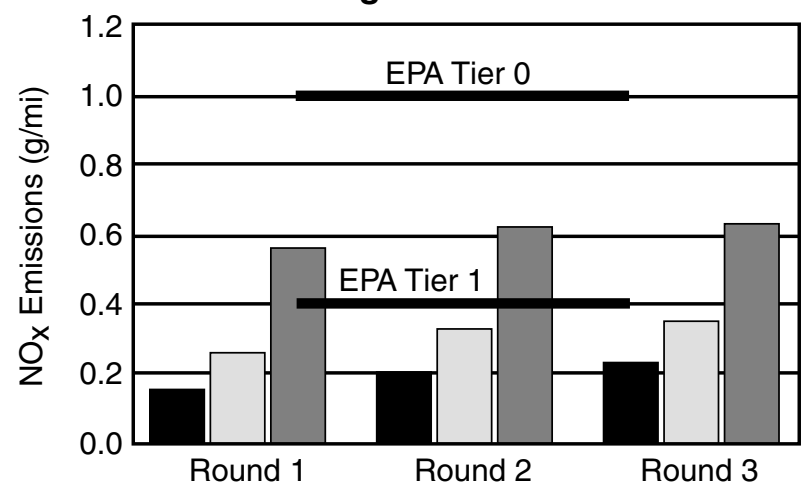

27d: Carbon Dioxide

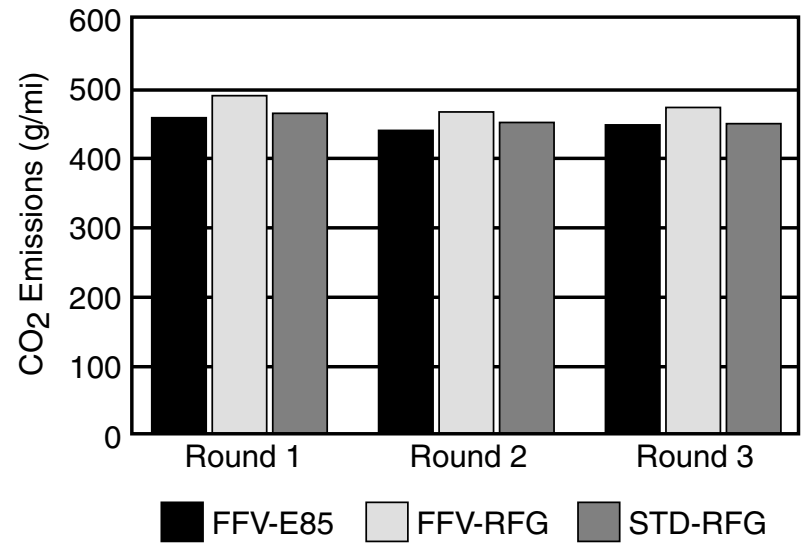

Figure 27. Emissions results from the Chevrolet Lumina

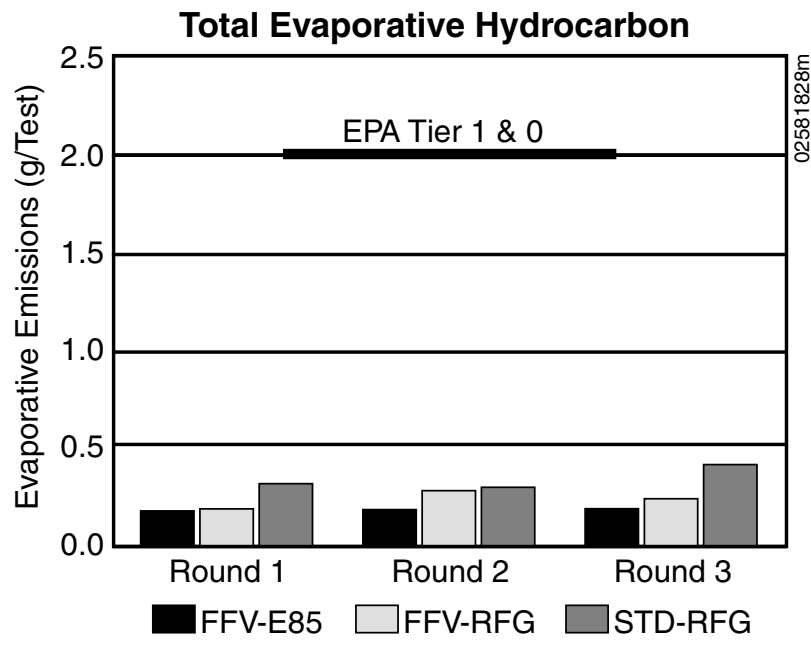

Figure 28. Evaporative emissions results from the Chevrolet Lumina

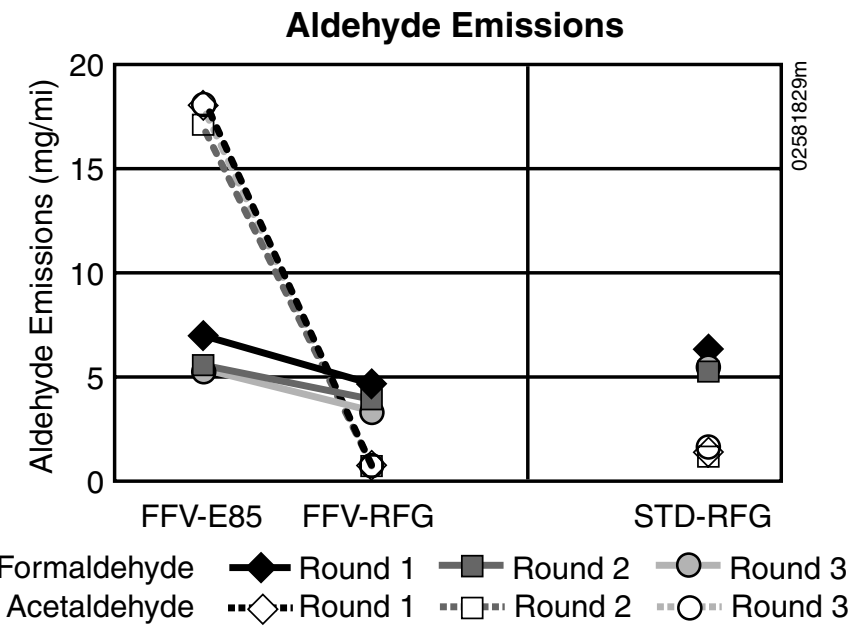

Figure 29. Aldehyde emissions from the Chevrolet Lumina 


\section{Compressed Natural Gas Vehicles}

Two different CNG vehicle models were tested during this study. These models include the Dodge B250 van and the Dodge Caravan minivan.

Both vans are dedicated natural gas vehicles, which means they are designed to operate on CNG only. To make fuel-to-fuel emissions comparisons, it was necessary to test closely matched gasoline vehicles.

The AFV and the gasoline models are both classified by the EPA as "heavy light-duty vehicles." See Table 2 on page 2 for the EPA intermediate useful life standards for the vans.

As with the other fuels, an overview of the general trends is presented first and then the detailed results for each of the test vehicles are presented in subsequent sections. Table 30 and Table 31 show summary comparisons of the average $\mathrm{CNG}$ emissions compared to the average RFG emissions. As in the sections on methanol and ethanol, the shaded blocks indicate differences between the averages that were statistically significant (at the $95 \%$ confidence level). Plus signs indicate that the average $\mathrm{CNG}$ emissions were higher than the average RFG emissions, and the minus signs indicate that the

Table 30. Summary Comparison of Average Emissions Results from CNG versus RFG

\begin{tabular}{|c|c|c|c|c|c|c|c|c|c|}
\hline & \multicolumn{8}{|c|}{ Dodge B250 } & \multirow{3}{*}{$\begin{array}{c}\begin{array}{c}\text { Dodge } \\
\text { Caravan }\end{array} \\
\text { Lab 1 } \\
\text { Round 1 }\end{array}$} \\
\hline & \multicolumn{2}{|c|}{ Lab 1} & \multicolumn{3}{|c|}{ Lab 2} & \multicolumn{3}{|c|}{ Lab 3} & \\
\hline & Round 1 & Round 2 & Round 1 & Round 2 & Round 3 & Round 1 & Round 2 & Round 3 & \\
\hline \multicolumn{10}{|c|}{ Regulated Emissions } \\
\hline NMHC & - & - & - & - & - & - & - & - & - \\
\hline $\mathrm{THC}$ & - & - & + & + & + & + & + & + & - \\
\hline $\mathrm{CO}$ & - & - & - & - & - & - & - & - & - \\
\hline $\mathrm{NO}_{\mathrm{x}}$ & - & - & - & - & + & - & - & - & - \\
\hline \multicolumn{10}{|c|}{ Evaporative Emissions } \\
\hline $\mathrm{THC}$ & - & - & - & - & - & - & - & - & - \\
\hline \multicolumn{10}{|c|}{ Greenhouse Gases } \\
\hline $\mathrm{CO}_{2}$ & - & - & - & - & - & - & - & - & - \\
\hline $\mathrm{CH}_{4}$ & + & + & + & + & + & + & + & + & + \\
\hline \multicolumn{10}{|l|}{ Aldehydes } \\
\hline $\mathrm{HCHO}$ & - & - & + & - & + & - & - & - & + \\
\hline $\mathrm{CH}_{3} \mathrm{CHO}$ & - & - & - & - & - & - & - & - & - \\
\hline \multicolumn{10}{|c|}{ Fuel Economy } \\
\hline $\mathrm{mpg}$ & $\mathrm{n} / \mathrm{a}$ & $\mathrm{n} / \mathrm{a}$ & $\mathrm{n} / \mathrm{a}$ & $\mathrm{n} / \mathrm{a}$ & $\mathrm{n} / \mathrm{a}$ & $\mathrm{n} / \mathrm{a}$ & $\mathrm{n} / \mathrm{a}$ & $\mathrm{n} / \mathrm{a}$ & $\mathrm{n} / \mathrm{a}$ \\
\hline mpeg & - & - & - & - & - & - & - & - & - \\
\hline
\end{tabular}

"+" Indicates results from CNG tests were higher than RFG tests

"-" Indicates results from CNG tests were lower than RFG tests

Highlighted blocks indicate a significant statistical difference. 
Table 31. Summary Comparison of Average Speciated Hydrocarbon Results from CNG versus RFG

\begin{tabular}{|l|c|c|}
\hline & \multicolumn{2}{|c|}{ Dodge B250 Van } \\
\hline Air Toxics & Lab 1 & Lab 3 \\
\hline $\mathrm{HCHO}$ & - & - \\
\hline $\mathrm{CH}_{3} \mathrm{CHO}$ & - & - \\
\hline 1,3-butadiene & - & - \\
\hline Benzene & - & - \\
\hline Total PWT & - & - \\
\hline Ozone Reactivity & \multicolumn{2}{|l}{} \\
\hline OFP & - & - \\
\hline SR & - & - \\
\hline
\end{tabular}

average $\mathrm{CNG}$ emissions were lower than the average RFG emissions. Table 30 includes mass emissions results from the B250s that were tested over multiple rounds at all 3 labs, and more limited results from the Caravans that were only tested during a single round at Lab 1 . Table 31 includes results from detailed hydrocarbon speciations of emissions from the B250 tests performed at Labs 1 and 3 .

Table 30 shows that there tend to be statistically significant differences between the average emissions from the CNG and RFG B250 vans, and that these results tend to be fairly consistent from lab to lab and from round to round. The average NMHC, $\mathrm{CO}, \mathrm{CO}_{2}, \mathrm{CH}_{3} \mathrm{CHO}$, and fuel economy results were significantly lower from the CNG tests than the RFG tests for all three labs and in all three test rounds. Average $\mathrm{CH}_{4}$ emissions were consistently higher from $\mathrm{CNG}$ than from RFG. $\mathrm{NO}_{\mathrm{x}}$ and "evaporative" hydrocarbons tended to be lower from the CNG tests, but in some cases the differences were not significant, and in one case (Lab 2, Round 3) the average $\mathrm{NO}_{\mathrm{x}}$ emissions were higher from CNG. The evapora- tive emissions test is a measure of the hydrocarbons emanating from two, 1-hour soaks in a sealed room with the engine off. Dedicated gaseous fuel vehicles typically do not have evaporative control systems because the fuel system is said to be sealed under pressure. Nevertheless, hydrocarbons (mostly methane) may still be found emanating from gaseous fuel vehicles. In all cases, the average THC measured during the evaporative tests were lower than from the RFG tests, but in a few cases the difference was not statistically significant.

Results from a subset of the vehicles (on which detailed speciation of the hydrocarbon emissions was performed) are summarized in Table 31. The general trend of these results was very consistent for the 2 labs where this analysis was performed. At both labs, the CNG emissions had lower average values of the four toxic emissions that were quantified, had lower PWT, lower average OFP, and lower average SR. These differences were all deemed statistically significant at the $95 \%$ confidence level.

\section{Dodge B250 VAN}

The CNG and the gasoline Dodge B250 vans are full-size passenger vans equipped with a $5.2 \mathrm{~L} \mathrm{V8}$ engine. Both models have multi-point fuel injection and 4 speed automatic transmissions. The gasoline model was certified to EPA Tier 0 standards. The CNG model had received a waiver on emissions certification. The vehicles tested in this project were a mixture of 1992 and 1994 model year vans. Figure 30 shows the 1992 model year CNG Dodge van.

The gasoline model has a 35-gallon fuel tank, and the CNG model was equipped with 3 or 4 fuel cylinders mounted under the vehicle. The $3-$ cylinder configuration gives a capacity of 11.1 equivalent gallons and the 4-cylinder configuration gives a capacity of 15.7 equivalent gallons.

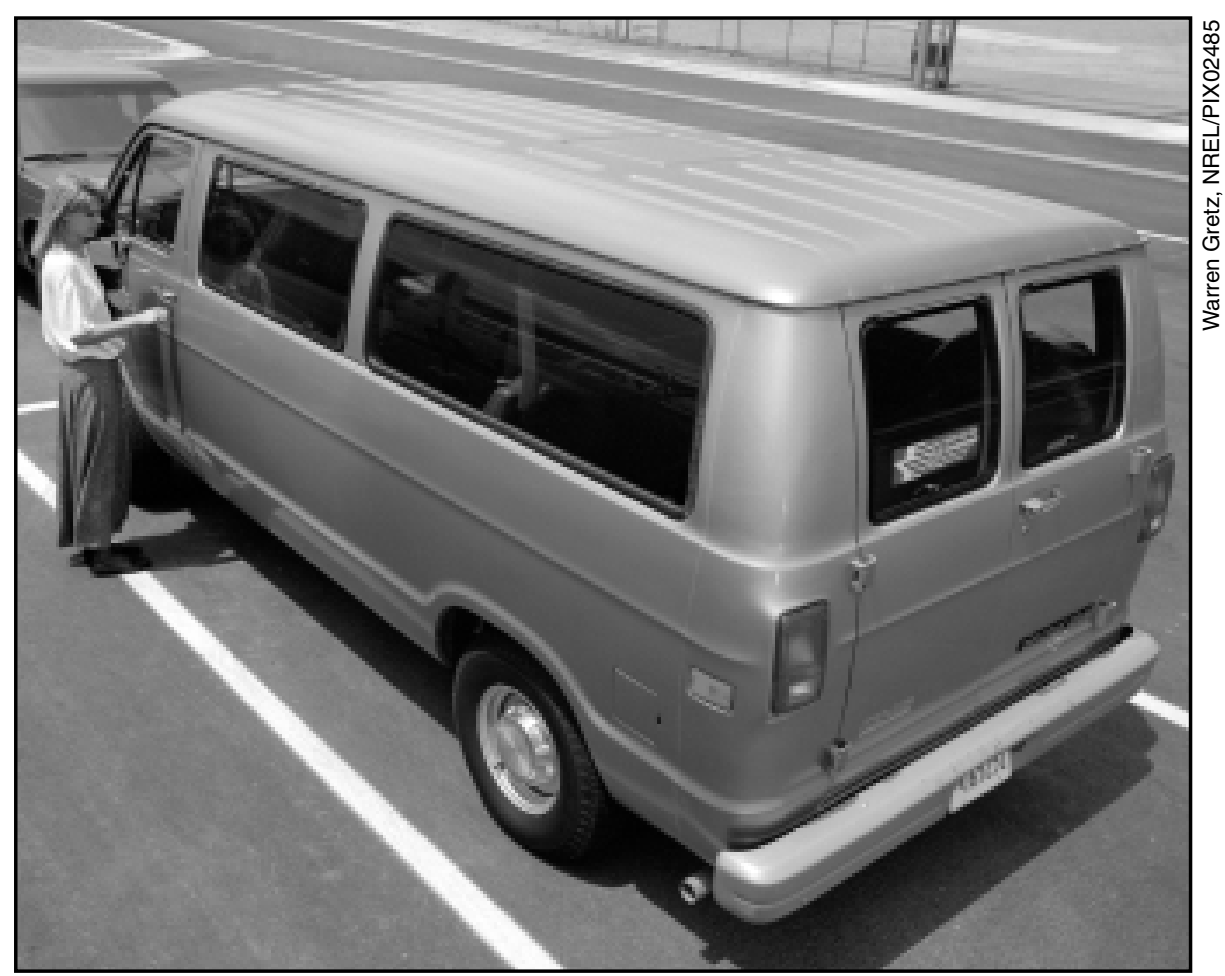

Figure 30. The 1992 CNG Dodge B250 van 
Two rounds of testing were completed on the Dodge B250 vans at Lab 1, and three rounds were completed at Labs 2 and 3. At Lab 1, 10 CNG vans and 8 gasoline controls were tested in both rounds. The vans tested at Lab 2 in all 3 rounds totaled 12 CNG vehicles and 13 gasoline vehicles. At Lab 3, 15 CNG vehicles and 14 gasoline models were tested in all 3 rounds. Mileage ranges and average odometer readings for the $\mathrm{B} 250$ vans tested at the three labs are listed in

Table 32. Odometer Readings for the Dodge B250 Van Tested at Lab 1

\begin{tabular}{|l|c|c|c|c|}
\hline & \multicolumn{2}{|c|}{ CNG } & \multicolumn{2}{c|}{ Gasoline } \\
\hline Round & 1 & 2 & 1 & 2 \\
\hline No. vehicles tested & 10 & 10 & 10 & 8 \\
\hline \multicolumn{4}{|c|}{ Odometer (miles) } \\
\hline Average & 5,412 & 12,154 & 39,749 & 45,755 \\
\hline Maximum & 6,611 & 15,527 & 107,350 & 60,261 \\
\hline Minimum & 3,455 & 8,047 & 23,991 & 33,050 \\
\hline
\end{tabular}

Table 33. Odometer Readings for the Dodge B250 Van Tested at Lab 2

\begin{tabular}{|l|c|c|c|c|c|c|}
\hline & \multicolumn{3}{|c|}{ CNG } & \multicolumn{3}{c|}{ Gasoline } \\
\hline Round & 1 & 2 & 3 & 1 & 2 & 3 \\
\hline No. vehicles tested & 12 & 12 & 12 & 13 & 13 & 13 \\
\hline \multicolumn{7}{|c|}{ Odometer (miles) } \\
\hline Average & 7,246 & 11,778 & 15,633 & 11,429 & 18,327 & 27,037 \\
\hline Maximum & 15,026 & 24,824 & 30,050 & 22,195 & 32,165 & 57,099 \\
\hline Minimum & 3,951 & 5,377 & 6,243 & 3,527 & 3834 & 9,363 \\
\hline
\end{tabular}

Table 34. Odometer Readings for the Dodge B250 Van Tested at Lab 3

\begin{tabular}{|l|c|c|c|c|c|c|}
\hline & \multicolumn{3}{|c|}{ CNG } & \multicolumn{3}{c|}{ Gasoline } \\
\hline Round & 1 & 2 & 3 & 1 & 2 & 3 \\
\hline No. vehicles tested & 15 & 15 & 15 & 14 & 14 & 14 \\
\hline \hline \multicolumn{8}{|c|}{ Odometer (miles) } \\
\hline Average & 6,978 & 12,051 & 18,515 & 13,321 & 17,338 & 19,670 \\
\hline Maximum & 22,245 & 29,585 & 45,147 & 30,493 & 36,629 & 38,485 \\
\hline Minimum & 2,121 & 3,455 & 6,782 & 3,875 & 5,210 & 6,720 \\
\hline
\end{tabular}

tested at Lab 2 and Table 37 for those tested at Lab 3. Figures 31-33 show the graphical representation of the average regulated and $\mathrm{CO}_{2}$ exhaust emissions for the Dodge B250 vans tested at Labs 1, 2, and 3, respectively. Regulated emissions results for both the CNG and gasoline vans were well below the Tier 0 standard. The CNG vans, although not certified, tended to be below the more stringent Tier 1 standard.

Average NMHC emissions are shown in Figures 31a, 32a, and 33a for Labs 1,2 , and 3, respectively. All NMHC values were not only below the Tier 0 full useful life standard of $0.67 \mathrm{~g} / \mathrm{mi}$, but were also below the more stringent Tier 1 full useful life standard of $0.4 \mathrm{~g} / \mathrm{mi}$. NMHC emissions for the B250 vans were significantly lower in the CNG model for all 3 labs. Lab 1 showed the largest percent difference at approximately $94 \%$ lower for the CNG model during both rounds.

Lab 2 showed a $76 \%$ to $85 \%$ decrease in NMHC for the CNG model. Lab 3 showed a decrease in NMHC of $81 \%$ in Round 1, 41\% in Round 2, and $45 \%$ in Round 3. The higher percentage for Lab 1 could be due partially to the discrepancy in odometer reading between the $\mathrm{CNG}$ and gasoline models. The average odometer for the CNG vans was 5,412 miles in Round 1 and 12,154 miles in Round 2 . In contrast, the average odometer for the gasoline model was 39,749 miles and 45,755 miles for Rounds 1 and 2, respectively. All of the vans tested at Lab 1 were from the 1994 model year. Round-to-round comparisons at Lab 1 showed a significant increase in NMHC for the RFG tests in Round 2, but no significant difference between rounds for the CNG tests at Lab 1. At Lab 2, the CNG tests showed a significant increase from Round 1 to Round 2, and the RFG tests increased significantly from Round 2 to Round 3. Lab 3 CNG tests increased significantly 
Table 35. Average Emissions Results from the Dodge B250 Van Tested at Lab 1

\begin{tabular}{|c|c|c|c|c|c|c|c|c|}
\hline & \multicolumn{4}{|c|}{ Round 1} & \multicolumn{4}{|c|}{ Round 2} \\
\hline & CNG & $\begin{array}{l}\text { STD- } \\
\text { RFG }\end{array}$ & $\begin{array}{c}\text { Percent } \\
\text { Difference }\end{array}$ & $\begin{array}{l}\text { Sig. Fuel } \\
\text { Effect? }\end{array}$ & CNG & $\begin{array}{l}\text { STD- } \\
\text { RFG }\end{array}$ & $\begin{array}{c}\text { Percent } \\
\text { Difference }\end{array}$ & $\begin{array}{l}\text { Sig. Fuel } \\
\text { Effect? }\end{array}$ \\
\hline $\mathrm{NMHC}$ & 0.018 & 0.323 & $-94.3 \%$ & $\mathrm{y}$ & 0.022 & 0.362 & $-93.8 \%$ & $\mathrm{y}$ \\
\hline $\mathrm{THC}$ & 0.288 & 0.387 & $-25.7 \%$ & $\mathrm{y}$ & 0.383 & 0.431 & $-11.1 \%$ & $\mathrm{y}$ \\
\hline $\mathrm{CO}$ & 0.651 & 5.615 & $-88.4 \%$ & $\mathrm{y}$ & 0.734 & 6.846 & $-89.3 \%$ & $\mathrm{y}$ \\
\hline $\mathrm{NO}_{\mathrm{x}}$ & 0.287 & 0.858 & $-66.6 \%$ & $\bar{y}$ & 0.521 & 0.888 & $-41.3 \%$ & $\bar{y}$ \\
\hline \multicolumn{9}{|c|}{ Evaporative Emissions (g/test) } \\
\hline Total Evaporative & 0.0684 & 0.6999 & $-90.2 \%$ & $\mathrm{y}$ & 0.4501 & 0.8749 & $-48.5 \%$ & $\mathrm{y}$ \\
\hline \multicolumn{9}{|c|}{ Greenhouse Gases (g/mi) } \\
\hline $\mathrm{CO}_{2}$ & 539.16 & 637.87 & $-15.5 \%$ & $\mathrm{y}$ & 526.54 & 617.84 & $-14.8 \%$ & $\mathrm{y}$ \\
\hline $\mathrm{CH}_{4}$ & 0.27 & 0.078 & $244.8 \%$ & $y$ & 0.362 & 0.085 & $325.2 \%$ & $y$ \\
\hline \multicolumn{9}{|c|}{ Aldehydes (mg/mi) } \\
\hline $\mathrm{HCHO}$ & 2.08 & 6.45 & $-67.7 \%$ & $\mathrm{y}$ & 2.31 & 6.13 & $-62.3 \%$ & $\mathrm{y}$ \\
\hline $\mathrm{CH}_{3} \mathrm{CHO}$ & 0.17 & 1.25 & $-86.7 \%$ & $\mathrm{y}$ & 0.26 & 1.38 & $-80.9 \%$ & $\mathrm{y}$ \\
\hline Fuel Economy & 12.97 & 13.49 & $-3.9 \%$ & $y$ & 12.5 & 13.73 & $-9.0 \%$ & $y$ \\
\hline
\end{tabular}

Table 36. Average Emissions Results from the Dodge B250 Van Tested at Lab 2

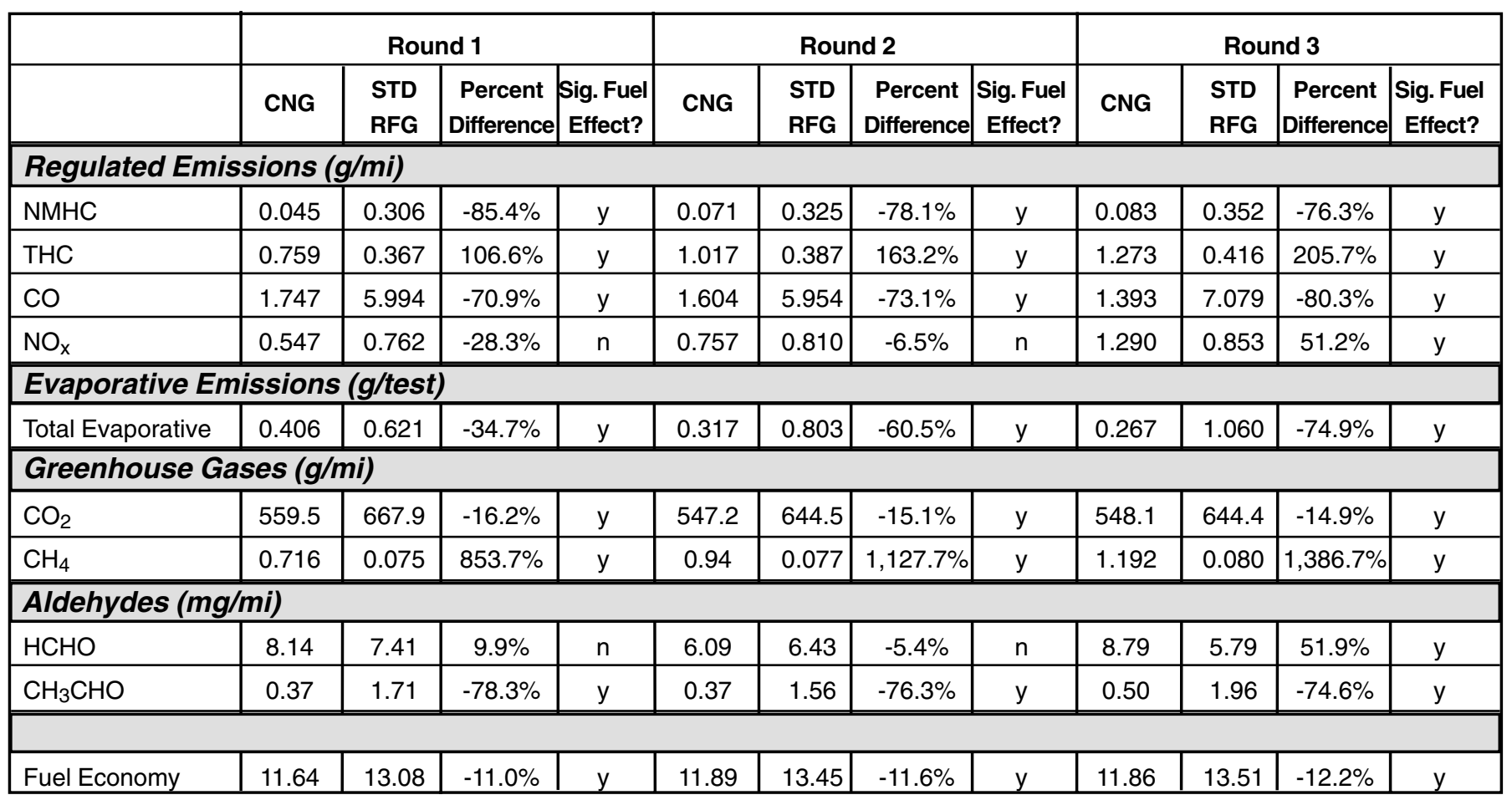


from Round 1 to 2, but the RFG tests did not show a significant difference between the rounds.

The average $\mathrm{CO}$ emissions for the B250 vans tested at the 3 labs are shown in Figures 31b, 32b, and 33b. Average results were below the Tier 0 full useful life standard for CO.

Although the $\mathrm{CNG}$ vans were not certified, the average $\mathrm{CO}$ emissions for these vehicles were below the more stringent Tier 1 levels at all 3 labs. The average $\mathrm{CO}$ emissions from the CNG vehicles at Lab 1 were $88 \%$ and $89 \%$ lower than the RFG emissions for Rounds 1 and 2, respectively. Lab 2 showed a decrease in $\mathrm{CO}$ for the CNG vans of $71 \%$ in Round $1,73 \%$ in Round 2, and 80\% in Round 3. Lab 3 showed a decrease of $35.5 \%$ in Round 1, 48\% in Round 2, and 53\% in Round 3. Round-to-round comparisons of $\mathrm{CO}$ emissions at Lab 1 show a significant increase in Round 2 for the RFG tests, but no significant dif- ference between rounds for the CNG tests. The only significant increase in $\mathrm{CO}$ emissions at $\mathrm{Lab} 2$ was for the RFG tests from Rounds 2 to 3 . The $\mathrm{CO}$ emissions for the $\mathrm{CNG}$ vans at Lab 2 showed a slight downward trend that was not significant at the 95\% confidence level. This same trend was seen with the CNG vans tested at Lab 3. The RFG vans at Lab 3 showed a significant $\mathrm{CO}$ increase in Round 2 and a significant decrease in Round 3.

Average $\mathrm{NO}_{\mathrm{x}}$ emissions for the B250s tested at the 3 labs are shown in Figures 31c, 32c, and 33c. The average $\mathrm{NO}_{\mathrm{x}}$ emissions for the $\mathrm{B} 250$ vans were below the federal Tier 0 standard of $1.7 \mathrm{~g} / \mathrm{mi}$. The average $\mathrm{NO}_{\mathrm{x}}$ emissions for the CNG vans were lower than that of the gasoline models except for the third round at Lab 2. At Lab 1, the CNG emissions were $66.5 \%$ lower in Round 1 and $41 \%$ lower in Round 2. Lab 3 also followed this trend; Round $1 \mathrm{CNG}$ emissions were $45.5 \%$ lower, Round 2 were $31 \%$ lower, and Round 3 were $10.7 \%$ lower. The average $\mathrm{NO}_{\mathrm{x}}$ emissions for both van models were below the Tier 0 as well as the more stringent Tier 1 limits. The exception to this trend was seen at Lab 2. Rounds 1 and 2 showed a decrease in $\mathrm{NO}_{\mathrm{x}}$ emissions for the CNG model, but this difference was not significant. In Round 3, the CNG average for $\mathrm{NO}_{\mathrm{x}}$ was $51 \%$ higher than the average for the gasoline model. This was mainly caused by one highemitting van, which was not tagged as an outlier. During Bag 3 of the FTP on this van, the check engine light came on, indicating a possible problem. If this value is removed, the CNG average is lowered to 0.997 $\mathrm{g} / \mathrm{mi}$, but this is still higher than the gasoline average by $16.9 \%$. Roundto-round comparisons of $\mathrm{NO}_{\mathrm{x}}$ emissions at all 3 labs showed an increasing trend for the $\mathrm{CNG}$ vans

Table 37. Average Emissions Results from the Dodge B250 Van Tested at Lab 3

\begin{tabular}{|c|c|c|c|c|c|c|c|c|c|c|c|c|}
\hline & \multicolumn{4}{|c|}{ Round 1} & \multicolumn{4}{|c|}{ Round 2} & \multicolumn{4}{|c|}{ Round 3} \\
\hline & CNG & $\begin{array}{l}\text { STD } \\
\text { RFG }\end{array}$ & $\begin{array}{c}\text { Percent } \\
\text { Difference }\end{array}$ & $\begin{array}{r}\text { Sig. Fuel } \\
\text { Effect? }\end{array}$ & CNG & $\begin{array}{l}\text { STD } \\
\text { RFG }\end{array}$ & $\begin{array}{c}\text { Percent } \\
\text { Difference }\end{array}$ & $\begin{array}{c}\text { Sig. Fuel } \\
\text { Effect? }\end{array}$ & CNG & $\begin{array}{l}\text { STD } \\
\text { RFG }\end{array}$ & $\mid \begin{array}{c}\text { Percent } \\
\text { Difference }\end{array}$ & $\begin{array}{l}\text { Sig. Fuel } \\
\text { Effect? }\end{array}$ \\
\hline \multicolumn{13}{|c|}{ Regulated Emissions (g/mi) } \\
\hline $\mathrm{NMHC}$ & 0.049 & 0.257 & $-80.9 \%$ & $\mathrm{y}$ & 0.179 & 0.304 & $-41.1 \%$ & $\mathrm{y}$ & 0.170 & 0.310 & $-45.2 \%$ & $\mathrm{y}$ \\
\hline THC & 0.710 & 0.311 & $128.1 \%$ & $\mathrm{y}$ & 0.741 & 0.353 & $109.9 \%$ & $\mathrm{y}$ & 0.797 & 0.365 & $118.4 \%$ & $y$ \\
\hline $\mathrm{CO}$ & 2.563 & 3.974 & $-35.5 \%$ & $\mathrm{y}$ & 2.458 & 4.713 & $-47.9 \%$ & $\mathrm{y}$ & 1.828 & 3.877 & $-52.9 \%$ & $\mathrm{y}$ \\
\hline $\mathrm{NO}_{\mathrm{x}}$ & 0.379 & 0.695 & $-45.5 \%$ & y & 0.506 & 0.738 & $-31.4 \%$ & $\mathrm{y}$ & 0.709 & 0.794 & $-10.7 \%$ & $\mathrm{n}$ \\
\hline \multicolumn{13}{|c|}{ Evaporative Emissions (g/test) } \\
\hline Total Evaporative & 0.571 & 1.041 & $-45.2 \%$ & $\mathrm{n}$ & 0.524 & 1.39 & $-62.3 \%$ & $\mathrm{y}$ & 0.764 & 1.35 & $-43.4 \%$ & $y$ \\
\hline \multicolumn{13}{|c|}{ Greenhouse Gases (g/mi) } \\
\hline $\mathrm{CO}_{2}$ & 502.3 & 616.0 & $-18.5 \%$ & $\mathrm{y}$ & 494.1 & 604.8 & $-18.3 \%$ & $\mathrm{y}$ & 488.1 & 606.25 & $-19.5 \%$ & $\mathrm{y}$ \\
\hline $\mathrm{CH}_{4}$ & 0.66 & 0.054 & $1,134.5 \%$ & $\mathrm{y}$ & 0.557 & 0.049 & $1,030.6 \%$ & $y$ & 0.617 & 0.055 & $1,026.3 \%$ & $y$ \\
\hline \multicolumn{13}{|c|}{ Aldehydes (mg/mi) } \\
\hline $\mathrm{HCHO}$ & 1.68 & 3.62 & $-53.6 \%$ & $\mathrm{y}$ & 1.82 & 3.85 & $-52.7 \%$ & $\mathrm{y}$ & 1.86 & 3.87 & $-51.9 \%$ & $\mathrm{y}$ \\
\hline $\mathrm{CH}_{3} \mathrm{CHO}$ & 0.089 & 1.03 & $-91.3 \%$ & $\mathrm{y}$ & 0.196 & 1.06 & $-81.4 \%$ & $\mathrm{y}$ & 0.2 & 1.08 & $-81.4 \%$ & $\mathrm{y}$ \\
\hline Fuel Economy & 13.32 & 13.93 & $-4.4 \%$ & $y$ & 13.66 & 14.16 & $-3.5 \%$ & $y$ & 13.86 & 14.15 & $-2.0 \%$ & $y$ \\
\hline
\end{tabular}


31a: Non-Methane Hydrocarbon

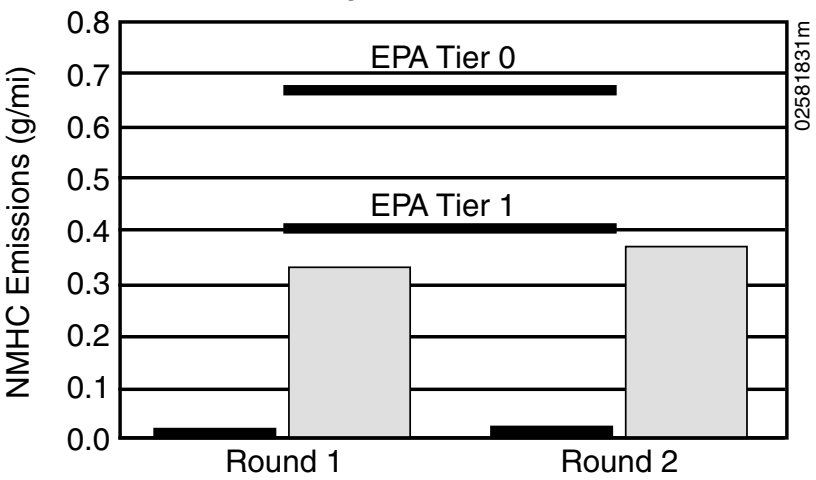

31b: Carbon Monoxide

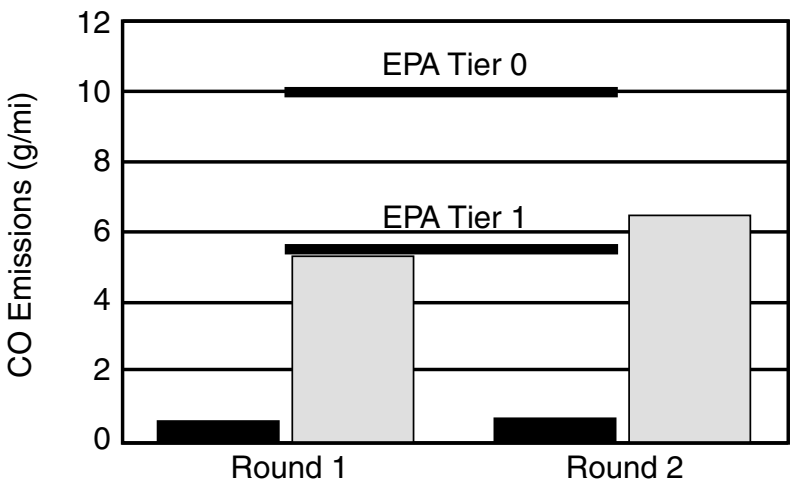

31c: Oxides of Nitrogen

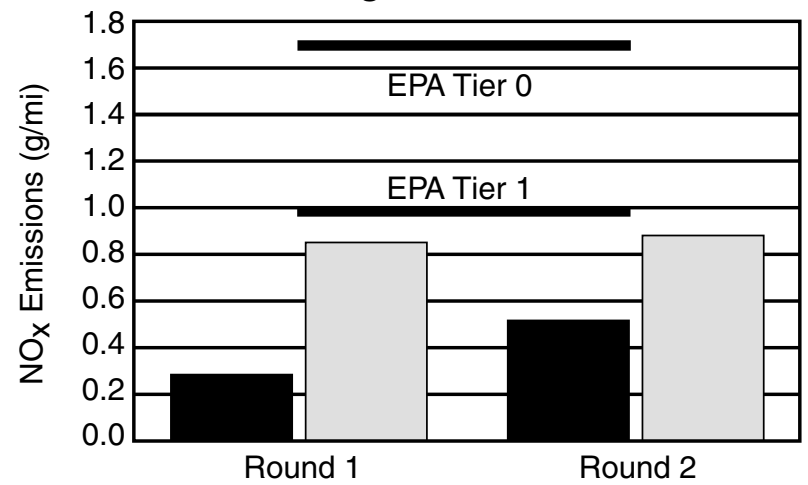

31d: Carbon Dioxide

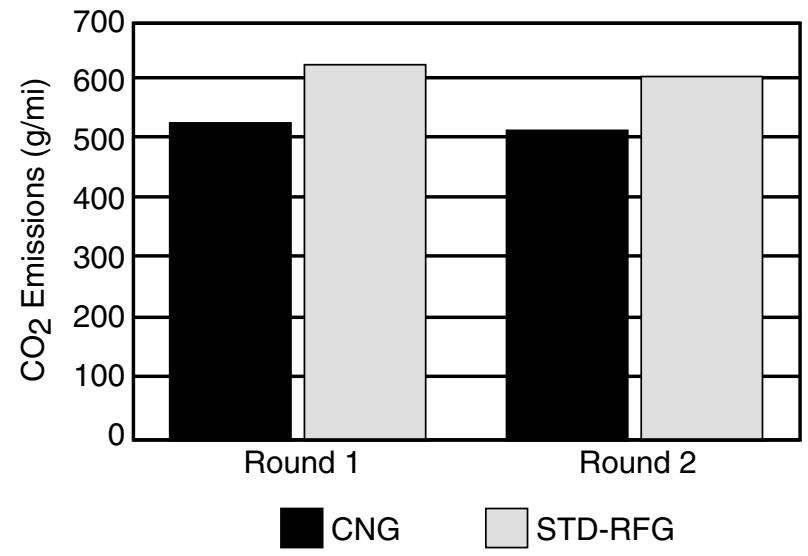

Figure 31. Emissions results from the Dodge B250 van tested at Lab 1 32a: Non-Methane Hydrocarbon

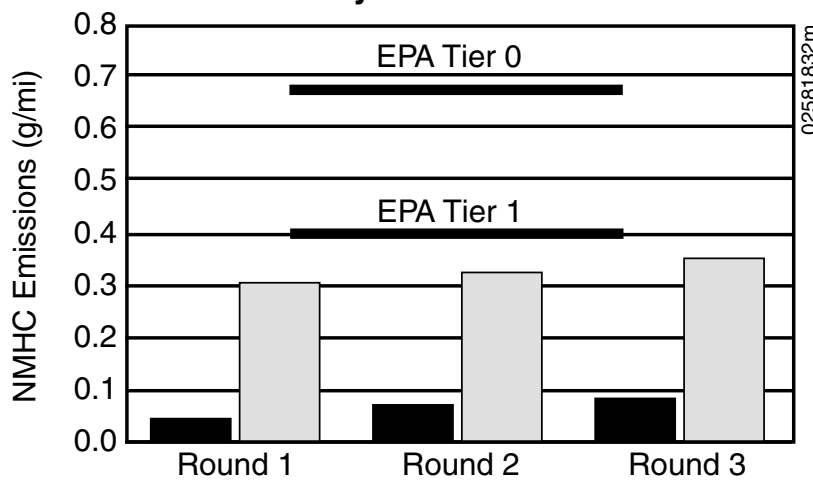

32b: Carbon Monoxide

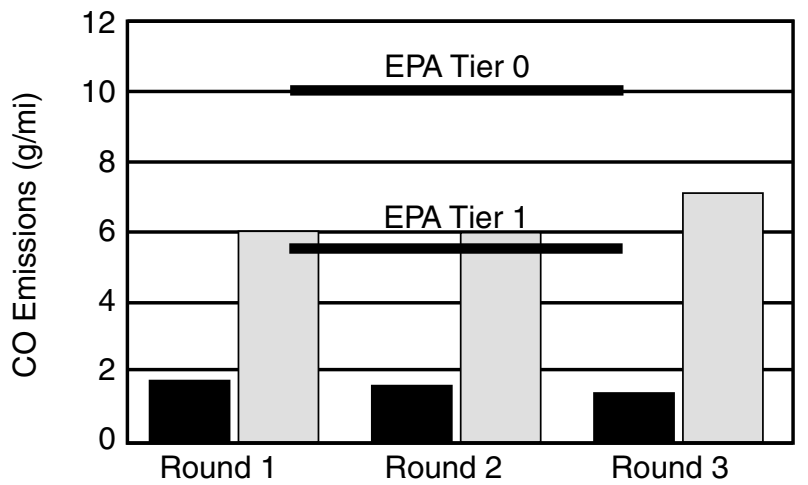

32c: Oxides of Nitrogen

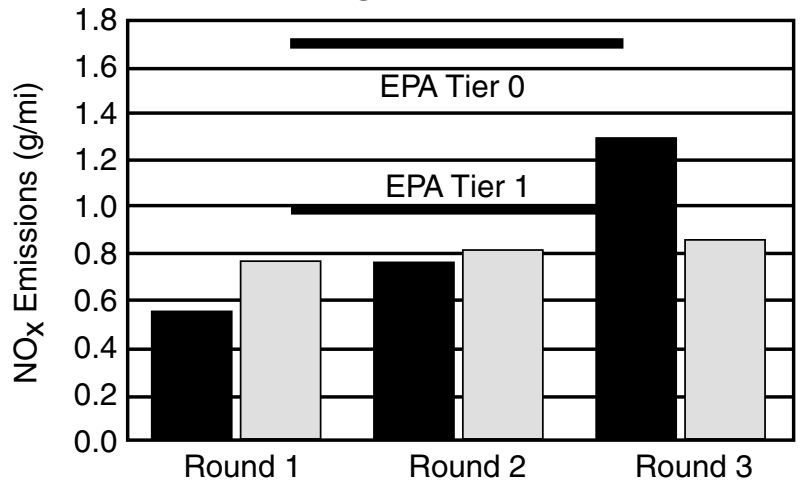

32d: Carbon Dioxide

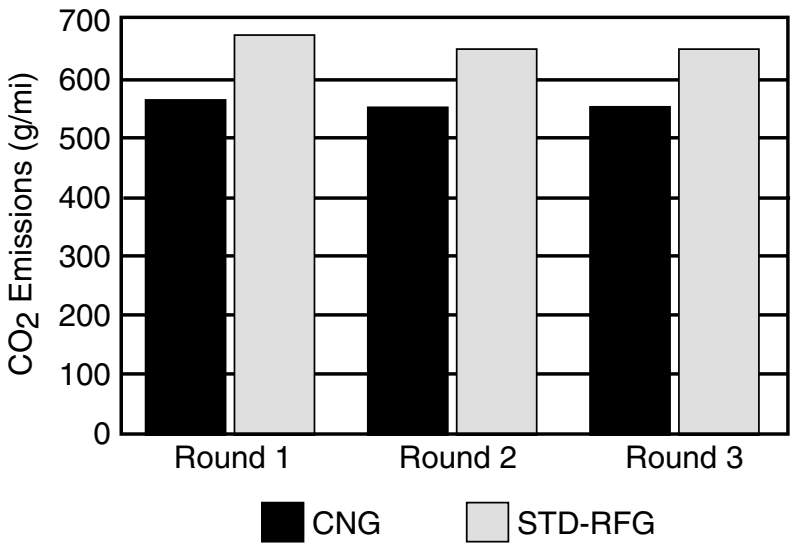

Figure 32. Emissions results from the Dodge B250 van tested at Lab 2 
33a: Non-Methane Hydrocarbon

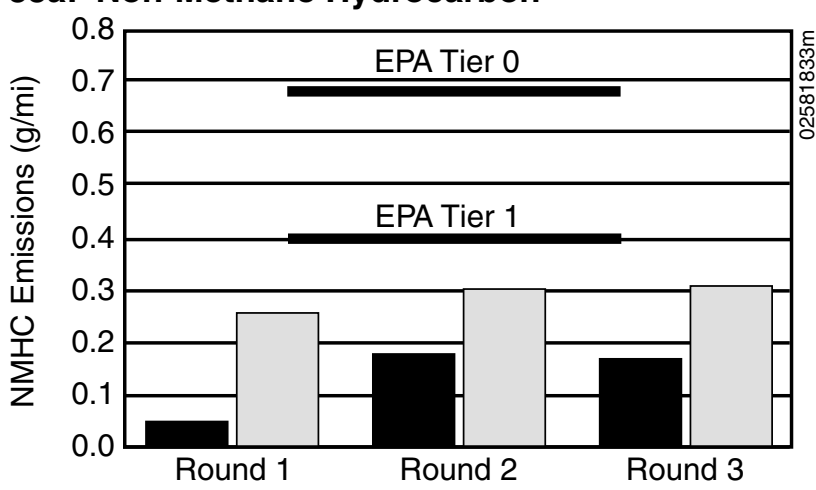

33b: Carbon Monoxide

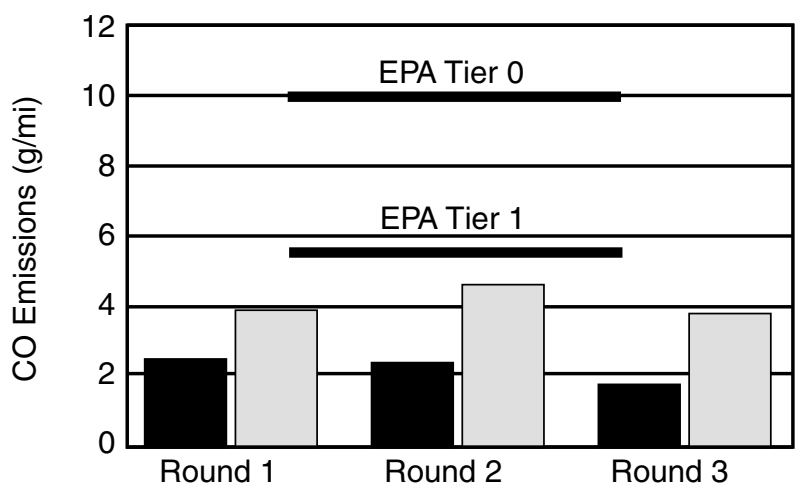

33c: Oxides of Nitrogen

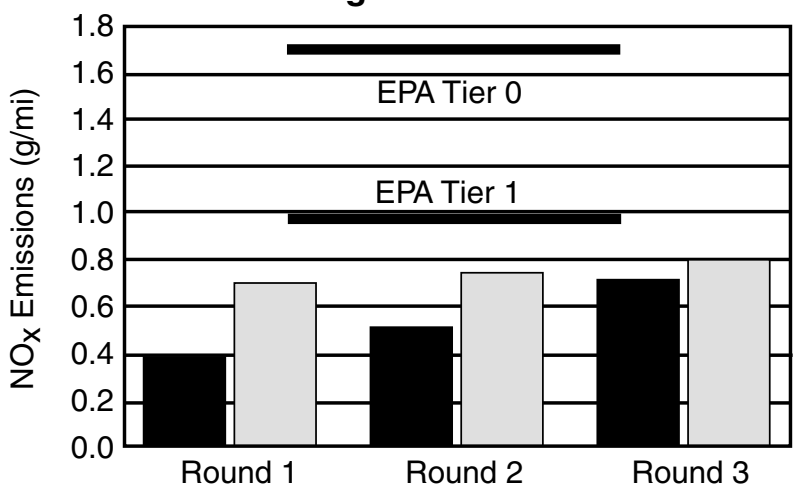

33d: Carbon Dioxide

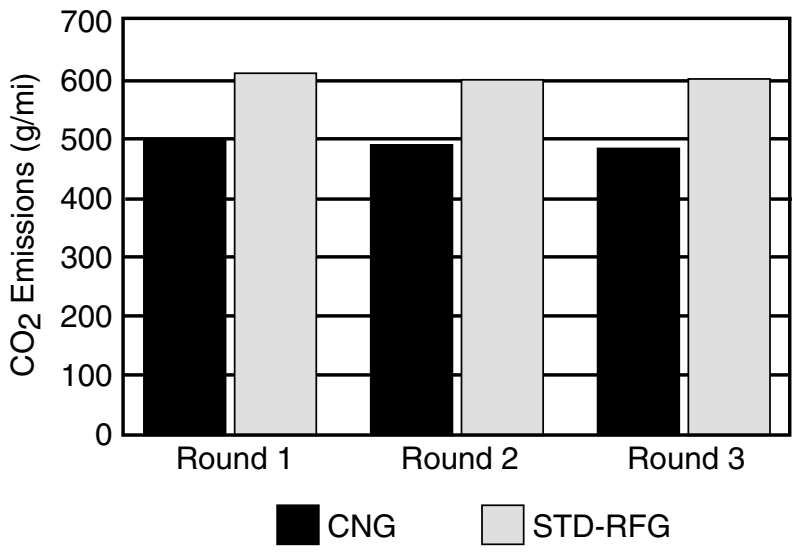

Figure 33. Emissions results from the Dodge B250 van tested at Lab 3 that tended to be significant. The differences between rounds for the RFG vans showed no significant difference at any of the labs.

\section{Evaporative Emissions}

CNG vehicles were designed with sealed fuel systems. To determine if the test vans were experiencing any leaks or "weepage" at any point in the natural gas fuel system, a modified evaporative test was performed. The gasoline vans received the standard evaporative test, which includes a heat build on the fuel tanks. The CNG vans were placed in the SHED for the two prescribed 1-hour tests, but without heating the tanks.

Average evaporative emissions for Labs 1, 2, and 3 are listed in Tables 35-37 and shown in Figures 34-36. The average evaporative emissions for the B250 van were well below the Tier 1 and Tier 0 limit of $2 \mathrm{~g}$ per test for all rounds at each lab. "Evaporative" $\mathrm{HC}$ emissions from the modified evaporative tests on the $\mathrm{CNG}$ vans were significantly lower than the evaporative emissions for the standard models for all labs during all test rounds. Evaporative emissions for the CNG vans tested at Lab 1 were $90 \%$ lower than those from the gasoline vans in Round 1 and $48.5 \%$ lower in Round 2 . The CNG vans tested at Lab 2 showed larger differences of 35\%, $61 \%$, and $75 \%$ lower than the gasoline controls for Rounds 1 , 2 , and 3, respectively. Lab 3 also showed decreases for the CNG vans, from $43 \%$ to $62 \%$. These differences tended to be statistically significant at the $95 \%$ confidence level.

Round-to-round comparisons showed significant increases for both fuels at Lab 1 . The CNG vans at Lab 2 showed no significant difference between rounds and the control vans showed a steady increase in evaporative emissions that was only significant between Round 2 and Round 3. The CNG vans tested at Lab 3 also showed no significant difference between rounds. The evaporative emissions for the control vans at Lab 3 showed an increase in Round 2 and a decrease in Round 3. Neither of these differences, however, was statistically significant.

\section{Greenhouse Gases}

The average $\mathrm{CO}_{2}$ emissions for the $\mathrm{CNG}$ vans were consistently lower than the average for the gasoline controls. Labs 1 and 2 showed a decrease of around 15\% for all rounds. Lab 3 had a slightly higher percent decrease at approximately $19 \%$ for the 3 rounds. The differences in $\mathrm{CO}_{2}$ emissions between CNG and RFG were statistically significant. The differences between rounds for both van types at all 3 labs tended not to be significant at the $95 \%$ confidence level.

Because $\mathrm{CNG}$ is $95 \% \mathrm{CH}_{4}$, emissions of this greenhouse gas are expected to be significantly higher for the CNG vans. 


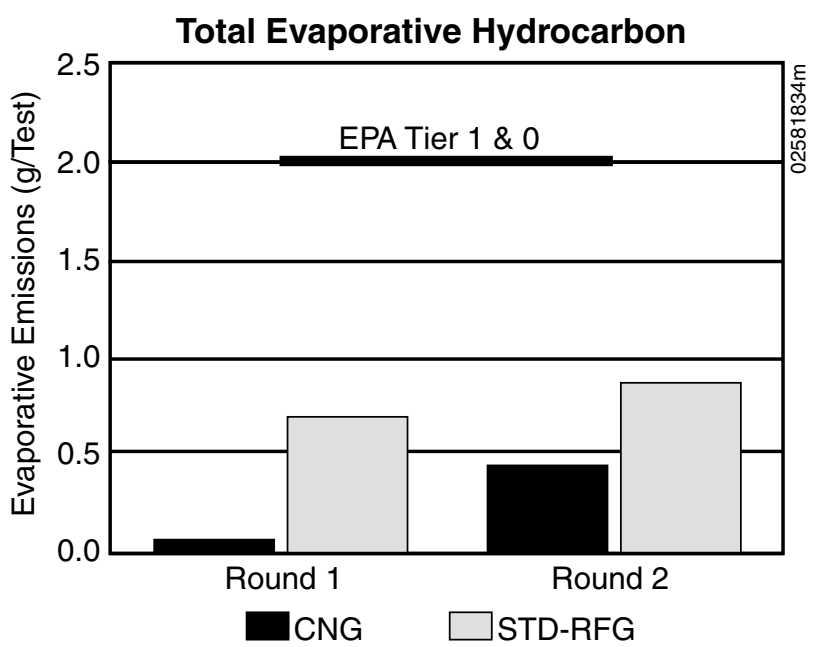

Figure 34. Evaporative emissions results from the Dodge B250 van tested at Lab 1

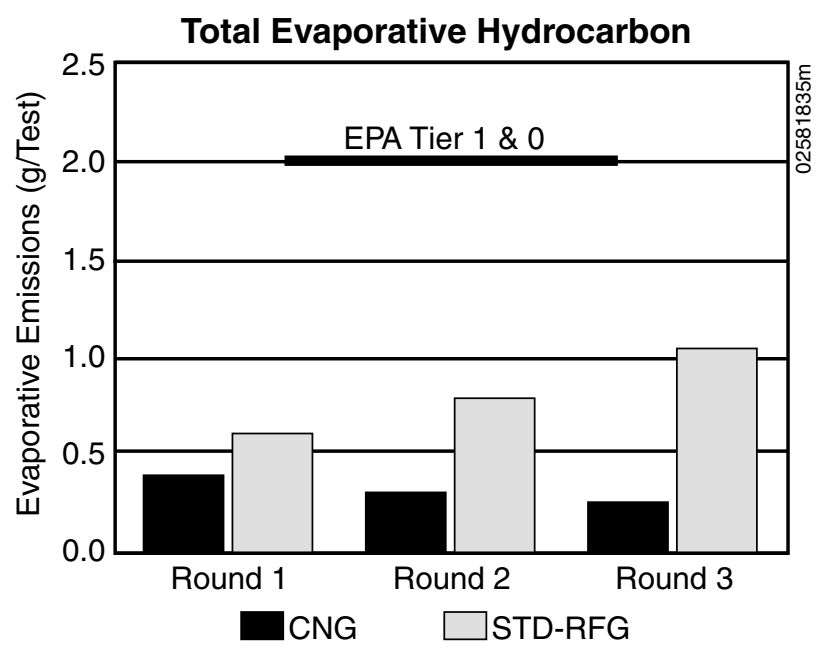

Figure 35. Evaporative emissions results from the Dodge B250 van tested at Lab 2

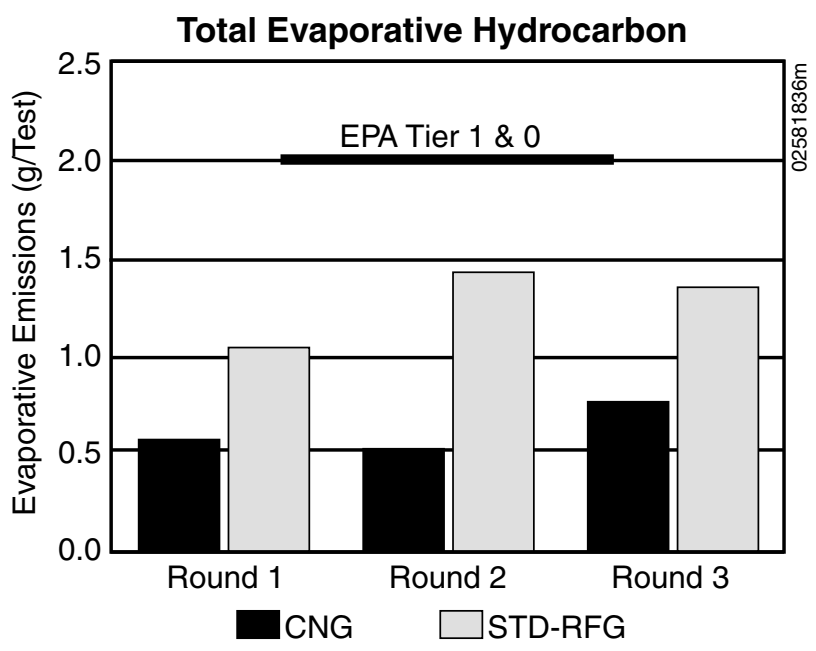

Figure 36. Evaporative emissions results from the Dodge B250 van tested at Lab 3
Differences in $\mathrm{CH}_{4}$ emissions between the $\mathrm{CNG}$ tests and the RFG tests range from $245 \%$ higher to $1,387 \%$ higher. Round-to-round comparisons of $\mathrm{CH}_{4}$ emissions at Labs 1 and 2 showed significant increases for the CNG tests over time. Lab 3 showed a significant increase in $\mathrm{CH}_{4}$ for the $\mathrm{CNG}$ tests in Round 2, but no significant difference in Round 3. The RFG tests showed no significant difference in $\mathrm{CH}_{4}$ emissions between rounds at any of the labs.

\section{Aldehydes}

Figures 37-39 present the average aldehyde emissions for the Dodge B250 vans at each lab. In general, aldehyde emissions from the CNG vans were much lower than those from the gasoline vans. The exception to this was the formaldehyde emissions at Lab 2. Labs 1 and 3 showed similar values between fuels for both formaldehyde and acetaldehyde with the CNG vans testing significantly lower than the gasoline control vans. Reductions in formaldehyde at Lab 1 were approximately $68 \%$ in Round 1 and 62\% in Round 2. Lab 3 showed reductions in formaldehyde of approximately 54\%, 53\%, and 52\% in Rounds 1, 2, and 3 respectively. Acetaldehyde emissions for the $\mathrm{CNG}$ vans at Lab 1 were $87 \%$ lower than those from the conventional vans in Round 1 and $81 \%$ lower in Round 2. Lab 3 showed similar reductions in acetaldehyde of $91 \%$ in Round 1 and $81 \%$ in Rounds 2 and 3.

Average formaldehyde emissions for the B250 vans tested at Lab 2 were not significantly different between fuels for the first 2 rounds. The CNG vans tested $9.9 \%$ higher than the gasoline controls in Round 1 and 5.4\% lower in Round 2. Round 3, however, showed a significant increase in formaldehyde emissions for the CNG vans (51.8\%). This could be due in part to the van mentioned earlier (on which the check engine light came on during the last phase of the FTP). The formaldehyde value for this van was considerably higher than that of the other vans tested. Removal of this value, which was not identified as an outlier, would reduce the percent difference to $26 \%$, but the CNG average is still greater than that of the conventional model. Acetaldehyde emissions at Lab 2 agree with the other 2 labs, with the CNG vans testing significantly lower than the gasoline vans. The average acetaldehyde emissions for the CNG vans tested at Lab 2 were $78 \%$ lower than those from the conventional model van in Round 1, 76\% lower in Round 2, and $75 \%$ lower in Round 3. The differences between rounds for aldehydes at all 3 labs tended to be not significant at the $95 \%$ confidence level. 


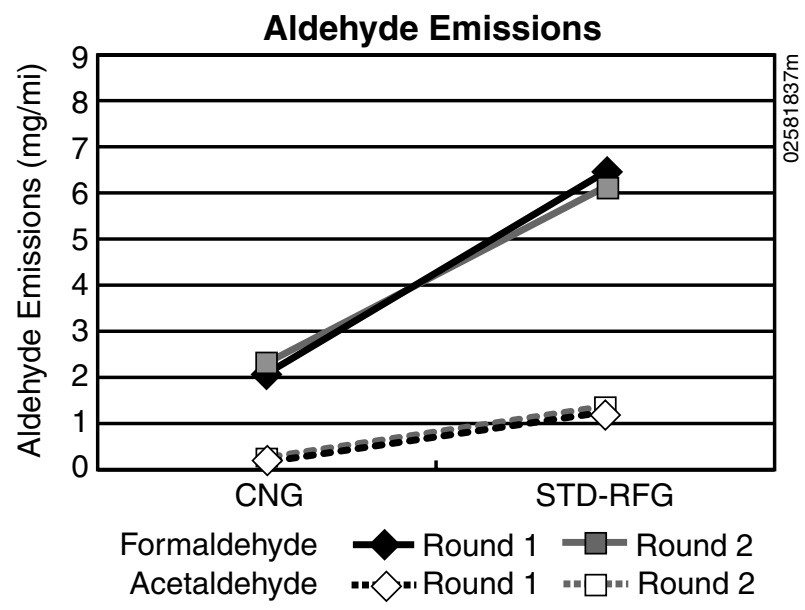

Figure 37. Aldehyde emissions from the Dodge B250 van tested at Lab 1

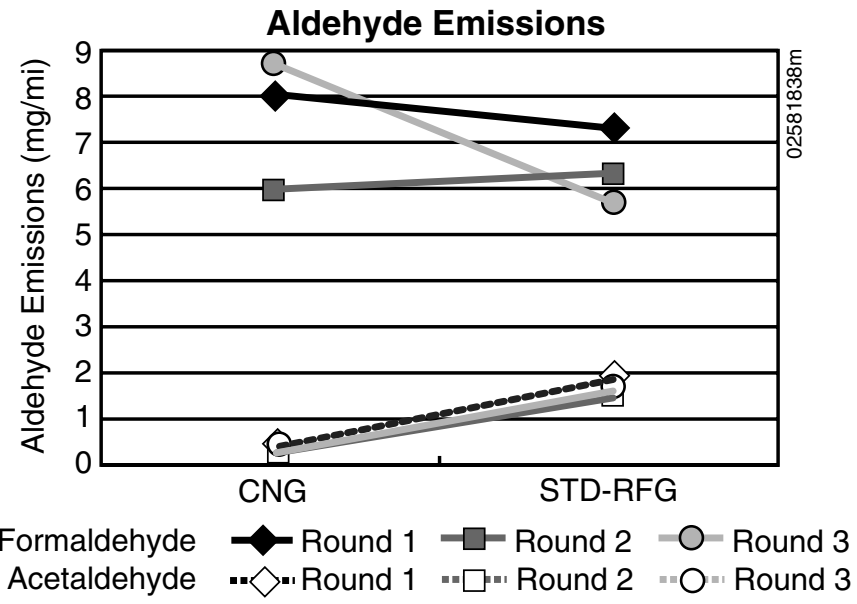

Figure 38. Aldehyde emissions from the Dodge B250 van tested at Lab 2

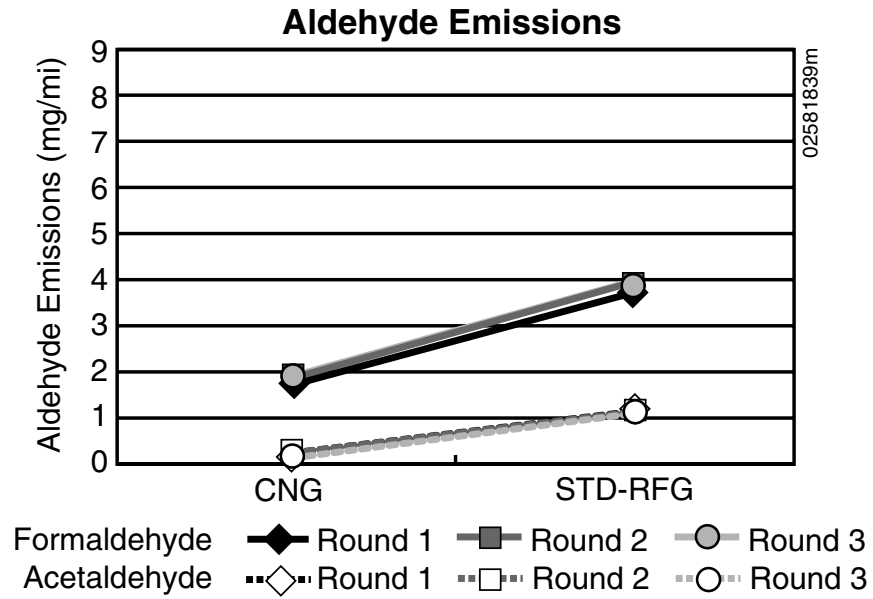

Figure 39. Aldehyde emissions from the Dodge B250 van tested at Lab 3 
Table 38. Toxic Emissions from the Dodge B250 Van Tested at Lab 1

\begin{tabular}{|c|c|c|c|c|c|c|}
\hline & \multicolumn{2}{|c|}{ CNG } & \multicolumn{2}{|c|}{ STD-RFG } & \multirow[b]{2}{*}{$\begin{array}{l}\text { Percent } \\
\text { Difference }\end{array}$} & \multirow[b]{2}{*}{$\begin{array}{c}\text { Sig. Fuel } \\
\text { Effect? }\end{array}$} \\
\hline & $\begin{array}{c}\text { Measured } \\
\text { Value }(\mathrm{mg} / \mathrm{mi})\end{array}$ & PWT & $\begin{array}{c}\text { Measured } \\
\text { Value }(\mathrm{mg} / \mathrm{mi})\end{array}$ & PWT & & \\
\hline $\mathrm{HCHO}$ & 1.878 & 0.086 & 5.741 & 0.264 & $-67.4 \%$ & $y$ \\
\hline $\mathrm{CH}_{3} \mathrm{CHO}$ & 0.152 & 0.001 & 1.167 & 0.009 & $-88.9 \%$ & $y$ \\
\hline 1,3-butadiene & 0 & 0 & 2.1 & 2.1 & $-100.0 \%$ & $y$ \\
\hline Benzene & 0.060 & 0.0018 & 14.15 & 0.425 & $-99.6 \%$ & $y$ \\
\hline Total & 2.09 & 0.089 & 23.16 & 2.798 & $-96.8 \%$ & $y$ \\
\hline
\end{tabular}

Table 39. Toxic Emissions from the Dodge B250 Van Tested at Lab 3

\begin{tabular}{|l|c|c|c|c|c|c|}
\hline & \multicolumn{2}{|c|}{ CNG } & \multicolumn{2}{c|}{ STD-RFG } & \multirow{2}{*}{$\begin{array}{c}\text { Percent } \\
\text { Difference }\end{array}$} & $\begin{array}{c}\text { Sig. Fuel } \\
\text { Effect? }\end{array}$ \\
\cline { 2 - 6 } & $\begin{array}{c}\text { Measured } \\
\text { Value (mg/mi) }\end{array}$ & PWT & $\begin{array}{c}\text { Measured } \\
\text { Value (mg/mi) }\end{array}$ & PWT & $-42.1 \%$ & $\mathrm{y}$ \\
\hline $\mathrm{HCHO}$ & 2.007 & 0.092 & 3.467 & 0.159 & $-467 \%$ & $\mathrm{y}$ \\
\hline $\mathrm{CH}_{3} \mathrm{CHO}$ & 0.171 & 0.0014 & 0.989 & 0.0079 & $-82.3 \%$ & $\mathrm{y}$ \\
\hline 1,3 -butadiene & 0.014 & 0.014 & 1.985 & 1.985 & $-99.3 \%$ & $\mathrm{y}$ \\
\hline Benzene & 0.25 & 0.0075 & 11.179 & 0.335 & $-97.8 \%$ & $\mathrm{y}$ \\
\hline Total & 2.442 & 0.115 & 17.62 & 2.488 & $-95.4 \%$ & \\
\hline
\end{tabular}

\section{Potency-Weighted Toxics and} Ozone-Forming Potential

Hydrocarbon speciation was performed on a percentage of the Dodge B250 vans at Labs 1 and 3. Four $\mathrm{CNG}$ and three gasoline control vans speciated at Lab 1 . The vans receiving full speciation at Lab 3 totaled four CNG and five gasoline control vans.

Tables 38 and 39 present the comparisons between van models for PWT emissions at Labs 1 and 3, respectively. Figures 40 and 41 show the results graphically. The aldehyde averages listed include the results for only those vehicles that were speciated. These results show a significant advantage in using CNG fuel over gasoline. All the toxics for the CNG vans tested at Lab 1 were significantly lower than the averages for the RFG tests. Lab 1 reported no 1,3-butadiene present in the $\mathrm{CNG}$ tests, which represented a $100 \%$ decrease over the RFG levels. Total PWT for the CNG vans was $96.8 \%$ lower than that of the gasoline control vans. Lab 3 showed agreement with Lab 1. All toxics for the CNG vans were significantly lower than the gasoline controls. Total PWT for the CNG vans was $95.4 \%$ lower than that of the gasoline controls.

Tables 40 and 41 present the NMOG, OFP, and SR results for the Dodge B250 vans. Average NMOG for the $\mathrm{CNG}$ vans was significantly lower than the average for the gasoline models. The OFP and SR results are graphically presented in Figures 42 and 43. OFP from the CNG vans was significantly lower than that from the gasoline vans by $96.5 \%$ at Lab 1 and $81 \%$ at Lab 3. SR also showed significant reductions for the CNG vans, approximately $46 \%$ at Lab 1 and 56\% at Lab 3.

\section{Fuel Economy}

Because CNG is a gaseous fuel, it must be converted to gallons of gasoline equivalent (gge) in order to make a comparison with a liquid fuel. An equivalent gallon of $\mathrm{CNG}$ is the quantity of CNG that has the same energy content as a gallon of gasoline. A gallon of RFG has 111,960 Btu.

Approximately 121 standard cubic foot (scf) of test CNG contains the same Btu as RFG. Therefore, $121 \mathrm{scf}$ equals one gge.

Fuel economy averages for the CNG van are listed in Tables 35-37 as miles per equivalent gallon of gasoline. Average fuel economy for the CNG Dodge B250 vans was only slightly less than that of the conventional models. All three labs were in 


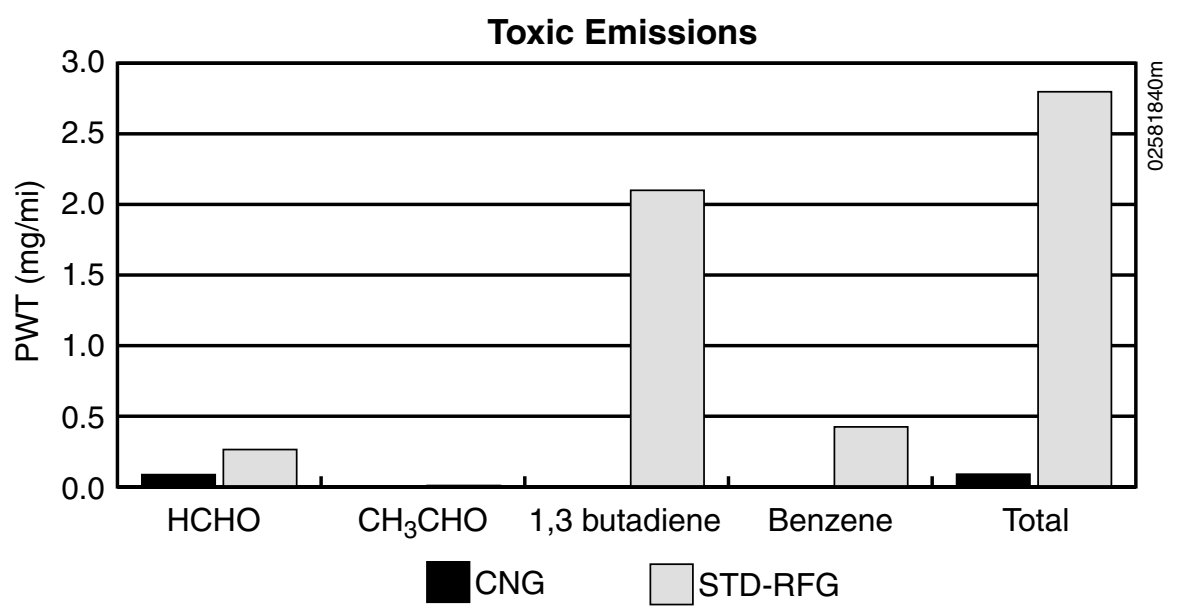

Figure 40. PWT emissions from the Dodge B250 van tested at Lab 1

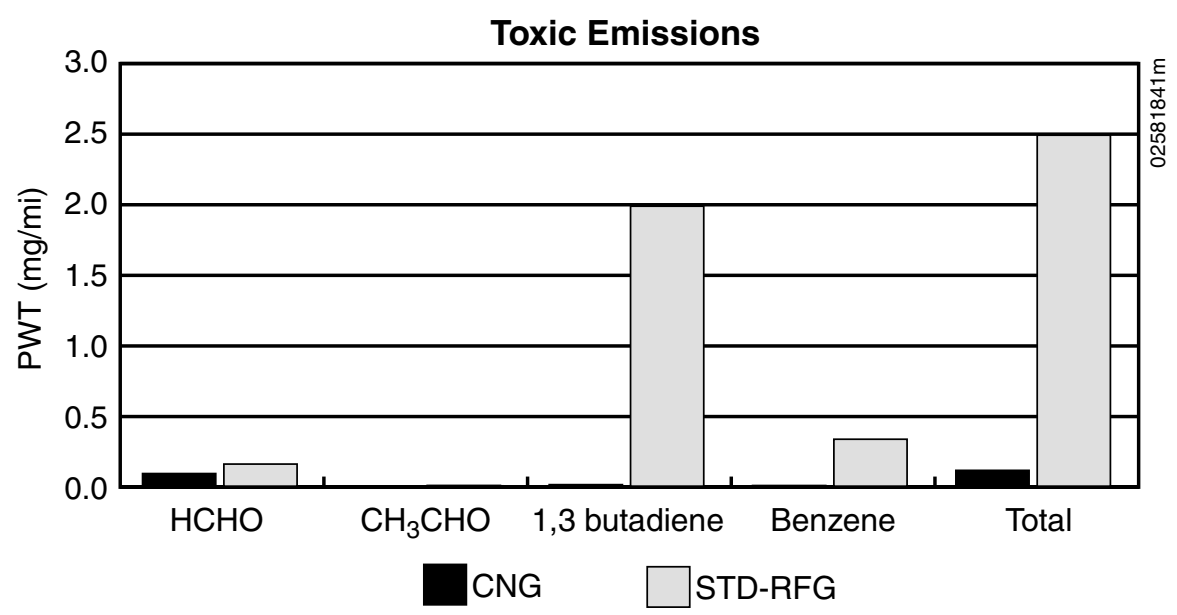

Figure 41. PWT emissions for the Dodge B250 van tested at Lab 3

Table 40. OFP for the Dodge B250 van Tested at Lab 1

\begin{tabular}{|l|c|c|c|c|}
\hline & CNG & $\begin{array}{c}\text { STD- } \\
\text { RFG }\end{array}$ & $\begin{array}{c}\text { Percent } \\
\text { Difference }\end{array}$ & $\begin{array}{c}\text { Sig. Fuel } \\
\text { Effect? }\end{array}$ \\
\hline NMOG $(\mathrm{mg} / \mathrm{mi})$ & 21.95 & 354.49 & $-93.8 \%$ & $\mathrm{y}$ \\
\hline OFP $\left(\mathrm{mg} \mathrm{O}_{3} / \mathrm{mi}\right)$ & 45.2 & $1,305.31$ & $-96.5 \%$ & $\mathrm{y}$ \\
\hline $\mathrm{SR}\left(\mathrm{mg} \mathrm{O}_{3} / \mathrm{mg} \mathrm{NMOG}\right)$ & 2.06 & 3.836 & $-46.3 \%$ & $\mathrm{y}$ \\
\hline
\end{tabular}


Table 41. OFP for the Dodge B250 Van Tested at Lab 3

\begin{tabular}{|l|c|c|c|c|}
\hline & CNG & $\begin{array}{c}\text { STD- } \\
\text { RFG }\end{array}$ & $\begin{array}{c}\text { Percent } \\
\text { Difference }\end{array}$ & $\begin{array}{c}\text { Sig. Fuel } \\
\text { Effect? }\end{array}$ \\
\hline NMOG $(\mathrm{mg} / \mathrm{mi})$ & 76.48 & 308.72 & $-75.2 \%$ & $\mathrm{y}$ \\
\hline OFP $\left(\mathrm{mg} \mathrm{O}_{3} / \mathrm{mi}\right)$ & 233.27 & 1208.9 & $-80.7 \%$ & $\mathrm{y}$ \\
\hline $\mathrm{SR}\left(\mathrm{mg} \mathrm{O}_{3} / \mathrm{mg} \mathrm{NMOG}\right)$ & 1.768 & 4.031 & $-56.1 \%$ & $\mathrm{y}$ \\
\hline
\end{tabular}

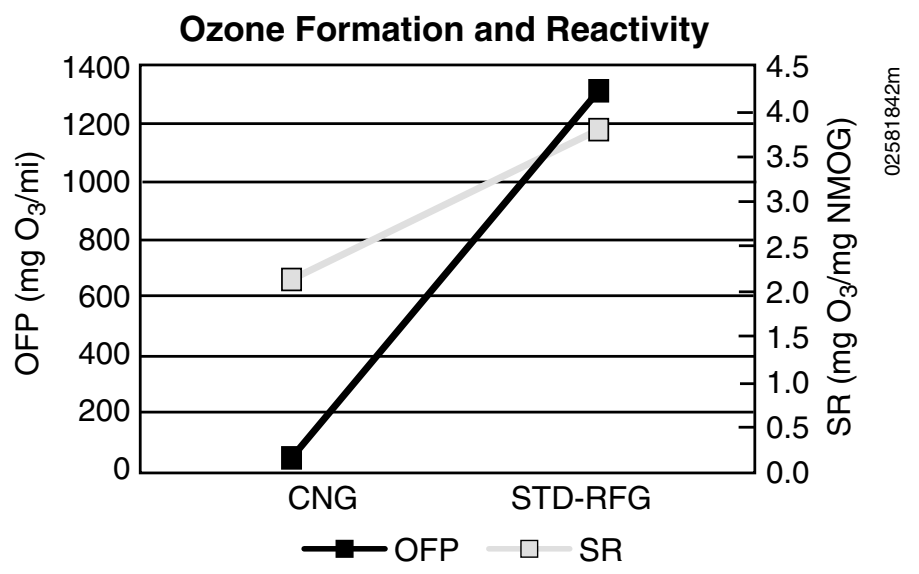

Figure 42. OFP and SR for the Dodge B250 van tested at Lab 1

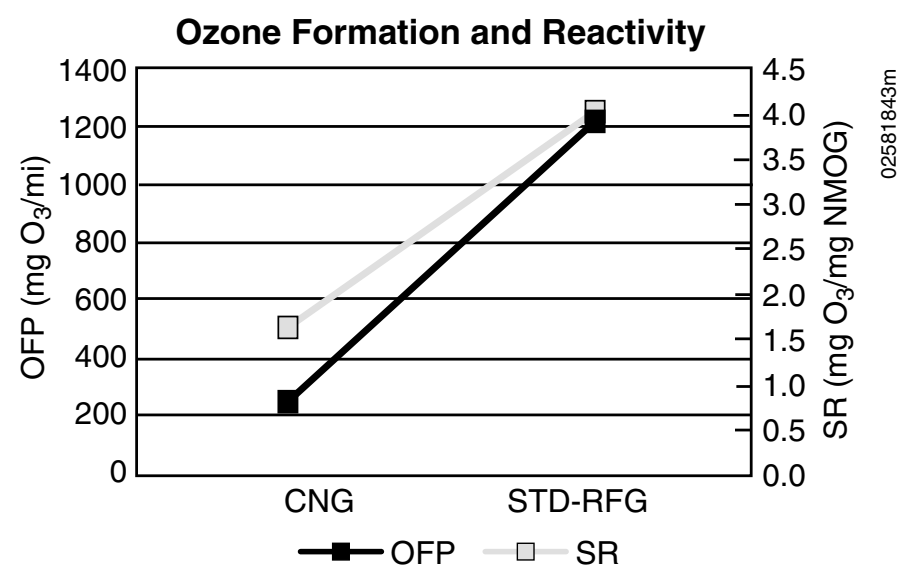

Figure 43. OFP and SR for the Dodge B250 van tested at Lab 3 
agreement, with percent differences ranging from $2 \%$ lower in the $\mathrm{CNG}$ vans to approximately $12 \%$ lower. These differences in fuel economy between CNG and RFG were significant for all rounds at all 3 labs.

\section{Dodge Caravan Minivan}

The 1994 Dodge Caravan is a minivan equipped with a $3.3 \mathrm{~L} \mathrm{V6}$ engine (Figure 44). Both models were certified to EPA Tier 1 emissions levels. Because there was a limited number of vehicles available, these vans were only tested in one round. There were 13 dedicated CNG vans and 6 standard gasoline vans tested. Mileage ranges and average odometer readings for the Caravans tested in this program are listed in Table 42.

Detailed hydrocarbon speciation was not performed on these vehicles.

\section{Regulated Emissions}

Table 43 lists the average emissions for the $\mathrm{CNG}$ and conventional model Caravans along with the percent differences and an indication of whether the differences are statistically significant at the $95 \%$ confidence level. Figure 45 shows the comparison of average regulated emissions and $\mathrm{CO}_{2}$ for these vans. All regulated emissions results for the Caravans were well below the EPA Tier 1 standard. When comparing regulated emissions for the CNG Caravan to those of the gasoline control vans, there was a sig-

Table 42. Odometer Readings for the Dodge Caravan Minivan

\begin{tabular}{|l|c|c|}
\hline & CNG & Gasoline \\
\hline $\begin{array}{l}\text { No. vehicles } \\
\text { tested }\end{array}$ & 6 & 13 \\
\hline \multicolumn{3}{|c|}{ Odometer (miles) } \\
\hline Average & 17,888 & 6,683 \\
\hline Maximum & 20,696 & 14,282 \\
\hline Minimum & 15,527 & 3,817 \\
\hline
\end{tabular}

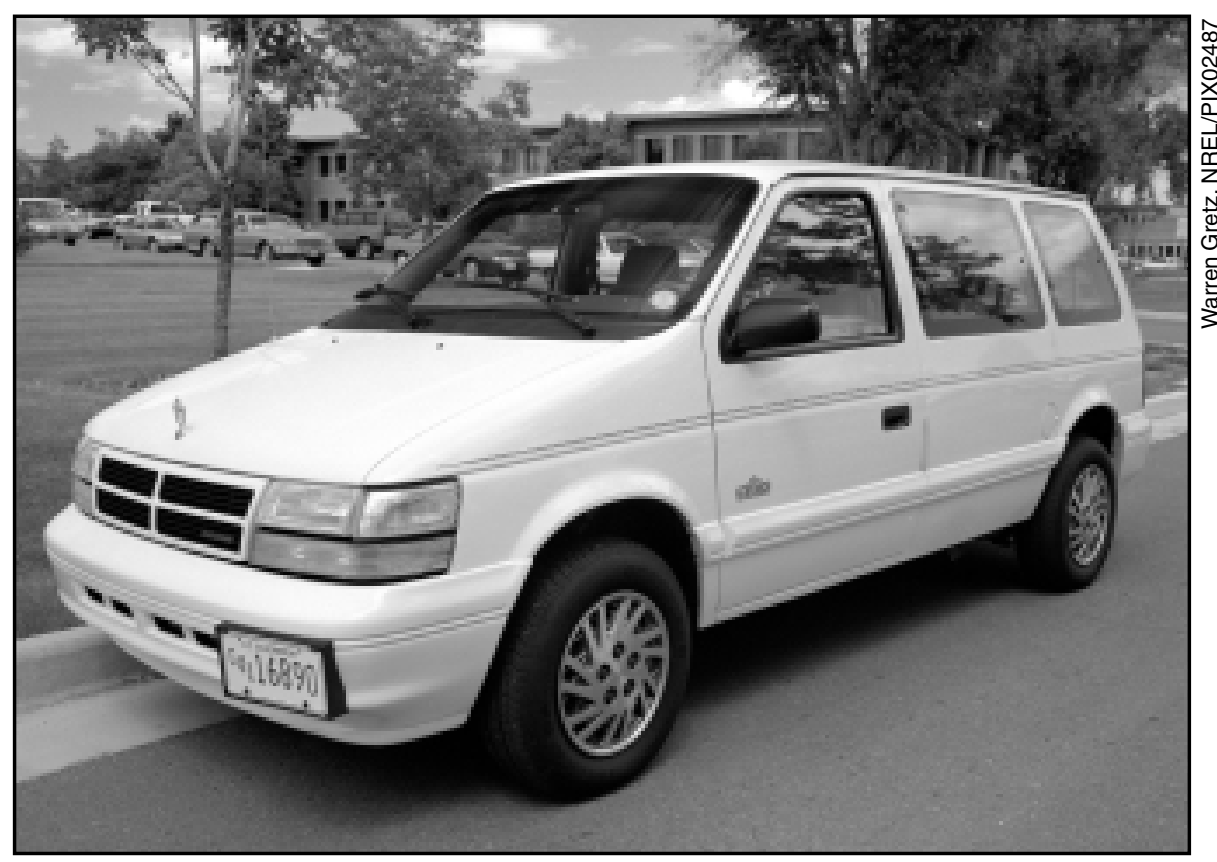

Figure 44. The 1994 CNG Dodge Caravan minivan

Table 43. Average Emissions Results from the Dodge Caravan Minivan

\begin{tabular}{|l|c|c|c|c|}
\hline & \multicolumn{5}{|c|}{ Round 1 } \\
\hline & CNG & $\begin{array}{c}\text { STD- } \\
\text { RFG }\end{array}$ & $\begin{array}{c}\text { Percent } \\
\text { Difference }\end{array}$ & $\begin{array}{c}\text { Sig. Fuel } \\
\text { Effect? }\end{array}$ \\
\hline \hline Regulated Emissions (g/mi) & 0.022 & 0.147 & $-84.8 \%$ & $\mathrm{y}$ \\
\hline $\mathrm{NMHC}$ & 0.166 & 0.169 & $-2.1 \%$ & $\mathrm{n}$ \\
\hline $\mathrm{THC}$ & 0.364 & 1.552 & $-76.5 \%$ & $\mathrm{y}$ \\
\hline $\mathrm{CO}$ & 0.187 & 0.296 & $-36.9 \%$ & $\mathrm{n}$ \\
\hline $\mathrm{NO}_{\mathrm{x}}$ & \multicolumn{5}{|c|}{} \\
\hline Evaporative Emissions (g/test) & 0.311 & 0.323 & $-3.7 \%$ & $\mathrm{n}$ \\
\hline Total Evaporative & $0.3 \%$ & $\mathrm{y}$ \\
\hline \hline Greenhouse Gases (g/mi) & 389.54 & 467.22 & $-16.6 \%$ & $\mathrm{y}$ \\
\hline $\mathrm{CO}_{2}$ & 0.142 & 0.028 & $415.0 \%$ & $\mathrm{y}$ \\
\hline $\mathrm{CH}_{4}$ & \multicolumn{5}{|l|}{} \\
\hline Aldehydes (mg/mi) & 4.036 & 3.468 & $16.4 \%$ & $\mathrm{n}$ \\
\hline $\mathrm{HCHO}$ & 0.322 & 0.902 & $-64.3 \%$ & $\mathrm{y}$ \\
\hline $\mathrm{CH}_{3} \mathrm{CHO}$ & 17.45 & 18.84 & $-7.3 \%$ & $\mathrm{y}$ \\
\hline Fuel Economy & \multicolumn{5}{|c|}{} \\
\hline Fuel Economy & \multicolumn{5}{|c|}{} \\
\hline
\end{tabular}


45a: Non-Methane Hydrocarbon

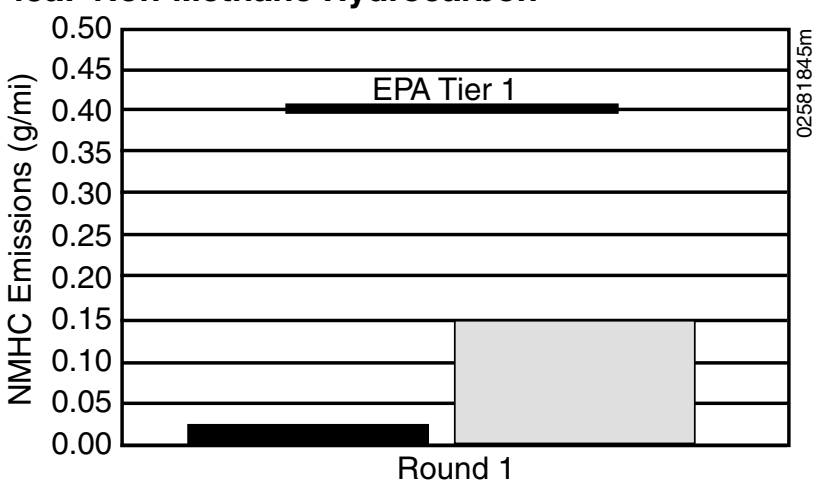

45b: Carbon Monoxide

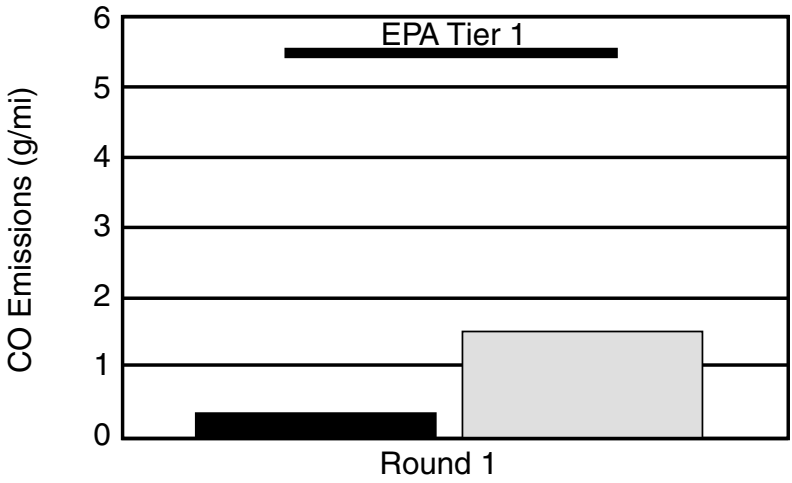

45c: Oxides of Nitrogen

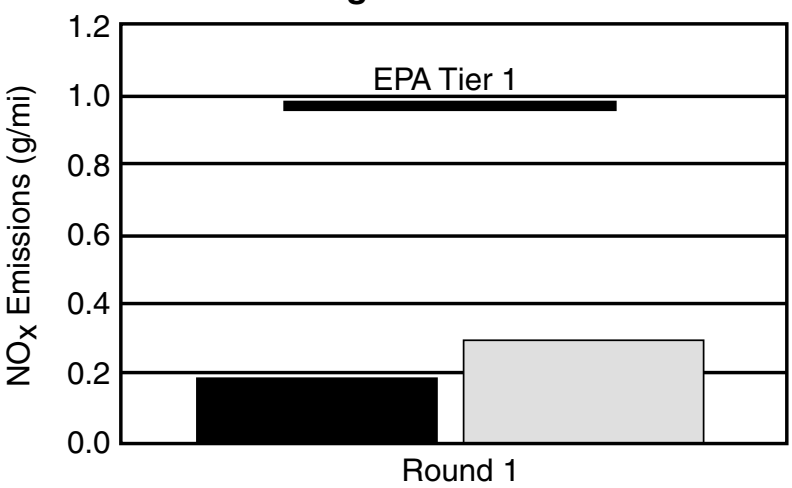

45d: Carbon Dioxide

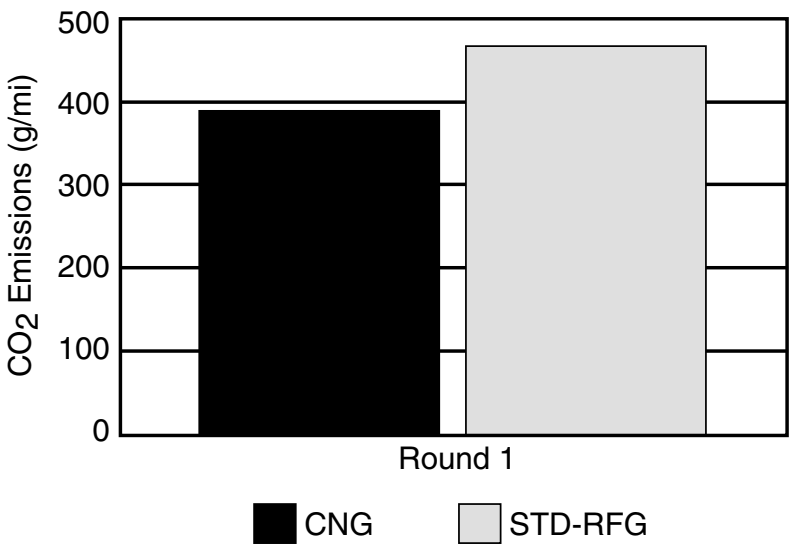

Figure 45. Emissions results from the Dodge Caravan minivan nificant decrease in NMHC, a significant decrease in $\mathrm{CO}$, and a decrease in $\mathrm{NO}_{\mathrm{x}}$ that was not significant at the $95 \%$ confidence level. NMHC was $85 \%$ lower for the $\mathrm{CNG}$ model. $\mathrm{CO}$ emissions were $76.5 \%$ lower and $\mathrm{NO}_{\mathrm{x}}$ emissions were $37 \%$ lower for the $\mathrm{CNG}$ vans.

\section{Evaporative Emissions}

The same modified evaporative emissions test described in the section on the B250 vans was performed on the CNG Dodge Caravans. Results for the Dodge Caravans are listed in Table 36 and graphically illustrated in Figure 46. Average "evaporative" emissions for both CNG and gasoline models were well below the Tier 0 and Tier 1 limit of $2 \mathrm{~g}$. As with the B250 van, the CNG Caravan emitted measurable HC during the test, but they were lower than the average evaporative emissions from the gasoline control. The reduction was 3.7\%, which was not statistically significant at the $95 \%$ confidence level.

\section{Greenhouse Gases}

As with the regulated emissions, average $\mathrm{CO}_{2}$ emissions were significantly lower for the CNG Caravans. Values for the CNG vans were approximately $16 \%$ lower than those of their gasoline counterparts. Average $\mathrm{CH}_{4}$ emissions, as expected, were higher for the CNG Caravans. Although the values for each van type were quite low, the CNG model showed a $415 \%$ increase in $\mathrm{CH}_{4}$ over the gasoline model.

\section{Aldehydes}

Aldehyde emissions levels for the Dodge Caravans are shown in Figure 47. Although the formaldehyde emissions from the CNG minivans were $16 \%$ higher than the gasoline model, this difference was not statistically significant at the $95 \%$ confidence level. Acetaldehyde emissions were $64 \%$ lower for the

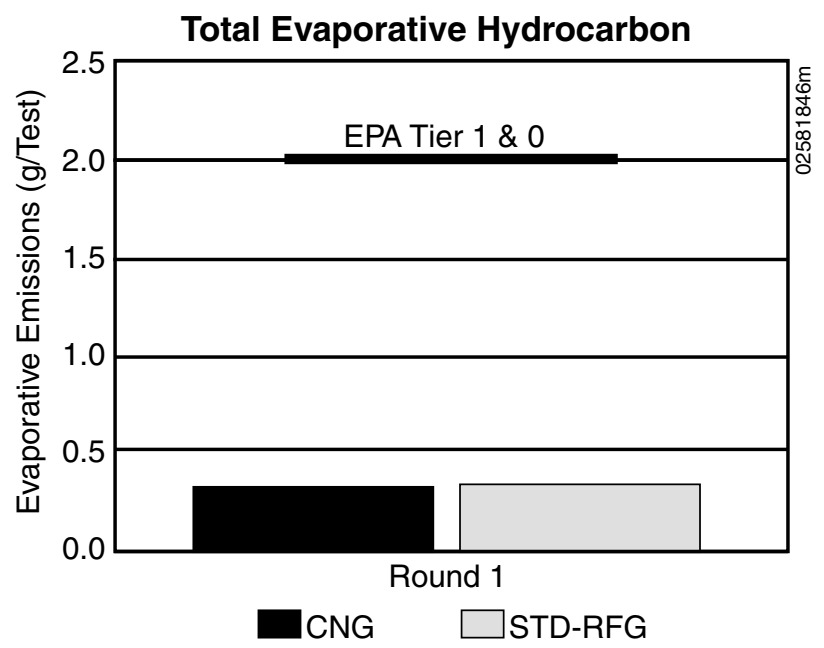

Figure 46. Evaporative emissions results from the Dodge Caravan minivan 


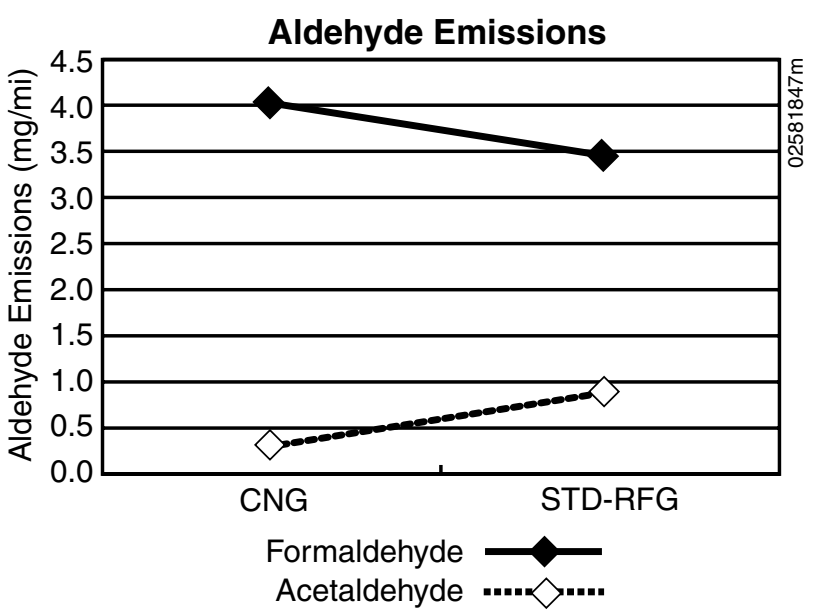

Figure 47. Aldehyde emissions from the Dodge Caravan minivan
CNG model compared to the RFG results.

\section{Fuel Economy}

Fuel economy comparisons for the Dodge Caravan showed very little difference when compared on a gasoline gallon equivalent between the $\mathrm{CNG}$ and standard models. The fuel economy for the CNG minivans was approximately $7 \%$ lower than that of the standard gasoline model. 


\section{SUMMARY}

In conclusion, these tests showed that, overall, there are emissions advantages to using alternative fuel over gasoline. The following points summarize the comparison between each alternative fuel and gasoline.

\section{Methanol Vehicles}

- NMHCE was significantly lower in M85 tests for both the Intrepid and Spirit.

- $\mathrm{CO}$ emissions were slightly higher for the M85 tests on the Intrepid and lower for the M85 tests on the Spirit. These differences, however, tended not to be significant at the $95 \%$ confidence level.

- $\mathrm{NO}_{\mathrm{x}}$ emissions tended to be significantly higher in the M85 tests for both FFV models.

- Greenhouse gases $\left(\mathrm{CO}_{2}\right.$ and $\left.\mathrm{CH}_{4}\right)$ were significantly lower in the M85 tests for both FFV models.

- Formaldehyde was significantly increased for the M85 tests, but acetaldehyde was significantly decreased.

- Benzene and 1,3-butadiene levels were significantly lower for the M85 tests.

- Evaporative results were varied, but tended not to be significant at the $95 \%$ confidence level.

- PWT, OFP, and SR were all significantly lower in the M85 tests for both FFV models.

\section{Ethanol VehicLes}

- Regulated emissions for the Taurus showed no significant difference between fuels.

- Regulated emissions results for the Lumina were mixed: NMHCE tended not to be significant between fuels, $\mathrm{CO}$ emissions were higher (but not significantly) for the E85 tests, and $\mathrm{NO}_{\mathrm{x}}$ emissions were significantly lower for the E85 tests.

- $\mathrm{CO}_{2}$ emissions were significantly lower for the tests on E85 for both FFV models.

- $\mathrm{CH}_{4}$ emissions were significantly higher for the tests on E85 for both FFV models.

- Formaldehyde and acetaldehyde emissions were significantly higher for the tests on E85 for both FFV models.

- Benzene and 1,3-butadiene levels were significantly lower for the E85 tests.

- Evaporative emissions for the ethanol FFVs tended to show no significant difference between fuels.

- PWT and SR were significantly lower for the E85 tests on the FFV Taurus.

- OFP was significantly higher for the E85 tests on the FFV Taurus.

\section{CNG VEHICLES}

- NMHC emissions for the CNG models were significantly lower than those of the gasoline vehicles.

- $\mathrm{CO}$ emissions were significantly lower for the $\mathrm{CNG}$ vans.

- $\mathrm{NO}_{\mathrm{x}}$ emissions results were mixed, but tended to be significantly lower for the CNG tests.

- $\mathrm{CO}_{2}$ emissions were significantly lower for the CNG tests.

- $\mathrm{CH}_{4}$ emissions were significantly higher for the $\mathrm{CNG}$ tests.

- Formaldehyde emissions tended to be significantly lower for the CNG tests.

- Acetaldehyde emissions from the CNG vehicles were significantly lower than the gasoline tests.

- Evaporative emissions results were significantly lower for the CNG tests.

- PWT, OFP, and SR were significantly lower for the CNG tests. 


\section{References}

1. L. Dodge, G. Bourn, T. Callahan, J. Grogan, D. Leone, D. Naegeli, K. Shouse, R. Thring, and K. Whitney. Development of a Dedicated Ethanol Ultra-Low Emissions Vehicle (ULEV): Final Report, NREL/SR-540-24603, Golden, CO: NREL.

2. Auto/Oil Air Quality Improvement Research Program, 1997. Program Final Report, Atlanta, GA: Coordinating Research Council.

3. Clean Air Act, Part C, Section 241 Definitions. EPA Web site: www. epa.gov/airprogm/oar/caa/caa.txt

4. Office of the Federal Register. 1993. Code of Federal Regulations, Title 40, Part 86. Washington, DC: U. S. Government Printing Office.

5. Fact Sheet OMS-5. August 1994. "Automobile Emissions: An Overview," EPA 400-F-92-007, Washington, DC: EPA.
6. Health Effects Notebook for Hazardous Air Pollutants, Office of Air Quality Planning \& Standards Unified Air Toxics Web site: www.epa.gov/ttn/ uatw/hapindex.html

7. V.R. Burns, J.D. Benson, A.M. Hochhuser, W.J. Koehl, W.M. Kreucher, and R.M. Reuter. 1992. "Description of Auto/Oil Air Quality Improvement Research Program," SAE Paper No. 912320 in Auto/Oil Air Quality Improvement Research Program. Warrendale, PA: Society of Automotive Engineers (SAE).

8. K.J. Kelly, B.K. Bailey,T.C. Coburn, W. Clark, L. Eudy, P. Lissiuk. May 1996. "FTP Emissions Test Results from Flexible-Fuel Methanol Dodge Spirits and Ford Econoline Vans," SAE Paper No. 961090, Warrendale, PA: SAE.
9. K.J. Kelly, B.K. Bailey, T.C. Coburn, W. Clark, P. Lissiuk. May 1996. "Federal Test Procedure Emissions Test Results from Ethanol Variable-Fuel Vehicle Chevrolet Luminas," SAE Paper No. 961092, Warrendale, PA: SAE. 


\section{Appendix A: \\ Emissions Data Sets}

A-1 
Table A-1. 1995 Standard Dodge Intrepid: RFG Tests at Lab 1 Round 1

\begin{tabular}{|c|c|c|c|c|c|c|c|c|c|c|c|c|c|c|}
\hline Decal ID & Test Date & Odometer & Fuel & MPG & $\mathrm{CH}_{3} \mathrm{CHO}$ & $\mathrm{CH}_{3} \mathrm{OH}$ & $\mathrm{CH}_{4}$ & $\mathrm{CO}$ & $\mathrm{CO}_{2}$ & $\mathrm{HCHO}$ & NMHCE & $\mathrm{NO}_{\mathrm{x}}$ & THC & Evap. THC \\
\hline AR304GNC & $7 / 12 / 95$ & 3336 & RFG & 19.22 & 0.00036 & & 0.019 & 0.78 & 451.8 & 0.0015 & 0.09 & 0.18 & 0.105 & 0.334 \\
\hline AR305GNC & $6 / 21 / 95$ & 3906 & RFG & 19.34 & 0.0003 & & 0.028 & 1.07 & 448.2 & 0.00188 & 0.109 & 0.16 & 0.131 & 0.368 \\
\hline AR306GNC & $7 / 18 / 95$ & 3853 & RFG & 19.43 & 0.00036 & & 0.021 & 0.59 & 447.1 & 0.0021 & 0.086 & 0.2 & 0.103 & 0.173 \\
\hline AR307GNC & $6 / 9 / 95$ & 3576 & RFG & 19.23 & 0.00035 & & 0.024 & 0.72 & 451.6 & 0.00164 & 0.093 & 0.19 & 0.112 & 0.437 \\
\hline AR308GNC & $6 / 9 / 95$ & 3869 & RFG & 19.61 & 0.00034 & & 0.026 & 0.82 & 442.6 & 0.00167 & 0.096 & 0.21 & 0.117 & 1.103 \\
\hline AR309GNC & $9 / 28 / 95$ & 4196 & RFG & 19.08 & 0.00039 & & 0.022 & 0.98 & 454.5 & 0.00217 & 0.105 & 0.14 & 0.123 & 0.492 \\
\hline AR310GNC & $6 / 21 / 95$ & 3681 & RFG & 19.44 & 0.00034 & & 0.024 & 0.67 & 446.7 & 0.00186 & 0.092 & 0.14 & 0.111 & 0.369 \\
\hline AR311GNC & $6 / 13 / 95$ & 3740 & RFG & 19.34 & 0.00039 & & 0.019 & 0.76 & 448.8 & 0.00173 & 0.097 & 0.12 & 0.112 & 1.069 \\
\hline AR312GNC & $7 / 18 / 95$ & 6293 & RFG & 19.78 & 0.0004 & & 0.02 & 0.81 & 438.7 & 0.0016 & 0.096 & 0.17 & 0.112 & 0.397 \\
\hline AR313GNC & $1 / 25 / 96$ & 3435 & RFG & 19.07 & 0.00041 & & 0.028 & 0.94 & 454.8 & 0.0015 & 0.131 & 0.1 & 0.153 & 1.381 \\
\hline DT301GNC & 9/27/95 & 4648 & RFG & 19.1 & 0.00035 & & 0.022 & 0.77 & 454.3 & 0.00196 & 0.103 & 0.11 & 0.121 & 0.374 \\
\hline DT302GNC & $11 / 3 / 95$ & 10056 & RFG & 19.4 & 0.00025 & & 0.022 & 0.75 & 447.4 & 0.00113 & 0.113 & 0.19 & 0.131 & $\dagger$ \\
\hline DT302GNC & $11 / 21 / 95$ & 10103 & RFG & 19.06 & 0.0004 & & 0.024 & 0.86 & 455.2 & 0.00141 & 0.107 & 0.23 & 0.126 & 0.353 \\
\hline Average & & & & 19.23 & 0.000325 & & 0.023 & 0.805 & 451.3 & 0.00137 & 0.11 & 0.21 & 0.1285 & 0.353 \\
\hline DT303GNC & $11 / 9 / 95$ & 4879 & RFG & 19.5 & 0.00031 & & 0.022 & 0.93 & 444.8 & 0.00163 & 0.113 & 0.13 & 0.131 & $t$ \\
\hline DT305GNC & $10 / 31 / 95$ & 5960 & RFG & 19.28 & 0.00036 & & 0.024 & 1 & 449.8 & 0.00187 & 0.111 & 0.14 & 0.13 & $\dagger$ \\
\hline DT306GNC & $10 / 31 / 95$ & 7007 & RFG & 19.26 & 0.00038 & & 0.028 & 1.03 & 450.2 & 0.00199 & 0.116 & 0.19 & 0.139 & $\dagger$ \\
\hline DT308GNC & $11 / 21 / 95$ & 5021 & RFG & 18.68 & 0.00037 & & 0.021 & 0.81 & 464.6 & 0.00135 & 0.102 & 0.12 & 0.118 & 1.04 \\
\hline DT309GNC & $12 / 23 / 95$ & 18783 & RFG & 19.66 & 0.00057 & & 0.028 & 0.97 & 440.9 & 0.00207 & 0.132 & 0.18 & 0.154 & 0.249 \\
\hline & & & & & & & & & & & & & & \\
\hline & COUNT & & & 17 & 16 & & 17 & 17 & 17 & 17 & 17 & 17 & 17 & 14 \\
\hline & AVG & & & 19.309 & 0.000358 & & 0.0235 & 0.8503 & 449.45 & 0.00176 & 0.1048 & 0.1582 & 0.1236 & 0.5813 \\
\hline & STD DEV & & & 0.2596 & 0.000031 & & 0.00316 & 0.135 & 6.0915 & 0.00025 & 0.0132 & 0.0359 & 0.0150 & 0.387 \\
\hline & $\mathrm{CV}$ & & & 0.0134 & 0.08729 & & 0.1348 & 0.1587 & 0.0135 & 0.1443 & 0.1263 & 0.2270 & 0.1217 & 0.6656 \\
\hline
\end{tabular}


Table A-2. 1995 FFV Dodge Intrepid: M85 Tests at Lab 1 Round 1

\begin{tabular}{|c|c|c|c|c|c|c|c|c|c|c|c|c|c|c|}
\hline Decal ID & Test Date & Odometer & Fuel & MPG & $\mathrm{CH}_{3} \mathrm{CHO}$ & $\mathrm{CH}_{3} \mathrm{OH}$ & $\mathrm{CH}_{4}$ & $\mathrm{CO}$ & $\mathrm{CO}_{2}$ & $\mathrm{HCHO}$ & NMHCE & $\mathrm{NO}_{\mathrm{x}}$ & THC & Evap. THC \\
\hline AR304MN & $7 / 19 / 95$ & 4559 & M85 & 11.47 & 0.00019 & 0.1245 & 0.015 & 0.86 & 420.6 & 0.01497 & 0.083 & 0.3 & 0.087 & 0.808 \\
\hline AR305MN & 9/18/95 & 3368 & M85 & 10.84 & 0.00014 & 0.1966 & 0.015 & 0.99 & 444.8 & 0.01553 & 0.105 & 0.48 & 0.11 & 1.036 \\
\hline AR306MN & 9/14/95 & 3139 & M85 & 11.38 & 0.00018 & 0.1834 & 0.013 & 0.96 & 423.8 & 0.01501 & 0.097 & 0.38 & 0.1 & 0.851 \\
\hline AR307MN & 9/22/95 & 3642 & M85 & 11.05 & 0.00015 & 0.2162 & 0.013 & 1.09 & 436.3 & 0.0165 & 0.115 & 0.37 & 0.118 & 0.698 \\
\hline AR308MN & 9/25/95 & 6191 & M85 & 10.99 & 0.00012 & 0.2434 & 0.016 & 1.43 & 438.1 & 0.01371 & 0.128 & 0.34 & 0.134 & 0.669 \\
\hline AR310MN & $10 / 6 / 95$ & 4099 & M85 & 11.57 & 0.00023 & 0.17 & 0.018 & 0.96 & 416.8 & 0.02154 & 0.102 & 0.37 & 0.107 & 1.02 \\
\hline AR311MN & $11 / 7 / 95$ & 3047 & M85 & 11.71 & 0.00012 & 0.1517 & 0.014 & 1.04 & 411.8 & 0.01467 & 0.101 & 0.27 & 0.106 & 0.895 \\
\hline AR312MN & $11 / 6 / 95$ & 9558 & M85 & 11.32 & 0.00016 & 0.1718 & 0.017 & 1.09 & 425.9 & 0.01849 & 0.117 & 0.41 & 0.122 & 0.793 \\
\hline AR313MN & $11 / 3 / 95$ & 3970 & M85 & 11.87 & 0.00015 & 0.1604 & 0.017 & 0.94 & 406.4 & 0.01559 & 0.113 & 0.32 & 0.119 & 0.922 \\
\hline AR314GNC & $2 / 9 / 96$ & 5924 & M85 & 12.1 & 0.00021 & 0.2111 & 0.019 & 0.97 & 398.6 & 0.0168 & 0.11 & 0.3 & 0.117 & 0.998 \\
\hline AR314MN & $11 / 2 / 95$ & 7230 & M85 & 11.8 & 0.00014 & 0.1447 & 0.017 & 0.98 & 408.8 & 0.01406 & 0.092 & 0.31 & 0.099 & 1.067 \\
\hline AR317MN & $1 / 24 / 96$ & 4854 & M85 & 11.82 & 0.00017 & 0.2231 & 0.017 & 1.18 & 407.7 & 0.01552 & 0.108 & 0.35 & 0.115 & 0.585 \\
\hline AR318MN & $1 / 30 / 96$ & 8062 & M85 & 12.1 & 0.00017 & 0.2475 & 0.017 & 1.17 & 398.3 & 0.01679 & 0.117 & 0.25 & 0.117 & 0.952 \\
\hline AR319MN & $2 / 8 / 96$ & 4828 & M85 & 12.19 & 0.00021 & 0.2309 & 0.016 & 0.95 & 395.6 & 0.01669 & 0.116 & 0.25 & 0.121 & 1.203 \\
\hline AR320MN & $2 / 27 / 96$ & 6068 & M85 & 12.29 & 0.00019 & 0.1873 & 0.015 & 0.98 & 392.2 & 0.01278 & 0.097 & 0.27 & 0.103 & 0.84 \\
\hline AR322MN & $4 / 29 / 96$ & 3516 & M85 & 12.12 & 0.00019 & 0.2214 & 0.017 & 0.99 & 397.6 & 0.01737 & 0.118 & 0.28 & 0.124 & 0.677 \\
\hline & COUNT & & & 16 & 16 & 16 & 16 & 15 & 16 & 16 & 16 & 16 & 16 & 16 \\
\hline & AVG & & & 11.664 & 0.00017 & 0.1928 & 0.016 & 1.01 & 413.96 & 0.016 & 0.1074 & 0.3281 & 0.1124 & 0.8759 \\
\hline & STD DEV & & & 0.455 & 0.000032 & 0.0369 & 0.0017 & 0.088 & 16.353 & 0.0021 & 0.0116 & 0.0632 & 0.0116 & 0.1684 \\
\hline & $\mathrm{CV}$ & & & 0.039 & 0.1909 & 0.1915 & 0.1070 & 0.087 & 0.0395 & 0.1296 & 0.1079 & 0.1925 & 0.1036 & 0.1922 \\
\hline
\end{tabular}


Table A-3. 1995 FFV Dodge Intrepid: RFG Tests at Lab 1 Round 1

\begin{tabular}{|c|c|c|c|c|c|c|c|c|c|c|c|c|c|c|}
\hline Decal ID & Test Date & Odometer & Fuel & MPG & $\mathrm{CH}_{3} \mathrm{CHO}$ & $\mathrm{CH}_{3} \mathrm{OH}$ & $\mathrm{CH}_{4}$ & $\mathrm{CO}$ & $\mathrm{CO}_{2}$ & $\mathrm{HCHO}$ & NMHCE & $\mathrm{NO}_{\mathrm{x}}$ & $\mathrm{THC}$ & Evap. THC \\
\hline AR304MN & $7 / 11 / 95$ & 4373 & RFG & 19.12 & 0.00039 & & 0.026 & 0.84 & 453.9 & 0.00188 & 0.116 & 0.14 & 0.137 & 0.337 \\
\hline AR304MN & $7 / 18 / 95$ & 4532 & RFG & 18.82 & 0.00043 & & 0.023 & 0.92 & 461.1 & 0.0022 & 0.119 & 0.17 & 0.138 & 1.142 \\
\hline Average & & & & 18.97 & 0.00041 & & 0.0245 & 0.88 & 457.5 & 0.00204 & 0.1175 & 0.155 & 0.1375 & 0.7395 \\
\hline AR305MN & 9/15/95 & 3342 & RFG & 18.65 & 0.00025 & & 0.025 & 0.85 & 465.5 & 0.00165 & 0.108 & 0.32 & 0.128 & 0.791 \\
\hline AR306MN & 9/13/95 & 3112 & RFG & 18.6 & 0.00043 & & 0.023 & 1.02 & 466.3 & 0.00189 & 0.118 & 0.2 & 0.137 & 0.846 \\
\hline AR307MN & $9 / 25 / 95$ & 3669 & RFG & 18.81 & 0.00084 & & 0.022 & 0.99 & 461.1 & 0.00193 & 0.122 & 0.27 & 0.139 & 0.508 \\
\hline AR308MN & 9/22/95 & 6164 & RFG & 18.65 & 0.00057 & & 0.025 & 0.9 & 465 & 0.00213 & 0.176 & 0.18 & 0.196 & 0.404 \\
\hline AR310MN & $10 / 5 / 95$ & 4072 & RFG & 19.11 & 0.00028 & & 0.036 & 0.84 & 454 & 0.00187 & 0.11 & 0.46 & 0.139 & 0.81 \\
\hline AR311MN & $11 / 6 / 95$ & 3020 & RFG & 17.95 & 0.00036 & & 0.027 & 1.26 & 482.6 & 0.00195 & 0.143 & 0.33 & 0.165 & 0.955 \\
\hline AR312MN & $11 / 3 / 95$ & 9531 & RFG & 19.99 & 0.00044 & & 0.028 & 1.05 & 433.5 & 0.00247 & 0.138 & 0.25 & 0.16 & 0.548 \\
\hline AR313MN & $11 / 2 / 95$ & 3943 & RFG & 19.08 & 0.00035 & & 0.031 & 0.82 & 454.6 & 0.00186 & 0.125 & 0.21 & 0.15 & 0.564 \\
\hline AR314GNC & $2 / 8 / 96$ & 5898 & RFG & 19.77 & 0.00046 & & 0.028 & 1.01 & 438.5 & 0.00163 & 0.14 & 0.18 & 0.162 & 0.716 \\
\hline AR314MN & $10 / 31 / 95$ & 7176 & RFG & 19.67 & 0.0003 & & 0.032 & 0.85 & 441.1 & 0.00158 & 0.083 & 0.25 & 0.108 & 0.74 \\
\hline AR317MN & $1 / 23 / 96$ & 4827 & RFG & 18.97 & 0.00048 & & 0.031 & 1.18 & 456.9 & 0.00184 & 0.117 & 0.36 & 0.142 & 0.476 \\
\hline AR318MN & $1 / 31 / 96$ & 8098 & RFG & 19.87 & 0.00055 & & 0.032 & 1.21 & 436 & 0.00194 & 0.138 & 0.22 & 0.163 & 0.665 \\
\hline AR319MN & $2 / 9 / 96$ & 4854 & RFG & 19.96 & 0.00043 & & 0.027 & 0.88 & 434.5 & 0.00178 & 0.127 & 0.2 & 0.148 & 0.882 \\
\hline AR320MN & $2 / 26 / 96$ & 6041 & RFG & 18.82 & 0.00047 & & 0.027 & 1.17 & 460.5 & 0.00171 & 0.132 & 0.16 & 0.153 & 0.618 \\
\hline AR322MN & $4 / 26 / 96$ & 3490 & RFG & 20.19 & 0.00053 & & 0.028 & 0.85 & 429.6 & 0.00213 & 0.138 & 0.18 & 0.161 & 0.449 \\
\hline & COUNT & & & 16 & 16 & & 16 & 15 & 16 & 16 & 16 & 16 & 16 & 16 \\
\hline & AVG & & & 19.191 & 0.00045 & & 0.0279 & 0.991 & 452.325 & 0.0019 & 0.127 & 0.245 & 0.149 & 0.6695 \\
\hline & STD DEV & & & 0.6391 & 0.00014 & & 0.0037 & 0.1533 & 15.095 & 0.00022 & 0.0202 & 0.0844 & 0.0196 & 0.166 \\
\hline & $\mathrm{CV}$ & & & 0.033 & 0.3144 & & 0.1335 & 0.1548 & 0.0334 & 0.1177 & 0.1588 & 0.3441 & 0.1313 & 0.2486 \\
\hline
\end{tabular}


Table A-4. 1995 Standard Dodge Intrepid: RFG Tests at Lab 1 Round 2

\begin{tabular}{|c|c|c|c|c|c|c|c|c|c|c|c|c|c|c|}
\hline Decal ID & Test Date & Odometer & Fuel & MPG & $\mathrm{CH}_{3} \mathrm{CHO}$ & $\mathrm{CH}_{3} \mathrm{OH}$ & $\mathrm{CH}_{4}$ & $\mathrm{CO}$ & $\mathrm{CO}_{2}$ & $\mathrm{HCHO}$ & NMHCE & $\mathrm{NO}_{\mathrm{x}}$ & THC & Evap. THC \\
\hline AR304GNC & $8 / 6 / 96$ & 14546 & RFG & 20.48 & 0.00051 & & 0.026 & 1.06 & 423.8 & 0.00196 & 0.124 & 0.15 & 0.145 & 0.35 \\
\hline AR304GNC & $8 / 7 / 96$ & 14596 & RFG & 20.81 & 0.00076 & & 0.021 & 0.78 & 417.4 & 0.00198 & 0.116 & 0.14 & 0.133 & 0.358 \\
\hline Average & & & & 20.645 & 0.000635 & & 0.0235 & 0.92 & 420.6 & 0.00197 & 0.12 & 0.145 & 0.139 & 0.354 \\
\hline AR305GNC & $9 / 26 / 96$ & 15883 & RFG & 20.24 & 0.00052 & & 0.03 & 1.19 & 428.7 & 0.00229 & 0.124 & 0.3 & 0.148 & 0.471 \\
\hline AR305GNC & $10 / 3 / 96$ & 15941 & RFG & 20.89 & 0.00045 & & 0.023 & 1.06 & 415.5 & 0.00185 & 0.124 & 0.18 & 0.142 & 0.632 \\
\hline Average & & & & 20.565 & 0.000485 & & 0.0265 & 1.125 & 422.1 & 0.00207 & 0.124 & 0.24 & 0.145 & 0.5515 \\
\hline AR306GNC & $6 / 3 / 96$ & 11116 & RFG & 20.4 & 0.00064 & & 0.025 & 0.8 & 425.9 & 0.00252 & 0.105 & 0.21 & 0.125 & 1.464 \\
\hline AR307GNC & $6 / 3 / 96$ & 16746 & RFG & 20.42 & 0.0006 & & 0.027 & 0.85 & 425.3 & 0.00239 & 0.129 & 0.14 & 0.15 & 0.637 \\
\hline AR308GNC & $9 / 26 / 96$ & 19953 & RFG & 20.45 & 0.00055 & & 0.03 & 1.05 & 424.5 & 0.00231 & 0.129 & 0.21 & 0.152 & 0.386 \\
\hline AR309GNC & $7 / 18 / 96$ & 15745 & RFG & 20.19 & 0.00074 & & 0.025 & 1.14 & 429.7 & 0.00273 & 0.146 & 0.21 & 0.165 & 0.394 \\
\hline AR310GNC & $8 / 2 / 96$ & 14018 & RFG & 19.82 & 0.00059 & & 0.024 & 1.03 & 437.9 & 0.00215 & 0.121 & 0.16 & 0.14 & 0.523 \\
\hline AR311GNC & $6 / 3 / 96$ & 20662 & RFG & 20.78 & 0.00064 & & 0.03 & 1.18 & 417.5 & 0.00261 & 0.137 & 0.13 & 0.161 & 0.377 \\
\hline AR312GNC & $7 / 26 / 96$ & 13840 & RFG & 20.05 & 0.00056 & & 0.024 & 1.05 & 433 & 0.00222 & 0.125 & 0.17 & 0.144 & 0.365 \\
\hline AR313GNC & $7 / 1 / 96$ & 5929 & RFG & 19.53 & 0.00051 & & 0.026 & 0.81 & 444.9 & 0.00203 & 0.142 & 0.1 & 0.163 & 1.008 \\
\hline DT301GNC & $7 / 1 / 96$ & 13201 & RFG & 19.86 & 0.00048 & & 0.023 & 0.9 & 437.4 & 0.00202 & 0.122 & 0.17 & 0.141 & 0.272 \\
\hline DT302GNC & $7 / 26 / 96$ & 25765 & RFG & 22.58 & 0.00061 & & 0.022 & 1.03 & 384.3 & 0.00245 & 0.119 & 0.1 & 0.137 & 0.378 \\
\hline DT303GNC & $9 / 4 / 96$ & 12494 & RFG & 20.265 & 0.000425 & & 0.0215 & 0.865 & 428.75 & 0.00179 & 0.114 & 0.14 & 0.131 & 0.872 \\
\hline DT305GNC & $7 / 22 / 96$ & 15174 & RFG & 20.49 & 0.00069 & & 0.027 & 0.98 & 423.7 & 0.00257 & 0.141 & 0.16 & 0.162 & 0.265 \\
\hline DT306GNC & $7 / 22 / 96$ & 21941 & RFG & 20.27 & 0.0007 & & 0.028 & 1.16 & 428 & 0.00272 & 0.153 & 0.17 & 0.175 & 1.242 \\
\hline DT308GNC & $9 / 3 / 96$ & 13177 & RFG & 20.04 & 0.00044 & & 0.023 & 0.91 & 433.4 & 0.00168 & 0.106 & 0.24 & 0.125 & 0.339 \\
\hline DT308GNC & 9/4/96 & 13196 & RFG & 20.04 & 0.00034 & & 0.024 & 0.92 & 433.5 & 0.00163 & 0.099 & 0.24 & 0.119 & 0.238 \\
\hline Average & & & & 20.04 & 0.00039 & & 0.0235 & 0.915 & 433.45 & 0.001655 & 0.1025 & 0.24 & 0.122 & 0.2885 \\
\hline DT309GNC & $10 / 17 / 96$ & 42738 & RFG & 21.23 & 0.00063 & & 0.032 & 1.13 & 408.5 & 0.00266 & 0.145 & 0.26 & 0.171 & 0.418 \\
\hline & COUNT & & & 16 & 17 & & 17 & 17 & 17 & 17 & 17 & 17 & 17 & 17 \\
\hline & AVG & & & 20.313 & 0.00058 & & 0.0258 & 0.9961 & 425.03 & 0.00229 & 0.1279 & 0.1738 & 0.1484 & 0.5762 \\
\hline & STD DEV & & & 0.4103 & 0.000097 & & 0.00297 & 0.1269 & 13.491 & 0.00033 & 0.0144 & 0.0477 & 0.0158 & 0.3581 \\
\hline & CV & & & 0.0202 & 0.1676 & & 0.1152 & 0.1273 & 0.0317 & 0.1448 & 0.1126 & 0.2747 & 0.1064 & 0.6216 \\
\hline
\end{tabular}


Table A-5. 1995 FFV Dodge Intrepid: M85 Tests at Lab 1 Round 2

\begin{tabular}{|c|c|c|c|c|c|c|c|c|c|c|c|c|c|c|}
\hline Decal ID & Test Date & Odometer & Fuel & MPG & $\mathrm{CH}_{3} \mathrm{CHO}$ & $\mathrm{CH}_{3} \mathrm{OH}$ & $\mathrm{CH}_{4}$ & $\mathrm{CO}$ & $\mathrm{CO}_{2}$ & $\mathrm{HCHO}$ & NMHCE & $\mathrm{NO}_{\mathrm{x}}$ & $\mathrm{THC}$ & Evap. THC \\
\hline AR304MN & $6 / 20 / 96$ & 26084 & M85 & 12.57 & 0.00027 & 0.1641 & 0.019 & 1.24 & 382.9 & 0.02224 & 0.133 & 0.24 & 0.138 & 1.101 \\
\hline AR305MN & $7 / 11 / 96$ & 9653 & M85 & 11.95 & 0.0002 & 0.1989 & 0.016 & 1.12 & 403.2 & 0.01641 & 0.132 & 0.3 & 0.137 & 0.886 \\
\hline AR306MN & $10 / 8 / 96$ & 10593 & M85 & 12.34 & 0.00021 & 0.2389 & 0.015 & 1.21 & 390.2 & 0.01559 & 0.117 & 0.3 & 0.121 & 0.964 \\
\hline AR307MN & $6 / 20 / 96$ & 12658 & M85 & 12.44 & 0.00026 & 0.2004 & 0.017 & 1.33 & 386.8 & 0.01952 & 0.142 & 0.36 & 0.146 & 0.64 \\
\hline AR308MN & $7 / 5 / 96$ & 16646 & M85 & 11.99 & 0.00032 & 0.2016 & 0.016 & 1.08 & 402 & 0.02111 & 0.141 & 0.28 & 0.144 & 0.832 \\
\hline AR310MN & $7 / 26 / 96$ & 10221 & M85 & 12.2 & 0.00027 & 0.1962 & 0.018 & 1.1 & 394.8 & 0.01788 & 0.123 & 0.29 & 0.129 & 0.521 \\
\hline AR311MN & $1 / 29 / 97$ & 10035 & M85 & 11.68 & 0.00027 & 0.2366 & 0.018 & 1.2 & 408.6 & 0.01543 & 0.124 & 0.25 & 0.13 & 0.549 \\
\hline AR312MN & $7 / 9 / 96$ & 21441 & M85 & 12.11 & 0.00024 & 0.1942 & 0.016 & 1.16 & 397.7 & 0.02006 & 0.133 & 0.31 & 0.137 & 0.875 \\
\hline AR313MN & $9 / 27 / 96$ & 13177 & M85 & 12.03 & 0.00024 & 0.2519 & 0.017 & 1.07 & 400.5 & 0.01815 & 0.132 & 0.26 & 0.138 & 0.57 \\
\hline AR314GNC & $1 / 6 / 97$ & 12431 & M85 & 12.31 & 0.0002 & 0.2409 & 0.017 & 1.07 & 387.8 & 0.01687 & 0.125 & 0.25 & 0.13 & 0.726 \\
\hline AR314GNC & $1 / 7 / 97$ & 12450 & M85 & 12.31 & 0.00024 & 0.2186 & 0.018 & 1.02 & 388.2 & 0.01665 & 0.109 & 0.27 & 0.115 & 0.666 \\
\hline Average & & & & 12.31 & 0.00022 & 0.22975 & 0.0175 & 1.045 & 388 & 0.01676 & 0.117 & 0.26 & 0.1225 & 0.696 \\
\hline AR314MN & $6 / 6 / 96$ & 14862 & M85 & 12.53 & 0.00023 & 0.1934 & 0.016 & 1.09 & 384.7 & 0.01831 & 0.105 & 0.26 & 0.11 & 0.835 \\
\hline AR317MN & $10 / 30 / 96$ & 18285 & M85 & 12 & 0.00021 & 0.2538 & 0.016 & 1.13 & 401.7 & 0.01625 & 0.123 & 0.29 & 0.119 & 0.761 \\
\hline AR317MN & $11 / 27 / 96$ & 18476 & M85 & 11.68 & 0.00017 & 0.2395 & 0.021 & 1.68 & 408 & 0.01645 & 0.122 & 0.31 & 0.131 & 0.72 \\
\hline Average & & & & 11.84 & 0.00019 & 0.24665 & 0.0185 & 1.405 & 404.85 & 0.01635 & 0.1225 & 0.3 & 0.125 & 0.7405 \\
\hline AR318MN & $12 / 13 / 96$ & 18284 & M85 & 11.86 & 0.0002 & 0.2187 & 0.019 & 1.13 & 402.6 & 0.01881 & 0.128 & 0.3 & 0.134 & 1.242 \\
\hline AR319MN & $12 / 23 / 96$ & 9818 & M85 & 12.24 & 0.00018 & 0.2916 & 0.018 & 1.06 & 390.3 & 0.01652 & 0.145 & 0.32 & 0.134 & 0.983 \\
\hline AR319MN & $1 / 3 / 97$ & 9837 & M85 & 12.06 & 0.00022 & 0.2654 & 0.017 & 1.05 & 396 & 0.01734 & 0.133 & 0.33 & 0.138 & 0.948 \\
\hline Average & & & & 12.15 & 0.0002 & 0.2785 & 0.0175 & 1.055 & 393.15 & 0.01693 & 0.139 & 0.325 & 0.136 & 0.9655 \\
\hline AR320MN & $11 / 4 / 96$ & 14261 & M85 & 12.54 & 0.00018 & 0.2241 & 0.017 & 1.04 & 380.8 & 0.0151 & 0.117 & 0.2 & 0.123 & 0.825 \\
\hline AR320MN & $11 / 5 / 96$ & 14280 & M85 & 12.08 & 0.00015 & 0.233 & 0.017 & 1.03 & 395.5 & 0.01517 & 0.123 & 0.23 & 0.128 & 0.804 \\
\hline Average & & & & 12.31 & 0.000165 & 0.22855 & 0.017 & 1.035 & 388.15 & 0.015135 & 0.12 & 0.215 & 0.1255 & 0.8145 \\
\hline AR322MN & $2 / 3 / 97$ & 10855 & M85 & 12.17 & 0.00022 & 0.2421 & 0.019 & 1.24 & 392.2 & 0.0133 & 0.128 & 0.27 & 0.137 & 0.831 \\
\hline & COUNT & & & 16 & 16 & 16 & 16 & 15 & 16 & 16 & 16 & 16 & 16 & 16 \\
\hline & AVG & & & 12.155 & 0.000232 & 0.220 & 0.0173 & 1.162 & 395.02 & 0.0176 & 0.1273 & 0.2825 & 0.1319 & 0.8164 \\
\hline & STD DEV & & & 0.2553 & 0.000039 & 0.0291 & 0.00125 & 0.1085 & 7.9310 & 0.00234 & 0.0099 & 0.0355 & 0.0093 & 0.1977 \\
\hline & $\mathrm{CV}$ & & & 0.0210 & 0.1694 & 0.1321 & 0.0724 & 0.0934 & 0.0201 & 0.1338 & 0.0777 & 0.1258 & 0.0708 & 0.2421 \\
\hline
\end{tabular}


Table A-6. 1995 FFV Dodge Intrepid: RFG Tests at Lab 1 Round 2

\begin{tabular}{|c|c|c|c|c|c|c|c|c|c|c|c|c|c|c|}
\hline Decal ID & Test Date & Odometer & Fuel & MPG & $\mathrm{CH}_{3} \mathrm{CHO}$ & $\mathrm{CH}_{3} \mathrm{OH}$ & $\mathrm{CH}_{4}$ & $\mathrm{CO}$ & $\mathrm{CO}_{2}$ & $\mathrm{HCHO}$ & NMHCE & $\mathrm{NO}_{\mathrm{x}}$ & THC & Evap. THC \\
\hline AR304MN & $6 / 21 / 96$ & 26110 & RFG & 20.42 & 0.00086 & & 0.038 & 1.59 & 424.1 & 0.00359 & 0.192 & 0.23 & 0.222 & 1.682 \\
\hline AR305MN & $7 / 5 / 96$ & 9599 & RFG & 20.04 & 0.00049 & & 0.03 & 1.06 & 433 & 0.0021 & 0.182 & 0.21 & 0.206 & 0.776 \\
\hline AR306MN & $10 / 3 / 96$ & 10566 & RFG & 20.5 & 0.00054 & & 0.029 & 1.29 & 422.9 & 0.00254 & 0.159 & 0.23 & 0.182 & 0.547 \\
\hline AR307MN & $6 / 19 / 96$ & 12632 & RFG & 20.64 & 0.00084 & & 0.031 & 1.36 & 419.7 & 0.0034 & 0.2 & 0.28 & 0.225 & 0.455 \\
\hline AR308MN & $7 / 9 / 96$ & 15673 & RFG & 19.45 & 0.00063 & & 0.029 & 1.25 & 445.9 & 0.00257 & 0.167 & 0.22 & 0.189 & 0.547 \\
\hline AR310MN & $7 / 25 / 96$ & 10194 & RFG & 19.99 & 0.00071 & & 0.036 & 1.02 & 434.1 & 0.00261 & 0.133 & 0.39 & 0.161 & 1.017 \\
\hline AR311MN & $1 / 30 / 97$ & 10062 & RFG & 19.67 & 0.00058 & & 0.031 & 1.18 & 441.2 & 0.00231 & 0.151 & 0.25 & 0.175 & 0.461 \\
\hline AR312MN & $7 / 5 / 96$ & 21414 & RFG & 20.61 & 0.00068 & & 0.032 & 1.26 & 420.7 & 0.00276 & 0.181 & 0.22 & 0.207 & 0.559 \\
\hline AR313MN & 9/26/96 & 13151 & RFG & 20.32 & 0.00059 & & 0.033 & 0.99 & 427.1 & 0.00263 & 0.156 & 0.21 & 0.182 & 0.361 \\
\hline AR314GNC & $12 / 11 / 96$ & 12339 & RFG & 20.1 & 0.0005 & & 0.031 & 1.18 & 431.5 & 0.00226 & 0.167 & 0.18 & 0.192 & 0.666 \\
\hline AR314GNC & $12 / 12 / 96$ & 12378 & RFG & 19.97 & 0.00055 & & 0.026 & 1.01 & 434.7 & 0.00246 & 0.149 & 0.19 & 0.17 & 0.611 \\
\hline Average & & & & 20.035 & 0.000525 & & 0.0285 & 1.095 & 433.1 & 0.00236 & 0.158 & 0.185 & 0.181 & 0.6385 \\
\hline AR314MN & $6 / 4 / 96$ & 14836 & RFG & 20.31 & 0.00045 & & 0.026 & 0.75 & 428 & 0.00179 & 0.088 & 0.19 & 0.108 & 0.867 \\
\hline AR317MN & $10 / 29 / 96$ & 18239 & RFG & 19.74 & 0.00047 & & 0.028 & 0.92 & 440 & 0.00248 & 0.131 & 0.27 & 0.153 & 0.438 \\
\hline AR317MN & $11 / 18 / 96$ & 18449 & RFG & 19.56 & 0.00051 & & 0.03 & 1.11 & 443.8 & 0.00213 & 0.124 & 0.29 & 0.148 & 0.384 \\
\hline Average & & & & 19.65 & 0.00049 & & 0.029 & 1.015 & 441.9 & 0.002305 & 0.1275 & 0.28 & 0.1505 & 0.411 \\
\hline AR318MN & $12 / 11 / 96$ & 18257 & RFG & 19.85 & 0.00064 & & 0.033 & 1.11 & 437.1 & 0.00293 & 0.168 & 0.32 & 0.195 & 1.09 \\
\hline AR319MN & 12/10/96 & 9725 & RFG & 19.78 & 0.00037 & & 0.031 & 1 & 439 & 0.00244 & 0.162 & 0.26 & 0.187 & 0.799 \\
\hline AR319MN & $12 / 12 / 96$ & 9764 & RFG & 20.03 & 0.00052 & & 0.024 & 0.82 & 433.7 & 0.00213 & 0.136 & 0.23 & 0.155 & 0.646 \\
\hline Average & & & & 19.905 & 0.000445 & & 0.0275 & 0.91 & 436.35 & 0.002285 & 0.149 & 0.245 & 0.171 & 0.7225 \\
\hline AR320MN & $11 / 7 / 96$ & 14341 & RFG & 19.96 & 0.00046 & & 0.024 & 0.88 & 435 & 0.00177 & 0.143 & 0.18 & 0.163 & 0.655 \\
\hline AR320MN & $11 / 8 / 96$ & 14384 & RFG & 20.63 & 0.0004 & & 0.024 & 0.88 & 421 & 0.00175 & 0.126 & 0.17 & 0.145 & 0.564 \\
\hline Average & & & & 20.295 & 0.00043 & & 0.024 & 0.88 & 428 & 0.00176 & 0.1345 & 0.175 & 0.154 & 0.6095 \\
\hline AR322MN & $1 / 31 / 97$ & 10828 & RFG & 20.38 & 0.00059 & & 0.034 & 1.26 & 425.5 & 0.0024 & 0.182 & 0.19 & 0.209 & 0.644 \\
\hline & COUNT & & & 16 & 16 & & 16 & 15 & 16 & 16 & 16 & 16 & 16 & 16 \\
\hline & AVG & & & 20.129 & 0.00059 & & 0.0307 & 1.118 & 431.17 & 0.0025 & 0.158 & 0.239 & 0.1823 & 0.7117 \\
\hline & STD DEV & & & 0.3596 & 0.00013 & & 0.0036 & 0.2123 & 7.911 & 0.00049 & 0.0282 & 0.0561 & 0.0299 & 0.3313 \\
\hline & $\mathrm{CV}$ & & & 0.0179 & 0.2198 & & 0.1178 & 0.1899 & 0.0183 & 0.1954 & 0.1784 & 0.2348 & 0.1643 & 0.4655 \\
\hline
\end{tabular}


Table A-7. 1993 Standard Dodge Spirit: RFG Tests at Lab 1 Round 1

\begin{tabular}{|c|c|c|c|c|c|c|c|c|c|c|c|c|c|c|}
\hline Decal ID & Date & Odometer & Fuel & MPG & $\mathrm{CH}_{3} \mathrm{CHO}$ & $\mathrm{CH}_{3} \mathrm{OH}$ & $\mathrm{CH}_{4}$ & $\mathrm{CO}$ & $\mathrm{CO}_{2}$ & $\mathrm{HCHO}$ & NMHCE & $\mathrm{NO}_{\mathrm{x}}$ & THC & Evap. THC \\
\hline DT201GSC & $5 / 12 / 94$ & 17018 & RFG & 24.44 & \begin{tabular}{|l|}
0.00017 \\
\end{tabular} & & 0.013 & 1.15 & 356.2 & 0.00047 & \begin{tabular}{|l|}
0.073 \\
\end{tabular} & 0.27 & 0.083 & 0.664 \\
\hline DT202GSC & $6 / 27 / 94$ & 20800 & RFG & 24.61 & 0.00052 & & 0.014 & 1.34 & 353.3 & 0.00191 & 0.084 & 0.26 & 0.095 & 0.328 \\
\hline DT203GSC & $6 / 22 / 94$ & 8831 & RFG & 23.7 & 0.00046 & & 0.011 & 0.94 & 367.7 & 0.00127 & 0.061 & 0.18 & 0.069 & 0.34 \\
\hline DT204GSC & $5 / 13 / 94$ & 5647 & RFG & 23.65 & 0.00038 & & 0.009 & 0.83 & 368.7 & 0.00108 & 0.071 & 0.22 & 0.078 & 0.33 \\
\hline DT206GSC & $7 / 1 / 94$ & 7706 & RFG & 24.05 & 0.0004 & & 0.011 & 0.8 & 362.5 & 0.00147 & 0.066 & 0.21 & 0.074 & 0.206 \\
\hline DT207GSC & $12 / 16 / 94$ & 35757 & RFG & 24.68 & 0.00043 & & 0.014 & 1.24 & 352.4 & 0.00155 & 0.088 & 0.44 & 0.099 & 0.235 \\
\hline DT207GSC & $12 / 19 / 94$ & 35784 & RFG & 24.88 & \begin{tabular}{|l|}
0.00046 \\
\end{tabular} & & 0.013 & 1.27 & 349.6 & 0.00163 & 0.084 & 0.41 & 0.095 & 0.25 \\
\hline Average & & & & 24.78 & 0.000445 & & 0.0135 & 1.255 & 351 & 0.00159 & 0.086 & 0.425 & 0.097 & 0.2425 \\
\hline DT208GSC & $5 / 13 / 94$ & 10225 & RFG & 24.31 & \begin{tabular}{|l|}
0.00043 \\
\end{tabular} & & 0.011 & 0.74 & 358.7 & 0.00148 & 0.071 & 0.28 & 0.08 & 0.305 \\
\hline DT209GSC & $4 / 20 / 94$ & 8362 & RFG & 23.91 & 0.00043 & & 0.011 & 1.2 & 364 & 0.00137 & 0.077 & 0.22 & 0.086 & 0.259 \\
\hline DT210GSC & $7 / 1 / 94$ & 19117 & RFG & 24.83 & 0.00088 & & 0.019 & 1.49 & 349.7 & 0.00355 & 0.121 & 0.55 & 0.136 & 0.191 \\
\hline DT210GSC & $7 / 6 / 94$ & 19143 & RFG & 24.98 & 0.00063 & & 0.018 & 1.45 & 347.7 & 0.00242 & 0.118 & 0.54 & 0.132 & 0.24 \\
\hline Average & & & & 24.905 & \begin{tabular}{|l|}
0.000755 \\
\end{tabular} & & 0.0185 & 1.47 & 348.7 & 0.002985 & \begin{tabular}{|l|}
0.1195 \\
\end{tabular} & 0.545 & 0.134 & 0.2155 \\
\hline DT211GSC & $3 / 21 / 94$ & 4339 & RFG & 23.57 & \begin{tabular}{|l|}
0.00037 \\
\end{tabular} & & 0.012 & 1.48 & 368.8 & 0.00106 & 0.082 & 0.12 & 0.091 & 0.381 \\
\hline DT212GSC & $6 / 28 / 94$ & 4923 & RFG & 24.02 & 0.00033 & & 0.012 & 0.93 & 362.8 & 0.00117 & 0.068 & 0.15 & 0.078 & 0.265 \\
\hline DT213GSC & $7 / 1 / 94$ & 6547 & RFG & 24.09 & 0.00042 & & 0.013 & 0.9 & 361.7 & 0.00147 & 0.07 & 0.2 & 0.08 & 0.289 \\
\hline DT214GSC & $5 / 9 / 94$ & 10632 & RFG & 24.49 & 0.00043 & & 0.009 & 0.64 & 356.2 & 0.00139 & 0.059 & 0.31 & 0.066 & 0.301 \\
\hline DT214GSC & $5 / 10 / 94$ & 10659 & RFG & 24.26 & 0.00037 & & 0.007 & 0.6 & 359.7 & 0.00131 & 0.06 & 0.34 & 0.065 & 0.249 \\
\hline Average & & & & 24.375 & 0.0004 & & 0.008 & 0.62 & 357.95 & 0.00135 & \begin{tabular}{|l|}
0.0595 \\
\end{tabular} & 0.325 & 0.066 & 0.275 \\
\hline DT215GSC & $4 / 21 / 94$ & 12278 & RFG & 24.37 & 0.00041 & & 0.013 & 1.39 & 356.8 & 0.00133 & 0.078 & 0.28 & 0.088 & 0.278 \\
\hline DT216GSC & $3 / 4 / 94$ & 11178 & RFG & 23.63 & 0.00059 & & 0.019 & 2 & 367 & 0.00166 & 0.091 & 0.27 & 0.106 & 0.264 \\
\hline DT216GSC & $3 / 8 / 94$ & 11204 & RFG & 23.77 & 0.00061 & & 0.015 & 1.68 & 365.3 & 0.00167 & 0.087 & 0.26 & 0.099 & 0.46 \\
\hline Average & & & & 23.7 & 0.0006 & & 0.017 & 1.84 & 366.15 & 0.001665 & 0.089 & 0.265 & 0.1025 & 0.362 \\
\hline DT217GSC & $4 / 20 / 94$ & 20267 & RFG & 24.37 & 0.00051 & & 0.015 & 1.81 & 356.1 & 0.00161 & 0.088 & 0.35 & 0.1 & 0.353 \\
\hline DT217GSC & $4 / 25 / 94$ & 20294 & RFG & 24.6 & 0.0005 & & 0.013 & 1.46 & 353.2 & 0.00 & 0.08 & 0.28 & 0.09 & 0.327 \\
\hline Average & & & & 24.485 & 0.000505 & & 0.014 & 1.635 & 354.65 & 0.00164 & 0.084 & 0.315 & 0.095 & 0.34 \\
\hline DT218GSC & $6 / 22 / 94$ & 12393 & RFG & 24.24 & \begin{tabular}{|l|}
0.00038 \\
\end{tabular} & & 0.016 & 1.43 & 358.6 & 109 & 0.078 & 0.33 & 0.09 & 0.175 \\
\hline DT218GSC & $6 / 23 / 94$ & 12419 & RFG & 24.56 & 0.00048 & & 0.013 & 1.22 & 354.3 & 0.00155 & 0.075 & 0.28 & 0.085 & 0.171 \\
\hline Average & & & & 24.4 & 0.00043 & & 0.0145 & 1.325 & 356.45 & 0.00132 & 0.0765 & 0.305 & 0.0875 & 0.173 \\
\hline DT219GSC & $5 / 12 / 94$ & 11700 & RFG & 24.24 & 0.00047 & & 0.01 & 0.82 & 359.7 & 0.0014 & 0.073 & 0.24 & 0.081 & 0.208 \\
\hline DT221GSC & $4 / 22 / 94$ & 8994 & RFG & 24.53 & 0.0004 & & 0.013 & 1.12 & 354.8 & 0.00123 & 0.071 & 0.22 & 0.081 & 0.23 \\
\hline DT222GSC & $6 / 23 / 94$ & 20051 & RFG & 24.65 & 0.0005 & & 0.017 & 1.74 & 352.1 & 0.00171 & 0.084 & 0.25 & 0.097 & 0.239 \\
\hline DT223GSC & $5 / 6 / 94$ & 6682 & RFG & 24.3 & 0.00031 & & 0.012 & 1.08 & 358.2 & 0.00121 & 0.075 & 0.2 & 0.085 & 0.316 \\
\hline DT224GSC & $3 / 1 / 94$ & 11363 & RFG & 23.38 & 0.00046 & & 0.013 & 1.2 & 372.3 & 0.0017 & 0.079 & 0.22 & 0.089 & 0.341 \\
\hline DT224GSC & $3 / 3 / 94$ & 11396 & RFG & 23.48 & & & 0.012 & 1.14 & 370.7 & 167 & 0.079 & 0.22 & 0.089 & 0.293 \\
\hline Average & & & & 23.43 & 0.00054 & & 0.0125 & 1.17 & 371.5 & 0.001685 & 0.079 & 0.22 & 0.089 & 0.317 \\
\hline DT225GSC & $5 / 18 / 94$ & 13037 & RFG & 23.87 & 0.00034 & & 0.017 & 1.42 & 364.2 & 0.00134 & 0.094 & 0.19 & 0.107 & 0.299 \\
\hline DT226GSC & $6 / 27 / 94$ & 5138 & RFG & 23.94 & 0.00038 & & 0.01 & 0.7 & 364.3 & 0.00123 & 0.063 & 0.24 & 0.071 & 0.332 \\
\hline & & & & & & & & & & & & & & \\
\hline & COUNT & & & 23 & 23 & & 23 & 23 & 23 & 23 & 23 & 23 & 23 & 23 \\
\hline & AVG & & & 24.15 & 0.00042 & & 0.0125 & 1.149 & 360.53 & 0.00137 & 0.0754 & 0.243 & 0.0853 & 0.3034 \\
\hline & STD DEV & & & 0.3776 & 0.00009 & & 0.0024 & 0.3388 & 5.7824 & 0.0003 & 0.0090 & 0.064 & 0.01058 & 0.095 \\
\hline & $\mathrm{CV}$ & & & 0.0156 & 0.2107 & & 0.1908 & 0.2949 & 0.0160 & 0.2125 & 0.1195 & 0.2643 & 0.124 & 0.3131 \\
\hline
\end{tabular}


Table A-8. 1993 FFV Dodge Spirit: M85 Tests at Lab 1 Round 1

\begin{tabular}{|c|c|c|c|c|c|c|c|c|c|c|c|c|c|c|}
\hline Decal ID & Date & Odometer & Fuel & MPG & $\mathrm{CH}_{3} \mathrm{CHO}$ & $\mathrm{CH}_{3} \mathrm{OH}$ & $\mathrm{CH}_{4}$ & $\mathrm{CO}$ & $\mathrm{CO}_{2}$ & $\mathrm{HCHO}$ & NMHCE & $\mathrm{NO}_{\mathrm{x}}$ & THC & Evap. THC \\
\hline AR206MS & $11 / 21 / 94$ & 6735 & M85 & 13.78 & 0.00017 & 0.1452 & 0.012 & 1.39 & 349 & 0.00928 & 0.09 & 0.1 & 0.095 & 0.53 \\
\hline AR209MS & $11 / 7 / 94$ & 6305 & M85 & 13.87 & 0.00017 & 0.1227 & 0.015 & 1.78 & 346.2 & 0.00642 & 0.087 & 0.04 & 0.095 & 0.54 \\
\hline AR212MS & $11 / 9 / 94$ & 7648 & M85 & 13.83 & 0.00016 & 0.1505 & 0.016 & 1.75 & 347.2 & 0.01133 & 0.097 & 0.18 & 0.104 & 0.599 \\
\hline DT203MS & $3 / 22 / 94$ & 4620 & M85 & 12.86 & 0.00037 & 0.2283 & 0.014 & 2.09 & 368.2 & 0.01157 & 0.142 & 0.04 & 0.147 & 0.576 \\
\hline DT208MS & $5 / 5 / 94$ & 11028 & M85 & 13.67 & 0.00037 & 0.23 & 0.019 & 1.97 & 350.9 & 0.01306 & 0.154 & 0.28 & 0.163 & 0.527 \\
\hline DT211MS & $5 / 24 / 94$ & 4826 & M85 & 13.59 & 0.00029 & 0.1273 & 0.014 & 1.08 & 349.9 & 0.01393 & 0.096 & 0.28 & 0.1 & 0.615 \\
\hline DT212MS & $3 / 25 / 94$ & 4339 & M85 & 13.86 & 0.00028 & 0.1595 & 0.011 & 1.12 & 343 & 0.01129 & 0.106 & 0.11 & 0.109 & 0.348 \\
\hline DT219MS & $6 / 13 / 94$ & 17116 & M85 & 13.61 & 0.00032 & 0.1465 & 0.017 & 1.16 & 349.2 & 0.01367 & 0.102 & 0.26 & 0.108 & 0.755 \\
\hline DT221MS & $5 / 3 / 94$ & 11588 & M85 & 13.84 & 0.0002 & 0.1189 & 0.012 & 1.05 & 343.5 & 0.01254 & 0.095 & 0.21 & 0.098 & 0.486 \\
\hline DT223MS & $3 / 3 / 94$ & 9666 & M85 & 13.83 & 0.00039 & 0.1429 & 0.012 & 1.2 & 343.6 & 0.01327 & 0.116 & 0.07 & 0.119 & 1.827 \\
\hline DT223MS & 3/9/94 & 9779 & M85 & 13.77 & 0.00054 & 0.1568 & 0.012 & 1.18 & 345.1 & 0.01394 & 0.099 & 0.06 & 0.102 & 1.549 \\
\hline Average & & & & 13.8 & 0.000465 & 0.14985 & 0.012 & 1.19 & 344.35 & 0.013605 & 0.1075 & 0.065 & 0.1105 & 1.688 \\
\hline DT225MS & $4 / 4 / 94$ & 8871 & M85 & 13.53 & 0.00041 & 0.2477 & 0.025 & 4.73 & 350 & 0.01256 & 0.162 & 0.63 & 0.176 & 0.693 \\
\hline DT225MS & $4 / 6 / 94$ & 8897 & M85 & 13.37 & 0.00035 & 0.166 & 0.015 & 1.16 & 355.4 & 0.01291 & 0.096 & 0.23 & 0.101 & 0.615 \\
\hline Average & & & & 13.45 & 0.00038 & 0.20685 & 0.02 & 2.945 & 352.7 & 0.012735 & 0.129 & 0.43 & 0.1385 & 0.654 \\
\hline DT226MSC & $6 / 2 / 94$ & 15299 & M85 & 13.68 & 0.00039 & 0.1338 & 0.019 & 1.19 & 347.3 & $\begin{array}{l}0.01874 \\
\end{array}$ & 0.101 & 0.43 & 0.106 & 0.865 \\
\hline DT226MSC & $6 / 3 / 94$ & 15325 & M85 & 13.59 & 0.00042 & 0.1568 & 0.02 & 1.25 & 349.6 & 0.01765 & 0.105 & 0.39 & 0.113 & 0.88 \\
\hline Average & & & & 13.635 & 0.000405 & 0.1453 & 0.0195 & 1.22 & 348.45 & 0.018195 & 0.103 & 0.41 & 0.1095 & 0.8725 \\
\hline DT229MS & $3 / 28 / 94$ & 9762 & M85 & 13.53 & 0.00025 & 0.1273 & 0.012 & 1.08 & 351.4 & 0.01174 & 0.088 & 0.21 & 0.092 & 0.53 \\
\hline DT230MS & $5 / 24 / 94$ & 5973 & M85 & 13.45 & 0.00026 & 0.1279 & 0.014 & 1.3 & 353.2 & 0.00971 & 0.104 & 0.11 & 0.11 & 0.459 \\
\hline DT233MS & $3 / 3 / 94$ & 4175 & M85 & 13.32 & 0.00035 & 0.1689 & 0.011 & 1.06 & 356.9 & 0.00977 & 0.113 & 0.06 & 0.117 & 2.582 \\
\hline DT233MS & $3 / 7 / 94$ & 4249 & M85 & 13.51 & 0.00039 & 0.1579 & 0.013 & 1.45 & 351.4 & 0.01253 & 0.121 & 0.04 & 0.125 & 0.434 \\
\hline Average & & & & 13.415 & 0.00037 & 0.1634 & 0.012 & 1.255 & 354.15 & 0.01115 & 0.117 & 0.05 & 0.121 & 1.508 \\
\hline DT238MS & $4 / 28 / 94$ & 270 & M85 & 13.45 & 0.00031 & 0.1893 & 0.022 & 1.77 & 352.3 & 0.01381 & 0.135 & 0.37 & 0.145 & 0.664 \\
\hline DT238MS & $4 / 29 / 94$ & 12296 & M85 & 13.55 & 0.00049 & 0.179 & 0.022 & 1.87 & 349.6 & 0.01962 & 0.137 & 0.35 & 0.145 & 0.692 \\
\hline Average & & & & 13.5 & & 0.18415 & 0.022 & 1.82 & 350.95 & 7715 & 0.136 & 0.36 & 0.145 & 0.678 \\
\hline DT241MS & $4 / 5 / 94$ & 4108 & M85 & 13.45 & 0.00029 & 0.1518 & 0.014 & 1.07 & 353.6 & 0.00996 & 0.093 & 0.35 & 0.098 & 0.348 \\
\hline DT241MS & $4 / 7 / 94$ & 4134 & M85 & 13.28 & 0.00034 & 0.1819 & 0.014 & 1.12 & 357.9 & 0.01261 & 0.1 & 0.34 & 0.105 & 0.302 \\
\hline Average & & & & 13.365 & 0.000315 & 0.16685 & 0.014 & 1.095 & 355.75 & 0.011285 & 0.0965 & 0.345 & 0.1015 & 0.325 \\
\hline DT245MS & $5 / 19 / 94$ & 3704 & M85 & 13.25 & 0.00017 & 0.2325 & 0.015 & 1 & 358.9 & 0.01189 & 0.132 & 0.3 & 0.104 & 0.918 \\
\hline DT245MS & $5 / 20 / 94$ & 3730 & M85 & 13.36 & 0.00026 & 0.1184 & 0.018 & 1 & 356.2 & & 0.088 & 0.32 & 0.094 & 0.821 \\
\hline Average & & & & 13.305 & 0.000215 & 0.17545 & 0.0165 & 1 & 357.55 & 0.012595 & 0.11 & 0.31 & 0.099 & 0.8695 \\
\hline DT250MS & $6 / 2 / 94$ & 9419 & M85 & 13.62 & 0.00031 & 0.1418 & 0.017 & 1.46 & 348.4 & 0.01163 & 0.103 & 0.29 & 0.108 & 0.474 \\
\hline DT250MS & $6 / 3 / 94$ & 9445 & M85 & 13.58 & & 0.136 & 0.016 & 1.02 & 350.1 & & 0.094 & 0.29 & 0.097 & 0.407 \\
\hline Average & & & & 13.6 & 0.000335 & 0.1389 & 0.0165 & 1.24 & 349.25 & 0.0144 & 0.0985 & 0.29 & 0.1025 & 0.4405 \\
\hline DT251MSC & $6 / 2 / 94$ & 18203 & M85 & 13.45 & 0.00037 & 0.1254 & 0.014 & 1.32 & 353.2 & 0.01652 & 0.102 & 0.1 & 0.104 & 0.859 \\
\hline DT252MS & $4 / 4 / 94$ & 9204 & M85 & 13.33 & 0.00043 & 0.2093 & 0.018 & 1.22 & 356.4 & 0.01522 & 0.115 & 0.28 & 0.108 & 1.007 \\
\hline & COUNT & & & 21 & & 21 & 20 & 21 & 19 & & 21 & 2 & 21 & 21 \\
\hline & AVG & & & 13.559 & 0.00031 & 0.1595 & 0.0149 & 1.432 & 350.28 & 0.0127 & 0.108 & 0.212 & 0.1124 & 0.7079 \\
\hline & STD DEV & & & 0.2423 & 0.00009 & 0.0345 & 0.0028 & 0.4742 & 4.265 & 0.0027 & 0.0181 & 0.1249 & 0.0194 & 0.346 \\
\hline & CV & & & 0.0179 & 0.293 & 0.2161 & 0.1855 & 0.3311 & 0.0122 & 0.211 & 0.167 & 0.588 & 0.173 & 0.4886 \\
\hline
\end{tabular}

\section{A-9}


Table A-9. 1993 FFV Dodge Spirit: RFG Tests at Lab 1 Round 1

\begin{tabular}{|c|c|c|c|c|c|c|c|c|c|c|c|c|c|c|}
\hline Decal ID & Date & Odometer & Fuel & MPG & $\mathrm{CH}_{3} \mathrm{CHO}$ & $\mathrm{CH}_{3} \mathrm{OH}$ & $\mathrm{CH}_{4}$ & $\mathrm{CO}$ & $\mathrm{CO}_{2}$ & $\mathrm{HCHO}$ & $\mathrm{NMHCE}$ & $\mathrm{NO}_{\mathrm{x}}$ & $\mathrm{THC}$ & Evap. THC \\
\hline AR206MS & $11 / 22 / 94$ & 6769 & RFG & 22.87 & 0.00039 & & 0.017 & 1.1 & 380.7 & 0.00123 & 0.112 & 0.2 & 0.126 & 0.583 \\
\hline AR209MS & $11 / 8 / 94$ & 6338 & RFG & 22.97 & 0.00035 & & 0.023 & 1.3 & 378.7 & 0.00094 & 0.11 & 0.06 & 0.129 & 1.472 \\
\hline AR212MS & $11 / 7 / 94$ & 7617 & RFG & 22.88 & 0.00042 & & 0.024 & 1.61 & 379.6 & 0.00124 & 0.111 & 0.21 & 0.131 & 0.17 \\
\hline DT203MS & $3 / 25 / 94$ & 4695 & RFG & 22.65 & 0.0005 & & 0.027 & 1.66 & 383.3 & 0.00112 & 0.141 & 0.08 & 0.163 & 0.602 \\
\hline DT208MS & $5 / 6 / 94$ & 11062 & RFG & 21.4 & 0.00052 & & 0.025 & 1.61 & 406.1 & 0.00142 & 0.12 & 0.13 & 0.139 & 0.741 \\
\hline DT211MS & $5 / 18 / 94$ & 4733 & RFG & 22.81 & 0.00056 & & 0.024 & 1.07 & 381.6 & 0.00148 & 0.112 & 0.27 & 0.131 & 0.438 \\
\hline DT212MS & $3 / 24 / 94$ & 4305 & RFG & 23.44 & 0.00049 & & 0.022 & 1.36 & 370.9 & 0.00131 & 0.109 & 0.08 & 0.126 & 0.703 \\
\hline DT219MS & 6/1/94 & 16919 & RFG & 22.95 & 0.00054 & & 0.032 & 1.69 & 378.2 & 0.00155 & 0.148 & 0.1 & 0.172 & 0.656 \\
\hline DT223MS & $3 / 2 / 94$ & 9633 & RFG & 23.36 & 0.00077 & & 0.025 & 1.42 & 371.9 & 0.0027 & 0.164 & 0.08 & 0.184 & 1.28 \\
\hline DT223MS & $3 / 8 / 94$ & 9745 & RFG & 23.38 & 0.00058 & & 0.024 & 1.37 & 371.8 & 0.00155 & 0.154 & 0.07 & 0.173 & 3.355 \\
\hline Average & & & & 23.37 & 0.000675 & & 0.0245 & 1.395 & 371.85 & 0.002125 & 0.159 & 0.075 & 0.1785 & 2.3175 \\
\hline DT225MS & $3 / 29 / 94$ & 8804 & RFG & 22.71 & \begin{tabular}{|l|}
0.00048 \\
\end{tabular} & & 0.023 & 1.19 & 383.2 & 0.00129 & 0.108 & 0.16 & 0.126 & 0.655 \\
\hline DT226MSC & $6 / 1 / 94$ & 15257 & RFG & 23.03 & 0.0007 & & 0.031 & 1.39 & 377.3 & 0.00263 & 0.163 & 0.23 & 0.187 & 0.832 \\
\hline DT229MS & $4 / 8 / 94$ & 9801 & RFG & 22.56 & 0.00048 & & 0.024 & 1.02 & 386 & 0.00131 & 0.1 & 0.4 & 0.119 & 0.516 \\
\hline DT229MS & $4 / 11 / 94$ & 9827 & RFG & 22.68 & 0.00047 & & 0.022 & 1.08 & 384 & 0.00123 & 0.109 & 0.32 & 0.126 & 0.417 \\
\hline Average & & & & 22.62 & 0.000475 & & 0.023 & 1.05 & 385 & 0.00127 & 0.1045 & 0.36 & 0.1225 & 0.4665 \\
\hline DT230MS & $5 / 26 / 94$ & 6032 & RFG & 23.15 & \begin{tabular}{|l|}
0.00048 \\
\end{tabular} & & 0.038 & 1.69 & 374.8 & 0.00131 & 0.17 & 0.09 & 0.2 & 0.461 \\
\hline DT233MS & $3 / 9 / 94$ & 4317 & RFG & 22.63 & \begin{tabular}{|l|}
0.00051 \\
\end{tabular} & & 0.035 & 1.76 & 383.4 & 0.00132 & 0.167 & 0.07 & 0.194 & 0.546 \\
\hline Average & & & & 22.62 & 0.000385 & & 0.0355 & 1.725 & 383.65 & 0.000935 & 0.1725 & 0.08 & 0.2 & 1.2475 \\
\hline DT238MS & $4 / 27 / 94$ & 12237 & RFG & 22.67 & 0.00048 & & 0.042 & 2.07 & 382.3 & 0.00175 & 0.156 & 0.25 & 0.189 & 0.534 \\
\hline DT241MS & $3 / 31 / 94$ & 4075 & RFG & 22.67 & 0.00044 & & 0.02 & 1.24 & 383.9 & 0.00117 & 0.104 & 0.11 & 0.12 & 0.354 \\
\hline DT245MS & $5 / 26 / 94$ & 3809 & RFG & 22.6 & 0.00044 & & 0.023 & 1.02 & 385.3 & 0.00128 & 0.108 & 0.19 & 0.126 & 0.943 \\
\hline DT250MS & $6 / 7 / 94$ & 9505 & RFG & 23.16 & 0.00054 & & 0.022 & 0.77 & 376.4 & 0.00186 & 0.109 & 0.18 & 0.125 & 0.604 \\
\hline DT251MSC & $6 / 6 / 94$ & 18237 & RFG & 22.6 & 0.00062 & & 0.039 & 2.84 & 382.3 & 0.00193 & 0.175 & 0.11 & 0.205 & 0.939 \\
\hline DT251MSC & $6 / 22 / 94$ & 18312 & RFG & 22.37 & 0.00063 & & 0.039 & 2.75 & 386.4 & 0.00207 & 0.19 & 0.1 & 0.221 & 0.58 \\
\hline Average & & & & 22.485 & 0.000625 & & 0.039 & 2.795 & 384.35 & 0.002 & 0.1825 & 0.105 & 0.213 & 0.7595 \\
\hline DT252MS & $4 / 7 / 94$ & 9245 & RFG & 22.48 & \begin{tabular}{|l|}
0.0006 \\
\end{tabular} & & 0.029 & 1.59 & 386.5 & 0.00158 & 0.121 & 0.12 & 0.143 & 0.462 \\
\hline & COUNT & & & 21 & 21 & & 20 & 21 & 19 & 21 & 21 & 21 & 21 & 21 \\
\hline & AVG & & & 22.82 & 0.0005 & & 0.0262 & 1.45 & 379.54 & 0.0015 & 0.130 & 0.151 & 0.151 & 0.7239 \\
\hline & STD DEV & & & 0.4611 & 0.00009 & & 0.006 & 0.438 & 5.403 & 0.0004 & 0.0267 & 0.0792 & 0.0312 & 0.476 \\
\hline & CV & & & 0.0202 & 0.1826 & & 0.229 & 0.3026 & 0.0142 & 0.279 & 0.2049 & 0.523 & 0.2064 & 0.6574 \\
\hline
\end{tabular}


Table A-10. 1993 Standard Dodge Spirit: RFG Tests at Lab 3 Round 1

\begin{tabular}{|c|c|c|c|c|c|c|c|c|c|c|c|c|c|c|}
\hline Decal ID & Date & Odometer & Fuel & MPG & $\mathrm{CH}_{3} \mathrm{CHO}$ & $\mathrm{CH}_{3} \mathrm{OH}$ & $\mathrm{CH}_{4}$ & $\mathrm{CO}$ & $\mathrm{CO}_{2}$ & $\mathrm{HCHO}$ & NMHCE & $\mathrm{NO}_{\mathrm{x}}$ & THC & Evap. THC \\
\hline DV201GSC & $8 / 30 / 94$ & 22240 & RFG & 24.86 & 0.0005 & & 0.0136 & 1.74 & 345.9 & 0.0012 & 0.0929 & 0.404 & 0.1029 & 0.1691 \\
\hline DV201GSC & $8 / 31 / 94$ & 22266 & RFG & 24.75 & 0.0006 & & 0.0122 & 1.576 & 347.73 & 0.0013 & 0.0899 & 0.449 & 0.1011 & * \\
\hline Average & & & & 24.80 & 0.00055 & & 0.0129 & 1.66015 & 346.81 & 0.00125 & 0.0891 & 0.42625 & 0.102 & 0.1691 \\
\hline DV203GSC & $4 / 12 / 95$ & 24331 & RFG & 25.63 & 0.0004 & & 0.0124 & 1.6073 & 335.69 & 0.0011 & 0.065 & 0.3923 & 0.0774 & 0.1442 \\
\hline DV204GSC & $3 / 24 / 95$ & 15918 & RFG & 25.39 & 0.0002 & & 0.0131 & 1.5448 & 338.92 & 0.0007 & 0.0652 & 0.4245 & 0.0783 & 0.3127 \\
\hline DV205GSC & $4 / 12 / 95$ & 21718 & RFG & 25.78 & 0.0003 & & 0.0119 & 1.7261 & 333.45 & 0.0009 & 0.0718 & 0.3389 & 0.0837 & 0.2399 \\
\hline DV208GSC & $3 / 7 / 95$ & 19846 & RFG & 25.25 & 0.0002 & & 0.0134 & 1.8154 & 340.39 & 0.0007 & 0.0659 & 0.4489 & 0.0793 & 0.2992 \\
\hline DV209GSC & $5 / 25 / 94$ & 11052 & RFG & 25.22 & 0.0002 & & 0.0095 & 1.2271 & 341.68 & 0.0009 & 0.0736 & 0.3688 & 0.0831 & 0.3456 \\
\hline DV211GSC & $3 / 23 / 94$ & 9783 & RFG & 25.06 & 0.0004 & & 0.0081 & 0.995 & 344.4 & 0.0007 & 0.0634 & 0.187 & 0.069 & 0.3965 \\
\hline Average & & & & 25.09 & 0.00035 & & 0.0085 & 1.0255 & 343.75 & 0.0007 & 0.06225 & 0.21315 & 0.07075 & 0.40835 \\
\hline DV212GSC & $7 / 29 / 94$ & 5743 & RFG & 24.46 & 0.0001 & & 0.0104 & 1.255 & 352.4 & 0.0009 & 0.0729 & 0.361 & 0.0805 & 0.2157 \\
\hline DV212GSC & $8 / 1 / 94$ & 5771 & RFG & 23.86 & 0.0002 & & 0.0103 & 1.438 & 361 & 0.001 & 0.0761 & 0.362 & 0.0836 & * \\
\hline Average & & & & 24.16 & 0.00015 & & 0.01035 & 1.3464 & 356.72 & 0.00095 & 0.0717 & 0.3616 & 0.08205 & 0.2157 \\
\hline DV213GSC & $3 / 11 / 94$ & 10425 & RFG & 24.9 & 0.0017 & & 0.0119 & 1.543 & 345.5 & 0.0016 & 0.0734 & 0.377 & 0.0819 & 0.2024 \\
\hline DV213GSC & $3 / 15 / 94$ & 10458 & RFG & 24.7 & 0.0011 & & 0.0078 & 0.981 & 349.1 & 0.0011 & 0.0694 & 0.301 & 0.0737 & 0.2438 \\
\hline Average & & & & 24.81 & 0.0014 & & 0.00985 & 1.26215 & 347.34 & 0.00135 & 0.06795 & 0.33905 & 0.0778 & 0.2231 \\
\hline DV214GSC & $9 / 20 / 94$ & 10301 & RFG & 25.15 & 0.0006 & & 0.0094 & 1.19 & 342.7 & 0.001 & 0.0748 & 0.339 & 0.081 & 0.2486 \\
\hline Average & & & & 24.96 & 0.0006 & & 0.00885 & 1.37175 & 345.05 & 0.001 & 0.0718 & 0.3102 & 0.08065 & 0.2486 \\
\hline DV215GSC & $3 / 14 / 95$ & 20166 & RFG & 26.00 & 0.0001 & & 0.0145 & 1.7798 & 330.48 & 0.0006 & 0.073 & 0.3607 & 0.0875 & 0.3508 \\
\hline DV216GSC & $3 / 23 / 95$ & 13427 & RFG & 25.44 & 0.0002 & & 0.0152 & 2.1305 & 337.26 & 0.0009 & 0.0746 & 0.4405 & 0.0898 & 0.3466 \\
\hline DV217GSC & $7 / 6 / 94$ & 14589 & RFG & 25.2 & 0.0004 & & 0.0104 & 1.228 & 341.99 & 0.0011 & 0.0711 & 0.401 & 0.0786 & 0.1289 \\
\hline DV217GSC & $7 / 7 / 94$ & 14614 & RFG & 24.97 & 0.0004 & & 0.0093 & 1.299 & 345.1 & 0.0013 & 0.0675 & 0.446 & 0.0737 & * \\
\hline Average & & & & 25.09 & 0.0004 & & 0.00985 & 1.2636 & 343.55 & 0.0012 & 0.0663 & 0.4233 & 0.07615 & 0.1289 \\
\hline DV219GSC & $3 / 9 / 95$ & 28005 & RFG & 24.97 & 0.0001 & & 0.0126 & 1.8194 & 344.33 & 0.0006 & 0.0584 & 0.5176 & 0.071 & 0.4365 \\
\hline DV220GSC & $3 / 9 / 95$ & 15570 & RFG & 25.66 & 0.0001 & & 0.0103 & 1.3683 & 335.68 & 0.0006 & 0.0649 & 0.3252 & 0.0752 & 0.2786 \\
\hline DV221GSC & $4 / 4 / 95$ & 19640 & RFG & 26.12 & 0.0001 & & 0.0092 & 1.1467 & 330.01 & 0.001 & 0.0643 & 0.5971 & 0.0735 & 0.4519 \\
\hline DV222GSC & $3 / 28 / 95$ & 16309 & RFG & 25.81 & 0.0002 & & 0.0117 & 1.4105 & 333.59 & 0.0006 & 0.0577 & 0.3634 & 0.0694 & 0.231 \\
\hline DV223GSC & $6 / 23 / 94$ & 10942 & RFG & 24.96 & 0.0002 & & 0.0167 & 2.777 & 342.9 & 0.0008 & 0.0848 & 0.403 & 0.0988 & 0.2567 \\
\hline DV223GSC & $6 / 24 / 94$ & 10974 & RFG & 25.11 & 0.0003 & & 0.0135 & 2.167 & 341.8 & 0.001 & 0.0769 & 0.366 & 0.0865 & * \\
\hline Average & & & & 25.03 & 0.00025 & & 0.0151 & 2.4721 & 342.36 & 0.0009 & 0.07755 & 0.3843 & 0.09265 & 0.2567 \\
\hline DV224GSC & $5 / 16 / 94$ & 22226 & RFG & 25.4 & 0.0003 & & 0.0065 & 1.482 & 338.6 & 0.0009 & 0.0774 & 0.3797 & 0.0813 & 0.254 \\
\hline DV224GSC & $5 / 18 / 94$ & 22252 & RFG & 25.7 & 0.0003 & & 0.0086 & 1.133 & 335.5 & 0.0007 & 0.0782 & 0.327 & 0.084 & * \\
\hline Average & & & & 25.56 & 0.0003 & & 0.00755 & 1.3078 & 337.05 & 0.0008 & 0.0751 & 0.35345 & 0.08265 & 0.254 \\
\hline DV226GSC & $2 / 15 / 95$ & 9051 & RFG & 25.17 & 0.0001 & & 0.0113 & 1.2387 & 342.39 & 0.0005 & 0.0698 & 0.5617 & 0.0738 & 6.8507 \\
\hline & STD DEV & & & 0.4699 & 0.0001 & & 0.0022 & 0.356 & 6.456 & 0.00024 & 0.0072 & 0.088 & 0.0081 & 1.4717 \\
\hline & $\mathrm{CV}$ & & & 0.0186 & 0.595 & & 0.1961 & 0.233 & 0.019 & 0.279 & 0.104 & 0.222 & 0.1006 & 2.414 \\
\hline
\end{tabular}


Table A-11. 1993 FFV Dodge Spirit: M85 Tests at Lab 3 Round 1

\begin{tabular}{|c|c|c|c|c|c|c|c|c|c|c|c|c|c|c|}
\hline Decal ID & Date & Odometer & Fuel & MPG & $\mathrm{CH}_{3} \mathrm{CHO}$ & $\mathrm{CH}_{3} \mathrm{OH}$ & $\mathrm{CH}_{4}$ & $\mathrm{CO}$ & $\mathrm{CO}_{2}$ & $\mathrm{HCHO}$ & NMHCE & $\mathrm{NO}_{\mathrm{x}}$ & $\mathrm{THC}$ & Evap. THC \\
\hline DV205MS & $6 / 1 / 94$ & 9621 & M85 & 12.87 & 0.0002 & 0.1313 & 0.0188 & 1.247 & 329.43 & 0.0114 & 0.0862 & 0.452 & 0.0414 & 0.2466 \\
\hline DV205MS & $6 / 2 / 94$ & 9647 & M85 & 12.69 & 0.0002 & 0.1277 & 0.0196 & 1.225 & 334.2 & 0.0108 & 0.1202 & 0.46 & 0.0777 & ${ }^{*}$ \\
\hline Average & & & & 12.78 & 0.0002 & 0.1295 & 0.0192 & 1.236 & 331.82 & 0.0111 & 0.1032 & 0.456 & 0.05955 & 0.2466 \\
\hline DV206MS & $6 / 9 / 94$ & 9015 & M85 & 12.47 & 0.0002 & 0.101 & 0.0142 & 1.397 & 339.82 & 0.0095 & 0.1011 & 0.236 & 0.066 & 0.5182 \\
\hline DV206MS & $8 / 16 / 94$ & 9921 & M85 & 12.86 & 0.0003 & 0.1164 & 0.0164 & 1.664 & 328.97 & 0.0068 & 0.1116 & 0.245 & 0.073 & 0.3431 \\
\hline Average & & & & 12.67 & 0.00025 & 0.1087 & 0.0153 & 1.530 & 334.39 & 0.00815 & 0.10635 & 0.24035 & 0.0694 & 0.43065 \\
\hline DV207MS & $5 / 24 / 94$ & 4138 & M85 & 12.45 & 0.0002 & 0.1286 & 0.0114 & 1.546 & 340.19 & 0.0066 & 0.1094 & 0.0501 & 0.0605 & 0.1965 \\
\hline DV208MS & $4 / 6 / 94$ & 9715 & M85 & 12.44 & 0.0002 & 0.1205 & 0.0133 & 1.327 & 340.89 & 0.0066 & 0.1123 & 0.15 & 0.069 & 0.2613 \\
\hline Average & & & & 12.47 & 0.00015 & 0.13745 & 0.01305 & 1.378 & 339.96 & 0.00665 & 0.1078 & 0.12605 & 0.05695 & 0.29325 \\
\hline DV209MS & $4 / 12 / 94$ & 6449 & M85 & 12.35 & 0.0004 & 0.095 & 0.0093 & 1.494 & 343.1 & 0.0086 & 0.1004 & 0.132 & 0.0633 & 0.2879 \\
\hline DV209MS & $4 / 28 / 94$ & 6641 & M85 & 12.64 & 0.0002 & 0.113 & 0.0146 & 1.709 & 334.8 & 0.0061 & 0.0992 & 0.106 & 0.061 & 0.5483 \\
\hline Average & & & & 12.49 & 0.0003 & 0.10415 & 0.01195 & 1.601 & 338.98 & 0.00735 & 0.0998 & 0.11895 & 0.062 & 0.4181 \\
\hline DV211MS & 9/13/94 & 21298 & M85 & 12.94 & 0.0002 & 0.1467 & 0.0156 & 1.924 & 326.66 & 0.0106 & 0.1209 & 0.1514 & 0.0665 & 0.7572 \\
\hline DV212MS & $8 / 2 / 94$ & 10896 & M85 & 12.73 & 0.0003 & 0.1558 & 0.0186 & 1.66 & 332.6 & 0.0112 & 0.097 & 0.5617 & 0.0418 & 0.1646 \\
\hline DV212MS & $8 / 3 / 94$ & 10922 & M85 & 12.5 & 0.0003 & 0.1269 & 0.0191 & 1.454 & 338.96 & 0.0114 & 0.1038 & 0.5164 & 0.0614 & ${ }^{*}$ \\
\hline Average & & & & 12.61 & 0.0003 & 0.14135 & 0.01885 & 1.555 & 335.77 & 0.0113 & 0.10045 & 0.53905 & 0.0516 & 0.1646 \\
\hline DV220MS & $12 / 6 / 94$ & 17369 & M85 & 12.94 & 0.0001 & 0.1204 & 0.0126 & 1.304 & 327.58 & 0.0102 & 0.1142 & 0.2737 & 0.0685 & 0.2527 \\
\hline DV227MS & $4 / 29 / 94$ & 5295 & M85 & 12.48 & 0.0003 & 0.074 & 0.01 & 1.079 & 340.15 & 0.0087 & 0.0796 & 0.2532 & 0.0524 & 0.2224 \\
\hline DV229MS & $7 / 21 / 94$ & 23103 & M85 & 12.72 & 0.0001 & 0.164 & 0.0176 & 1.969 & 332.16 & 0.0104 & 0.138 & 0.378 & 0.078 & 0.3542 \\
\hline DV229MS & $7 / 22 / 94$ & 23129 & M85 & 12.79 & 0.0001 & 0.2 & 0.0177 & 1.824 & 330.62 & 0.0122 & 0.14 & 0.369 & 0.064 & ${ }^{*}$ \\
\hline Average & & & & 12.76 & 0.0001 & 0.18205 & 0.01765 & 1.896 & 331.39 & 0.0113 & 0.13935 & 0.37355 & 0.0712 & 0.3542 \\
\hline DV230MS & $12 / 14 / 94$ & 19021 & M85 & 12.93 & 0.0001 & 0.1646 & 0.0157 & 2.240 & 326.25 & 0.0084 & 0.1363 & 0.2563 & 0.0755 & 0.3952 \\
\hline DV231MS & $7 / 14 / 94$ & 22041 & M85 & 12.72 & 0.0001 & 0.1786 & 0.0227 & 2.674 & 331.13 & 0.0125 & 0.124 & 0.1896 & 0.0618 & 0.2852 \\
\hline DV233MS & $6 / 21 / 94$ & 20380 & M85 & 12.67 & 0.0002 & 0.1537 & 0.0183 & 1.642 & 334.20 & 0.0133 & 0.0886 & 0.2928 & 0.0324 & 0.2673 \\
\hline DV242MS & $6 / 14 / 94$ & 4080 & M85 & 12.71 & 0.0002 & 0.1332 & 0.0125 & 1.095 & 333.79 & 0.0096 & 0.0926 & 0.1856 & 0.0416 & 0.4552 \\
\hline DV244MS & $9 / 9 / 94$ & 10055 & M85 & 12.89 & 0.0003 & 0.1424 & 0.0109 & 1.526 & 328.57 & 0.0072 & 0.1438 & 0.0955 & 0.0881 & 0.3572 \\
\hline DV246MS & $6 / 28 / 94$ & 8838 & M85 & 13.16 & 0.0001 & 0.1301 & 0.0158 & 1.235 & 322.18 & 0.0111 & 0.1133 & 0.2448 & 0.066 & 0.243 \\
\hline DV248MS & $7 / 22 / 94$ & 9292 & M85 & 12.67 & 0.0003 & 0.1468 & 0.02 & 2.13 & 333.35 & 0.0075 & 0.1105 & 0.1341 & 0.0619 & 0.4245 \\
\hline DV249MS & $2 / 2 / 95$ & 13241 & M85 & 12.88 & 0.0002 & 0.1314 & 0.0172 & 2.020 & 327.89 & 0.0073 & 0.1096 & 0.2481 & 0.0651 & 0.7784 \\
\hline DV251MS & $11 / 2 / 94$ & 24502 & M85 & 13.03 & 0.0001 & 0.1741 & 0.0103 & 1.961 & 324.13 & 0.011 & 0.1521 & 0.184 & 0.0804 & 0.2466 \\
\hline DV257MS & $10 / 25 / 94$ & 26058 & M85 & 12.9 & 0.0001 & 0.137 & 0.0079 & 1.431 & 328.34 & 0.0076 & 0.1156 & 0.1926 & 0.0595 & 0.2128 \\
\hline DV258MS & $12 / 1 / 94$ & 24187 & M85 & 13.13 & 0.0002 & 0.125 & 0.0132 & 1.702 & 322.18 & 0.0085 & 0.1208 & 0.2104 & 0.0749 & 0.6462 \\
\hline & COUNT & & & 22 & 22 & 22 & 20 & 21 & 22 & 21 & 21 & 20 & 21 & 22 \\
\hline & AVG & & & 12.78 & 0.00019 & 0.139 & 0.014 & 1.630 & 331.26 & 0.009 & 0.1123 & 0.207 & 0.061 & 0.3708 \\
\hline
\end{tabular}


Table A-12. 1993 FFV Dodge Spirit: RFG Tests at Lab 3 Round 1

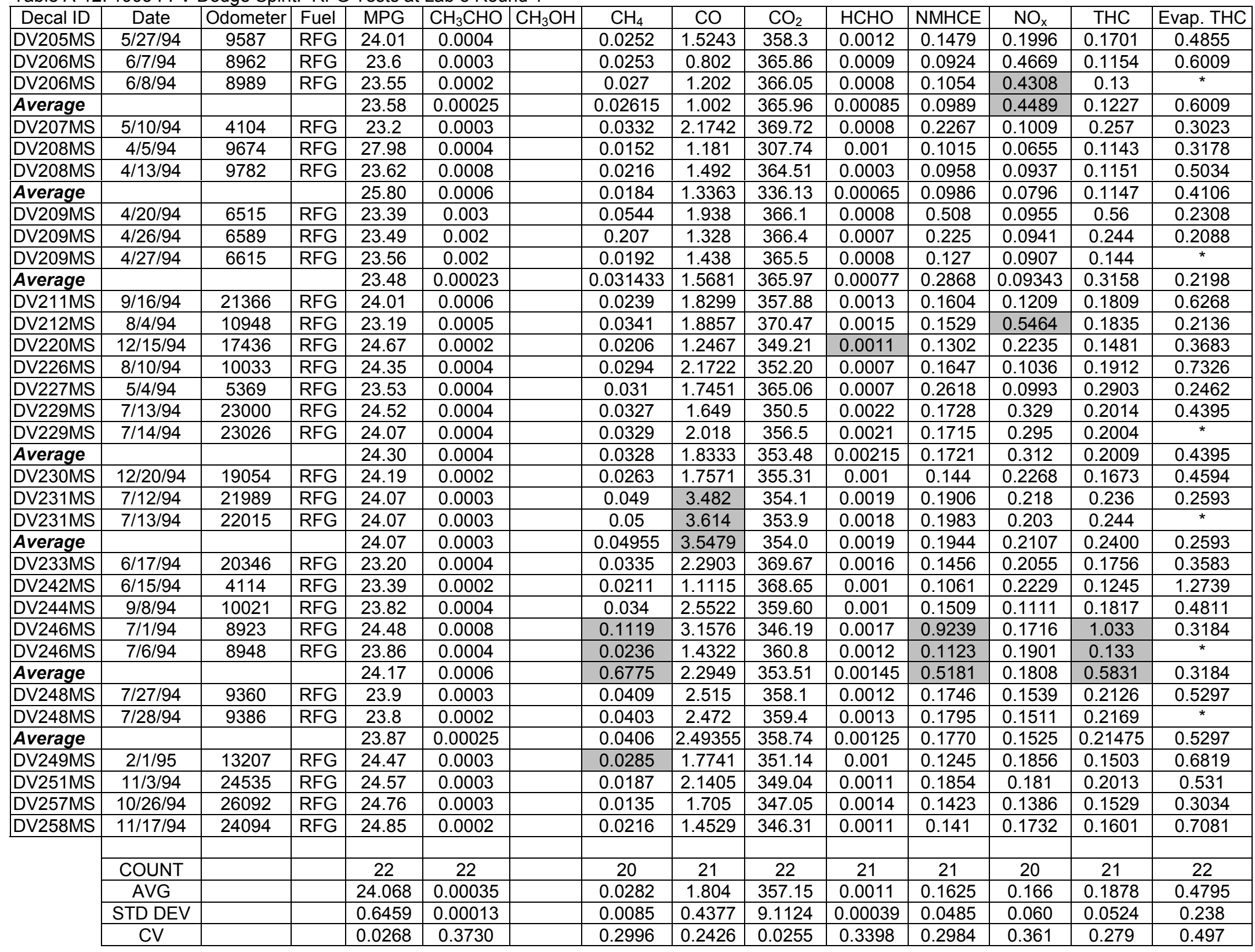


Table A-13. 1993 Standard Dodge Spirit: RFG Tests at Lab 1 Round 2

\begin{tabular}{|c|c|c|c|c|c|c|c|c|c|c|c|c|c|c|}
\hline Decal ID & Date & Odometer & Fuel & MPG & $\mathrm{CH}_{3} \mathrm{CHO}$ & $\mathrm{CH}_{3} \mathrm{OH}$ & $\mathrm{CH}_{4}$ & $\mathrm{CO}$ & $\mathrm{CO}_{2}$ & $\mathrm{HCHO}$ & NMHCE & $\mathrm{NO}_{\mathrm{x}}$ & $\mathrm{THC}$ & Evap. THC \\
\hline DT201GSC & $9 / 1 / 95$ & 49527 & RFG & 23.07 & 0.00029 & & 0.014 & 1.76 & 374.6 & 0.00133 & 0.071 & 0.38 & 0.083 & 0.227 \\
\hline DT202GSC & $8 / 23 / 95$ & 47024 & RFG & 23.59 & 0.00039 & & 0.019 & 2.19 & 365.4 & 0.00195 & 0.107 & 0.39 & 0.122 & 0.145 \\
\hline DT203GSC & $8 / 24 / 95$ & 24411 & RFG & 23.66 & 0.00032 & & 0.014 & 1.48 & 365.6 & 0.00145 & 0.066 & 0.29 & 0.077 & 0.233 \\
\hline DT204GSC & $3 / 21 / 95$ & 16373 & RFG & 24.18 & 0.00031 & & 0.011 & 1.07 & 360.1 & 0.00102 & 0.069 & 0.28 & 0.078 & 0.27 \\
\hline DT206GSC & $3 / 21 / 95$ & 15745 & RFG & 24.26 & 0.00033 & & 0.013 & 1.17 & 358.8 & 0.00108 & 0.071 & 0.23 & 0.081 & 0.227 \\
\hline \begin{tabular}{|l|} 
DT207GSC \\
\end{tabular} & $1 / 31 / 96$ & 61638 & RFG & 20.81 & 0.01024 & & 0.34 & 75.36 & 293.8 & 0.0102 & 1.767 & 0.39 & 2.06 & 0.258 \\
\hline DT207GSC & $2 / 1 / 96$ & 61638 & RFG & 21.27 & 0.0084 & & 0.296 & 67.14 & 298.2 & 0.00888 & 1.566 & 0.35 & 1.82 & 0.183 \\
\hline Average & & & & 21.04 & 0.00932 & & 0.318 & 71.25 & 296 & 0.00954 & 1.6665 & 0.37 & 1.94 & 0.157 \\
\hline DT208GSC & $12 / 22 / 94$ & 21005 & RFG & 24.32 & 0.00041 & & 0.015 & 1.18 & 357.7 & 0.00158 & 0.078 & 0.35 & 0.09 & 0.465 \\
\hline DT208GSC & $12 / 23 / 94$ & 21031 & RFG & 23.45 & 0.00036 & & 0.012 & 1.25 & 371.1 & 0.00132 & 0.07 & 0.31 & 0.081 & 0.31 \\
\hline Average & & & & 23.885 & 0.000385 & & 0.0135 & 1.215 & 364.4 & 0.00145 & 0.074 & 0.33 & 0.0855 & 0.3875 \\
\hline DT209GSC & $8 / 15 / 95$ & 25494 & RFG & 23.79 & 0.00025 & & 0.017 & 1.67 & 363.3 & 0.00135 & 0.091 & 0.32 & 0.104 & 0.147 \\
\hline DT210GSC & $4 / 5 / 95$ & 32837 & RFG & 22.73 & 0.00069 & & 0.026 & 2.43 & 380.7 & 0.00294 & 0.142 & 0.71 & 0.163 & 0.297 \\
\hline DT211GSC & $5 / 19 / 95$ & 14354 & RFG & 24.54 & 0.00026 & & 0.009 & 0.89 & 355.2 & 0.00115 & 0.06 & 0.2 & 0.067 & 0.211 \\
\hline DT212GSC & $5 / 25 / 95$ & 18101 & RFG & 24.31 & 0.00024 & & 0.013 & 1.55 & 355.7 & 0.00101 & 0.07 & 0.22 & 0.08 & 0.226 \\
\hline DT213GSC & $4 / 5 / 95$ & 10036 & RFG & 23.66 & 0.00032 & & 0.014 & 1.26 & 367.8 & 0.001 & 0.076 & 0.21 & 0.087 & 0.218 \\
\hline DT214GSC & $8 / 10 / 95$ & 32278 & RFG & 23.64 & 0.00033 & & 0.013 & 1.38 & 366.1 & 0.00186 & 0.072 & 0.42 & 0.082 & 0.184 \\
\hline DT215GSC & $3 / 29 / 95$ & 28083 & RFG & 23.76 & 0.00037 & & 0.015 & 1.47 & 365.9 & 0.00138 & 0.07 & 0.36 & 0.082 & 0.335 \\
\hline DT216GSC & $4 / 6 / 95$ & 27787 & RFG & 24.53 & 0.00044 & & 0.021 & 2 & 353.3 & 0.00164 & 0.1 & 0.3 & 0.116 & 0.291 \\
\hline DT217GSC & $4 / 12 / 95$ & 44023 & RFG & 23.9 & 0.00047 & & 0.018 & 2.07 & 362.6 & 0.00178 & 0.095 & 0.39 & 0.109 & 0.257 \\
\hline DT218GSC & $12 / 22 / 94$ & 20036 & RFG & 24.32 & 0.00032 & & 0.015 & 1.29 & 357.6 & 0.00132 & 0.074 & 0.035 & 0.086 & 0.249 \\
\hline DT218GSC & $12 / 23 / 94$ & 20062 & RFG & 24.58 & 0.00034 & & 0.013 & 1.22 & 354 & 0.00145 & 0.072 & 0.035 & 0.082 & 0.187 \\
\hline Average & & & & 24.45 & 0.00033 & & 0.014 & 1.255 & 355.8 & 0.001385 & 0.073 & 0.35 & 0.084 & 0.218 \\
\hline DT219GSC & $8 / 23 / 95$ & 32426 & RFG & 23.04 & 0.00025 & & 0.014 & 1.05 & 376.2 & 0.00126 & 0.085 & 0.36 & 0.096 & 0.286 \\
\hline DT221GSC & $8 / 16 / 95$ & 23507 & RFG & 22.02 & 0.00032 & & 0.022 & 2.53 & 391.4 & 0.00147 & 0.083 & 0.3 & 0.1 & 0.154 \\
\hline DT222GSC & $4 / 12 / 95$ & 34350 & RFG & 23.74 & 0.00042 & & 0.022 & 2.58 & 364.3 & 0.00127 & 0.097 & 0.33 & 0.114 & 0.288 \\
\hline DT223GSC & $12 / 22 / 94$ & 10667 & RFG & 23.85 & 0.00036 & & 0.015 & 1.18 & 365 & 0.00129 & 0.075 & 0.22 & 0.087 & 0.25 \\
\hline DT224GSC & $3 / 21 / 95$ & 39548 & RFG & 23.91 & 0.00042 & & 0.015 & 1.86 & 362.9 & 0.00146 & 0.083 & 0.33 & 0.096 & 0.28 \\
\hline DT225GSC & $5 / 15 / 95$ & 25452 & RFG & 24.45 & 0.00031 & & 0.019 & 1.54 & 355.3 & 0.00129 & 0.086 & 0.22 & 0.101 & 0.219 \\
\hline DT226GSC & $3 / 21 / 95$ & 13310 & RFG & 24.14 & 0.00035 & & 0.016 & 1.61 & 359.8 & 0.00117 & 0.083 & 0.25 & 0.095 & 0.327 \\
\hline & & & & & & & & & & & & & & \\
\hline & COUNT & & & 22 & 22 & & 22 & 22 & 21 & 22 & 22 & 22 & 22 & 22 \\
\hline & AVG & & & 23.83 & 0.00034 & & 0.0155 & 1.581 & 362.77 & 0.0014 & 0.0799 & 0.3036 & 0.0921 & 0.2446 \\
\hline & STD DEV & & & 0.5796 & 6.33E-05 & & 0.0034 & 0.466 & 6.0199 & 0.00026 & 0.012 & 0.0672 & 0.0143 & 0.0613 \\
\hline & CV & & & 0.0243 & 0.1864 & & 0.2201 & 0.2948 & 0.0166 & 0.1922 & 0.1526 & 0.2212 & 0.1558 & 0.2505 \\
\hline
\end{tabular}


Table A-14. 1993 FFV Dodge Spirit: M85 Tests at Lab 1 Round 2

\begin{tabular}{|c|c|c|c|c|c|c|c|c|c|c|c|c|c|c|}
\hline Decal ID & Date & Odometer & Fuel & MPG & $\mathrm{CH}_{3} \mathrm{CHO}$ & $\mathrm{CH}_{3} \mathrm{OH}$ & $\mathrm{CH}_{4}$ & $\mathrm{CO}$ & $\mathrm{CO}_{2}$ & $\mathrm{HCHO}$ & NMHCE & $\mathrm{NO}_{\mathrm{x}}$ & THC & Evap. THC \\
\hline AR206MS & $11 / 9 / 95$ & 10516 & M85 & 13.48 & 0.00011 & 0.1379 & 0.015 & 1.53 & 356.6 & 0.01001 & 0.095 & 0.28 & 0.102 & 0.399 \\
\hline AR209MS & $11 / 14 / 95$ & 13755 & M85 & 13.76 & 0.00016 & 0.1355 & 0.015 & 1.34 & 349.5 & 0.01026 & 0.092 & 0.12 & 0.1 & 0.957 \\
\hline AR212MS & $11 / 10 / 95$ & 12365 & M85 & 13.76 & 0.00014 & 0.1201 & 0.012 & 1.28 & 349.8 & 0.01182 & 0.085 & 0.39 & 0.089 & 0.419 \\
\hline DT203MS & $5 / 4 / 95$ & 9523 & M85 & 13.73 & 0.00018 & 0.1166 & 0.016 & 2.01 & 349.3 & 0.00826 & 0.097 & 0.06 & 0.106 & 1.177 \\
\hline DT208MS & $3 / 24 / 95$ & 23723 & M85 & 14.05 & 0.00019 & 0.1694 & 0.019 & 1.74 & 341.8 & 0.0122 & 0.122 & 0.26 & 0.131 & 1.578 \\
\hline DT211MS & $3 / 17 / 95$ & 8257 & M85 & 14.01 & 0.00016 & 0.1539 & 0.015 & 1.14 & 343.6 & 0.01133 & 0.092 & 0.21 & 0.099 & 0.823 \\
\hline DT212MS & $3 / 23 / 95$ & 8916 & M85 & 13.82 & 0.00016 & 0.1383 & 0.013 & 1.17 & 348.3 & 0.00989 & 0.091 & 0.18 & 0.097 & 0.711 \\
\hline DT219MS & $6 / 22 / 95$ & 29679 & M85 & 13.67 & 0.00023 & 0.1663 & 0.016 & 1.77 & 351.2 & 0.01729 & 0.113 & 0.13 & 0.118 & 0.784 \\
\hline DT221MS & $3 / 16 / 95$ & 22320 & M85 & 14.46 & 0.0002 & 0.1794 & 0.015 & 1.45 & 332.4 & 0.01269 & 0.104 & 0.13 & 0.11 & 0.444 \\
\hline DT223MS & $3 / 16 / 95$ & 26844 & M85 & 14.06 & 0.00022 & 0.1544 & 0.018 & 2.09 & 340.8 & 0.01355 & 0.117 & 0.08 & 0.125 & 0.877 \\
\hline DT225MS & $3 / 10 / 95$ & 18838 & M85 & 14.16 & 0.00027 & 0.167 & 0.015 & 1.64 & 339.1 & 0.01241 & 0.106 & 0.12 & 0.112 & 0.731 \\
\hline DT226MSC & $3 / 20 / 95$ & 26934 & M85 & 13.7 & 0.00024 & 0.1833 & 0.019 & 1.6 & 350.7 & 0.0154 & 0.115 & 0.35 & 0.123 & 1.019 \\
\hline DT229MS & $6 / 20 / 95$ & 17743 & M85 & 13.81 & 0.00022 & 0.1365 & 0.015 & 1.27 & 348.4 & 0.01385 & 0.097 & 0.2 & 0.103 & 0.451 \\
\hline DT230MS & $4 / 3 / 95$ & 8633 & M85 & 13.65 & 0.00018 & 0.1398 & 0.013 & 1.33 & 352.6 & 0.00888 & 0.086 & 0.07 & 0.092 & 0.508 \\
\hline DT233MS & $5 / 8 / 95$ & 9446 & M85 & 13.71 & 0.00016 & 0.1716 & 0.017 & 2.08 & 349.7 & 0.01085 & 0.116 & 0.04 & 0.124 & 0.809 \\
\hline DT238MS & $3 / 14 / 95$ & 27009 & M85 & 13.6 & 0.00028 & 0.2181 & 0.027 & 2.25 & 352.2 & 0.01674 & 0.142 & 0.33 & 0.155 & 1.24 \\
\hline DT241MS & $5 / 19 / 95$ & 9014 & M85 & 13.53 & 0.00018 & 0.0797 & 0.016 & 1.13 & 356.1 & 0.00791 & 0.076 & 0.17 & 0.085 & 0.484 \\
\hline DT245MS & $6 / 22 / 95$ & 7683 & M85 & 13.37 & 0.00015 & 0.1594 & 0.014 & 1.02 & 360.5 & 0.01325 & 0.096 & 0.24 & 0.101 & 0.774 \\
\hline DT250MS & $3 / 10 / 95$ & 21533 & M85 & 13.92 & 0.00025 & 0.1639 & 0.018 & 2.3 & 344.1 & 0.01318 & 0.111 & 0.18 & 0.119 & 0.658 \\
\hline DT251MSC & $6 / 20 / 95$ & 27849 & M85 & 13.5 & 0.00019 & 0.1804 & 0.019 & 1.95 & 355.4 & 0.01598 & 0.12 & 0.11 & 0.127 & 0.805 \\
\hline DT252MS & $3 / 16 / 95$ & 17953 & M85 & 14.01 & 0.00024 & 0.1711 & 0.017 & 1.81 & 342.6 & 0.01422 & 0.109 & 0.18 & 0.115 & 0.731 \\
\hline & COUNT & & & 21 & 21 & 21 & 20 & 21 & 19 & 21 & 21 & 21 & 21 & 21 \\
\hline & AVG & & & 13.798 & 0.00019 & 0.154 & 0.0159 & 1.6143 & 348.61 & 0.0124 & 0.1039 & 0.182 & 0.111 & 0.7799 \\
\hline & STD DEV & & & 0.2602 & 4.49E-05 & 0.0292 & 0.0020 & 0.3934 & 6.858 & 0.0027 & 0.0155 & 0.097 & 0.0166 & 0.2991 \\
\hline & $\mathrm{CV}$ & & & 0.0189 & 0.2294 & 0.1889 & 0.1299 & 0.2437 & 0.0197 & 0.2159 & 0.1489 & 0.534 & 0.149 & 0.3835 \\
\hline
\end{tabular}


Table A-15. 1993 FFV Dodge Spirit: RFG Tests at Lab 1 Round 2

\begin{tabular}{|c|c|c|c|c|c|c|c|c|c|c|c|c|c|c|}
\hline Decal ID & Date & Odometer & Fuel & MPG & $\mathrm{CH}_{3} \mathrm{CHO}$ & $\mathrm{CH}_{3} \mathrm{OH}$ & $\mathrm{CH}_{4}$ & $\mathrm{CO}$ & $\mathrm{CO}_{2}$ & $\mathrm{HCHO}$ & NMHCE & $\mathrm{NO}_{\mathrm{x}}$ & THC & Evap. THC \\
\hline AR206MS & $11 / 10 / 95$ & 10542 & RFG & 22.54 & 0.00019 & & 0.021 & 1.03 & 384.4 & 0.00087 & 0.11 & 0.68 & 0.127 & \begin{tabular}{|l|}
0.544 \\
\end{tabular} \\
\hline AR209MS & $11 / 10 / 95$ & 13729 & RFG & 22.71 & 0.00021 & & 0.029 & 0.97 & 381.6 & 0.001 & 0.098 & 0.49 & 0.121 & 0.297 \\
\hline AR212MS & $11 / 9 / 95$ & 12339 & RFG & 22.55 & 0.00034 & & 0.021 & 1.43 & 383.4 & 0.0017 & 0.119 & 0.54 & 0.136 & 0.214 \\
\hline DT203MS & $5 / 8 / 95$ & 9649 & RFG & 23.08 & 0.00034 & & 0.035 & 2.42 & 374.9 & 0.00118 & 0.165 & 0.09 & 0.193 & 1.113 \\
\hline DT208MS & $3 / 22 / 95$ & 23698 & RFG & 23.32 & 0.00044 & & 0.036 & 1.55 & 372.4 & 0.00146 & 0.125 & 0.24 & 0.153 & 1.859 \\
\hline DT211MS & $3 / 15 / 95$ & 8230 & RFG & 23.52 & 0.0004 & & 0.031 & 1.15 & 369.9 & 0.00119 & 0.118 & 0.33 & 0.143 & 0.559 \\
\hline DT212MS & $3 / 22 / 95$ & 8890 & RFG & 23.14 & 0.00036 & & 0.023 & 1.22 & 376 & 0.00108 & 0.115 & 0.11 & 0.133 & 1.365 \\
\hline DT219MS & $6 / 20 / 95$ & 29653 & RFG & 22.65 & 0.00045 & & 0.031 & 1.82 & 381.2 & 0.00201 & 0.154 & 0.11 & 0.179 & 0.64 \\
\hline DT223MS & $3 / 17 / 95$ & 26870 & RFG & 23.45 & 0.00048 & & 0.041 & 2.43 & 368.9 & 0.00147 & 0.178 & 0.11 & 0.21 & 1.838 \\
\hline DT225MS & $3 / 14 / 95$ & 18864 & RFG & 23.66 & 0.00051 & & 0.027 & 1.58 & 367.1 & 0.00142 & 0.126 & 0.12 & 0.148 & 0.845 \\
\hline DT226MSC & $3 / 17 / 95$ & 26907 & RFG & 23.18 & 0.00054 & & 0.038 & 2.47 & 373.2 & 0.00185 & 0.164 & 0.22 & 0.194 & 1.136 \\
\hline DT229MS & $6 / 21 / 95$ & 17754 & RFG & 22.09 & 0.00031 & & 0.028 & 1.17 & 392.1 & 0.00157 & 0.109 & 0.33 & 0.132 & 0.595 \\
\hline DT230MS & $5 / 16 / 95$ & 8776 & RFG & 22.6 & 0.00036 & & 0.044 & 2.43 & 382.9 & 0.00111 & 0.198 & 0.08 & 0.233 & 0.415 \\
\hline DT233MS & $5 / 5 / 95$ & 9420 & RFG & 23.13 & 0.00035 & & 0.051 & 3.1 & 372.8 & 0.00114 & 0.213 & 0.1 & 0.253 & 0.46 \\
\hline DT238MS & $3 / 10 / 95$ & 26976 & RFG & 22.89 & 0.00064 & & 0.049 & 3.06 & 376.8 & 0.00208 & 0.195 & 0.3 & 0.234 & 0.374 \\
\hline DT241MS & $5 / 22 / 95$ & 9041 & RFG & 23.06 & 0.00027 & & 0.026 & 1.56 & 376.7 & 0.00128 & 0.115 & 0.1 & 0.135 & 1.475 \\
\hline DT245MS & $6 / 20 / 95$ & 7672 & RFG & 22.49 & 0.00027 & & 0.021 & 1.1 & 385.2 & 0.00136 & 0.114 & 0.11 & 0.131 & 1.495 \\
\hline DT251MSC & $6 / 21 / 95$ & 27875 & RFG & 21.89 & 0.00037 & & 0.037 & 2.56 & 393.3 & 0.00212 & 0.184 & 0.12 & 0.213 & 0.799 \\
\hline DT252MS & $3 / 15 / 95$ & 17927 & RFG & 23.72 & 0.00051 & & 0.037 & 2.11 & 365.2 & 0.00154 & 0.152 & 0.15 & 0.181 & 1.06 \\
\hline & & & & & & & & & & & & & & \\
\hline & COUNT & & & 21 & 21 & & 20 & 21 & 19 & 21 & 21 & 21 & 21 & 21 \\
\hline & AVG & & & 23.019 & 0.00039 & & 0.0315 & 1.811 & 376.79 & 0.0014 & 0.1423 & 0.219 & 0.1679 & 0.8867 \\
\hline & STD DEV & & & 0.572 & 0.00011 & & 0.0082 & 0.673 & 9.183 & 0.00036 & 0.0349 & 0.169 & 0.041 & 0.5075 \\
\hline & CV & & & 0.0248 & 0.285 & & 0.2611 & 0.372 & 0.0244 & 0.249 & 0.2457 & 0.771 & 0.246 & 0.572 \\
\hline
\end{tabular}


Table A-16. 1993 Standard Dodge Spirit: RFG Tests at Lab 3 Round 2

\begin{tabular}{|c|c|c|c|c|c|c|c|c|c|c|c|c|c|c|}
\hline Decal ID & Date & Odometer & Fuel & MPG & $\mathrm{CH}_{3} \mathrm{CHO}$ & $\mathrm{CH}_{3} \mathrm{OH}$ & $\mathrm{CH}_{4}$ & $\mathrm{CO}$ & $\mathrm{CO}_{2}$ & $\mathrm{HCHO}$ & NMHCE & $\mathrm{NO}_{\mathrm{x}}$ & $\mathrm{THC}$ & Evap. THC \\
\hline DV201GSC & $10 / 17 / 95$ & 45797 & RFG & 24.89 & 0.0004 & & 0.0112 & 2.013 & 344.98 & 0.0013 & 0.0913 & 0.5262 & 0.1022 & 0.3627 \\
\hline DV203GSC & $2 / 9 / 96$ & 32081 & RFG & 25.28 & 0.0003 & & 0.0073 & 1.5135 & 340.50 & 0.001 & 0.0648 & 0.3923 & 0.072 & 0.2032 \\
\hline DV204GSC & $2 / 13 / 96$ & 28431 & RFG & 25.2 & 0.0003 & & 0.012 & 2.1882 & 340.48 & 0.0011 & 0.0827 & 0.4545 & 0.0947 & 0.2684 \\
\hline DV205GSC & $2 / 9 / 96$ & 21702 & RFG & 23.76 & 0.0002 & & 0.0097 & 1.7265 & 362.07 & 0.0012 & 0.0736 & 0.3397 & 0.0833 & 0.3773 \\
\hline DV208GSC & $2 / 7 / 96$ & 35723 & RFG & 25.28 & 0.0003 & & 0.0117 & 2.3536 & 338.982 & 0.001 & 0.1051 & 0.4782 & 0.1168 & 0.4553 \\
\hline DV209GSC & 9/29/95 & 32665 & RFG & 25.62 & 0.0003 & & 0.0118 & 1.6075 & 335.77 & 0.0011 & 0.078 & 0.448 & 0.0894 & 0.1986 \\
\hline DV211GSC & $10 / 30 / 95$ & 28969 & RFG & 26.51 & 0.0004 & & 0.0092 & 1.4337 & 324.71 & 0.0008 & 0.0812 & 0.3023 & 0.09 & 0.1705 \\
\hline DV212GSC & $2 / 23 / 95$ & 9467 & RFG & 24.58 & 0.0001 & & 0.0493 & 1.4733 & 350.39 & 0.0007 & 0.0708 & 0.3442 & 0.0758 & 0.2235 \\
\hline DV213GSC & $8 / 26 / 94$ & 17661 & RFG & 25.2 & 0.0004 & & 0.0136 & 2.0124 & 340.76 & 0.0009 & 0.0915 & 0.4202 & 0.102 & 0.2106 \\
\hline DV213GSC & $8 / 30 / 94$ & 17691 & RFG & 26.42 & 0.0006 & & 0.0108 & 1.417 & 325.84 & 0.0018 & 0.0803 & 0.3696 & 0.0874 & 0.7326 \\
\hline Average & & & & 25.81 & 0.0005 & & 0.0122 & 1.7148 & 333.30 & 0.00135 & 0.0825 & 0.3949 & 0.0947 & 0.4716 \\
\hline DV214GSC & $10 / 25 / 95$ & 21216 & RFG & 25.77 & 0.0005 & & 0.006 & 1.6136 & 333.71 & 0.0008 & 0.0827 & 0.3934 & 0.0883 & 0.2307 \\
\hline DV215GSC & $2 / 15 / 96$ & 24493 & RFG & 26.10 & 0.0003 & & 0.0102 & 1.6307 & 329.51 & 0.0011 & 0.088 & 0.3665 & 0.0984 & 0.2671 \\
\hline DV216GSC & $11 / 22 / 95$ & 21344 & RFG & 26.02 & 0.0004 & & 0.0143 & 1.9511 & 329.99 & 0.0012 & 0.0785 & 0.4264 & 0.0926 & 0.1983 \\
\hline DV217GSC & $10 / 4 / 95$ & 41567 & RFG & 25.91 & 0.0004 & & 0.0161 & 2.4568 & 330.56 & 0.001 & 0.0894 & 0.5074 & 0.1052 & 0.1835 \\
\hline DV219GSC & $11 / 28 / 95$ & 47989 & RFG & 24.59 & 0.0004 & & 0.0116 & 1.4986 & 350.088 & 0.0013 & 0.0723 & 0.5618 & 0.0835 & 0.1198 \\
\hline DV220GSC & $2 / 16 / 96$ & 22416 & RFG & 23.57 & 0.0002 & & 0.0064 & 1.5785 & 365.33 & 0.0007 & 0.064 & 0.352 & 0.0703 & 0.2559 \\
\hline DV221GSC & $2 / 7 / 96$ & 28027 & RFG & 23.43 & 0.0003 & & 0.0097 & 1.4518 & 367.61 & 0.0011 & 0.0638 & 0.7279 & 0.0737 & 2.0176 \\
\hline DV223GSC & $10 / 12 / 95$ & 33618 & RFG & 23.59 & 0.0005 & & 0.0096 & 1.7672 & 364.66 & 0.001 & 0.0721 & 0.6602 & 0.0812 & 0.4284 \\
\hline DV224GSC & $9 / 12 / 95$ & 38148 & RFG & 24.71 & 0.0003 & & 0.0146 & 1.7943 & 347.89 & 0.0011 & 0.0867 & 0.3192 & 0.1013 & 0.1949 \\
\hline DV226GSC & $2 / 20 / 96$ & 13090 & RFG & 25.47 & 0.0002 & & 0.0074 & 1.3653 & 338.10 & 0.0009 & 0.0789 & 0.4972 & 0.0864 & 0.2931 \\
\hline & COUNT & & & 20 & 20 & & 19 & 20 & 20 & 20 & 20 & 20 & 20 & 20 \\
\hline & AVG & & & 25.099 & 0.00033 & & 0.0104 & 1.732 & 343.06 & 0.001 & 0.079 & 0.444 & 0.089 & 0.3623 \\
\hline & STD DEV & & & 0.9299 & 0.00011 & & 0.0028 & 0.3108 & 13.185 & 0.0002 & 0.0102 & 0.1118 & 0.012 & 0.402 \\
\hline & $\mathrm{CV}$ & & & 0.037 & 0.3275 & & 0.2678 & 0.1794 & 0.038 & 0.1904 & 0.129 & 0.2516 & 0.1347 & 1.1096 \\
\hline
\end{tabular}


Table A-17. 1993 FFV Dodge Spirit: M85 Tests at Lab 3 Round 2

\begin{tabular}{|c|c|c|c|c|c|c|c|c|c|c|c|c|c|c|}
\hline Decal ID & Date & Odometer & Fuel & MPG & $\mathrm{CH}_{3} \mathrm{CHO}$ & $\mathrm{CH}_{3} \mathrm{OH}$ & $\mathrm{CH}_{4}$ & $\mathrm{CO}$ & $\mathrm{CO}_{2}$ & $\mathrm{HCHO}$ & NMHCE & $\mathrm{NO}_{\mathrm{x}}$ & $\mathrm{THC}$ & Evap. THC \\
\hline DV205MS & 10/18/95 & 20922 & M85 & 14.94 & 0.0005 & 0.1758 & 0.0152 & 2.0845 & 328.57 & 0.0115 & 0.1429 & 0.4377 & 0.0747 & 1.2286 \\
\hline DV206MS & $12 / 5 / 95$ & 15864 & M85 & 14.68 & 0.0003 & 0.1899 & 0.0152 & 2.7763 & 333.43 & 0.0097 & 0.1368 & 0.1825 & 0.063 & 0.5508 \\
\hline DV207MS & $10 / 3 / 95$ & 26750 & M85 & 13.24 & 0.0003 & 0.2457 & 0.0213 & 2.7213 & 317.91 & 0.0121 & 0.1629 & 0.1344 & 0.0703 & 3.3838 \\
\hline DV208MS & $10 / 24 / 95$ & 22635 & M85 & 14.86 & 0.0004 & 0.1377 & 0.0072 & 1.5443 & 331.17 & 0.0088 & 0.1037 & 0.0963 & 0.046 & 0.5554 \\
\hline DV209MS & $10 / 11 / 95$ & 33179 & M85 & 14.28 & 0.0004 & 0.1801 & 0.0123 & 1.7827 & 344.30 & 0.0113 & 0.1312 & 0.1507 & 0.0581 & 1.8408 \\
\hline DV211MS & $12 / 7 / 95$ & 29850 & M85 & 14.66 & 0.0001 & 0.1673 & 0.0133 & 1.5714 & 335.79 & 0.0121 & 0.1269 & 0.229 & 0.0599 & 5.6498 \\
\hline DV212MS & $11 / 14 / 95$ & 17920 & M85 & 15.15 & 0.0003 & 0.1645 & 0.0161 & 1.4523 & 324.88 & 0.0141 & 0.132 & 0.5411 & 0.0687 & 0.341 \\
\hline DV220MS & $12 / 21 / 95$ & 24371 & M85 & 15.47 & 0.0002 & 0.2242 & 0.014 & 1.8115 & 317.70 & 0.0097 & 0.1303 & 0.1361 & 0.041 & 0.2556 \\
\hline DV226MS & $12 / 6 / 95$ & 16717 & M85 & 15.08 & 0.0005 & 0.1711 & 0.0147 & 2.5551 & 324.85 & 0.0081 & 0.1227 & 0.2012 & 0.0575 & 0.6656 \\
\hline DV227MS & $11 / 15 / 95$ & 18738 & M85 & 15.32 & 0.0003 & 0.0554 & 0.0134 & 1.3521 & 321.50 & 0.0078 & 0.0893 & 0.4285 & 0.0739 & 0.5787 \\
\hline DV229MS & 10/19/95 & 34407 & M85 & 14.05 & 0.0004 & 0.1416 & 0.0158 & 2.2514 & 349.34 & 0.0131 & 0.1443 & 0.4386 & 0.0908 & 0.3792 \\
\hline DV230MS & $12 / 18 / 95$ & 23075 & M85 & 14.27 & 0.0002 & 0.1763 & 0.0151 & 2.0679 & 344.19 & 0.0095 & 0.1243 & 0.3165 & 0.0571 & 0.7603 \\
\hline DV231MS & $8 / 17 / 95$ & 35780 & M85 & 12.81 & 0.0002 & 0.1809 & 0.0226 & 3.4275 & 327.51 & 0.0109 & 0.1466 & 0.2736 & 0.0841 & 0.4278 \\
\hline DV233MS & $8 / 22 / 95$ & 38506 & M85 & 11.72 & 0.0002 & 0.1581 & 0.0184 & 2.5778 & 359.86 & 0.0154 & 0.0931 & 0.3726 & 0.0343 & 0.2211 \\
\hline DV242MS & 2/8/95 & 8746 & M85 & 12.76 & 0.0001 & 0.1224 & 0.0137 & 1.1271 & 332.43 & 0.0069 & 0.0997 & 0.2761 & 0.0556 & 0.737 \\
\hline DV244MS & $11 / 16 / 95$ & 18290 & M85 & 15.38 & 0.0003 & 0.2023 & 0.012 & 1.9702 & 319.21 & 0.0117 & 0.1259 & 0.126 & 0.0434 & 0.4081 \\
\hline DV246MS & $12 / 13 / 95$ & 14491 & M85 & 15.26 & 0.0002 & 0.2064 & 0.0134 & 1.7786 & 322.08 & 0.009 & 0.1242 & 0.1716 & 0.0424 & 5.8978 \\
\hline DV248MS & $11 / 7 / 95$ & 18349 & M85 & 15.57 & 0.0003 & 0.184 & 0.0162 & 2.0714 & 315.27 & 0.0094 & 0.1234 & 0.1469 & 0.054 & 0.5876 \\
\hline DV249MS & $11 / 28 / 95$ & 20873 & M85 & 15.03 & 0.0003 & 0.2064 & 0.0143 & 2.1499 & 326.57 & 0.0119 & 0.1266 & 0.2586 & 0.0445 & 0.7706 \\
\hline DV251MS & $12 / 1 / 95$ & 29497 & M85 & 15.64 & 0.0004 & 0.1981 & 0.017 & 2.3808 & 313.25 & 0.009 & 0.1506 & 0.228 & 0.0753 & 0.3673 \\
\hline DV257MS & $2 / 21 / 96$ & 34214 & M85 & 13.97 & 0.0002 & 0.21 & 0.01 & 1.851 & 352.09 & 0.0061 & 0.1414 & 0.1951 & 0.0556 & 0.1305 \\
\hline DV258MS & $2 / 28 / 96$ & 30096 & M85 & 14.01 & 0.0002 & 0.1763 & 0.0129 & 1.6333 & 351.24 & 0.0108 & 0.1321 & 0.4119 & 0.0616 & 0.8146 \\
\hline & & & & & & & & & & & & & & \\
\hline & COUNT & & & 22 & 22 & 22 & 20 & 21 & 22 & 21 & 21 & 20 & 21 & 22 \\
\hline & AVG & & & 14.46 & 0.00029 & 0.176 & 0.015 & 1.977 & 331.51 & 0.0104 & 0.1279 & 0.251 & 0.0604 & 1.2069 \\
\hline & STD DEV & & & 1.042 & 0.00011 & 0.039 & 0.0035 & 0.4562 & 13.33 & 0.0023 & 0.0188 & 0.1142 & 0.0145 & 1.6329 \\
\hline & CV & & & 0.072 & 0.3929 & 0.2226 & 0.235 & 0.231 & 0.040 & 0.224 & 0.1467 & 0.4542 & 0.2394 & 1.353 \\
\hline
\end{tabular}


Table A-18. 1993 FFV Dodge Spirit: RFG Tests at Lab 3 Round 2

\begin{tabular}{|c|c|c|c|c|c|c|c|c|c|c|c|c|c|c|}
\hline Decal ID & Date & Odometer & Fuel & MPG & $\mathrm{CH}_{3} \mathrm{CHO}$ & $\mathrm{CH}_{3} \mathrm{OH}$ & $\mathrm{CH}_{4}$ & $\mathrm{CO}$ & $\mathrm{CO}_{2}$ & $\mathrm{HCHO}$ & NMHCE & $\mathrm{NO}_{\mathrm{x}}$ & THC & Evap. THC \\
\hline DV205MS & $10 / 17 / 95$ & 20896 & RFG & 23.93 & \begin{tabular}{|l|}
0.0008 \\
\end{tabular} & & 0.0414 & 2.719 & 356.77 & 0.0028 & 0.4036 & 0.3213 & 0.4431 & 3.7161 \\
\hline DV206MS & $8 / 17 / 94$ & 9955 & RFG & 22.81 & 0.0004 & & 0.0297 & 1.035 & 378.1 & 0.0008 & 0.1214 & 0.4946 & 0.1486 & 0.3113 \\
\hline DV206MS & $8 / 19 / 94$ & 9988 & RFG & 23.39 & 0.0003 & & 0.0311 & 1.325 & 368.3 & 0.0053 & 0.1169 & 0.5275 & 0.1433 & * \\
\hline Average & & & & 23.10 & 0.00035 & & 0.0304 & 1.1798 & 373.22 & 0.00305 & 0.11555 & 0.511 & 0.14595 & 0.3113 \\
\hline DV207MS & $10 / 5 / 95$ & 26776 & RFG & 24.65 & 0.0006 & & 0.0494 & 3.882 & 344.96 & 0.0017 & 0.1969 & 0.201 & 0.2459 & 3.9389 \\
\hline DV208MS & $10 / 26 / 95$ & 22617 & RFG & 23.45 & 0.0006 & & 0.0324 & 3.0928 & 364.49 & 0.001 & 0.1423 & 0.0885 & 0.1744 & 0.4175 \\
\hline DV209MS & $10 / 12 / 95$ & 33205 & RFG & 22.94 & 0.0006 & & 0.0441 & 2.7913 & 372.12 & 0.0016 & 0.4551 & 0.1675 & 0.4974 & 2.457 \\
\hline DV211MS & $12 / 8 / 95$ & 29876 & RFG & 23.46 & 0.0004 & & 0.0211 & 1.7054 & 366.62 & 0.0016 & 0.1319 & 0.2056 & 0.1525 & 1.7463 \\
\hline DV212MS & $11 / 10 / 95$ & 17887 & RFG & 24.44 & 0.0004 & & 0.0335 & 2.3053 & 350.74 & 0.0014 & 0.1408 & 0.6689 & 0.1738 & 0.3784 \\
\hline DV220MS & $12 / 20 / 95$ & 24344 & RFG & 26.79 & 0.0003 & & 0.0183 & 1.9599 & 320.35 & 0.0054 & 0.1013 & 0.1539 & 0.1193 & 0.2984 \\
\hline DV226MS & $12 / 5 / 95$ & 16691 & RFG & 24.92 & 0.0004 & & 0.0208 & 1.9311 & 344.49 & 0.0012 & 0.1455 & 0.1651 & 0.1657 & 0.6651 \\
\hline DV227MS & $11 / 14 / 95$ & 18711 & RFG & 24.73 & 0.0005 & & 0.0177 & 1.5921 & 347.82 & 0.0014 & 0.1159 & 0.1932 & 0.133 & 0.7363 \\
\hline DV229MS & $10 / 20 / 95$ & 34433 & RFG & 22.87 & 0.0006 & & 0.0285 & 1.8772 & 375.74 & 0.0022 & 0.1569 & 0.5304 & 0.1848 & 0.4242 \\
\hline DV230MS & $12 / 13 / 95$ & 23038 & RFG & 23.39 & 0.0005 & & 0.0303 & 1.9915 & 367.18 & 0.0015 & 0.1199 & 0.4944 & 0.1497 & 0.8017 \\
\hline DV231MS & $8 / 16 / 95$ & 35753 & RFG & 23.79 & 0.0004 & & 0.0458 & 4.264 & 357.23 & 0.0015 & 0.1622 & 0.2857 & 0.2077 & 0.3921 \\
\hline DV233MS & $8 / 23 / 95$ & 38355 & RFG & 21.90 & 0.0003 & & 0.0491 & 2.598 & 390.71 & 0.0026 & 0.3526 & 0.3757 & 0.4001 & 0.3034 \\
\hline DV242MS & $2 / 10 / 95$ & 8791 & RFG & 24.22 & 0.0002 & & 0.0233 & 1.381 & 355.47 & 0.0011 & 0.1464 & 0.1887 & 0.1425 & 0.7806 \\
\hline DV244MS & $11 / 17 / 95$ & 18316 & RFG & 25.01 & 0.0005 & & 0.0325 & 2.6644 & 342.05 & 0.0014 & 0.1768 & 0.1394 & 0.2087 & 0.4404 \\
\hline DV246MS & $12 / 12 / 95$ & 14465 & RFG & 24.16 & 0.0004 & & 0.0277 & 1.5717 & 355.76 & 0.0011 & 0.2499 & 0.1763 & 0.274 & 2.7281 \\
\hline DV248MS & $11 / 8 / 95$ & 18375 & RFG & 25.15 & 0.0005 & & 0.0253 & 1.6251 & 341.81 & 0.0014 & 0.1466 & 0.1951 & 0.1716 & 0.7037 \\
\hline DV249MS & $11 / 29 / 95$ & 20900 & RFG & 24.66 & 0.0006 & & 0.1848 & 1.7495 & 348.13 & 0.002 & 0.1064 & 0.2091 & 0.2926 & 0.5954 \\
\hline DV251MS & $11 / 30 / 95$ & 29470 & RFG & 25.13 & 0.0005 & & 0.0316 & 2.2323 & 340.75 & 0.0015 & 0.2626 & 0.1661 & 0.2926 & 0.3436 \\
\hline DV257MS & $2 / 20 / 96$ & 34188 & RFG & 22.61 & 0.0004 & & 0.0187 & 2.0275 & 379.95 & 0.0011 & 0.1464 & 0.1484 & 0.1654 & 0.5861 \\
\hline DV258MS & $2 / 29 / 96$ & 30122 & RFG & 22.78 & 0.0004 & & 0.0187 & 1.4266 & 378.05 & 0.0011 & 0.1285 & 0.3244 & 0.1473 & 0.7097 \\
\hline & COUNT & & & 22 & 22 & & 20 & 21 & 22 & 21 & 21 & 20 & 21 & 22 \\
\hline & AVG & & & 24.004 & 0.00047 & & 0.0306 & 2.11 & 357.93 & 0.0016 & 0.1835 & 0.236 & 0.2197 & 1.0670 \\
\hline & STD DEV & & & 1.111 & 0.00013 & & 0.0105 & 0.656 & 16.549 & 0.0005 & 0.0998 & 0.1176 & 0.1068 & 1.112 \\
\hline & $\mathrm{CV}$ & & & 0.0463 & 0.287 & & 0.3443 & 0.3112 & 0.046 & 0.3565 & 0.5437 & 0.497 & 0.4863 & 1.0424 \\
\hline
\end{tabular}


Table A-19. 1994-95 Standard Ford Taurus: RFG Tests at Lab 1 Round 1

\begin{tabular}{|c|c|c|c|c|c|c|c|c|c|c|c|c|c|c|}
\hline Decal ID & Date & Odometer & Fuel & MPG & $\mathrm{CH}_{3} \mathrm{CHO}$ & $\mathrm{CH}_{4}$ & $\mathrm{CO}$ & $\mathrm{CO}_{2}$ & ETOH & $\mathrm{HCHO}$ & NMHCE & $\mathrm{NO}_{\mathrm{x}}$ & THC & Evap. THC \\
\hline AR304GTC & $7 / 11 / 95$ & 3027 & RFG & 20.31 & 0.00023 & 0.011 & 0.8 & 427.4 & & 0.00099 & 0.063 & 0.21 & 0.071 & 0.203 \\
\hline AR305GTC & $11 / 2 / 95$ & 12822 & RFG & 20.42 & 0.00023 & 0.012 & 1.14 & 424.3 & & 0.00108 & 0.09 & 0.13 & 0.099 & 0.236 \\
\hline AR306GTC & $12 / 12 / 95$ & 5195 & RFG & 19.8 & 0.00029 & 0.016 & 1.62 & 436.9 & & 0.00084 & 0.117 & 0.15 & 0.13 & 0.334 \\
\hline AR307GTC & $12 / 15 / 95$ & 4767 & RFG & 20.18 & 0.00025 & 0.014 & 1.13 & 429.4 & & 0.00092 & 0.101 & 0.08 & 0.112 & 0.298 \\
\hline AR308GTC & 12/13/95 & 4884 & RFG & 20.06 & 0.00025 & 0.012 & 1.39 & 431.7 & & 0.00078 & 0.095 & 0.16 & 0.105 & 0.432 \\
\hline AR310GTC & $12 / 18 / 95$ & 5273 & RFG & 20.24 & 0.00026 & 0.014 & 1.56 & 427.4 & & 0.00091 & 0.117 & 0.1 & 0.129 & 0.249 \\
\hline AR313GTC & $2 / 19 / 96$ & 3176 & RFG & 20.42 & 0.00022 & 0.012 & 1.3 & 424.1 & & 0.00078 & 0.084 & 0.13 & 0.093 & 0.179 \\
\hline DT301GTC & $8 / 11 / 95$ & 3403 & RFG & 19.95 & 0.00029 & 0.011 & 0.82 & 435.2 & & 0.001 & 0.073 & 0.13 & 0.082 & 0.215 \\
\hline DT302GTC & 9/28/95 & 3359 & RFG & 20.13 & 0.00026 & 0.012 & 0.94 & 430.9 & & 0.0011 & 0.082 & 0.09 & 0.091 & 0.309 \\
\hline DT303GTC & $10 / 25 / 95$ & 4157 & RFG & 20.35 & 0.00018 & 0.01 & 0.74 & 426.6 & & 0.0009 & 0.064 & 0.15 & 0.072 & 0.23 \\
\hline DT304GTC & $10 / 25 / 95$ & 5601 & RFG & 20.19 & 0.00022 & 0.011 & 0.97 & 429.5 & & 0.00096 & 0.083 & 0.09 & 0.091 & 0.239 \\
\hline DT305GTC & $10 / 25 / 95$ & 4060 & RFG & 20.34 & 0.00024 & 0.009 & 0.79 & 426.6 & & 0.00098 & 0.079 & 0.11 & 0.086 & 0.182 \\
\hline DT306GTC & $11 / 10 / 95$ & 3775 & RFG & 20.17 & 0.00019 & 0.013 & 0.96 & 429.9 & & 0.00071 & 0.096 & 0.06 & 0.106 & 0.186 \\
\hline DT308GTC & $12 / 21 / 95$ & 3929 & RFG & 20.2 & 0.00026 & 0.014 & 1.51 & 428.5 & & 0.00086 & 0.098 & 0.08 & 0.109 & 0.276 \\
\hline DT311GTC & $1 / 26 / 96$ & 5076 & RFG & 19.98 & 0.0002 & 0.011 & 1.07 & 434 & & 0.00066 & 0.075 & 0.14 & 0.084 & 0.316 \\
\hline DT314GTC & $2 / 13 / 96$ & 5241 & RFG & 19.95 & 0.00025 & 0.014 & 1.48 & 433.9 & & 0.00086 & 0.101 & 0.11 & 0.112 & 0.218 \\
\hline & & & & & & & & & & & & & & \\
\hline & AVG & & & $\frac{16}{20.168}$ & $\begin{array}{c}16 \\
0.00024\end{array}$ & $\begin{array}{c}16 \\
0.0123\end{array}$ & $\frac{16}{1139}$ & $\frac{16}{42977}$ & & $\frac{16}{0.0009}$ & $\frac{16}{0.0886}$ & $\frac{16}{0.12}$ & $\begin{array}{c}16 \\
0.098\end{array}$ & $\begin{array}{c}16 \\
02564\end{array}$ \\
\hline & STD DEV & & & 0.1818 & 0.00003 & 0.0018 & 0.3005 & 3.7905 & & 0.00012 & 0.0163 & 0.0378 & 0.0178 & 0.0679 \\
\hline & $\mathrm{CV}$ & & & 0.009 & 0.1332 & 0.1475 & 0.2638 & 0.0088 & & 0.1382 & 0.1839 & 0.315 & 0.1808 & 0.265 \\
\hline
\end{tabular}

Table A-20. 1994-95 FFV Ford Taurus: E85 Tests at Lab 1 Round 1

\begin{tabular}{|c|c|c|c|c|c|c|c|c|c|c|c|c|c|c|}
\hline Decal ID & Date & Odometer & Fuel & MPG & $\mathrm{CH}_{3} \mathrm{CHO}$ & $\mathrm{CH}_{4}$ & $\mathrm{CO}$ & $\mathrm{CO}_{2}$ & ETOH & $\mathrm{HCHO}$ & NMHCE & $\mathrm{NO}_{\mathrm{x}}$ & THC & Evap. THC \\
\hline AR309ET & $3 / 30 / 95$ & 6483 & E85 & 14.82 & 0.01012 & 0.025 & 1.43 & 416.1 & 0.0749 & 0.00174 & 0.086 & 0.1 & 0.1 & 0.289 \\
\hline AR310ET & $3 / 29 / 95$ & 7363 & E85 & 15.5 & 0.01281 & 0.032 & 1.29 & 397.9 & 0.0815 & 0.00221 & 0.098 & 0.11 & 0.115 & 0.397 \\
\hline AR314ET & $5 / 2 / 95$ & 4295 & E85 & 15.45 & 0.00901 & 0.027 & 1.04 & 399.5 & 0.0593 & 0.00173 & 0.097 & 0.09 & 0.113 & 0.411 \\
\hline AR315ET & $5 / 4 / 95$ & 10253 & E85 & 15.06 & 0.00935 & 0.028 & 1.31 & 409.4 & 0.0703 & 0.00204 & 0.104 & 0.11 & 0.12 & 0.369 \\
\hline AR316ET & $5 / 1 / 95$ & 8561 & E85 & 15.16 & 0.00987 & 0.031 & 1.33 & 406.9 & 0.0708 & 0.00232 & 0.094 & 0.09 & 0.112 & 0.386 \\
\hline AR317ET & $5 / 25 / 95$ & 3067 & E85 & 15.08 & 0.00627 & 0.021 & 1.01 & 409.4 & 0.0512 & 0.00204 & 0.076 & 0.13 & 0.089 & 0.271 \\
\hline AR318ET & $5 / 15 / 95$ & 3077 & E85 & 15.1 & 0.00934 & 0.02 & 1.12 & 408.7 & 0.088 & 0.00209 & 0.101 & 0.08 & 0.111 & 0.308 \\
\hline AR319ET & $5 / 16 / 95$ & 3836 & E85 & 15.24 & 0.00859 & 0.023 & 1.12 & 404.9 & 0.0655 & 0.00171 & 0.095 & 0.1 & 0.108 & 0.531 \\
\hline AR320ET & $5 / 25 / 95$ & 3076 & E85 & 15.36 & 0.00859 & 0.024 & 1.21 & 401.6 & 0.0577 & 0.00156 & 0.086 & 0.08 & 0.1 & 0.325 \\
\hline AR321ET & $5 / 17 / 95$ & 3316 & E85 & 15.36 & 0.00892 & 0.024 & 1.13 & 401.7 & 0.0666 & 0.00173 & 0.083 & 0.07 & 0.093 & 0.337 \\
\hline \begin{tabular}{|l} 
AR322ET \\
\end{tabular} & $6 / 22 / 95$ & 3217 & E85 & 15.4 & 0.00885 & 0.029 & 1.41 & 400.3 & 0.0768 & 0.00244 & 0.088 & 0.13 & 0.105 & 0.242 \\
\hline AR323ET & $7 / 14 / 95$ & 7688 & E85 & 15.29 & 0.00763 & 0.022 & 0.88 & 404.2 & 0.0626 & 0.00248 & 0.071 & 0.12 & 0.084 & 0.201 \\
\hline AR324ET & $7 / 13 / 95$ & 3328 & E85 & 15.09 & 0.00889 & 0.023 & 1.04 & 409.1 & 0.0696 & 0.00207 & 0.086 & 0.1 & 0.099 & 0.3 \\
\hline AR325ET & $9 / 13 / 95$ & 3406 & E85 & 15.17 & 0.00783 & 0.025 & 0.95 & 407 & 0.0832 & 0.00226 & 0.083 & 0.14 & 0.098 & 0.23 \\
\hline & COUNT & & & 14 & 13 & 14 & 14 & 14 & 14 & 14 & 14 & 14 & 14 & 14 \\
\hline & AVG & & & 15.22 & 0.009 & 0.0253 & 1.162 & 405.48 & 0.0698 & 0.0020 & 0.089 & 0.1036 & 0.1033 & 0.3284 \\
\hline & STD DEV & & & 0.1862 & 0.0015 & 0.0036 & 0.1719 & 4.982 & 0.0104 & 0.00029 & 0.0094 & 0.021 & 0.0105 & 0.0864 \\
\hline & $\mathrm{CV}$ & & & 0.0122 & 0.1692 & 0.144 & 0.1479 & 0.0123 & 0.1489 & 0.1454 & 0.1063 & 0.2025 & 0.1012 & 0.2632 \\
\hline
\end{tabular}


Table A-21. 1994-95 FFV Ford Taurus: RFG Tests at Lab 1 Round 1

\begin{tabular}{|c|c|c|c|c|c|c|c|c|c|c|c|c|c|c|}
\hline Decal ID & Date & Odometer & Fuel & MPG & $\mathrm{CH}_{3} \mathrm{CHO}$ & $\mathrm{CH}_{4}$ & $\mathrm{CO}$ & $\mathrm{CO}_{2}$ & $\mathrm{ETOH}$ & $\mathrm{HCHO}$ & NMHCE & $\mathrm{NO}_{\mathrm{x}}$ & THC & Evap. THC \\
\hline AR309ET & $3 / 29 / 95$ & 6458 & RFG & 20.51 & 0.0004 & 0.014 & 1.24 & 424.6 & & 0.00131 & 0.09 & 0.06 & 0.101 & 0.314 \\
\hline AR310ET & $3 / 30 / 95$ & 7389 & RFG & 20.66 & 0.00047 & 0.013 & 1.06 & 421.7 & & 0.00122 & 0.089 & 0.11 & 0.1 & 0.348 \\
\hline AR314ET & $5 / 1 / 95$ & 4270 & RFG & 20.45 & 0.00099 & 0.016 & 1.02 & 426 & & 0.0015 & 0.128 & 0.08 & 0.14 & 0.355 \\
\hline AR315ET & $5 / 5 / 95$ & 10278 & RFG & 20.46 & 0.00039 & 0.012 & 1.09 & 425.9 & & 0.00132 & 0.093 & 0.12 & 0.103 & 0.415 \\
\hline AR316ET & $5 / 3 / 95$ & 8594 & RFG & 20.42 & 0.00024 & 0.011 & 1.13 & 426.6 & & 0.00117 & 0.095 & 0.09 & 0.103 & 0.327 \\
\hline AR317ET & $5 / 24 / 95$ & 3042 & RFG & 20.4 & 0.00025 & 0.014 & 1.08 & 427.1 & & 0.00125 & 0.086 & 0.16 & 0.096 & 0.31 \\
\hline AR318ET & $5 / 12 / 95$ & 3051 & RFG & 20.48 & 0.00022 & 0.009 & 0.97 & 425.6 & & 0.00106 & 0.083 & 0.09 & 0.09 & 0.321 \\
\hline AR319ET & $5 / 12 / 95$ & 3810 & RFG & 20.65 & 0.00044 & 0.011 & 1.24 & 421.7 & & 0.00134 & 0.1 & 0.11 & 0.109 & 0.335 \\
\hline AR320ET & $5 / 24 / 95$ & 3047 & RFG & 20.33 & 0.00038 & 0.012 & 1.21 & 428.3 & & 0.00107 & 0.09 & 0.1 & 0.099 & 0.392 \\
\hline AR321ET & $5 / 16 / 95$ & 3291 & RFG & 20.31 & 0.00067 & 0.012 & 1.15 & 428.9 & & 0.00112 & 0.098 & 0.07 & 0.108 & 0.338 \\
\hline AR322ET & $6 / 21 / 95$ & 3191 & RFG & 20.45 & 0.00032 & 0.014 & 1.17 & 423.7 & & 0.00148 & 0.091 & 0.12 & 0.102 & 0.428 \\
\hline AR323ET & $7 / 13 / 95$ & 7654 & RFG & 20.26 & 0.0003 & 0.012 & 0.98 & 428.2 & & 0.00137 & 0.077 & 0.2 & 0.086 & 0.266 \\
\hline AR324ET & $7 / 14 / 95$ & 3354 & RFG & 20.08 & 0.00043 & 0.01 & 0.87 & 432.2 & & 0.00157 & 0.078 & 0.16 & 0.086 & 0.262 \\
\hline AR325ET & 9/14/95 & 3432 & RFG & 20.14 & 0.00029 & 0.011 & 0.84 & 431 & & 0.00131 & 0.076 & 0.28 & 0.085 & 0.23 \\
\hline & COUNT & & & 14 & 13 & 14 & 14 & 14 & & 14 & 14 & 14 & 14 & 14 \\
\hline & AVG & & & 20.4 & 0.0004 & 0.0122 & 1.075 & 426.54 & & 0.00129 & 0.091 & 0.125 & 0.1006 & 0.3315 \\
\hline & STD DEV & & & 0.1665 & 0.00012 & 0.0018 & 0.1274 & 3.0876 & & 0.00016 & 0.013 & 0.0588 & 0.014 & 0.0563 \\
\hline & $\mathrm{CV}$ & & & 0.008 & 0.3294 & 0.1512 & 0.1185 & 0.0072 & & 0.1215 & 0.143 & 0.4704 & 0.1378 & 0.1697 \\
\hline
\end{tabular}


Table A-22. 1994-95 Standard Ford Taurus: RFG Tests at Lab 1 Round 2

\begin{tabular}{|c|c|c|c|c|c|c|c|c|c|c|c|c|c|c|}
\hline Decal ID & Date & Odometer & Fuel & MPG & $\mathrm{CH}_{3} \mathrm{CHO}$ & $\mathrm{CH}_{4}$ & $\mathrm{CO}$ & $\mathrm{CO}_{2}$ & ETOH & $\mathrm{HCHO}$ & NMHCE & $\mathrm{NO}_{\mathrm{x}}$ & $\mathrm{THC}$ & Evap. THC \\
\hline AR304GTC & $8 / 5 / 96$ & 25175 & RFG & 20.39 & 0.00028 & 0.014 & 1.49 & 425.2 & & 0.00092 & 0.088 & 0.22 & 0.1 & 0.207 \\
\hline AR304GTC & $8 / 6 / 96$ & 25212 & RFG & 20.55 & 0.00028 & 0.013 & 1.34 & 422 & & 0.00086 & 0.08 & 0.22 & 0.091 & 0.106 \\
\hline Average & & & & 20.47 & 0.00028 & 0.0135 & 1.415 & 423.6 & & 0.00089 & 0.084 & 0.22 & 0.0955 & 0.1565 \\
\hline AR305GTC & $7 / 1 / 96$ & 31503 & RFG & 20.77 & 0.00031 & 0.015 & 1.65 & 417.1 & & 0.00128 & 0.111 & 0.19 & 0.123 & 0.159 \\
\hline AR306GTC & $10 / 16 / 96$ & 11930 & RFG & 20.61 & 0.00027 & 0.012 & 1.07 & 421.2 & & 0.00109 & 0.071 & 0.24 & 0.081 & 0.258 \\
\hline AR307GTC & $10 / 4 / 96$ & 12192 & RFG & 20.42 & 0.00023 & 0.013 & 1.18 & 425.1 & & 0.00094 & 0.082 & 0.13 & 0.092 & 0.352 \\
\hline AR308GTC & $10 / 8 / 96$ & 12167 & RFG & 21.01 & 0.00023 & 0.013 & 1.12 & 413 & & 0.0009 & 0.087 & 0.18 & 0.097 & 0.223 \\
\hline AR310GTC & $10 / 16 / 96$ & 11682 & RFG & 21.05 & 0.00024 & 0.015 & 1.31 & 412.1 & & 0.00114 & 0.096 & 0.13 & 0.108 & 0.261 \\
\hline AR313GTC & $10 / 24 / 96$ & 8055 & RFG & 20.6 & 0.00031 & 0.013 & 1.13 & 421.3 & & 0.001 & 0.093 & 0.14 & 0.103 & 0.255 \\
\hline DT301GTC & $9 / 3 / 96$ & 15635 & RFG & 20.41 & 0.00026 & 0.013 & 1.15 & 425.2 & & 0.00094 & 0.085 & 0.17 & 0.096 & 0.168 \\
\hline DT301GTC & $9 / 4 / 96$ & 15688 & RFG & 20.47 & 0.00024 & 0.013 & 1.02 & 424.2 & & 0.0009 & 0.073 & 0.21 & 0.084 & 0.13 \\
\hline Average & & & & 20.44 & 0.00025 & 0.013 & 1.085 & 424.7 & & 0.00092 & 0.079 & 0.19 & 0.09 & 0.149 \\
\hline DT302GTC & $7 / 18 / 96$ & 9478 & RFG & 20.65 & 0.00034 & 0.014 & 1.57 & 419.6 & & 0.00111 & 0.108 & 0.12 & 0.119 & 0.288 \\
\hline DT303GTC & 9/9/96 & 11683 & RFG & 20.29 & 0.00019 & 0.012 & 1.21 & 427.7 & & 0.00068 & 0.084 & 0.18 & 0.094 & 0.259 \\
\hline DT304GTC & $7 / 15 / 96$ & 12700 & RFG & 20.73 & 0.00029 & 0.011 & 0.99 & 419 & & 0.00109 & 0.086 & 0.1 & 0.095 & 0.157 \\
\hline DT305GTC & 9/9/96 & 12208 & RFG & 20.32 & 0.00021 & 0.012 & 1.25 & 426.9 & & 0.00082 & 0.089 & 0.16 & 0.098 & 0.194 \\
\hline DT305GTC & $9 / 10 / 96$ & 12226 & RFG & 20.33 & 0.00019 & 0.012 & 1.14 & 426.9 & & 0.00083 & 0.085 & 0.16 & 0.094 & 0.156 \\
\hline Average & & & & 20.325 & 0.0002 & 0.012 & 1.195 & 426.9 & & 0.000825 & 0.087 & 0.16 & 0.096 & 0.175 \\
\hline DT306GTC & 9/6/96 & 12053 & RFG & 20.72 & 0.00022 & 0.012 & 0.93 & 419.2 & & 0.00086 & 0.082 & 0.15 & 0.092 & 0.14 \\
\hline DT306GTC & $9 / 10 / 96$ & 12071 & RFG & 20.52 & 0.00019 & 0.012 & 1.31 & 422.7 & & 0.00074 & 0.085 & 0.13 & 0.095 & 0.144 \\
\hline Average & & & & 20.62 & 0.000205 & 0.012 & 1.12 & 420.95 & & 0.0008 & 0.0835 & 0.14 & 0.0935 & 0.142 \\
\hline DT308GTC & $7 / 15 / 96$ & 11241 & RFG & 20.37 & 0.00026 & 0.012 & 1.44 & 425.7 & & 0.00088 & 0.104 & 0.17 & 0.113 & 0.179 \\
\hline DT311GTC & $7 / 15 / 96$ & 14840 & RFG & 20.1 & 0.00029 & 0.013 & 1.38 & 431.5 & & 0.00116 & 0.086 & 0.28 & 0.096 & 0.139 \\
\hline DT314GTC & $9 / 20 / 96$ & 14681 & RFG & 20.59 & 0.00024 & 0.012 & 0.91 & 422 & & 0.00089 & 0.076 & 0.18 & 0.086 & 0.153 \\
\hline & COUNT & & & 16 & 16 & 16 & 16 & 16 & & 16 & 16 & 16 & 16 & 16 \\
\hline & AVG & & & 20.565 & 0.00026 & 0.0128 & 1.2359 & 421.97 & & 0.001 & 0.0886 & 0.1718 & 0.0989 & 0.2066 \\
\hline & STD DEV & & & 0.2516 & 0.00004 & 0.0011 & 0.207 & 5.1633 & & 0.00016 & 0.0112 & 0.0469 & 0.0115 & 0.0646 \\
\hline & CV & & & 0.0122 & 0.1668 & 0.0873 & 0.1675 & 0.0122 & & 0.1618 & 0.1264 & 0.273 & 0.1167 & 0.3128 \\
\hline
\end{tabular}


Table A-23. 1994-95 FFV Ford Taurus: E85 Tests at Lab 1 Round 2

\begin{tabular}{|c|c|c|c|c|c|c|c|c|c|c|c|c|c|c|}
\hline Decal ID & Date & Odometer & Fuel & MPG & $\mathrm{CH}_{3} \mathrm{CHO}$ & $\mathrm{CH}_{4}$ & $\mathrm{CO}$ & $\mathrm{CO}_{2}$ & $\mathrm{ETOH}$ & $\mathrm{HCHO}$ & NMHCE & $\mathrm{NO}_{\mathrm{x}}$ & $\mathrm{THC}$ & Evap. THC \\
\hline AR309ET & 35494 & 19297 & E85 & 15.38 & 0.01201 & 0.059 & 2.2 & 399.5 & 0.1168 & 0.00316 & 0.128 & 0.29 & 0.168 & 0.203 \\
\hline AR310ET & $3 / 7 / 97$ & 18574 & E85 & 14.89 & 0.01135 & 0.051 & 1.4 & 413.8 & 0.1159 & 0.00316 & 0.128 & 0.45 & 0.161 & 0.435 \\
\hline AR314ET & $6 / 11 / 96$ & 16529 & E85 & 15.51 & 0.01666 & 0.03 & 1.48 & 397.1 & 0.0744 & 0.00265 & 0.198 & 0.15 & 0.216 & 0.341 \\
\hline AR315ET & $6 / 11 / 96$ & 28678 & E85 & 15.03 & 0.01752 & 0.051 & 2.33 & 408 & 0.198 & 0.00358 & 0.314 & 0.29 & 0.347 & 0.415 \\
\hline AR316ET & $6 / 13 / 96$ & 29184 & E85 & 15.58 & 0.01694 & 0.037 & 1.5 & 395.1 & 0.1639 & 0.00329 & 0.184 & 0.16 & 0.207 & 0.38 \\
\hline AR317ET & $11 / 11 / 96$ & 8211 & E85 & 15.32 & 0.01025 & 0.031 & 1.22 & 402.7 & 0.1154 & 0.002 & 0.112 & 0.13 & 0.13 & 0.282 \\
\hline AR317ET & $11 / 12 / 96$ & 8247 & E85 & 15.67 & 0.01148 & 0.026 & 1.33 & 393.4 & 0.1981 & 0.00214 & 0.134 & 0.1 & 0.144 & 0.308 \\
\hline Average & & & & 15.495 & 0.010865 & 0.0285 & 1.275 & 398.05 & 0.15675 & 0.00207 & 0.123 & 0.115 & 0.137 & 0.295 \\
\hline AR318ET & $10 / 17 / 96$ & 11122 & E85 & 15.78 & 0.01007 & 0.023 & 1.06 & 391.1 & 0.1687 & 0.00248 & 0.116 & 0.11 & 0.128 & 0.236 \\
\hline Average & & & & 15.7 & 0.00989 & 0.023 & 1.07 & 393.1 & 0.1544 & 0.00237 & 0.1185 & 0.105 & 0.1305 & 0.2205 \\
\hline AR319ET & $6 / 17 / 96$ & 10956 & E85 & 15.45 & 0.01708 & 0.03 & 1.37 & 398.7 & 0.1744 & 0.00318 & 0.189 & 0.11 & 0.206 & 0.38 \\
\hline AR320ET & $11 / 15 / 96$ & 9713 & E85 & 15.73 & 0.00924 & 0.028 & 1.29 & 392 & 0.1149 & 0.00173 & 0.106 & 0.1 & 0.123 & 0.386 \\
\hline AR320ET & 11/18/96 & 9750 & E85 & 15.84 & 1087 & 0.025 & 1.14 & 389.4 & 0.1643 & 0.00213 & 0.117 & 0.11 & 0.13 & 0.667 \\
\hline Average & & & & 15.785 & 0.010055 & 0.0265 & 1.215 & 390.7 & 0.1396 & 0.00193 & 0.1115 & 0.105 & 0.1265 & 0.5265 \\
\hline AR321ET & $6 / 13 / 96$ & 14476 & E85 & 15.67 & 0.01349 & 0.02 & 1.41 & 393 & 0.1483 & 0.0021 & 0.196 & 0.17 & 0.206 & 0.318 \\
\hline AR322ET & $6 / 13 / 96$ & 8158 & E85 & 15.63 & 0.01379 & 0.039 & 1.81 & 393.5 & 0.0785 & 0.00302 & 0.162 & 0.15 & 0.187 & 0.367 \\
\hline AR323ET & $6 / 6 / 96$ & 19940 & E85 & 15.53 & 0.0155 & 0.033 & 1.54 & 396.6 & 0.1331 & 0.00272 & 0.135 & 0.16 & 0.155 & 0.203 \\
\hline AR325ET & $8 / 29 / 96$ & 15178 & E85 & 15.22 & 0.0132 & 0.028 & 1.44 & 404.7 & 0.145 & 0.00255 & 0.153 & 0.16 & 0.167 & 0.282 \\
\hline AR325ET & 9/9/96 & 15233 & E85 & 15.24 & 0.0116 & 0.03 & 0.91 & 405.2 & 0.156 & 0.00357 & 0.154 & 0.18 & 0.171 & 0.241 \\
\hline Average & & & & 15.23 & 0.012405 & 0.029 & 1.175 & 404.95 & 0.1507 & 0.00306 & 0.1535 & 0.17 & 0.169 & 0.2615 \\
\hline & & & & & & & & & & & & & & \\
\hline & COUNT & & & 14 & 13 & 14 & 14 & 14 & 14 & 14 & 14 & 14 & 14 & 14 \\
\hline & AVG & & & 15.456 & 0.0136 & 0.035 & 1.5218 & 398.54 & 0.139 & 0.0029 & 0.163 & 0.1832 & 0.1838 & 0.3615 \\
\hline & STD DEV & & & 0.2526 & 0.0028 & 0.0114 & 0.3646 & 6.3896 & 0.0341 & 0.0008 & 0.0529 & 0.09678 & 0.0554 & 0.1383 \\
\hline & CV & & & 0.0163 & 0.204 & 0.325 & 0.2396 & 0.016 & 0.244 & 0.270 & 0.3252 & 0.5282 & 0.3017 & 0.383 \\
\hline
\end{tabular}


Table A-24. 1994-95 FFV Ford Taurus: RFG Tests at Lab 1 Round 2

\begin{tabular}{|c|c|c|c|c|c|c|c|c|c|c|c|c|c|c|}
\hline Decal ID & Date & Odometer & Fuel & MPG & $\mathrm{CH}_{3} \mathrm{CHO}$ & $\mathrm{CH}_{4}$ & $\mathrm{CO}$ & $\mathrm{CO}_{2}$ & ETOH & $\mathrm{HCHO}$ & NMHCE & $\mathrm{NO}_{\mathrm{x}}$ & $\mathrm{THC}$ & Evap. THC \\
\hline AR309ET & $3 / 6 / 97$ & 19271 & RFG & 20.38 & 0.00047 & 0.023 & 1.73 & 425 & & 0.00181 & 0.141 & 0.26 & 0.16 & 0.213 \\
\hline AR310ET & $3 / 6 / 97$ & 18548 & RFG & 20.48 & 0.00046 & 0.024 & 1.32 & 423.6 & & 0.00202 & 0.121 & 0.27 & 0.141 & 0.548 \\
\hline AR314ET & $6 / 10 / 96$ & 16504 & RFG & 20.41 & 0.00041 & 0.015 & 1.68 & 424 & & 0.00173 & 0.245 & 0.2 & 0.256 & 0.343 \\
\hline AR315ET & $6 / 12 / 96$ & 28689 & RFG & 20.27 & 0.00045 & 0.018 & 1.83 & 426.8 & & 0.00195 & 0.163 & 0.22 & 0.177 & 0.343 \\
\hline AR316ET & $6 / 12 / 96$ & 29158 & RFG & 20.68 & 0.00035 & 0.017 & 1.76 & 418.4 & & 0.00163 & 0.175 & 0.16 & 0.188 & 0.324 \\
\hline AR317ET & $11 / 18 / 96$ & 8311 & RFG & 20.71 & 0.00033 & 0.012 & 0.97 & 419.4 & & 0.00115 & 0.09 & 0.17 & 0.1 & 0.386 \\
\hline AR317ET & $11 / 20 / 96$ & 8355 & RFG & 20.88 & 0.00028 & 0.012 & 0.9 & 416.2 & & 0.0011 & 0.077 & 0.17 & 0.086 & 0.268 \\
\hline Average & & & & 20.795 & 0.000305 & 0.012 & 0.935 & 417.8 & & 0.001125 & 0.0835 & 0.17 & 0.093 & 0.327 \\
\hline AR318ET & $10 / 10 / 96$ & 11042 & RFG & 20.95 & 0.00031 & 0.013 & 1.14 & 414.1 & & 0.00124 & 0.107 & 0.1 & 0.117 & 0.25 \\
\hline AR318ET & $10 / 11 / 96$ & 11060 & RFG & 20.88 & 0.00026 & 0.012 & 1.06 & 415.7 & & 0.00137 & 0.103 & 0.09 & 0.113 & 0.241 \\
\hline Average & & & & 20.915 & 0.000285 & 0.0125 & 1.1 & 414.9 & & 0.001305 & 0.105 & 0.095 & 0.115 & 0.2455 \\
\hline AR319ET & $6 / 14 / 96$ & 10930 & RFG & 20.46 & 0.00045 & 0.014 & 1.6 & 423.2 & & 0.00184 & 0.166 & 0.1 & 0.177 & 0.305 \\
\hline AR320ET & $11 / 11 / 96$ & 9627 & RFG & 20.38 & 0.00026 & 0.011 & 1.14 & 425.8 & & 0.00104 & 0.099 & 0.1 & 0.109 & 0.391 \\
\hline AR320ET & $11 / 12 / 96$ & 9645 & RFG & 20.29 & 0.00019 & 0.012 & 1.08 & 427.9 & & 0.00095 & 0.09 & 0.11 & 0.099 & 0.346 \\
\hline Average & & & & 20.335 & 0.000225 & 0.0115 & 1.11 & 426.85 & & 0.000995 & 0.0945 & 0.105 & 0.104 & 0.373 \\
\hline AR321ET & $6 / 14 / 96$ & 14501 & RFG & 20.81 & 0.00038 & 0.014 & 1.66 & 416.1 & & 0.00149 & 0.137 & 0.21 & 0.149 & 0.346 \\
\hline AR322ET & $6 / 14 / 96$ & 8183 & RFG & 20.69 & 0.00041 & 0.015 & 1.58 & 418.6 & & 0.00153 & 0.142 & 0.16 & 0.154 & 0.323 \\
\hline AR323ET & $6 / 5 / 96$ & 19915 & RFG & 20.61 & 0.00032 & 0.015 & 1.38 & 420.7 & & 0.00142 & 0.106 & 0.19 & 0.118 & 0.224 \\
\hline AR324ET & $6 / 10 / 96$ & 15360 & RFG & 19.92 & 0.0003 & 0.015 & 1.66 & 434.4 & & 0.00124 & 0.228 & 0.14 & 0.24 & 0.304 \\
\hline AR325ET & $8 / 14 / 96$ & 15012 & RFG & 19.92 & 0.00038 & 0.015 & 1.82 & 434.7 & & 0.0014 & 0.125 & 0.19 & 0.137 & 0.288 \\
\hline AR325ET & $8 / 16 / 96$ & 15049 & RFG & 20.38 & 0.00037 & 0.012 & 1.11 & 425.9 & & 0.00163 & 0.09 & 0.24 & 0.1 & 0.219 \\
\hline Average & & & & 20.15 & 0.00037 & 0.0135 & 1.465 & 430.3 & & 0.00151 & 0.1075 & 0.215 & 0.1185 & 0.2535 \\
\hline & COUNT & & & 14 & 13 & 14 & 14 & 14 & & 14 & 14 & 14 & 14 & 14 \\
\hline & AVG & & & 20.493 & 0.00037 & 0.0157 & 1.486 & 422.90 & & 0.0015 & 0.1439 & 0.1782 & 0.1565 & 0.3194 \\
\hline & STD DEV & & & 0.2772 & 0.000078 & 0.0038 & 0.2782 & 5.5736 & & 0.00031 & 0.0481 & 0.0558 & 0.0484 & 0.0821 \\
\hline & $\mathrm{CV}$ & & & 0.0135 & 0.2119 & 0.2395 & 0.1872 & 0.0132 & & 0.1999 & 0.334 & 0.3129 & 0.3093 & 0.257 \\
\hline
\end{tabular}


Table A-25. 1993 Standard Chevrolet Lumina: RFG Tests at Lab 2 Round 1

\begin{tabular}{|c|c|c|c|c|c|c|c|c|c|c|c|c|c|c|}
\hline Decal ID & Date & Odometer & Fuel & MPG & $\mathrm{CH}_{3} \mathrm{CHO}$ & $\mathrm{CH}_{4}$ & $\mathrm{CO}$ & $\mathrm{CO}_{2}$ & ETOH & $\mathrm{HCHO}$ & NMHCE & $\mathrm{NO}_{\mathrm{x}}$ & THC & Evap. THC \\
\hline DC202GLC & $7 / 7 / 94$ & \begin{tabular}{|l|}
2981 \\
\end{tabular} & RFG & 19.18 & 0.00084 & 0.0377 & 3.1927 & 456.07 & & 0.00447 & 0.1655 & 0.8232 & 0.1955 & 1.0974 \\
\hline DC203GLC & $2 / 20 / 95$ & 10253 & RFG & 19.33 & 0.00123 & 0.0506 & 3.9845 & 451.49 & & 0.01191 & 0.2149 & 1.376 & 0.258 & 0.2209 \\
\hline DC205GLC & $9 / 12 / 94$ & 4379 & RFG & 18.42 & 0.00097 & 0.0437 & 4.5333 & 472.56 & & 0.00463 & 0.2089 & 0.4146 & 0.2464 & 0.1343 \\
\hline DC206GLC & $1 / 24 / 95$ & 7996 & RFG & 18.62 & 0.00116 & 0.0409 & 4.371 & 468.05 & & 0.007 & 0.2188 & 0.6438 & 0.2536 & 0.1736 \\
\hline DC207GLC & $6 / 13 / 94$ & 9405 & RFG & 19.43 & 0.00135 & 0.0348 & 3.33 & 449.6 & & 0.0064 & 0.172 & 0.476 & 0.1996 & 0.1856 \\
\hline DC207GLC & $6 / 14 / 94$ & 9432 & RFG & 19.45 & 0.00122 & 0.0502 & 5.46 & 445.9 & & 0.0051 & 0.204 & 0.381 & 0.2444 & 0.1899 \\
\hline Average & & & & 19.44 & 0.001285 & 0.0425 & 4.39835 & 447.74 & & 0.00579 & 0.18815 & 0.42825 & 0.222 & 0.18775 \\
\hline DC208GLC & $1 / 5 / 95$ & 3098 & RFG & 18.21 & 0.00115 & 0.0363 & 3.5554 & 480.39 & & 0.00589 & 0.1908 & 0.4593 & 0.2214 & 0.1572 \\
\hline DC209GLC & $5 / 27 / 94$ & 2903 & RFG & 20.14 & 0.00117 & 0.0336 & 2.579 & 435.1 & & 0.0071 & 0.1804 & 0.71 & 0.207 & 0.114 \\
\hline DC209GLC & $5 / 31 / 94$ & 2930 & RFG & 19.83 & 0.0018 & 0.0335 & 2.558 & 442.5 & & 0.0093 & 0.1582 & 0.609 & 0.185 & 0.208 \\
\hline Average & & & & 19.985 & 0.001485 & 0.03355 & 2.56845 & 438.8 & & 0.008225 & 0.1693 & 0.65955 & 0.19605 & 0.161 \\
\hline DC210GLC & $1 / 23 / 95$ & 8767 & RFG & 18.94 & 0.00126 & 0.0365 & 3.7953 & 460.73 & & 0.00657 & 0.1834 & 0.5661 & 0.2143 & 0.2003 \\
\hline DC211GLC & $12 / 28 / 94$ & 5906 & RFG & 18.44 & 0.00159 & 0.0331 & 3.6526 & 473.629 & & 0.00551 & 0.1739 & 0.6723 & 0.2019 & $t$ \\
\hline DC215GLC & $6 / 28 / 94$ & 3385 & RFG & 19.36 & 0.00084 & 0.0302 & 3.1609 & 451.95 & & 0.00364 & 0.1659 & 0.485 & 0.1899 & 0.2456 \\
\hline DC218GLC & $9 / 2 / 94$ & 10713 & RFG & 18.76 & 0.0012 & 0.0386 & 4.1363 & 464.59 & & 0.00603 & 0.194 & 0.466 & 0.2247 & 0.1445 \\
\hline & COUNT & & & 11 & 11 & 11 & 11 & 11 & & 11 & 11 & 10 & 11 & 10 \\
\hline & AVG & & & 18.971 & 0.0012 & 0.0385 & 3.759 & 460.54 & & 0.0063 & 0.1885 & 0.562 & 0.2203 & 0.2723 \\
\hline & STD DEV & & & 0.539 & 0.00023 & 0.0057 & 0.6104 & 12.628 & & 0.0022 & 0.0193 & 0.1341 & 0.0239 & 0.292 \\
\hline & $\mathrm{CV}$ & & & 0.0284 & 0.1997 & 0.1485 & 0.1624 & 0.0274 & & 0.3533 & 0.1022 & 0.239 & 0.1087 & 1.0724 \\
\hline
\end{tabular}

Table A-26. 1992-93 FFV Chevrolet Lumina: E85 Tests at Lab 2 Round 1

\begin{tabular}{|c|c|c|c|c|c|c|c|c|c|c|c|c|c|c|}
\hline Decal ID & Date & Odometer & Fuel & MPG & $\mathrm{CH}_{3} \mathrm{CHO}$ & $\mathrm{CH}_{4}$ & $\mathrm{CO}$ & $\mathrm{CO}_{2}$ & ETOH & $\mathrm{HCHO}$ & NMHCE & $\mathrm{NO}_{\mathrm{x}}$ & $\mathrm{THC}$ & Evap. THC \\
\hline DC206EL & $6 / 16 / 94$ & 8338 & E85 & 13.69 & 0.02616 & 0.0549 & 1.673 & 451.4 & 0.0768 & 0.0087 & 0.0957 & 0.179 & 0.112 & 0.1345 \\
\hline DC206EL & $6 / 17 / 94$ & 8365 & E85 & 13.85 & 0.02401 & 0.0504 & 1.527 & 446.5 & 0.0991 & 0.0082 & 0.0906 & 0.219 & 0.097 & 0.1586 \\
\hline Average & & & & 13.77 & 0.025085 & 0.05265 & 1.59975 & 448.93 & 0.08795 & 0.00845 & 0.09314 & 0.19915 & 0.1043 & 0.14655 \\
\hline DC211EL & $8 / 1 / 94$ & 10411 & E85 & 13.93 & 0.02265 & 0.0594 & 2.452 & 441.7 & 0.0929 & 0.00757 & 0.09882 & 0.1994 & 0.115 & 0.1634 \\
\hline DC218ELC & $8 / 26 / 94$ & 10778 & E85 & 13.4 & 0.01456 & 0.0635 & 2.7832 & 459.30 & 0.0727 & 0.00439 & 0.09469 & 0.1196 & 0.1231 & 0.1213 \\
\hline DC219ELC & $1 / 19 / 95$ & 10613 & E85 & 13.37 & 0.01961 & 0.0523 & 1.7598 & 461.91 & 0.0644 & 0.00928 & 0.08218 & 0.1295 & 0.1018 & 0.1897 \\
\hline DC221EL & $7 / 27 / 94$ & 10224 & E85 & 13.8 & 0.01342 & 0.0752 & 3.2155 & 444.92 & 0.1143 & 0.00789 & 0.11528 & 0.1684 & 0.1417 & 0.0732 \\
\hline DC225EL & $1 / 25 / 95$ & 8939 & E85 & 13.07 & 0.01816 & 0.0303 & 2.1375 & 471.90 & 0.0797 & 0.00763 & 0.08156 & 0.1523 & 0.078 & 0.199 \\
\hline DC227ELC & $8 / 17 / 94$ & 11151 & E85 & 13.8 & 0.01347 & 0.0598 & 2.7002 & 445.56 & 0.0612 & 0.00703 & 0.08598 & 0.134 & 0.115 & 0.1726 \\
\hline DC229EL & $9 / 20 / 94$ & 10033 & E85 & 13.5 & 0.01729 & 0.046 & 1.4359 & 457.54 & 0.0779 & 0.00551 & 0.06054 & 0.1802 & 0.0714 & 0.2016 \\
\hline DC230EL & $10 / 7 / 94$ & 8218 & E85 & 13.53 & 0.01848 & 0.0681 & 1.9388 & 455.86 & 0.065 & 0.00511 & 0.0751 & 0.117 & 0.1086 & 0.1592 \\
\hline DC231EL & $8 / 22 / 94$ & 12409 & E85 & 13.24 & 0.01489 & 0.0613 & 2.025 & 466.3 & 0.0758 & 0.00573 & 0.1064 & 0.125 & 0.132 & 0.3292 \\
\hline & COUNT & & & 9 & 9 & 9 & 9 & 9 & 9 & 9 & 9 & 9 & 9 & 8 \\
\hline & AVG & & & 13.574 & 0.0181 & 0.0564 & 2.2247 & 454.18 & 0.0796 & 0.00698 & 0.0875 & 0.1555 & 0.1065 & 0.1534 \\
\hline & STD DEV & & & 0.2740 & 0.004 & 0.0131 & 0.601 & 9.7299 & 0.0169 & 0.0016 & 0.0155 & 0.0326 & 0.0216 & 0.041 \\
\hline & $\mathrm{CV}$ & & & 0.0202 & 0.2216 & 0.2332 & 0.2701 & 0.0214 & 0.2124 & 0.2343 & 0.1775 & 0.21 & 0.2028 & 0.2659 \\
\hline
\end{tabular}


Table A-27. 1992-93 FFV Chevrolet Lumina: RFG Tests at Lab 2 Round 1

\begin{tabular}{|c|c|c|c|c|c|c|c|c|c|c|c|c|c|c|}
\hline Decal ID & Date & Odometer & Fuel & MPG & $\mathrm{CH}_{3} \mathrm{CHO}$ & $\mathrm{CH}_{4}$ & $\mathrm{CO}$ & $\mathrm{CO}_{2}$ & $\mathrm{ETOH}$ & $\mathrm{HCHO}$ & NMHCE & $\mathrm{NO}_{\mathrm{x}}$ & $\mathrm{THC}$ & Evap. THC \\
\hline DC206EL & $6 / 14 / 94$ & 8296 & RFG & 18.12 & 0.00113 & 0.0428 & 3.307 & 483.1 & & 0.00604 & 0.1356 & 0.197 & 0.17 & 0.1691 \\
\hline DC206EL & $6 / 20 / 94$ & 8400 & RFG & 18.27 & 0.00088 & 0.033 & 2.122 & 481.2 & & 0.00428 & 0.1252 & 0.236 & 0.152 & 0.1506 \\
\hline Average & & & & 18.195 & 0.00100 & 0.0379 & 2.71455 & 482.1379 & & 0.00516 & 0.1304 & 0.2164 & 0.1606 & 0.15985 \\
\hline DC211EL & $7 / 29 / 94$ & 10376 & RFG & 18.63 & 0.00135 & 0.0418 & 3.0465 & 469.9074 & & 0.00654 & 0.1429 & 0.2311 & 0.1762 & 0.1507 \\
\hline DC218ELC & $8 / 30 / 94$ & 10849 & RFG & 17.79 & 0.0006 & 0.0282 & 2.8616 & 492.5368 & & 0.00273 & 0.1007 & 0.2686 & 0.1232 & 0.202 \\
\hline DC219ELC & $1 / 17 / 95$ & 10544 & RFG & 18.03 & 0.00061 & 0.0264 & 1.2194 & 489.3387 & & 0.00718 & 0.0964 & 0.2995 & 0.1188 & 0.2806 \\
\hline DC221EL & $7 / 29 / 94$ & 10293 & RFG & 18.06 & 0.0004 & 0.0282 & 1.9395 & 487.4542 & & 0.00383 & 0.086 & 0.3324 & 0.1085 & 0.1059 \\
\hline DC225EL & $1 / 24 / 95$ & 8904 & RFG & 17.4 & 0.00064 & 0.0225 & 1.6005 & 505.6165 & & 0.00461 & 0.0952 & 0.328 & 0.1148 & 0.09 \\
\hline DC227ELC & $8 / 15 / 94$ & 11081 & RFG & 18.24 & 0.00059 & 0.026 & 2.6576 & 481.1846 & & 0.00387 & 0.0942 & 0.2248 & 0.1149 & 0.0882 \\
\hline DC229EL & $9 / 21 / 94$ & 10067 & RFG & 18.21 & 0.00068 & 0.0223 & 1.3119 & 484.3811 & & 0.00229 & 0.0781 & 0.2455 & 0.0971 & 0.1922 \\
\hline DC230EL & $6 / 16 / 95$ & 14668 & RFG & 18.32 & 0.00072 & 0.0202 & 1.264 & 480.7151 & & 0.00573 & 0.0915 & 0.203 & 0.1076 & 0.1199 \\
\hline DC231EL & $8 / 24 / 94$ & 12444 & RFG & 18.05 & 0.00052 & 0.0278 & 2.005 & 487.4 & & 0.0031 & 0.1036 & 0.193 & 0.1257 & 0.2203 \\
\hline & & & & & & & & & & & & & & \\
\hline & COUNT & & & 9 & 9 & 9 & 9 & 9 & & 9 & $y$ & 9 & 9 & 8 \\
\hline & AVG & & & 18.097 & 0.00073 & 0.0282 & 2.0684 & 485.92 & & 0.0047 & 0.1017 & 0.2610 & 0.1246 & 0.1624 \\
\hline & STD DEV & & & 0.3469 & 0.00028 & 0.0072 & 0.7522 & 9.8003 & & 0.0017 & 0.0211 & 0.0486 & 0.0262 & 0.0623 \\
\hline & CV & & & 0.0192 & 0.3831 & 0.2568 & 0.3636 & 0.0202 & & 0.3553 & 0.2073 & 0.1863 & 0.2102 & 0.3829 \\
\hline
\end{tabular}

Table A-28. 1993 Standard Chevrolet Lumina: RFG Tests at Lab 2 Round 2

\begin{tabular}{|c|c|c|c|c|c|c|c|c|c|c|c|c|c|c|}
\hline Decal ID & Date & Odometer & Fuel & MPG & $\mathrm{CH}_{3} \mathrm{CHO}$ & $\mathrm{CH}_{4}$ & $\mathrm{CO}$ & $\mathrm{CO}_{2}$ & ETOH & $\mathrm{HCHO}$ & NMHCE & $\mathrm{NO}_{\mathrm{x}}$ & $\mathrm{THC}$ & Evap. THC \\
\hline DC202GLC & $7 / 11 / 95$ & 6826 & RFG & 19.13 & 0.00092 & 0.0386 & 3.3524 & 457.23 & & 0.00518 & 0.1979 & 0.8413 & 0.2287 & 0.6901 \\
\hline DC203GLC & $3 / 8 / 96$ & 17084 & RFG & 20.21 & 0.00088 & 0.0441 & 4.7191 & 429.70 & & 0.00498 & 0.1951 & 1.0044 & 0.2302 & 0.1091 \\
\hline DC205GLC & $11 / 30 / 95$ & 10105 & RFG & 19.8 & 0.00103 & 0.0464 & 4.6601 & 439.03 & & 0.0035 & 0.3053 & 0.4898 & 0.3422 & 0.1589 \\
\hline DC206GLC & $1 / 31 / 96$ & 13420 & RFG & 19.58 & 0.00084 & 0.034 & 3.5337 & 446.34 & & 0.00438 & 0.2092 & 0.7099 & 0.2363 & 0.1733 \\
\hline DC207GLC & $5 / 26 / 95$ & 13071 & RFG & 18.94 & 0.00177 & 0.0461 & 5.4588 & 458.17 & & 0.0075 & 0.2512 & 0.5286 & 0.288 & 0.1136 \\
\hline DC208GLC & $2 / 15 / 96$ & 9445 & RFG & 19.48 & 0.00088 & 0.0361 & 3.7509 & 447.75 & & 0.00376 & 0.202 & 0.5505 & 0.2307 & 0.568 \\
\hline DC209GLC & $7 / 10 / 95$ & 6956 & RFG & 19.14 & 0.00088 & 0.0465 & 3.7942 & 455.85 & & 0.00485 & 0.2089 & 0.4936 & 0.2459 & 0.3673 \\
\hline DC210GLC & $2 / 14 / 96$ & 17618 & RFG & 19.85 & 0.00092 & 0.0428 & 4.6888 & 438.26 & & 0.00433 & 0.2309 & 0.5516 & 0.265 & 0.1868 \\
\hline DC211GLC & $12 / 20 / 95$ & 12316 & RFG & 19.88 & 0.00086 & 0.039 & 3.6273 & 438.52 & & 0.00516 & 0.1999 & 0.724 & 0.231 & 0.1165 \\
\hline DC215GLC & $5 / 15 / 95$ & 10965 & RFG & 18.81 & 0.00122 & 0.0416 & 3.9527 & 463.76 & & 0.00675 & 0.189 & 0.4691 & 0.2242 & 0.183 \\
\hline DC218GLC & $6 / 1 / 95$ & 18970 & RFG & 19.44 & 0.0012 & 0.0492 & 4.969 & 446.53 & & 0.00555 & 0.2157 & 0.4831 & 0.2549 & 0.1545 \\
\hline & & & & & & & & & & & & & & \\
\hline & COUNT & & & 11 & 11 & 11 & 11 & 11 & & 11 & 11 & 11 & 11 & 11 \\
\hline & AVG & & & 19.478 & 0.0010 & 0.0422 & 4.2279 & 447.37 & & 0.0051 & 0.2186 & 0.6223 & 0.2525 & 0.2565 \\
\hline & STD DEV & & & 0.4384 & 0.00028 & 0.005 & 0.6932 & 10.486 & & 0.0012 & 0.0338 & 0.1755 & 0.0355 & 0.199 \\
\hline & CV & & & 0.0225 & 0.2675 & 0.1142 & 0.1639 & 0.023 & & 0.2346 & 0.154 & 0.2819 & 0.1405 & 0.776 \\
\hline
\end{tabular}


Table A-29. 1992-93 FFV Chevrolet Lumina: E85 Tests at Lab 2 Round 2

\begin{tabular}{|c|c|c|c|c|c|c|c|c|c|c|c|c|c|c|}
\hline Decal ID & Date & Odometer & Fuel & MPG & $\mathrm{CH}_{3} \mathrm{CHO}$ & $\mathrm{CH}_{4}$ & $\mathrm{CO}$ & $\mathrm{CO}_{2}$ & $\mathrm{ETOH}$ & $\mathrm{HCHO}$ & NMHCE & $\mathrm{NO}_{\mathrm{x}}$ & $\mathrm{THC}$ & Evap. THC \\
\hline DC206EL & $6 / 22 / 95$ & 12991 & E85 & 13.82 & 0.02926 & 0.0993 & 3.9558 & 442.95 & 0.0973 & 0.01149 & 0.13669 & 0.3178 & 0.184 & 0.1681 \\
\hline DC211EL & $8 / 5 / 96$ & 28678 & E85 & 14.41 & 0.01928 & 0.0908 & 4.249 & 424.11 & 0.0876 & 0.00623 & 0.12949 & 0.2528 & 0.1756 & 0.169 \\
\hline DC218ELC & $6 / 7 / 95$ & 24617 & E85 & 14.18 & 0.02266 & 0.1036 & 4.9086 & 429.57 & 0.0851 & 0.00615 & 0.14352 & 0.1531 & 0.2003 & 0.0921 \\
\hline DC219ELC & $6 / 16 / 96$ & 17880 & E85 & 13.54 & 0.0136 & 0.0551 & 1.8236 & 455.90 & 0.0592 & 0.00415 & 0.08526 & 0.1987 & 0.1107 & 0.2004 \\
\hline DC221EL & $9 / 11 / 95$ & 22408 & E85 & 14.2 & 0.01297 & 0.072 & 3.3206 & 432.16 & 0.0858 & 0.00331 & 0.08567 & 0.2202 & 0.118 & 0.1519 \\
\hline DC225EL & $6 / 27 / 96$ & 16922 & E85 & 14.14 & 0.01129 & 0.0416 & 2.1502 & 436.23 & 0.0688 & 0.00419 & 0.08338 & 0.1854 & 0.0951 & 0.1772 \\
\hline DC227ELC & $7 / 10 / 96$ & 35842 & E85 & 14.44 & 0.01395 & 0.0745 & 3.152 & 425.22 & 0.0796 & 0.00346 & 0.10791 & 0.1808 & 0.1439 & 0.21 \\
\hline DC229EL & $7 / 9 / 96$ & 27166 & E85 & 14.6 & 0.01186 & 0.069 & 2.1545 & 422.26 & 0.0799 & 0.00371 & 0.09439 & 0.2283 & 0.1262 & 0.1282 \\
\hline DC230EL & $6 / 20 / 95$ & 14695 & E85 & 13.56 & 0.01849 & 0.0636 & 2.0234 & 455.10 & 0.0677 & 0.00737 & 0.08067 & 0.1138 & 0.1094 & 0.1534 \\
\hline DC231EL & $6 / 6 / 95$ & 24478 & E85 & 13.27 & 0.0268 & 0.236 & 11.09 & 450.2 & 0.1325 & 0.007 & 0.2074 & 0.1256 & 0.363 & 0.1863 \\
\hline & COUNT & & & 9 & 9 & 9 & 9 & 9 & 9 & 9 & 9 & 9 & 9 & 8 \\
\hline & AVG & & & 14.099 & 0.017 & 0.0744 & 3.082 & 435.94 & 0.079 & 0.0056 & 0.105 & 0.2057 & 0.1404 & 0.1591 \\
\hline & STD DEV & & & 0.3813 & 0.0059 & 0.0204 & 1.1156 & 12.802 & 0.0118 & 0.0026 & 0.0251 & 0.0589 & 0.0376 & 0.0378 \\
\hline & CV & & & 0.0270 & 0.3508 & 0.2747 & 0.362 & 0.0294 & 0.149 & 0.4757 & 0.2383 & 0.2866 & 0.2682 & 0.2375 \\
\hline
\end{tabular}

Table A-30. 1992-93 FFV Chevrolet Lumina: RFG Tests at Lab 2 Round 2

\begin{tabular}{|c|c|c|c|c|c|c|c|c|c|c|c|c|c|c|}
\hline Decal ID & Date & Odometer & Fuel & MPG & $\mathrm{CH}_{3} \mathrm{CHO}$ & $\mathrm{CH}_{4}$ & $\mathrm{CO}$ & $\mathrm{CO}_{2}$ & $\mathrm{ETOH}$ & $\mathrm{HCHO}$ & NMHCE & $\mathrm{NO}_{\mathrm{x}}$ & $\mathrm{THC}$ & Evap. THC \\
\hline DC206EL & $6 / 21 / 95$ & 12964 & RFG & 18.6 & 0.00117 & 0.0546 & 4.1236 & 468.59 & & 0.00767 & 0.1747 & 0.3672 & 0.2182 & \begin{tabular}{|l|}
0.1748 \\
\end{tabular} \\
\hline DC211EL & $8 / 6 / 96$ & 28704 & RFG & 19.43 & 0.00118 & 0.0492 & 4.5941 & 448.45 & & 0.00393 & 0.1357 & 0.3365 & 0.1748 & 0.2333 \\
\hline DC218ELC & $6 / 8 / 95$ & 24644 & RFG & 19.24 & 0.001 & 0.0236 & 1.8161 & 457.47 & & 0.00481 & 0.0962 & 0.2941 & 0.115 & 0.1103 \\
\hline DC219ELC & $6 / 17 / 96$ & 17907 & RFG & 18.03 & 0.00058 & 0.0237 & 1.2778 & 488.83 & & 0.00264 & 0.0787 & 0.3235 & 0.0975 & 0.3557 \\
\hline DC221EL & $9 / 12 / 95$ & 22435 & RFG & 19.19 & 0.00066 & 0.0278 & 2.5216 & 457.36 & & 0.00253 & 0.1141 & 0.4089 & 0.1363 & 0.1201 \\
\hline DC225EL & $6 / 26 / 96$ & 16895 & RFG & 19.17 & 0.00061 & 0.0269 & 1.6901 & 459.26 & & 0.003 & 0.0894 & 0.2904 & 0.1108 & 0.1095 \\
\hline DC227ELC & $7 / 8 / 96$ & 35816 & RFG & 19.08 & 0.00063 & 0.0228 & 1.7157 & 461.36 & & 0.00412 & 0.0984 & 0.2924 & 0.1165 & 0.4131 \\
\hline DC229EL & $7 / 11 / 96$ & 27193 & RFG & 19.22 & 0.00059 & 0.0261 & 1.4904 & 458.16 & & 0.00256 & 0.0914 & 0.3751 & 0.1122 & 0.2058 \\
\hline DC230EL & $12 / 2 / 96$ & 25119 & RFG & 19.01 & 0.00062 & 0.0222 & 1.64 & 463.15 & & 0.00399 & 0.106 & 0.2764 & 0.1237 & 0.3215 \\
\hline DC231EL & $6 / 5 / 95$ & 24451 & RFG & 17.78 & 0.00076 & 0.052 & 5.382 & 488.8 & & 0.00509 & 0.174 & 0.325 & 0.215 & 0.1711 \\
\hline & COUNT & & & 9 & 9 & 9 & 9 & 9 & & 9 & 9 & 9 & 9 & 8 \\
\hline & AVG & & & 18.997 & 0.00078 & 0.0308 & 2.3188 & 462.516 & & 0.0039 & 0.1094 & 0.3294 & 0.1339 & 0.2418 \\
\hline & STD DEV & & & 0.4277 & 0.00026 & 0.0122 & 1.2102 & 11.24 & & 0.0016 & 0.0295 & 0.0459 & 0.0385 & 0.1112 \\
\hline & $\mathrm{CV}$ & & & 0.0225 & 0.3284 & 0.3967 & 0.5219 & 0.0243 & & 0.4153 & 0.2694 & 0.1394 & 0.2878 & 0.460 \\
\hline
\end{tabular}


Table A-31. 1993 Standard Chevrolet Lumina: RFG Tests at Lab 2 Round 3

\begin{tabular}{|c|c|c|c|c|c|c|c|c|c|c|c|c|c|c|}
\hline Decal ID & Date & Odometer & Fuel & MPG & $\mathrm{CH}_{3} \mathrm{CHO}$ & $\mathrm{CH}_{4}$ & $\mathrm{CO}$ & $\mathrm{CO}_{2}$ & ETOH & $\mathrm{HCHO}$ & NMHCE & $\mathrm{NO}_{\mathrm{x}}$ & THC & Evap. THC \\
\hline DC202GLC & $12 / 3 / 96$ & 12606 & RFG & 19.6 & 0.0012 & 0.0519 & 5.614 & 442 & & 0.0051 & 0.289 & 0.88 & 0.3304 & 0.9515 \\
\hline DC202GLC & $12 / 4 / 96$ & 12625 & RFG & 19.56 & 0.00099 & 0.044 & 4.425 & 444.6 & & 0.00469 & 0.244 & 0.882 & 0.2786 & 1.929 \\
\hline Average & & & & 19.58 & 0.00109 & 0.04795 & 5.0195 & 443.33 & & 0.004895 & 0.26635 & 0.8806 & 0.3045 & 1.44025 \\
\hline DC203GLC & $2 / 7 / 97$ & 23624 & RFG & 19.58 & 0.00112 & 0.0498 & 5.4366 & 442.79 & & 0.00515 & 0.2425 & 0.777 & 0.2821 & 0.1425 \\
\hline DC205GLC & 12/17/96 & 13632 & RFG & 20.11 & 0.00121 & 0.0406 & 4.2348 & 433.44 & & 0.00538 & 0.234 & 0.4665 & 0.2663 & 0.263 \\
\hline DC206GLC & $1 / 21 / 97$ & 15937 & RFG & 18.53 & 0.00117 & 0.0335 & 3.9654 & 470.95 & & 0.00465 & 0.2219 & 0.5354 & 0.2486 & 0.3996 \\
\hline DC207GLC & $12 / 11 / 96$ & 25036 & RFG & 20.11 & 0.00114 & 0.0494 & 6.6103 & 429.04 & & 0.00504 & 0.2551 & 0.5343 & 0.2944 & 0.1983 \\
\hline DC208GLC & $12 / 31 / 96$ & 16210 & RFG & 19.08 & 0.00106 & 0.0658 & 6.3726 & 452.70 & & 0.00447 & 0.3216 & 0.5909 & 0.3739 & 0.1814 \\
\hline DC209GLC & $1 / 16 / 97$ & 11365 & RFG & 19.74 & 0.00129 & 0.0405 & 4.3047 & 440.71 & & 0.00541 & 0.2309 & 0.6621 & 0.2631 & 0.184 \\
\hline DC210GLC & 12/16/96 & 22244 & RFG & 18.49 & 0.00115 & 0.0438 & 5.2616 & 470.22 & & 0.00509 & 0.235 & 0.5838 & 0.2699 & 0.3229 \\
\hline DC211GLC & $12 / 10 / 96$ & 19479 & RFG & 19.88 & 0.00116 & 0.0398 & 3.733 & 439.3 & & 0.0048 & 0.1927 & 0.7847 & 0.2244 & 0.3796 \\
\hline DC211GLC & $12 / 11 / 96$ & 19498 & RFG & 19.82 & 0.0011 & 0.0388 & 3.949 & 440.3 & & 0.0054 & 0.2033 & 0.7852 & 0.2342 & 0.2952 \\
\hline Average & & & & 19.85 & 0.00113 & 0.0393 & 3.8407 & 439.82 & & 0.00508 & 0.198 & 0.78495 & 0.2293 & 0.3374 \\
\hline DC215GLC & $11 / 2 / 95$ & 15403 & RFG & 19.44 & 0.00108 & 0.0487 & 4.9376 & 446.88 & & 0.00418 & 0.2306 & 0.4743 & 0.2694 & 0.0973 \\
\hline DC218GLC & $1 / 23 / 97$ & 37902 & RFG & 20 & 0.00125 & 0.0517 & 6.3134 & 432.33 & & 0.00613 & 0.2783 & 0.655 & 0.3194 & 0.3456 \\
\hline & & & & & & & & & & & & & & \\
\hline & COUNT & & & 11 & 11 & 11 & 11 & 11 & & 11 & 11 & 11 & 11 & 11 \\
\hline & AVG & & & 19.501 & 0.0012 & 0.0465 & 5.1179 & 445.66 & & 0.0050 & 0.247 & 0.631 & 0.2837 & 0.3556 \\
\hline & STD DEV & & & 0.5769 & $7.13 \mathrm{E}-05$ & 0.0085 & 0.9897 & 14.031 & & 0.0005 & 0.033 & 0.1352 & 0.0391 & 0.3722 \\
\hline & CV & & & 0.0296 & 0.0618 & 0.1832 & 0.1934 & 0.0315 & & 0.1029 & 0.1336 & 0.214 & 0.1377 & 1.0464 \\
\hline
\end{tabular}

Table A-32. 1992-93 FFV Chevrolet Lumina: E85 Tests at Lab 2 Round 3

\begin{tabular}{|c|c|c|c|c|c|c|c|c|c|c|c|c|c|c|}
\hline Decal ID & Date & Odometer & Fuel & MPG & $\mathrm{CH}_{3} \mathrm{CHO}$ & $\mathrm{CH}_{4}$ & $\mathrm{CO}$ & $\mathrm{CO}_{2}$ & ETOH & $\mathrm{HCHO}$ & NMHCE & $\mathrm{NO}_{\mathrm{x}}$ & $\mathrm{THC}$ & Evap. THC \\
\hline DC206EL & $2 / 5 / 97$ & 19700 & E85 & 14.74 & 0.01867 & 0.0687 & 1.9598 & 417.502 & 0.0914 & 0.00676 & 0.12006 & 0.4431 & 0.1461 & 0.1502 \\
\hline $\mathrm{DC} 211 \mathrm{EL}$ & $2 / 21 / 97$ & 34399 & E85 & 13.61 & 0.02658 & 0.0725 & 3.2296 & 451.16 & 0.1214 & 0.00809 & 0.13241 & 0.2338 & 0.1501 & 0.1631 \\
\hline DC218ELC & $11 / 19 / 96$ & 41326 & E85 & 13.64 & 0.01449 & 0.0784 & 4.465 & 448.2 & 0.1006 & 0.00397 & 0.1436 & 0.184 & 0.1766 & 0.1807 \\
\hline DC218ELC & $11 / 20 / 96$ & 41345 & E85 & 13.69 & 0.01704 & 0.0806 & 4.695 & 445.9 & 0.0933 & 0.00375 & 0.1651 & 0.1844 & 0.2013 & 0.1444 \\
\hline Average & & & & 13.665 & 0.015765 & 0.0795 & 4.5799 & 447.06 & 0.09695 & 0.00386 & 0.15434 & 0.1842 & 0.18895 & 0.16255 \\
\hline DC219ELC & $11 / 7 / 96$ & 22155 & E85 & 13.54 & 0.01289 & 0.0685 & 3.0595 & 454.02 & 0.0727 & 0.00371 & 0.08971 & 0.1915 & 0.123 & 0.1942 \\
\hline $\mathrm{DC} 221 \mathrm{EL}$ & $1 / 24 / 97$ & 37950 & E85 & 13.7 & 0.01783 & 0.0672 & 3.4155 & 447.55 & 0.0697 & 0.0058 & 0.12677 & 0.2797 & 0.1583 & 0.1484 \\
\hline DC225EL & $1 / 28 / 97$ & 19962 & E85 & 13.99 & 0.02014 & 0.0395 & 1.8418 & 440.86 & 0.0883 & 0.00599 & 0.09768 & 0.2102 & 0.0989 & 0.1524 \\
\hline DC227ELC & $12 / 30 / 96$ & 42538 & E85 & 13.16 & 0.01923 & 0.0619 & 2.3662 & 468.35 & 0.1124 & 0.00554 & 0.12559 & 0.1872 & 0.1392 & 0.1494 \\
\hline DC229EL & $11 / 8 / 96$ & 29758 & E85 & 14.37 & 0.01323 & 0.0696 & 2.6712 & 427.76 & 0.0858 & 0.0042 & 0.0991 & 0.22 & 0.1292 & 0.2304 \\
\hline DC230EL & $11 / 27 / 96$ & 25092 & E85 & 13.96 & 0.01749 & 0.0636 & 2.445 & 440.77 & 0.0922 & 0.00446 & 0.11357 & 0.1459 & 0.1353 & 0.1067 \\
\hline DC231EL & $7 / 2 / 96$ & 35946 & E85 & 13.47 & 0.0318 & 0.292 & 18.294 & 430.6 & 0.2358 & 0.0033 & 0.379 & 0.0999 & 0.551 & 0.2221 \\
\hline & COUNT & & & 9 & 9 & 9 & 9 & 9 & 9 & 9 & 9 & 9 & 9 & 8 \\
\hline & AVG & & & 13.859 & 0.018 & 0.0657 & 2.8409 & 443.89 & 0.0923 & 0.0054 & 0.1177 & 0.2328 & 0.141 & 0.1631 \\
\hline & STD DEV & & & 0.4717 & 0.0041 & 0.0110 & 0.8469 & 14.801 & 0.0167 & 0.0015 & 0.0202 & 0.0872 & 0.0249 & 0.0363 \\
\hline & CV & & & 0.0340 & 0.2279 & 0.1682 & 0.2981 & 0.0333 & 0.1807 & 0.2723 & 0.171 & 0.3744 & 0.177 & 0.2228 \\
\hline
\end{tabular}


Table A-33. 1992-93 FFV Chevrolet Lumina: RFG Tests at Lab 2 Round 3

\begin{tabular}{|c|c|c|c|c|c|c|c|c|c|c|c|c|c|c|}
\hline Decal ID & Date & Odometer & Fuel & MPG & $\mathrm{CH}_{3} \mathrm{CHO}$ & $\mathrm{CH}_{4}$ & $\mathrm{CO}$ & $\mathrm{CO}_{2}$ & ETOH & $\mathrm{HCHO}$ & NMHCE & $\mathrm{NO}_{\mathrm{x}}$ & $\mathrm{THC}$ & Evap THC \\
\hline DC206EL & $2 / 4 / 97$ & 19673 & RFG & 19.61 & 0.00083 & 0.0508 & 2.5923 & 446.63 & & 0.00401 & 0.1419 & 0.5285 & 0.1823 & 0.1212 \\
\hline $\mathrm{DC} 211 \mathrm{EL}$ & $2 / 22 / 97$ & 34425 & RFG & 18.13 & 0.00095 & 0.0474 & 4.4354 & 481.01 & & 0.00394 & 0.1457 & 0.3015 & 0.1834 & 0.2081 \\
\hline DC218ELC & $11 / 21 / 96$ & 41371 & RFG & 18.45 & 0.00061 & 0.0322 & 2.968 & 475 & & 0.0025 & 0.1227 & 0.294 & 0.1483 & 0.1796 \\
\hline DC218ELC & $11 / 22 / 96$ & 41390 & RFG & 18.43 & 0.00053 & 0.0275 & 2.605 & 475.7 & & 0.0022 & 0.1175 & 0.523 & 0.1394 & 0.3139 \\
\hline Average & & & & 18.44 & 0.00057 & 0.02985 & 2.78625 & 475.32 & & 0.002385 & 0.1201 & 0.2733 & 0.14385 & 0.24675 \\
\hline DC219ELC & $11 / 6 / 96$ & 22129 & RFG & 18.12 & 0.00055 & 0.0241 & 1.6483 & 485.65 & & 0.00242 & 0.0845 & 0.3221 & 0.1037 & 0.1223 \\
\hline $\mathrm{DC} 221 \mathrm{EL}$ & $1 / 22 / 97$ & 37923 & RFG & 18.82 & 0.00063 & 0.0273 & 2.6481 & 465.75 & & 0.00321 & 0.1289 & 0.4382 & 0.1506 & 0.1265 \\
\hline DC225EL & $1 / 27 / 97$ & 19935 & RFG & 19 & 0.00066 & 0.0266 & 1.7936 & 463.18 & & 0.00408 & 0.0987 & 0.3439 & 0.1199 & 0.2387 \\
\hline DC227ELC & $12 / 27 / 96$ & 42511 & RFG & 18 & 0.00083 & 0.0249 & 1.6506 & 486.13 & & 0.00355 & 0.1182 & 0.2774 & 0.138 & 0.1689 \\
\hline DC229EL & $11 / 12 / 96$ & 29792 & RFG & 19.37 & 0.00066 & 0.0272 & 1.7956 & 453.69 & & 0.00263 & 0.106 & 0.4028 & 0.1276 & 0.3375 \\
\hline DC230EL & $12 / 2 / 96$ & 25119 & RFG & 19 & 0.00062 & 0.0222 & 1.64 & 463.15 & & 0.00399 & 0.106 & 0.2764 & 0.1237 & 0.3215 \\
\hline DC231EL & $7 / 1 / 96$ & 35919 & RFG & 17.83 & 0.00085 & 0.0842 & 12.15 & 476.2 & & 0.0044 & 0.416 & 0.168 & 0.483 & 0.234 \\
\hline & & & & & & & & & & & & & & \\
\hline & COUNT & & & 9 & 9 & 9 & 9 & 9 & & 9 & 9 & 9 & 9 & 8 \\
\hline & AVG & & & 18.721 & 0.0007 & 0.0311 & 2.332 & 468.95 & & 0.0033 & 0.1167 & 0.3516 & 0.141 & 0.2066 \\
\hline & STD DEV & & & 0.5795 & 0.00013 & 0.0104 & 0.921 & 14.001 & & 0.00072 & 0.0201 & 0.0881 & 0.0272 & 0.088 \\
\hline & $\mathrm{CV}$ & & & 0.0309 & 0.1957 & 0.3351 & 0.3949 & 0.0299 & & 0.2132 & 0.172 & 0.2507 & 0.1924 & 0.4259 \\
\hline
\end{tabular}

Table A-34. 1992/94 Dodge B250 Van: CNG Tests at Lab 1 Round 1

\begin{tabular}{|c|c|c|c|c|c|c|c|c|c|c|c|c|c|}
\hline Decal ID & Date & Odometer & Fuel & MPG & $\mathrm{CH}_{3} \mathrm{CHO}$ & $\mathrm{CH}_{4}$ & $\mathrm{CO}$ & $\mathrm{CO}_{2}$ & $\mathrm{HCHO}$ & $\mathrm{NMHC}$ & $\mathrm{NO}_{\mathrm{x}}$ & THC & Evap. THC \\
\hline $\mathrm{OH} 301 \mathrm{CR}$ & $8 / 2 / 95$ & 5508 & CNG & 12.07 & 0.00015 & 0.365 & 1.01 & 576.7 & 0.00186 & 0.018 & 0.09 & 0.382 & 0.134 \\
\hline $\mathrm{OH} 302 \mathrm{CR}$ & $7 / 27 / 95$ & 6611 & CNG & 12.16 & 0.00013 & 0.258 & 0.71 & 573 & 0.00204 & 0.017 & 0.28 & 0.274 & 0.073 \\
\hline $\mathrm{OH} 303 \mathrm{CR}$ & $7 / 20 / 95$ & 5372 & CNG & 14 & 0.00011 & 0.244 & 0.55 & 497.7 & 0.00169 & 0.027 & 0.32 & 0.27 & 0.06 \\
\hline $\mathrm{OH} 304 \mathrm{CR}$ & $7 / 25 / 95$ & 5622 & CNG & 13.49 & $\ddagger$ & 0.252 & 0.75 & 516.6 & $\ddagger$ & 0.017 & 0.22 & 0.268 & 0.028 \\
\hline $\mathrm{OH} 305 \mathrm{CR}$ & $7 / 31 / 95$ & 4913 & CNG & 12.28 & 0.00022 & 0.247 & 0.58 & 567.8 & 0.00247 & 0.019 & 0.24 & 0.265 & 0.061 \\
\hline $\mathrm{OH} 306 \mathrm{CR}$ & $7 / 20 / 95$ & 3455 & CNG & 12.41 & 0.0002 & 0.232 & 0.43 & 562.2 & 0.00212 & 0.013 & 0.3 & 0.244 & 0.069 \\
\hline $\mathrm{OH} 307 \mathrm{CR}$ & $8 / 2 / 95$ & 4883 & CNG & 12.41 & 0.0002 & 0.221 & 0.53 & 561.8 & 0.00204 & 0.013 & 0.34 & 0.233 & 0.097 \\
\hline $\mathrm{OH} 308 \mathrm{CR}$ & $7 / 25 / 95$ & 6517 & CNG & 13.92 & $\ddagger$ & 0.279 & 0.58 & 500.5 & $\ddagger$ & 0.021 & 0.4 & 0.299 & 0.031 \\
\hline OH309CR & $7 / 27 / 95$ & 5433 & CNG & 13.98 & 0.00015 & 0.259 & 0.49 & 498.7 & 0.00203 & 0.018 & 0.4 & 0.275 & 0.022 \\
\hline $\mathrm{OH} 310 \mathrm{CR}$ & $7 / 31 / 95$ & 5807 & CNG & 12.97 & 0.00017 & 0.346 & 0.88 & 536.6 & 0.00242 & 0.021 & 0.28 & 0.366 & 0.109 \\
\hline & COINT & & & 10 & 8 & 10 & 10 & 10 & 8 & 10 & 10 & 10 & 10 \\
\hline & AVG & & & 12.969 & 0.00017 & 0.27 & 0.651 & 539.16 & 0.0021 & 0.018 & 0.287 & 0.2876 & 0.0684 \\
\hline & STD DEV & & & 0.8044 & 0.00004 & 0.0477 & 0.1839 & 32.971 & 0.00026 & 0.0041 & 0.0914 & 0.049 & 0.0367 \\
\hline & $\mathrm{CV}$ & & & 0.0620 & 0.2295 & 0.1766 & 0.282 & 0.0611 & 0.1251 & 0.222 & 0.3185 & 0.1704 & 0.536 \\
\hline
\end{tabular}


Table A-35. 1992/94 Dodge B250 Van: RFG Tests at Lab 1 Round 1

\begin{tabular}{|c|c|c|c|c|c|c|c|c|c|c|c|c|c|}
\hline Decal ID & Date & Odometer & Fuel & MPG & $\mathrm{CH}_{3} \mathrm{CHO}$ & $\mathrm{CH}_{4}$ & $\mathrm{CO}$ & $\mathrm{CO}_{2}$ & $\mathrm{HCHO}$ & $\mathrm{NMHC}$ & $\mathrm{NO}_{\mathrm{x}}$ & $\mathrm{THC}$ & Evap. THC \\
\hline AR301GRC & $8 / 15 / 95$ & 36218 & RFG & 13.9 & 0.00111 & 0.078 & 5.76 & 616.4 & 0.00612 & 0.315 & 0.88 & 0.379 & 0.901 \\
\hline AR302GRC & $9 / 8 / 95$ & 43839 & RFG & 13.75 & 0.00113 & 0.088 & 5.73 & 623.4 & 0.00582 & 0.376 & 0.86 & 0.448 & 1.259 \\
\hline DT301GRC & $9 / 18 / 95$ & 23991 & RFG & 12.84 & 0.00069 & 0.065 & 3.86 & 671.5 & 0.00428 & 0.218 & 0.68 & 0.27 & 0.646 \\
\hline DT302GRC & 9/18/95 & 26443 & RFG & 14.1 & 0.00095 & 0.074 & 5.37 & 608.1 & 0.00566 & 0.302 & 0.81 & 0.362 & 0.517 \\
\hline DT303GRC & 9/21/95 & 34217 & RFG & 13.9 & 0.00094 & 0.072 & 4.91 & 617.8 & 0.00557 & 0.279 & 0.77 & 0.338 & 0.427 \\
\hline DT304GRC & 9/27/95 & 25006 & RFG & 13.79 & 0.00143 & 0.073 & 5.62 & 621.6 & 0.00528 & 0.288 & 0.57 & 0.348 & 0.553 \\
\hline DT305GRC & 9/26/95 & 36963 & RFG & 14.09 & 0.00128 & 0.076 & 4.68 & 610 & 0.0068 & 0.295 & 0.89 & 0.357 & 0.814 \\
\hline DT306GRC & $4 / 1 / 96$ & 107350 & RFG & 13.65 & 0.00253 & 0.106 & 9.31 & 621.4 & 0.01251 & 0.58 & 1.44 & 0.667 & 0.519 \\
\hline DT307GRC & $4 / 2 / 96$ & 32764 & RFG & 13.37 & 0.00119 & 0.083 & 6.92 & 639.5 & 0.00641 & 0.329 & 0.84 & 0.398 & 0.692 \\
\hline DT308GRC & $4 / 19 / 96$ & 30703 & RFG & 11.52 & 0.00126 & 0.069 & 3.99 & 749 & 0.00609 & 0.249 & 0.84 & 0.304 & 0.671 \\
\hline & COUNT & & & 10 & 10 & 10 & 10 & 10 & 10 & 10 & 10 & 10 & 10 \\
\hline & AVG & & & 13.491 & 0.0013 & 0.078 & 5.615 & 637.87 & 0.0064 & 0.323 & 0.858 & 0.387 & 0.6999 \\
\hline & STD DEV & & & 0.7866 & 0.00049 & 0.0117 & 1.5826 & 43.148 & 0.0022 & 0.0999 & 0.227 & 0.1097 & 0.2431 \\
\hline & $\mathrm{CV}$ & & & 0.0583 & 0.396 & 0.1496 & 0.2818 & 0.0676 & 0.3463 & 0.3092 & 0.2651 & 0.2834 & 0.3474 \\
\hline
\end{tabular}

Table A-36. 1992/94 Dodge B250 Van: CNG Tests at Lab 2 Round 1

\begin{tabular}{|c|c|c|c|c|c|c|c|c|c|c|c|c|c|}
\hline Decal ID & Date & Odometer & Fuel & MPG & $\mathrm{CH}_{3} \mathrm{CHO}$ & $\mathrm{CH}_{4}$ & $\mathrm{CO}$ & $\mathrm{CO}_{2}$ & $\mathrm{HCHO}$ & $\mathrm{NMHC}$ & $\mathrm{NO}_{\mathrm{x}}$ & $\mathrm{THC}$ & Evap. THC \\
\hline DC202CR & $4 / 20 / 94$ & 4906 & CNG & 12.17 & 0.00032 & 0.6412 & 2.2326 & 533.57 & 0.00657 & 0.0258 & 0.3293 & 0.6639 & $\bullet$ \\
\hline DC202CR & $4 / 21 / 94$ & 4925 & CNG & 12.19 & 0.00035 & 0.5636 & 1.3078 & 535.40 & 0.00628 & 0.0227 & 0.5532 & 0.5835 & $\bullet$ \\
\hline Average & & & & 12.18 & 0.000335 & 0.6024 & 1.7702 & 534.49 & 0.006425 & 0.02425 & 0.44125 & 0.6237 & $\bullet$ \\
\hline DC203CR & $11 / 15 / 94$ & 4108 & CNG & 11.55 & 0.00032 & 0.6896 & 1.326 & 563.80 & 0.00725 & 0.067 & 0.633 & 0.756 & 1.4556 \\
\hline DC204CR & $12 / 6 / 94$ & 15026 & CNG & 11.82 & 0.00049 & 0.9928 & 3.6231 & 546.91 & 0.01322 & 0.0422 & 0.5234 & 1.0303 & 0.5909 \\
\hline DC208CR & $4 / 12 / 94$ & 4382 & CNG & 12.37 & 0.00032 & 0.535 & 1.416 & 527.49 & 0.0078 & 0.0364 & 0.3378 & 0.5698 & $\bullet$ \\
\hline DC208CR & $4 / 13 / 94$ & 4407 & $\mathrm{CNG}$ & 12.43 & 0.00026 & 0.5067 & 1.1212 & 524.71 & 0.00635 & 0.0344 & 0.4094 & 0.5396 & $\bullet$ \\
\hline Average & & & & 12.4 & 0.00029 & 0.52085 & 1.2686 & 526.10 & 0.007075 & 0.0354 & 0.3736 & 0.5547 & $\bullet$ \\
\hline DC210CR & $11 / 29 / 94$ & 9492 & CNG & 11.61 & 0.00038 & 0.8428 & 0.4693 & 562.36 & 0.00802 & 0.0413 & 1.2035 & 0.8805 & 0.2509 \\
\hline DC211CR & $5 / 13 / 94$ & 5481 & CNG & 11.73 & 0.00041 & 0.8629 & 1.8766 & 553.90 & 0.00733 & 0.0767 & 0.3722 & 0.9383 & $\bullet$ \\
\hline DC212CR & $11 / 15 / 94$ & 6595 & CNG & 11.11 & 0.00026 & 0.4438 & 1.5938 & 586.70 & 0.00884 & 0.039 & 0.2991 & 0.4821 & 0.0566 \\
\hline DC220CR & $11 / 17 / 94$ & 10091 & CNG & 11.53 & 0.00029 & 0.348 & 0.8387 & 566.82 & 0.00849 & 0.023 & 0.3908 & 0.37 & 0.1409 \\
\hline DC222CR & $11 / 17 / 94$ & 4771 & $\mathrm{CNG}$ & 11.6 & 0.00046 & 0.4692 & 0.8227 & 562.72 & 0.01268 & 0.0495 & 0.9348 & 0.5185 & 0.0532 \\
\hline DC223CR & $12 / 1 / 94$ & 10435 & CNG & 11.51 & 0.00042 & 0.6211 & 2.6836 & 564.40 & 0.00418 & 0.0429 & 0.528 & 0.6623 & 0.1617 \\
\hline NY201CR & $10 / 27 / 94$ & 3951 & $\mathrm{CNG}$ & 11.15 & 0.0004 & 1.2872 & 3.637 & 579.29 & 0.00332 & 0.0485 & 0.1366 & 1.3292 & 0.8547 \\
\hline NY202CR & $10 / 28 / 94$ & 7717 & CNG & 11.49 & 0.00041 & 0.9168 & 1.0538 & 566.96 & 0.01087 & 0.0464 & 0.7234 & 0.9594 & 0.085 \\
\hline & & & & & & & & & & & & & \\
\hline & COUNT & & & 12 & 12 & 12 & 12 & 12 & 12 & 12 & 12 & 12 & 9 \\
\hline & AVG & & & 11.64 & 0.00037 & 0.7164 & 1.7469 & 559.54 & 0.0081 & 0.0447 & 0.5466 & 0.759 & 0.4055 \\
\hline & STD DEV & & & 0.3684 & 0.00007 & 0.2717 & 1.0535 & 17.143 & 0.003 & 0.0153 & 0.2934 & 0.2765 & 0.4797 \\
\hline & CV & & & 0.0316 & 0.1948 & 0.3792 & 0.6030 & 0.0306 & 0.3684 & 0.343 & 0.5367 & 0.364 & 1.183 \\
\hline
\end{tabular}


Table A-37. 1992/94 Dodge B250 Van: RFG Tests at Lab 2 Round 1

\begin{tabular}{|c|c|c|c|c|c|c|c|c|c|c|c|c|c|}
\hline Decal ID & Date & Odometer & Fuel & MPG & $\mathrm{CH}_{3} \mathrm{CHO}$ & $\mathrm{CH}_{4}$ & $\mathrm{CO}$ & $\mathrm{CO}_{2}$ & $\mathrm{HCHO}$ & $\mathrm{NMHC}$ & $\mathrm{NO}_{\mathrm{x}}$ & THC & Evap. THC \\
\hline DC202GRC & $7 / 26 / 94$ & 11449 & RFG & 13.69 & 0.00142 & 0.0666 & 5.6306 & 636.58 & 0.00858 & 0.3003 & 0.8617 & 0.3533 & \begin{tabular}{|l}
0.5542 \\
\end{tabular} \\
\hline DC203GRC & $8 / 11 / 94$ & 5086 & RFG & 13.09 & 0.00104 & 0.0712 & 5.5072 & 667.49 & 0.00617 & 0.2808 & 0.8535 & 0.3375 & 0.3826 \\
\hline DC204GRC & $1 / 25 / 95$ & 8115 & RFG & 13.08 & 0.00159 & 0.0618 & 5.1202 & 667.91 & 0.01043 & 0.2472 & 0.8556 & 0.2984 & 0.4137 \\
\hline DC205GRC & $1 / 19 / 95$ & 3527 & RFG & 13.11 & 0.00151 & 0.0666 & 4.9574 & 667.07 & 0.0096 & 0.2624 & 0.7151 & 0.318 & 0.4613 \\
\hline DC208GRC & $3 / 15 / 95$ & 22195 & RFG & 13.32 & 0.00185 & 0.0799 & 6.7894 & 653.14 & 0.01309 & 0.2957 & 0.8748 & 0.3623 & 0.6277 \\
\hline DC209GRC & $7 / 15 / 94$ & 15312 & RFG & 13.84 & 0.00099 & 0.0584 & 3.8402 & 632.72 & 0.00626 & 0.2164 & 0.8525 & 0.2629 & 0.3249 \\
\hline DC209GRC & $7 / 18 / 94$ & 15339 & RFG & 13.71 & 0.00097 & 0.06 & 4.4795 & 638.04 & 0.0055 & 0.2366 & 0.7931 & 0.2843 & 0.3795 \\
\hline Average & & & & 13.775 & 0.00098 & 0.0592 & 4.15985 & 635.38 & 0.00588 & 0.2265 & 0.8228 & 0.2736 & 0.3522 \\
\hline DC210GRC & $8 / 3 / 94$ & 10916 & RFG & 13.57 & 0.00166 & 0.0734 & 4.6491 & 643.63 & 0.00632 & 0.3121 & 1.0212 & 0.3705 & 0.3539 \\
\hline DC211GRC & $7 / 11 / 94$ & 6277 & RFG & 13.78 & 0.00104 & 0.0581 & 4.4168 & 634.69 & 0.0047 & 0.2467 & 0.589 & 0.293 & 0.765 \\
\hline DC211GRC & $7 / 12 / 94$ & 6304 & RFG & 13.8 & 0.00112 & 0.0486 & 3.6444 & 635.37 & 0.00416 & 0.2457 & 0.5534 & 0.2844 & 0.6398 \\
\hline Average & & & & 13.79 & 0.00108 & 0.05335 & 4.0306 & 635.03 & 0.00443 & 0.2462 & 0.5712 & 0.2887 & 0.7024 \\
\hline NJ201GRC & $10 / 13 / 94$ & 20423 & RFG & 12.43 & 0.00244 & 0.096 & 8.1747 & 698.34 & 0.00518 & 0.4139 & 0.6588 & 0.4943 & 0.7744 \\
\hline NJ202GRC & $10 / 12 / 94$ & 12381 & RFG & 12.21 & 0.00234 & 0.0979 & 9.3336 & 709.17 & 0.00584 & 0.4342 & 0.6041 & 0.5164 & 0.8197 \\
\hline NJ203GRC & $10 / 14 / 94$ & 15463 & RFG & 12.56 & 0.0021 & 0.0938 & 7.6116 & 692 & 0.006 & 0.3387 & 0.6483 & 0.4164 & 1.0386 \\
\hline NY201GRC & $10 / 21 / 94$ & 3550 & RFG & 12.23 & 0.00137 & 0.0598 & 4.5631 & 715.51 & 0.00663 & 0.265 & 0.3939 & 0.3151 & 0.7587 \\
\hline NY202GRC & $10 / 20 / 94$ & 13879 & RFG & 13.14 & 0.00288 & 0.0971 & 7.3946 & 660.98 & 0.00813 & 0.3497 & 1.0246 & 0.4303 & 0.8348 \\
\hline & COUNT & & & 13 & 13 & 13 & 13 & 13 & 13 & 13 & 13 & 13 & 13 \\
\hline & AVG & & & 13.076 & 0.0017 & 0.0751 & 5.994 & 667.86 & 0.0074 & 0.3056 & 0.762 & 0.3673 & 0.6211 \\
\hline & STD DEV & & & 0.5652 & 0.00058 & 0.0161 & 1.6932 & 28.063 & 0.0024 & 0.0638 & 0.1831 & 0.0768 & 0.2202 \\
\hline & $\mathrm{CV}$ & & & 0.0432 & 0.3416 & 0.2144 & 0.2825 & 0.0420 & 0.3308 & 0.209 & 0.2403 & 0.209 & 0.3546 \\
\hline
\end{tabular}


Table A-38. 1992/94 Dodge B250 Van: CNG Tests at Lab 3 Round 1

\begin{tabular}{|c|c|c|c|c|c|c|c|c|c|c|c|c|c|}
\hline Decal ID & Date & Odometer & Fuel & MPG & $\mathrm{CH}_{3} \mathrm{CHO}$ & $\mathrm{CH}_{4}$ & $\mathrm{CO}$ & $\mathrm{CO}_{2}$ & $\mathrm{HCHO}$ & $\mathrm{NMHC}$ & $\mathrm{NO}_{\mathrm{x}}$ & $\mathrm{THC}$ & Evap. THC \\
\hline DV203CR & $7 / 15 / 94$ & 22245 & CNG & 13.41 & 0.0001 & 0.7312 & 0.394 & 506.89 & 0.0024 & 0.0354 & 1.6684 & 0.7666 & $\bullet$ \\
\hline DV203CR & $7 / 17 / 94$ & 22272 & CNG & 13.58 & 0.0001 & 0.7717 & 0.6207 & 499.83 & 0.0025 & 0.067 & 1.433 & 0.8387 & $\bullet$ \\
\hline Average & & & & 13.50 & 0.0001 & 0.75145 & 0.50735 & 503.36 & 0.00245 & 0.0512 & 1.5507 & 0.80265 & $\bullet$ \\
\hline DV204CR & $2 / 16 / 95$ & 5271 & CNG & 13.32 & 0.0007 & 1.6612 & 18.308 & 479.17 & 0.0108 & 0.1836 & 1.3804 & 1.8448 & 1.3659 \\
\hline DV205CR & $5 / 16 / 94$ & 10107 & CNG & 13.12 & 0.0001 & 0.7726 & 2.1214 & 515.08 & 0.0018 & 0.1487 & 0.2565 & 0.9213 & $\bullet$ \\
\hline DV205CR & $5 / 18 / 94$ & 10141 & CNG & 13.03 & 0.0002 & 0.905 & 1.3144 & 519.94 & 0.0023 & 0.0848 & 0.3631 & 0.9898 & $\bullet$ \\
\hline Average & & & & 13.07 & 0.00015 & 0.8388 & 1.7179 & 517.51 & 0.00205 & 0.11675 & 0.3098 & 0.95555 & $\bullet$ \\
\hline DV206CR & $4 / 4 / 95$ & 4522 & CNG & 13.19 & 0 & 0.5615 & 4.2485 & 509.89 & 0.0015 & 0.037 & 0.1124 & 0.5985 & 2.5033 \\
\hline DV208CR & $6 / 15 / 94$ & 4180 & CNG & 13.45 & 0.0002 & 0.4378 & 2.2634 & 503.42 & 0.0018 & 0.0257 & 0.2988 & 0.4635 & $\bullet$ \\
\hline DV209CR & $6 / 10 / 94$ & 3607 & CNG & 13.31 & 0.0001 & 0.4324 & 2.2416 & 508.89 & 0.0014 & 0.0223 & 0.1724 & 0.4547 & $\bullet$ \\
\hline DV210CR & $7 / 1 / 94$ & 4830 & CNG & 13.74 & 0.0001 & 0.4964 & 2.1915 & 492.38 & 0.0013 & 0.0531 & 0.2055 & 0.5495 & $\bullet$ \\
\hline DV211CR & $3 / 7 / 95$ & 4342 & CNG & 13.09 & 0 & 1.1719 & 7.3207 & 507.24 & 0.0017 & 0.0398 & 0.297 & 1.2117 & 0.2892 \\
\hline DV212CR & $3 / 1 / 95$ & 9514 & CNG & 15.55 & 0.0001 & 0.6196 & 0.7192 & 436.66 & 0.0018 & 0.0602 & 0.9169 & 0.6765 & 0.0877 \\
\hline DV214CR & $3 / 14 / 95$ & 5790 & CNG & 12.51 & 0.0001 & 0.5793 & 3.3715 & 539.26 & 0.0015 & 0.0408 & 0.1449 & 0.6201 & 0.5133 \\
\hline DV215CR & 9/13/95 & 10252 & CNG & 13.92 & 0.0001 & 0.6129 & 1.2924 & 487.12 & 0.0014 & 0.0306 & 0.6804 & 0.6508 & 0.3211 \\
\hline DV217CR & $4 / 27 / 94$ & 4253 & CNG & 13.47 & 0.0001 & 0.6418 & 1.2116 & 503.54 & 0.0016 & 0.085 & 0.4094 & 0.7268 & $\bullet$ \\
\hline DV217CR & $5 / 11 / 94$ & 4302 & CNG & 13.15 & 0.0001 & 0.7071 & 0.8014 & 516.28 & 0.002 & 0.1214 & 0.5035 & 0.8285 & $\bullet$ \\
\hline Average & & & & 13.31 & 0.0001 & 0.67445 & 1.0065 & 509.91 & 0.0018 & 0.1032 & 0.45645 & 0.77765 & $\bullet$ \\
\hline DV218CR & $3 / 7 / 95$ & 5647 & CNG & 13.57 & 0 & 0.6082 & 2.4929 & 497.82 & 0.0012 & 0.0353 & 0.4935 & 0.6435 & $\bullet$ \\
\hline DV219CR & $2 / 22 / 95$ & 2121 & CNG & 12.84 & 0 & 0.4035 & 1.2628 & 529.33 & 0.0014 & 0.023 & 0.0858 & 0.4265 & 0.2223 \\
\hline DV220CR & $4 / 11 / 95$ & 7991 & CNG & 13.65 & 0.0002 & 1.061 & 5.2411 & 489.55 & 0.0022 & 0.0504 & 0.7511 & 1.1114 & 0.0587 \\
\hline & COUNT & & & 14 & 14 & 14 & 14 & 14 & 14 & 14 & 13 & 14 & 7 \\
\hline & AVG & & & 13.32 & 0.000089 & 0.6606 & 2.5627 & 502.31 & 0.00168 & 0.0492 & 0.3788 & 0.7102 & 0.5708 \\
\hline & STD DEV & & & 0.3699 & 0.000068 & 0.2287 & 1.9156 & 23.752 & 0.00036 & 0.0283 & 0.2646 & 0.2398 & 0.8657 \\
\hline & $\mathrm{CV}$ & & & 0.0278 & 0.7665 & 0.3461 & 0.7475 & 0.0473 & 0.2166 & 0.5752 & 0.6985 & 0.3377 & 1.5166 \\
\hline
\end{tabular}


Table A-39. 1992/94 Dodge B250 Van: RFG Tests at Lab 3 Round 1

\begin{tabular}{|c|c|c|c|c|c|c|c|c|c|c|c|c|c|}
\hline Decal ID & Date & Odometer & Fuel & MPG & $\mathrm{CH}_{3} \mathrm{CHO}$ & $\mathrm{CH}_{4}$ & $\mathrm{CO}$ & $\mathrm{CO}_{2}$ & $\mathrm{HCHO}$ & $\mathrm{NMHC}$ & $\mathrm{NO}_{\mathrm{x}}$ & $\mathrm{THC}$ & Evap. THC \\
\hline DV203GRC & $3 / 21 / 95$ & 29165 & RFG & 14.00 & 0.0007 & 0.0625 & 4.3218 & 611.64 & 0.003 & 0.261 & 0.8026 & 0.3235 & 1.2378 \\
\hline DV204GRC & $5 / 2 / 95$ & 17831 & RFG & 13.25 & 0.0009 & 0.057 & 4.8186 & 646.09 & 0.0028 & 0.2798 & 0.5782 & 0.3368 & 0.9169 \\
\hline DV206GRC & $3 / 17 / 95$ & 10962 & RFG & 13.0 & 0.0006 & 0.0625 & 3.5236 & 660.96 & 0.0026 & 0.2294 & 1.1198 & 0.2919 & 0.8809 \\
\hline DV207GRC & $3 / 28 / 95$ & 17687 & RFG & 13.71 & 0.001 & 0.0553 & 4.0869 & 625.12 & 0.0036 & 0.2487 & 0.6583 & 0.304 & 1.3379 \\
\hline DV208GRC & $3 / 17 / 94$ & 10004 & RFG & 13.82 & 0.0022 & 0.051 & 4.2185 & 619.79 & 0.0055 & 0.3051 & 0.5599 & 0.3561 & 0.8638 \\
\hline DV208GRC & $3 / 18 / 94$ & 10030 & RFG & 13.72 & 0.0024 & 0.0471 & 3.5191 & 625.41 & 0.0074 & 0.3778 & 0.5957 & 0.4249 & 0.7558 \\
\hline Average & & & & 13.77 & 0.0023 & 0.04905 & 3.8688 & 622.60 & 0.00645 & 0.34145 & 0.5778 & 0.3905 & 0.8098 \\
\hline DV209GRC & $4 / 18 / 95$ & 10123 & RFG & 13.96 & 0.001 & 0.0459 & 3.58 & 614.97 & 0.0037 & 0.2206 & 0.4855 & 0.2665 & 1.5237 \\
\hline DV210GRC & $4 / 13 / 95$ & 30493 & RFG & 14.44 & 0.0013 & 0.0626 & 4.5459 & 592.49 & 0.0044 & 0.2664 & 0.686 & 0.329 & 1.3368 \\
\hline DV211GRC & $4 / 20 / 95$ & 27240 & RFG & 13.83 & 0.002 & 0.0656 & 4.4495 & 619.01 & 0.0065 & 0.3237 & 0.518 & 0.3893 & 1.6569 \\
\hline DV212GRC & $5 / 26 / 94$ & 3875 & RFG & 13.46 & 0.0008 & 0.0453 & 2.8978 & 639.08 & 0.0029 & 0.2102 & 0.5457 & 0.2555 & 1.5393 \\
\hline DV214GRC & $4 / 27 / 95$ & 7287 & RFG & 14.60 & 0.0006 & 0.0494 & 3.8342 & 587.02 & 0.0023 & 0.2305 & 0.6358 & 0.2799 & 1.1214 \\
\hline DV215GRC & $4 / 8 / 94$ & 4291 & RFG & 14.31 & 0.0009 & 0.0432 & 3.8976 & 599.21 & 0.0033 & 0.2873 & 0.594 & 0.3305 & 0.8125 \\
\hline DV215GRC & $4 / 11 / 94$ & 4325 & RFG & 14.03 & 0.0007 & 0.048 & 3.564 & 611.50 & 0.003 & 0.2524 & 0.6234 & 0.3004 & 0.6688 \\
\hline Average & & & & 14.17 & 0.0008 & 0.0456 & 3.7308 & 605.35 & 0.00315 & 0.26985 & 0.6087 & 0.31545 & 0.7407 \\
\hline DV216GRC & $6 / 24 / 94$ & 8937 & RFG & 13.86 & 0.0009 & 0.0513 & 4.009 & 618.43 & 0.0037 & 0.2549 & 0.9035 & 0.3062 & 0.4798 \\
\hline DV216GRC & $6 / 28 / 94$ & 8963 & RFG & 14.21 & 0.0008 & 0.0467 & 3.5984 & 603.63 & 0.0033 & 0.266 & 0.9029 & 0.3127 & * \\
\hline Average & & & & 14.04 & 0.00085 & 0.049 & 3.8037 & 611.03 & 0.0035 & 0.26045 & 0.9032 & 0.30945 & 0.4798 \\
\hline DV218GRC & $5 / 9 / 95$ & 4110 & RFG & 14.57 & 0.0007 & 0.0458 & 3.4402 & 589.13 & 0.0029 & 0.2317 & 0.7511 & 0.2775 & 0.4543 \\
\hline DV219GRC & $5 / 11 / 95$ & 4484 & RFG & 14.27 & 0.0008 & 0.0537 & 4.7317 & 599.35 & 0.0029 & 0.2355 & 0.8565 & 0.2892 & 0.5415 \\
\hline & COUNT & & & 14 & 14 & 14 & 14 & 14 & 14 & 14 & 14 & 14 & 14 \\
\hline & AVG & & & 13.934 & 0.001 & 0.0535 & 3.9738 & 615.99 & 0.0036 & 0.2578 & 0.695 & 0.3113 & 1.0413 \\
\hline & STD DEV & & & 0.4768 & 0.00051 & 0.0074 & 0.5473 & 21.742 & 0.0013 & 0.0377 & 0.1758 & 0.041 & 0.409 \\
\hline & $\mathrm{CV}$ & & & 0.0342 & 0.50067 & 0.138 & 0.1377 & 0.0353 & 0.3637 & 0.1464 & 0.2530 & 0.1311 & 0.393 \\
\hline
\end{tabular}


Table A-40. 1992/94 Dodge B250 Van: CNG Tests at Lab 1 Round 2

\begin{tabular}{|c|c|c|c|c|c|c|c|c|c|c|c|c|c|}
\hline Decal ID & Date & Odometer & Fuel & MPG & $\mathrm{CH}_{3} \mathrm{CHO}$ & $\mathrm{CH}_{4}$ & $\mathrm{CO}$ & $\mathrm{CO}_{2}$ & $\mathrm{HCHO}$ & $\mathrm{NMHC}$ & $\mathrm{NO}_{\mathrm{x}}$ & THC & Evap. THC \\
\hline $\mathrm{OH} 301 \mathrm{CR}$ & $1 / 15 / 97$ & 13434 & CNG & 11.75 & 0.00016 & 0.299 & 0.71 & 558 & 0.00212 & 0.02 & 0.22 & 0.318 & 0.655 \\
\hline $\mathrm{OH} 302 \mathrm{CR}$ & $6 / 24 / 97$ & 14497 & CNG & 11.8 & 0.00016 & 0.325 & 0.54 & 556 & 0.00229 & 0.019 & 0.48 & 0.343 & 0.969 \\
\hline $\mathrm{OH} 302 \mathrm{CR}$ & $6 / 25 / 97$ & 14516 & CNG & 11.82 & 0.00017 & 0.341 & 0.74 & 554.5 & 0.00249 & 0.023 & 0.49 & 0.363 & 0.054 \\
\hline Average & & & & 11.81 & 0.000165 & 0.333 & 0.64 & 555.25 & 0.00239 & 0.021 & 0.485 & 0.353 & 0.5115 \\
\hline $\mathrm{OH} 303 \mathrm{CR}$ & $8 / 5 / 97$ & 12557 & CNG & 13.23 & 0.00031 & 0.368 & 0.61 & 495.3 & 0.00252 & 0.025 & 0.45 & 0.393 & 0.302 \\
\hline $\mathrm{OH} 304 \mathrm{CR}$ & $8 / 1 / 97$ & 12467 & CNG & 13.69 & 0.00055 & 0.4 & 0.74 & 478.5 & 0.00237 & 0.028 & 0.5 & 0.426 & 0.105 \\
\hline $\mathrm{OH} 305 \mathrm{CR}$ & $12 / 2 / 96$ & 11457 & CNG & 11.64 & 0.00015 & 0.458 & 0.87 & 562.9 & 0.00232 & 0.026 & 0.83 & 0.482 & 0.275 \\
\hline $\mathrm{OH} 305 \mathrm{CR}$ & $12 / 10 / 96$ & 11503 & $\mathrm{CNG}$ & 11.57 & 0.00021 & 0.305 & 0.54 & 566.9 & 0.00254 & 0.017 & 0.55 & 0.315 & 0.157 \\
\hline Average & & & & 11.605 & 0.00018 & 0.3815 & 0.705 & 564.9 & 0.00243 & 0.0215 & 0.69 & 0.3985 & 0.216 \\
\hline $\mathrm{OH} 306 \mathrm{CR}$ & $7 / 18 / 97$ & 8047 & CNG & 11.73 & 0.00039 & 0.423 & 1.57 & 557.2 & 0.00284 & 0.023 & 0.66 & 0.444 & $\ddagger$ \\
\hline $\mathrm{OH} 307 \mathrm{CR}$ & $12 / 10 / 96$ & 9014 & CNG & 11.74 & 0.00016 & 0.208 & 0.38 & 559.6 & 0.00144 & 0.014 & 0.47 & 0.222 & 0.241 \\
\hline $\mathrm{OH} 308 \mathrm{CR}$ & $1 / 28 / 97$ & 12246 & CNG & 13.43 & 0.00011 & 0.304 & 0.49 & 488.5 & 0.00154 & 0.023 & 0.35 & 0.326 & 0.73 \\
\hline OH309CR & $7 / 11 / 97$ & 12295 & CNG & 13.7 & 0.00016 & 0.513 & 0.61 & 477.9 & 0.00271 & 0.035 & 0.77 & 0.547 & 0.908 \\
\hline $\mathrm{OH} 309 \mathrm{CR}$ & $7 / 14 / 97$ & 12325 & CNG & 13.5 & 0.00034 & 0.519 & 0.66 & 484.9 & 0.00289 & 0.027 & 0.82 & 0.541 & 0.899 \\
\hline Average & & & & 13.6 & 0.00025 & 0.516 & 0.635 & 481.4 & 0.0028 & 0.031 & 0.795 & 0.544 & 0.9035 \\
\hline $\mathrm{OH} 310 \mathrm{CR}$ & $7 / 14 / 97$ & 15527 & CNG & 12.44 & 0.00035 & 0.39 & 0.86 & 526.7 & 0.00269 & 0.018 & 0.59 & 0.406 & 0.387 \\
\hline & COUNT & & & 10 & 10 & 10 & 10 & 10 & 10 & 10 & 10 & 10 & 9 \\
\hline & AVG & & & 12.503 & 0.00026 & 0.362 & 0.734 & 526.54 & 0.0023 & 0.0225 & 0.521 & 0.383 & 0.4501 \\
\hline & STD DEV & & & 0.884 & 0.00014 & 0.083 & 0.3223 & 36.647 & 0.00048 & 0.0048 & 0.169 & 0.086 & 0.2677 \\
\hline & $\mathrm{CV}$ & & & 0.0707 & 0.5229 & 0.2291 & 0.4391 & 0.0696 & 0.2097 & 0.2158 & 0.3243 & 0.224 & 0.5947 \\
\hline
\end{tabular}

Table A-41. 1992/94 Dodge B250 Van: RFG Tests at Lab 1 Round 2

\begin{tabular}{|c|c|c|c|c|c|c|c|c|c|c|c|c|c|}
\hline Decal ID & Date & Odometer & Fuel & MPG & $\mathrm{CH}_{3} \mathrm{CHO}$ & $\mathrm{CH}_{4}$ & $\mathrm{CO}$ & $\mathrm{CO}_{2}$ & $\mathrm{HCHO}$ & $\mathrm{NMHC}$ & $\mathrm{NO}_{\mathrm{x}}$ & $\mathrm{THC}$ & Evap. THC \\
\hline AR301GRC & $8 / 28 / 97$ & 60261 & RFG & 12.41 & 0.0011 & 0.089 & 7.24 & 675.7 & 0.0049 & 0.345 & 0.94 & 0.416 & 0.823 \\
\hline DT301GRC & $2 / 4 / 97$ & 33050 & RFG & 13.76 & 0.00097 & 0.078 & 5.61 & 623.9 & 0.00491 & 0.331 & 0.89 & 0.393 & 0.729 \\
\hline DT302GRC & $10 / 14 / 97$ & 45288 & RFG & 13.91 & 0.00141 & 0.087 & 7.14 & 601.6 & 0.00624 & 0.363 & 0.79 & 0.436 & 0.531 \\
\hline DT303GRC & $1 / 24 / 97$ & 51733 & RFG & 14 & 0.00155 & 0.093 & 9.13 & 607.3 & 0.00713 & 0.416 & 0.99 & 0.491 & 0.647 \\
\hline DT303GRC & $1 / 31 / 97$ & 51772 & RFG & 14.08 & 0.00134 & 0.08 & 6.6 & 607.8 & 0.00592 & 0.391 & 0.86 & 0.455 & 0.896 \\
\hline Average & & & & 14.04 & 0.001445 & 0.0865 & 7.865 & 607.55 & 0.006525 & 0.4035 & 0.925 & 0.473 & 0.7715 \\
\hline DT304GRC & $10 / 10 / 97$ & 40152 & RFG & 13.91 & 0.00123 & 0.078 & 7.55 & 601.2 & 0.0055 & 0.345 & 0.78 & 0.409 & 1.026 \\
\hline DT305GRC & $1 / 27 / 97$ & 55239 & RFG & 13.88 & 0.00182 & 0.087 & 5.76 & 617.9 & 0.00804 & 0.388 & 1.1 & 0.458 & 1.301 \\
\hline DT307GRC & $7 / 22 / 97$ & 42417 & RFG & 13.54 & 0.00194 & 0.107 & 8.81 & 615.8 & 0.00753 & 0.408 & 1.19 & 0.494 & 1.294 \\
\hline DT307GRC & $7 / 23 / 97$ & 42436 & RFG & 15.13 & 0.00199 & 0.095 & 7.95 & 551 & 0.00828 & 0.368 & 0.83 & 0.443 & 1.159 \\
\hline Average & & & & 14.335 & 0.001965 & 0.101 & 8.38 & 583.4 & 0.007905 & 0.388 & 1.01 & 0.4685 & 1.2265 \\
\hline DT308GRC & $2 / 6 / 97$ & 37896 & RFG & 13.62 & 0.00106 & 0.075 & 5.22 & 631.5 & 0.00503 & 0.334 & 0.67 & 0.393 & 0.591 \\
\hline & & & & & & & & & & & & & \\
\hline & COUNT & & & 8 & 8 & 8 & 8 & 8 & 8 & 8 & 8 & 8 & 8 \\
\hline & AVG & & & 13.733 & 0.0014 & 0.0852 & 6.846 & 617.84 & 0.0061 & 0.3622 & 0.8881 & 0.4308 & 0.8749 \\
\hline & STD DEV & & & 0.5738 & 0.00036 & 0.0083 & 1.1637 & 27.784 & 0.0013 & 0.0278 & 0.1377 & 0.0328 & 0.2832 \\
\hline & $\mathrm{CV}$ & & & 0.0418 & 0.2625 & 0.0972 & 0.17 & 0.045 & 0.2097 & 0.0767 & 0.155 & 0.0761 & 0.3237 \\
\hline
\end{tabular}


Table A-42. 1992/94 Dodge B250 Van: CNG Tests at Lab 2 Round 2

\begin{tabular}{|c|c|c|c|c|c|c|c|c|c|c|c|c|c|}
\hline Decal ID & Date & Odometer & Fuel & MPG & $\mathrm{CH}_{3} \mathrm{CHO}$ & $\mathrm{CH}_{4}$ & $\mathrm{CO}$ & $\mathrm{CO}_{2}$ & $\mathrm{HCHO}$ & $\mathrm{NMHC}$ & $\mathrm{NO}_{\mathrm{x}}$ & THC & Evap. THC \\
\hline DC202CR & $7 / 10 / 95$ & 8077 & CNG & 11.77 & 0.00027 & 1.0776 & 1.7787 & 552.14 & 0.0066 & 0.0591 & 0.3925 & 1.1326 & 0.3865 \\
\hline DC203CR & $12 / 15 / 95$ & 5377 & CNG & 12.05 & 0.00046 & 1.1851 & 1.6078 & 539.25 & 0.00627 & 0.0824 & 0.6246 & 1.3641 & 0.205 \\
\hline DC204CR & $12 / 12 / 95$ & 23563 & CNG & 12.1 & 0.00039 & 1.9101 & 3.1705 & 532.28 & 0.00523 & 0.1335 & 1.5548 & 2.0382 & 0.0923 \\
\hline DC208CR & $7 / 12 / 95$ & 5926 & CNG & 12.06 & 0.00024 & 0.4939 & 1.094 & 541.20 & 0.00688 & 0.0792 & 0.3608 & 0.5748 & 0.215 \\
\hline DC210CR & $1 / 23 / 96$ & 18104 & CNG & 12.3 & 0.00032 & 1.2282 & 0.6899 & 528.53 & 0.00741 & 0.1032 & 1.4599 & 1.3292 & 0.5173 \\
\hline DC211CR & $6 / 2 / 95$ & 10857 & CNG & 11.01 & 0.00048 & 0.729 & 1.2682 & 592.05 & 0.00921 & 0.0424 & 0.3964 & 0.7688 & 0.4859 \\
\hline DC212CR & $1 / 30 / 96$ & 8943 & CNG & 11.79 & 0.00028 & 0.5537 & 2.6021 & 550.79 & 0.00452 & 0.046 & 0.1059 & 0.5987 & 0.3825 \\
\hline DC220CR & $12 / 12 / 95$ & 12084 & CNG & 11.84 & 0.0003 & 0.3754 & 1.3699 & 550.90 & 0.0034 & 0.0525 & 0.2371 & 0.4287 & 0.1117 \\
\hline DC222CR & $12 / 13 / 95$ & 7907 & CNG & 11.91 & 0.00032 & 0.6383 & 0.76 & 547.76 & 0.00519 & 0.0747 & 1.1319 & 0.7133 & 0.0464 \\
\hline DC223CR & $7 / 31 / 96$ & 24824 & CNG & 11.84 & 0.00068 & 0.8105 & 0.5811 & 551.26 & 0.00843 & 0.0371 & 1.5381 & 0.844 & 0.5274 \\
\hline NY201CR & $2 / 15 / 96$ & 5446 & CNG & 11.86 & 0.0004 & 1.3332 & 2.8986 & 544.71 & 0.00432 & 0.0912 & 0.3044 & 1.4206 & 0.7459 \\
\hline NY202CR & $2 / 13 / 96$ & 10233 & CNG & 12.14 & 0.00031 & 0.9478 & 1.4213 & 535.63 & 0.00559 & 0.0522 & 0.9742 & 0.9964 & 0.0871 \\
\hline & COUNT & & & 12 & 12 & 12 & 12 & 12 & 12 & 12 & 12 & 12 & 12 \\
\hline & AVG & & & 11.889 & 0.00037 & 0.9402 & 1.6035 & 547.21 & 0.0061 & 0.0711 & 0.757 & 1.017 & 0.3169 \\
\hline & STD DEV & & & 0.3211 & 0.0001 & 0.4345 & 0.864 & 16.208 & 0.0017 & 0.029 & 0.5448 & 0.461 & 0.223 \\
\hline & $\mathrm{CV}$ & & & 0.027 & 0.3313 & 0.462 & 0.5388 & 0.0296 & 0.2824 & 0.402 & 0.7199 & 0.4531 & 0.704 \\
\hline
\end{tabular}

Table A-43. 1992/94 Dodge B250 Van: RFG Tests at Lab 2 Round 2

\begin{tabular}{|c|c|c|c|c|c|c|c|c|c|c|c|c|c|}
\hline Decal ID & Date & Odometer & Fuel & MPG & $\mathrm{CH}_{3} \mathrm{CHO}$ & $\mathrm{CH}_{4}$ & $\mathrm{CO}$ & $\mathrm{CO}_{2}$ & $\mathrm{HCHO}$ & $\mathrm{NMHC}$ & $\mathrm{NO}_{\mathrm{x}}$ & THC & Evap. THC \\
\hline DC202GRC & $6 / 2 / 95$ & 19331 & RFG & 13.82 & 0.00197 & 0.0855 & 6.9213 & 629.17 & 0.00861 & 0.3048 & 0.9641 & 0.3729 & 0.3121 \\
\hline DC203GRC & $5 / 22 / 95$ & 8642 & RFG & 13.45 & 0.00161 & 0.0749 & 5.8232 & 648.36 & 0.00651 & 0.3049 & 0.7 & 0.3675 & 0.9556 \\
\hline DC204GRC & $2 / 22 / 96$ & 14336 & RFG & 13.5 & 0.0011 & 0.0679 & 4.643 & 647.69 & 0.00416 & 0.2519 & 0.8829 & 0.3059 & 0.7377 \\
\hline DC205GRC & $2 / 16 / 96$ & 15101 & RFG & 13.7 & 0.00143 & 0.0757 & 5.7762 & 636.13 & 0.00416 & 0.3205 & 0.9657 & 0.3807 & 0.6805 \\
\hline DC208GRC & $7 / 14 / 96$ & 32165 & RFG & 13.6 & 0.00155 & 0.0747 & 5.894 & 641.21 & 0.00833 & 0.3048 & 1.0227 & 0.3643 & 0.7798 \\
\hline DC209GRC & $6 / 21 / 95$ & 29589 & RFG & 13.82 & 0.00207 & 0.0757 & 5.6656 & 631.34 & 0.01067 & 0.3023 & 1.0361 & 0.3626 & 0.5517 \\
\hline DC210GRC & $6 / 23 / 95$ & 21733 & RFG & 13.73 & 0.00243 & 0.0872 & 6.7691 & 632.93 & 0.0097 & 0.3373 & 0.9081 & 0.4067 & 0.5328 \\
\hline DC211GRC & $8 / 10 / 95$ & 13088 & RFG & 13.65 & 0.0012 & 0.0735 & 5.597 & 638.53 & 0.00742 & 0.2757 & 0.946 & 0.3342 & 0.8102 \\
\hline NJ201GRC & $12 / 4 / 95$ & 26407 & RFG & 13.37 & 0.00174 & 0.0936 & 7.4255 & 649.22 & 0.00564 & 0.4189 & 0.7576 & 0.4934 & 0.6908 \\
\hline NJ202GRC & $12 / 7 / 95$ & 15625 & RFG & 13.1 & 0.00143 & 0.0721 & 6.0946 & 664.82 & 0.00478 & 0.4052 & 0.6237 & 0.4626 & 0.9195 \\
\hline NJ203GRC & $12 / 1 / 95$ & 18925 & RFG & 13.29 & 0.00392 & 0.0817 & 6.4836 & 654.57 & 0.00521 & 0.3781 & 0.6344 & 0.4432 & 0.9907 \\
\hline NY201GRC & $11 / 20 / 95$ & 3834 & RFG & 12.57 & 0.00102 & 0.0512 & 4.18 & 697.47 & 0.00427 & 0.2516 & 0.4108 & 0.2924 & 1.0382 \\
\hline NY202GRC & $11 / 27 / 95$ & 19477 & RFG & 13.22 & 0.00121 & 0.0819 & 6.1239 & 659.46 & 0.00419 & 0.3732 & 0.6738 & 0.4384 & 1.442 \\
\hline & COUNT & & & 13 & 12 & 13 & 13 & 12 & 13 & 13 & 13 & 13 & 13 \\
\hline & AVG & & & 13.448 & $\frac{12}{0.00156}$ & 0.0766 & 5.954 & $\frac{12}{644.45}$ & 0.0064 & 0.3253 & 0.8097 & 0.3865 & 0.8032 \\
\hline & STD DEV & & & 0.349 & 0.00043 & 0.0104 & 0.8767 & 11.457 & 0.0023 & 0.0543 & 0.1906 & 0.060 & 0.2807 \\
\hline & $\mathrm{CV}$ & & & 0.0259 & 0.2734 & 0.1356 & 0.1473 & 0.0178 & 0.3556 & 0.167 & 0.2354 & 0.1553 & 0.3494 \\
\hline
\end{tabular}


Table A-44. 1992/94 Dodge B250 Van: CNG Tests at Lab 3 Round 2

\begin{tabular}{|c|c|c|c|c|c|c|c|c|c|c|c|c|c|}
\hline Decal ID & Date & Odometer & Fuel & MPG & $\mathrm{CH}_{3} \mathrm{CHO}$ & $\mathrm{CH}_{4}$ & $\mathrm{CO}$ & $\mathrm{CO}_{2}$ & $\mathrm{HCHO}$ & $\mathrm{NMHC}$ & $\mathrm{NO}_{\mathrm{x}}$ & THC & Evap. THC \\
\hline DV203CR & $1 / 9 / 96$ & 29585 & CNG & 14.15 & 0.0004 & 0.4127 & 3.2595 & 476.28 & 0.003 & 0.2377 & 0.2578 & 0.6549 & 0.0842 \\
\hline DV204CR & $1 / 5 / 96$ & 6857 & CNG & 13.59 & 0.0016 & 1.34 & 15.203 & 472.9 & 0.0183 & 0.8451 & 1.476 & 2.2013 & 0.3189 \\
\hline DV205CR & $8 / 17 / 95$ & 22821 & CNG & 13.11 & 0.0001 & 1.0357 & 1.7903 & 515.42 & 0.0011 & 0.0524 & 0.5604 & 1.1005 & 0.5263 \\
\hline DV206CR & $1 / 24 / 96$ & 5368 & CNG & 13.21 & 0.0002 & 0.3879 & 3.7094 & 510.07 & 0.002 & 0.108 & 0.0985 & 0.5005 & 0.8637 \\
\hline DV208CR & $3 / 20 / 95$ & 10668 & CNG & 13.44 & 0.0001 & 0.5936 & 2.0116 & 503.78 & 0.0013 & 0.0275 & 0.7097 & 0.6211 & 0.2047 \\
\hline DV209CR & $8 / 18 / 95$ & 8275 & CNG & 12.92 & 0.0002 & 3.0291 & 3.6381 & 512.35 & 0.0019 & 0.9198 & 0.4321 & 3.9833 & 0.0422 \\
\hline DV209CR & $8 / 21 / 95$ & 8293 & CNG & 13.01 & 0.0001 & 2.6108 & 3.7372 & 510.17 & 0.0011 & 0.7764 & 0.3909 & 3.4128 & 0.1788 \\
\hline Average & & & & 12.96 & 0.00015 & 2.81995 & 3.68765 & 511.26 & 0.0015 & 0.8481 & 0.4115 & 3.69805 & 0.1105 \\
\hline DV210CR & $3 / 21 / 95$ & 6095 & CNG & 13.88 & 0 & 0.4579 & 2.9621 & 486.46 & 0.0011 & 0.0437 & 0.2087 & 0.5016 & 0.0672 \\
\hline DV211CR & $1 / 19 / 96$ & 7215 & CNG & 14.07 & 0.0003 & 0.6172 & 4.9885 & 475.70 & 0.0019 & 0.2347 & 0.3905 & 0.8595 & 0.0636 \\
\hline DV212CR & $3 / 12 / 96$ & 13753 & CNG & 13.91 & 0.0002 & 0.4719 & 0.6958 & 487.78 & 0.0024 & 0.3735 & 0.9728 & 0.8512 & 1.0647 \\
\hline DV214CR & $3 / 27 / 96$ & 11397 & CNG & 13.43 & 0.0002 & 0.2913 & 2.1117 & 503.92 & 0.0015 & 0.2545 & 0.3239 & 0.5494 & 0.1095 \\
\hline DV215CR & $3 / 5 / 96$ & 10679 & CNG & 13.64 & 0.0002 & 0.3277 & 0.4595 & 499.00 & 0.0017 & 0.1329 & 0.4992 & 0.4646 & 1.2486 \\
\hline DV217CR & $8 / 22 / 95$ & 13004 & CNG & 14.01 & 0.0002 & 1.0313 & 2.2387 & 481.46 & 0.0018 & 0.0572 & 0.7967 & 1.101 & 0.7193 \\
\hline DV218CR & $5 / 1 / 96$ & 11382 & CNG & 13.80 & 0.0002 & 0.8034 & 2.5954 & 488.26 & 0.002 & 0.2235 & 0.6712 & 1.0367 & 2.0798 \\
\hline DV219CR & $1 / 10 / 96$ & 12536 & CNG & 13.90 & 0.0002 & 0.3666 & 2.365 & 486.40 & 0.0014 & 0.2161 & 0.1536 & 0.5867 & 0.0849 \\
\hline DV220CR & $3 / 15 / 96$ & 11124 & CNG & 13.76 & 0.0003 & 0.4413 & 1.5352 & 492.08 & 0.0028 & 0.3642 & 1.0364 & 0.8108 & 0.1063 \\
\hline & COUNT & & & 14 & 14 & 13 & 14 & 14 & 14 & 13 & 14 & 13 & 14 \\
\hline & AVG & & & 13.663 & 0.0002 & 0.5568 & 2.458 & 494.13 & 0.0018 & 0.1789 & 0.506 & 0.7414 & 0.5238 \\
\hline & STD DEV & & & 0.3727 & 0.0001 & 0.2515 & 1.214 & 13.096 & 0.0006 & 0.118 & 0.2975 & 0.2329 & 0.6087 \\
\hline & $\mathrm{CV}$ & & & 0.0273 & 0.4938 & 0.4517 & 0.494 & 0.0265 & 0.3217 & 0.6594 & 0.5875 & 0.3142 & 1.162 \\
\hline
\end{tabular}


Table A-45. 1992/94 Dodge B250 Van: RFG Tests at Lab 3 Round 2

\begin{tabular}{|c|c|c|c|c|c|c|c|c|c|c|c|c|c|}
\hline Decal ID & Date & Odometer & Fuel & MPG & $\mathrm{CH}_{3} \mathrm{CHO}$ & $\mathrm{CH}_{4}$ & $\mathrm{CO}$ & $\mathrm{CO}_{2}$ & $\mathrm{HCHO}$ & $\mathrm{NMHC}$ & $\mathrm{NO}_{\mathrm{x}}$ & $\mathrm{THC}$ & Evap. THC \\
\hline DV203GRC & $2 / 23 / 96$ & 32417 & RFG & 14.0 & 0.0013 & 0.0618 & 6.7021 & 607.78 & 0.0044 & 0.3835 & 0.8918 & 0.4459 & 0.9752 \\
\hline DV204GRC & $3 / 21 / 96$ & 19111 & RFG & 14.94 & 0.001 & 0.0315 & 3.8854 & 573.45 & 0.003 & 0.2923 & 0.3701 & 0.3242 & 1.1099 \\
\hline DV206GRC & $1 / 30 / 96$ & 13968 & RFG & 13.50 & 0.0011 & 0.0626 & 5.172 & 633.19 & 0.0038 & 0.2843 & 1.0141 & 0.3477 & 1.6591 \\
\hline DV207GRC & $3 / 19 / 96$ & 19818 & RFG & 13.65 & 0.0014 & 0.041 & 5.424 & 625.83 & 0.0047 & 0.369 & 0.6579 & 0.4106 & 1.0453 \\
\hline DV208GRC & $3 / 15 / 95$ & 13012 & RFG & 13.65 & 0.0006 & 0.049 & 3.773 & 628.74 & 0.0024 & 0.2383 & 0.556 & 0.2873 & 1.6412 \\
\hline DV209GRC & $4 / 9 / 96$ & 12982 & RFG & 13.87 & 0.0012 & 0.0476 & 3.3502 & 618.96 & 0.0043 & 0.268 & 0.6542 & 0.3162 & 1.4272 \\
\hline DV210GRC & $1 / 12 / 96$ & 36629 & RFG & 14.54 & 0.0013 & 0.0461 & 4.7842 & 587.92 & 0.0046 & 0.3187 & 0.8132 & 0.364 & 2.2384 \\
\hline DV211GRC & $3 / 8 / 96$ & 29480 & RFG & 14.19 & 0.0015 & 0.0643 & 6.2224 & 599.86 & 0.0054 & 0.3981 & 0.7168 & 0.4634 & 1.6088 \\
\hline DV212GRC & $4 / 5 / 95$ & 5210 & RFG & 13.85 & 0.0005 & 0.0504 & 3.5843 & 620.0 & 0.0026 & 0.2218 & 0.6065 & 0.2722 & 2.2984 \\
\hline DV214GRC & $3 / 20 / 96$ & 8913 & RFG & 13.712 & 0.0011 & 0.0343 & 4.1921 & 624.89 & 0.0034 & 0.3166 & 0.563 & 0.3512 & 2.2903 \\
\hline DV215GRC & $8 / 24 / 95$ & 11392 & RFG & 14.72 & 0.0007 & 0.0607 & 4.833 & 580.50 & 0.0028 & 0.2594 & 0.911 & 0.3191 & 0.3809 \\
\hline DV216GRC & $1 / 24 / 96$ & 15936 & RFG & 14.38 & 0.0013 & 0.0668 & 6.762 & 591.19 & 0.0049 & 0.3661 & 0.9499 & 0.4336 & 1.293 \\
\hline DV218GRC & $4 / 30 / 96$ & 17470 & RFG & 14.70 & 0.0009 & 0.0417 & 3.1454 & 584.11 & 0.0043 & 0.2482 & 0.8673 & 0.2904 & 0.906 \\
\hline DV219GRC & $3 / 15 / 96$ & 6394 & RFG & 14.49 & 0.0009 & 0.0317 & 4.1567 & 591.09 & 0.0033 & 0.2875 & 0.7662 & 0.3195 & 0.5852 \\
\hline & COUNT & & & 14 & 14 & 14 & 14 & 14 & 14 & 14 & 14 & 14 & 14 \\
\hline & AVG & & & 14.157 & 0.00106 & 0.0492 & 4.713 & 604.82 & 0.0038 & 0.304 & 0.7384 & 0.3532 & 1.3899 \\
\hline & STD DEV & & & 0.4716 & 0.0003 & 0.0124 & 1.206 & 20.284 & 0.0009 & 0.0568 & 0.1815 & 0.0620 & 0.6089 \\
\hline & $\mathrm{CV}$ & & & 0.0333 & 0.2891 & 0.251 & 0.2559 & 0.0335 & 0.2442 & 0.1869 & 0.2458 & 0.1756 & 0.4381 \\
\hline
\end{tabular}


Table A-46. 1992/94 Dodge B250 Van: CNG Tests at Lab 2 Round 3

\begin{tabular}{|c|c|c|c|c|c|c|c|c|c|c|c|c|c|}
\hline Decal ID & Date & Odometer & Fuel & MPG & $\mathrm{CH}_{3} \mathrm{CHO}$ & $\mathrm{CH}_{4}$ & $\mathrm{CO}$ & $\mathrm{CO}_{2}$ & $\mathrm{HCHO}$ & $\mathrm{NMHC}$ & $\mathrm{NO}_{\mathrm{x}}$ & THC & Evap. THC \\
\hline DC202CR & $11 / 4 / 96$ & 11226 & CNG & 11.72 & 0.00031 & 0.6158 & 1.3536 & 556.29 & 0.0043 & 0.0404 & 0.5866 & 0.6543 & 0.0365 \\
\hline DC202CR & $11 / 5 / 96$ & 11245 & CNG & 11.7 & 0.00052 & 0.9355 & 1.5998 & 556.39 & 0.00466 & 0.0401 & 0.5165 & 0.9712 & 0.0555 \\
\hline Average & & & & 11.71 & 0.000415 & 0.7756 & 1.4767 & 556.34 & 0.00448 & 0.04025 & 0.55155 & 0.81275 & 0.046 \\
\hline DC203CR & $12 / 9 / 96$ & 10023 & CNG & 12.24 & 0.00052 & 1.4174 & 1.3417 & 530.40 & 0.00828 & 0.1 & 1.6841 & 1.5135 & 0.2903 \\
\hline DC204CR & $11 / 25 / 96$ & 30050 & $\mathrm{CNG}$ & 11.39 & 0.0007 & 2.5318 & 1.7748 & 565.59 & 0.00931 & 0.1104 & 1.7883 & 2.6305 & 0.1194 \\
\hline DC204CR & $11 / 26 / 96$ & 30068 & CNG & 11.61 & 0.00062 & 2.5934 & 1.2607 & 555.93 & 0.01111 & 0.1308 & 1.9197 & 2.7134 & 0.1062 \\
\hline Average & & & & 11.5 & 0.00066 & 2.5626 & 1.51775 & 560.76 & 0.01021 & 0.1206 & 1.854 & 2.67195 & 0.1128 \\
\hline DC208CR & $1 / 6 / 97$ & 7621 & CNG & 12.08 & 0.00024 & 0.7132 & 2.1283 & 538.26 & 0.00535 & 0.0706 & 0.4495 & 0.7832 & 0.073 \\
\hline DC210CR & $1 / 15 / 97$ & 24159 & CNG & 11.74 & 0.00067 & 0.9521 & 0.8176 & 554.99 & 0.00767 & 0.0607 & 1.1059 & 1.0098 & 0.4841 \\
\hline DC211CR & $11 / 12 / 96$ & 17163 & CNG & 11.62 & 0.0005 & 2.2048 & 0.1669 & 557.51 & 0.02523 & 0.1681 & 4.5083 & 2.3677 & 0.1828 \\
\hline DC212CR & $12 / 13 / 96$ & 12544 & CNG & 12 & 0.00041 & 0.4329 & 1.7739 & 543.49 & 0.005 & 0.04 & 0.2049 & 0.4724 & 0.4037 \\
\hline DC220CR & $1 / 2 / 97$ & 14209 & CNG & 12.09 & 0.00044 & 0.3895 & 1.2709 & 539.84 & 0.00459 & 0.0563 & 0.2806 & 0.4468 & 0.3341 \\
\hline DC222CR & $12 / 23 / 96$ & 15708 & CNG & 12.16 & 0.00048 & 1.8854 & 0.3883 & 533.77 & 0.01267 & 0.1212 & 2.7087 & 2.0007 & 0.0886 \\
\hline DC223CR & $12 / 18 / 96$ & 28104 & CNG & 11.99 & 0.00058 & 0.6873 & 0.9973 & 544.01 & 0.00875 & 0.0744 & 1.1205 & 0.7616 & 0.0955 \\
\hline NY201CR & $12 / 27 / 96$ & 6243 & CNG & 11.35 & 0.00049 & 1.162 & 3.5345 & 569.42 & 0.00587 & 0.0755 & 0.1694 & 1.2339 & 1.0165 \\
\hline NY202CR & $12 / 26 / 96$ & 10551 & CNG & 11.86 & 0.00058 & 1.1262 & 1.3038 & 547.74 & 0.00736 & 0.0742 & 0.8389 & 1.1969 & 0.0717 \\
\hline & COUNT & & & 12 & 12 & 12 & 12 & 12 & 12 & 12 & 12 & 12 & 12 \\
\hline & AVG & & & 11.862 & 0.0005 & 1.1924 & 1.393 & 548.045 & 0.0088 & 0.0835 & 1.2897 & 1.273 & 0.2666 \\
\hline & STD DEV & & & 0.279 & 0.00012 & 0.6991 & 0.8697 & 11.833 & 0.0057 & 0.0377 & 1.272 & 0.7296 & 0.2779 \\
\hline & CV & & & 0.0235 & 0.2378 & 0.5863 & 0.6243 & 0.0216 & 0.6526 & 0.4518 & 0.9867 & 0.5733 & 1.0423 \\
\hline
\end{tabular}


Table A-47. 1992/94 Dodge B250 Van: RFG Tests at Lab 2 Round 3

\begin{tabular}{|c|c|c|c|c|c|c|c|c|c|c|c|c|c|}
\hline Decal ID & Date & Odometer & Fuel & MPG & $\mathrm{CH}_{3} \mathrm{CHO}$ & $\mathrm{CH}_{4}$ & $\mathrm{CO}$ & $\mathrm{CO}_{2}$ & $\mathrm{HCHO}$ & $\mathrm{NMHC}$ & $\mathrm{NO}_{\mathrm{x}}$ & $\mathrm{THC}$ & Evap. THC \\
\hline DC202GRC & $11 / 14 / 96$ & 34184 & RFG & 13.22 & 0.00201 & 0.0893 & 8.0457 & 655.95 & 0.0056 & 0.3813 & 1.0338 & 0.4524 & 1.1153 \\
\hline DC202GRC & $11 / 15 / 96$ & 34203 & RFG & 13.17 & 0.00225 & 0.0913 & 8.4206 & 657.82 & 0.00579 & 0.3878 & 1.0222 & 0.4605 & 0.7572 \\
\hline Average & & & & 13.195 & 0.00213 & 0.0903 & 8.23315 & 656.89 & 0.005695 & 0.38455 & 1.028 & 0.45645 & 0.93625 \\
\hline DC203GRC & 8/8/96 & 13663 & RFG & 13.48 & 0.00124 & 0.0756 & 6.7742 & 645.36 & 0.0043 & 0.2984 & 1.0017 & 0.3586 & 1.601 \\
\hline DC204GRC & $12 / 12 / 96$ & 18645 & RFG & 13.42 & 0.0014 & 0.0723 & 6.388 & 648.53 & 0.00515 & 0.2969 & 0.8659 & 0.3544 & 0.7242 \\
\hline DC205GRC & $12 / 4 / 96$ & 23956 & RFG & 13.44 & 0.00162 & 0.0861 & 7.5648 & 646.27 & 0.00442 & 0.3348 & 1.0445 & 0.4034 & 1.2084 \\
\hline DC205GRC & $12 / 5 / 96$ & 23975 & RFG & 13.49 & 0.00157 & 0.0789 & 7.1964 & 644.43 & 0.00419 & 0.3284 & 0.964 & 0.3912 & 0.8702 \\
\hline Average & & & & 13.465 & 0.001595 & 0.0825 & 7.3806 & 645.35 & 0.004305 & 0.3316 & 1.00425 & 0.3973 & 1.0393 \\
\hline DC208GRC & $1 / 10 / 97$ & 33691 & RFG & 13.49 & 0.00172 & 0.0746 & 6.4265 & 645.20 & 0.00654 & 0.3288 & 0.9472 & 0.3882 & 0.9268 \\
\hline DC209GRC & $1 / 7 / 97$ & 57099 & RFG & 13.79 & 0.00212 & 0.0857 & 8.2844 & 627.68 & 0.00811 & 0.3745 & 1.1918 & 0.4427 & 0.4141 \\
\hline DC210GRC & $1 / 14 / 97$ & 41056 & RFG & 13.89 & 0.00271 & 0.0934 & 8.9268 & 622.44 & 0.00751 & 0.4586 & 1.0592 & 0.5329 & 0.8369 \\
\hline DC211GRC & $1 / 17 / 97$ & 23774 & RFG & 13.79 & 0.00157 & 0.0686 & 6.9849 & 630.30 & 0.00493 & 0.3164 & 0.9133 & 0.371 & 0.9305 \\
\hline NJ201GRC & $12 / 19 / 96$ & 29053 & RFG & 13.81 & 0.00206 & 0.085 & 7.5649 & 628.19 & 0.00734 & 0.3847 & 0.7192 & 0.4524 & 1.0741 \\
\hline NJ202GRC & 12/20/96 & 19602 & RFG & 12.6 & 0.00173 & 0.0769 & 5.9418 & 692.49 & 0.00455 & 0.3606 & 0.5627 & 0.4218 & 1.1734 \\
\hline NJ203GRC & $1 / 3 / 97$ & 21990 & RFG & 12.82 & 0.00208 & 0.0863 & 6.0959 & 680.09 & 0.00611 & 0.4118 & 0.4941 & 0.4805 & 1.8371 \\
\hline NY201GRC & $1 / 9 / 97$ & 9363 & RFG & 12.94 & 0.00137 & 0.063 & 5.2188 & 675.19 & 0.00545 & 0.2897 & 0.4332 & 0.3398 & 1.0233 \\
\hline NY202GRC & $1 / 13 / 97$ & 25409 & RFG & 14.95 & 0.00379 & 0.0885 & 7.8023 & 579.37 & 0.00525 & 0.3452 & 0.8714 & 0.4156 & 1.2639 \\
\hline & COUNT & & & 13 & 13 & 13 & 13 & 13 & 13 & 3 & 13 & 13 & 13 \\
\hline & AVG & & & 13.511 & 0.00196 & 0.0802 & 7.079 & 644.39 & 0.0058 & 0.3524 & 0.853 & 0.416 & 1.060 \\
\hline & STD DEV & & & 0.5919 & 0.00068 & 0.0091 & 1.0714 & 29.10 & 0.0013 & 0.0497 & 0.233 & 0.0559 & 0.363 \\
\hline & $\mathrm{CV}$ & & & 0.0438 & 0.347 & 0.1136 & 0.1514 & 0.0451 & 0.217 & 0.141 & 0.2734 & 0.1344 & 0.3426 \\
\hline
\end{tabular}


Table A-48. 1992/94 Dodge B250 Van: CNG Tests at Lab 3 Round 3

\begin{tabular}{|c|c|c|c|c|c|c|c|c|c|c|c|c|c|}
\hline Decal ID & Date & Odometer & Fuel & MPG & $\mathrm{CH}_{3} \mathrm{CHO}$ & $\mathrm{CH}_{4}$ & $\mathrm{CO}$ & $\mathrm{CO}_{2}$ & $\mathrm{HCHO}$ & NMHC & $\mathrm{NO}_{\mathrm{x}}$ & THC & Evap. THC \\
\hline DV203CR & 9/5/96 & \begin{tabular}{|l|}
36774 \\
\end{tabular} & CNG & 14.31 & 0.0003 & 0.4818 & 1.0882 & 474.34 & 0.0023 & 0.106 & 0.7334 & 0.5937 & 0.0779 \\
\hline DV204CR & 9/24/96 & 9230 & CNG & 13.88 & 0.0014 & 1.6339 & 12.102 & 467.62 & 0.0196 & 0.4769 & 1.6314 & 2.1308 & 1.1548 \\
\hline DV204CR & 9/25/96 & 9257 & CNG & 13.88 & 0.0013 & 1.5274 & 11.2897 & 469.10 & 0.0184 & 0.4334 & 1.6835 & 1.9794 & 0.8663 \\
\hline Average & & & & 13.88 & 0.00135 & 1.58065 & 11.69585 & 468.36 & 0.019 & 0.45515 & 1.65745 & 2.0551 & 1.01055 \\
\hline DV205CR & 9/12/96 & 45147 & CNG & 13.31 & 0.0002 & 0.906 & 3.0784 & 505.39 & 0.0021 & 0.2262 & 0.6332 & 1.1434 & 1.2182 \\
\hline DV205CR & 9/13/96 & 45159 & CNG & 13.27 & 0.0002 & 0.8958 & 2.838 & 507.29 & 0.0021 & 0.2425 & 0.6371 & 1.1491 & 2.9654 \\
\hline Average & & & & 13.29 & 0.0002 & 0.9009 & 2.9582 & 506.34 & 0.0021 & 0.23435 & 0.63515 & 1.14625 & 2.0918 \\
\hline DV206CR & 10/25/96 & 6782 & CNG & 13.93 & 0.0002 & 0.266 & 1.8155 & 486.80 & 0.0013 & 0.0749 & 0.0944 & 0.3441 & 1.2241 \\
\hline DV208CR & $1 / 26 / 96$ & 16344 & CNG & 13.57 & 0.0003 & 0.6373 & 1.1734 & 499.46 & 0.0029 & 0.2496 & 1.0934 & 0.8947 & 1.4518 \\
\hline DV209CR & $11 / 21 / 96$ & 16896 & CNG & 13.82 & 0.0001 & 0.7146 & 4.4678 & 485.15 & 0.0014 & 0.1703 & 0.187 & 0.8936 & 0.5875 \\
\hline DV210CR & 1/18/96 & 10209 & CNG & 13.85 & 0.0003 & 0.4776 & 1.4405 & 489.38 & 0.0016 & 0.1976 & 0.4876 & 0.681 & 2.4167 \\
\hline DV211CR & $10 / 3 / 96$ & 10093 & CNG & 13.88 & 0.0002 & 0.4733 & 2.9597 & 486.06 & 0.002 & 0.1141 & 0.2786 & 0.5931 & 0.3981 \\
\hline DV212CR & $10 / 31 / 96$ & 16705 & CNG & 13.75 & 0.0002 & 2.7378 & 1.069 & 487.44 & 0.0031 & 0.0898 & 1.624 & 2.861 & 0.0392 \\
\hline DV212CR & 11/1/96 & 16731 & CNG & 13.76 & 0.0002 & 3.184 & 0.8535 & 486.14 & 0.003 & 0.1855 & 1.8426 & 3.4085 & 0.5714 \\
\hline Average & & & & 13.75 & 0.0002 & 2.9609 & 0.96125 & 486.79 & 0.00305 & 0.13765 & 1.7333 & 3.13475 & 0.3053 \\
\hline DV214CR & $11 / 5 / 96$ & 17501 & CNG & 13.44 & 0.0002 & 0.7419 & 1.872 & 503.02 & 0.0016 & 0.2024 & 0.5194 & 0.9534 & 0.2673 \\
\hline DV215CR & $10 / 29 / 96$ & 18805 & CNG & 14.36 & 0.0001 & 0.31 & 0.649 & 473.72 & 0.0014 & 0.0956 & 0.5512 & 0.4094 & 0.0095 \\
\hline DV217CR & 9/18/96 & 21647 & CNG & 13.58 & 0.0002 & 1.0422 & 2.046 & 496.33 & 0.0018 & 0.2503 & 1.0635 & 1.3053 & 0.0381 \\
\hline DV217CR & 9/19/96 & 21673 & CNG & 13.67 & 0.0002 & 0.8945 & 1.2252 & 495.08 & 0.0021 & 0.2349 & 1.0512 & 1.1402 & 1.9553 \\
\hline Average & & & & 13.62 & 0.0002 & 0.96835 & 1.6356 & 495.71 & 0.00195 & 0.2426 & 1.05735 & 1.22275 & 0.9967 \\
\hline DV218CR & $10 / 29 / 96$ & 12007 & CNG & 14.60 & 0.0002 & 1.0044 & 1.9796 & 461.33 & 0.0019 & 0.3087 & 0.8395 & 1.3253 & 0.0126 \\
\hline DV219CR & $12 / 11 / 96$ & 24274 & CNG & 13.36 & 0.0001 & 0.3712 & 1.6964 & 507.46 & 0.001 & 0.0928 & 0.1819 & 0.4685 & 0.6636 \\
\hline DV220CR & 10/1/96 & 15313 & CNG & 14.22 & 0.0002 & 0.6807 & 0.8908 & 476.85 & 0.0016 & 0.1487 & 1.5328 & 0.8376 & 0.1985 \\
\hline & COUNT & & & 15 & 14 & 13 & 14 & 14 & 14 & 14 & 14 & 13 & 14 \\
\hline & AVG & & & 13.86 & 0.0002 & 0.6175 & 1.828 & 488.03 & 0.0019 & 0.1697 & 0.7089 & 0.797 & 0.7644 \\
\hline & STD DEV & & & 0.382 & 0.000068 & 0.245 & 1.0285 & 13.514 & 0.00059 & 0.0713 & 0.4995 & 0.3145 & 0.774 \\
\hline & $\mathrm{CV}$ & & & 0.0275 & 0.3397 & 0.3966 & 0.5627 & 0.028 & 0.314 & 0.420 & 0.7045 & 0.3945 & 1.013 \\
\hline
\end{tabular}


Table A-49. 1992/94 Dodge B250 Van: RFG Tests at Lab 3 Round 3

\begin{tabular}{|c|c|c|c|c|c|c|c|c|c|c|c|c|c|}
\hline Decal ID & Date & Odometer & Fuel & MPG & $\mathrm{CH}_{3} \mathrm{CHO}$ & $\mathrm{CH}_{4}$ & $\mathrm{CO}$ & $\mathrm{CO}_{2}$ & $\mathrm{HCHO}$ & $\mathrm{NMHC}$ & $\mathrm{NO}_{\mathrm{x}}$ & THC & Evap. THC \\
\hline DV203GRC & $11 / 19 / 96$ & 34525 & RFG & 14.56 & 0.0012 & 0.0652 & 3.7451 & 588.47 & 0.0042 & 0.3683 & 0.7973 & 0.4343 & 1.4031 \\
\hline DV204GRC & $11 / 13 / 96$ & 19768 & RFG & 13.78 & 0.0009 & 0.0506 & 3.4684 & 623.01 & 0.003 & 0.2781 & 0.4379 & 0.3292 & 1.675 \\
\hline DV206GRC & $10 / 31 / 96$ & 15820 & RFG & 14.0 & 0.001 & 0.0602 & 3.45 & 613.11 & 0.0037 & 0.2943 & 1.1483 & 0.3553 & 0.019 \\
\hline DV207GRC & $10 / 10 / 96$ & 17662 & RFG & 14.25 & 0.0011 & 0.0634 & 5.1086 & 599.22 & 0.004 & 0.3666 & 0.6971 & 0.4308 & 1.3119 \\
\hline DV208GRC & $3 / 7 / 96$ & 15426 & RFG & 13.61 & 0.0011 & 0.0516 & 4.8743 & 628.38 & 0.0039 & 0.3073 & 0.6404 & 0.3595 & 0.9998 \\
\hline DV209GRC & $9 / 24 / 96$ & 15482 & RFG & 13.40 & 0.001 & 0.0528 & 3.6502 & 640.36 & 0.0035 & 0.2776 & 0.742 & 0.3309 & 1.0993 \\
\hline DV209GRC & $9 / 26 / 96$ & 15508 & RFG & 13.72 & 0.001 & 0.051 & 3.6794 & 625.25 & 0.0037 & 0.2778 & 0.7536 & 0.3294 & 1.0694 \\
\hline Average & & & & 13.56 & 0.001 & 0.0519 & 3.6648 & 632.81 & 0.0036 & 0.2777 & 0.7478 & 0.33015 & 1.0844 \\
\hline DV210GRC & $10 / 22 / 96$ & 38485 & RFG & 14.19 & 0.0012 & 0.0554 & 4.4815 & 602.83 & 0.0041 & 0.3233 & 0.7189 & 0.3795 & 1.9489 \\
\hline DV211GRC & $10 / 8 / 96$ & 31006 & RFG & 13.88 & 0.0013 & 0.0592 & 4.4585 & 616.88 & 0.0043 & 0.3463 & 0.7055 & 0.4061 & 1.9078 \\
\hline DV212GRC & $4 / 2 / 96$ & 6720 & RFG & 13.88 & 0.001 & 0.0443 & 3.3549 & 618.53 & 0.0038 & 0.2497 & 0.5861 & 0.2944 & 1.7316 \\
\hline DV214GRC & $9 / 17 / 96$ & 10361 & RFG & 14.36 & 0.0012 & 0.0543 & 3.9008 & 596.53 & 0.0041 & 0.3157 & 0.7033 & 0.3705 & 1.5589 \\
\hline DV214GRC & $9 / 18 / 96$ & 10387 & RFG & 14.29 & 0.0013 & 0.0587 & 4.4716 & 598.61 & 0.0042 & 0.3386 & 0.742 & 0.3979 & 1.6713 \\
\hline Average & & & & 14.33 & 0.00125 & 0.0565 & 4.1862 & 597.57 & 0.00415 & 0.32715 & 0.72265 & 0.3842 & 1.6151 \\
\hline DV215GRC & 10/11/96 & 17425 & RFG & 14.40 & 0.0019 & 0.0547 & 3.9063 & 594.90 & 0.0071 & 0.3259 & 0.9212 & 0.3813 & 0.9225 \\
\hline DV215GRC & $10 / 15 / 96$ & 17452 & RFG & 14.46 & 0.0011 & 0.0549 & 3.8514 & 592.65 & 0.0042 & 0.2967 & 0.9605 & 0.3523 & 1.3422 \\
\hline Average & & & & 14.432 & 0.0015 & 0.0548 & 3.87885 & 593.78 & 0.00565 & 0.3113 & 0.94085 & 0.3668 & 1.1324 \\
\hline DV216GRC & $11 / 14 / 96$ & 20459 & RFG & 14.06 & 0.0009 & 0.0503 & 2.6234 & 611.72 & 0.0038 & 0.3003 & \begin{tabular}{|l|}
1.0158 \\
\end{tabular} & 0.3513 & 0.7371 \\
\hline DV218GRC & $11 / 21 / 96$ & 24356 & RFG & 14.83 & 0.0008 & 0.0521 & 3.02 & 579.01 & 0.0031 & 0.2808 & 1.02 & 0.3334 & 0.9739 \\
\hline DV219GRC & $11 / 22 / 96$ & 7888 & RFG & 14.71 & 0.0008 & 0.0521 & 3.9684 & 582.19 & 0.0029 & 0.3029 & 0.934 & 0.3557 & 2.3532 \\
\hline & COUNT & & & 14 & 14 & 14 & 14 & 14 & 14 & 14 & 14 & 14 & 14 \\
\hline & AVG & & & 14.149 & 0.0011 & 0.0548 & 3.877 & 606.25 & 0.0039 & 0.3096 & 0.7938 & 0.365 & 1.3495 \\
\hline & STD DEV & & & 0.3944 & 0.0002 & 0.0056 & 0.6966 & 16.974 & 0.00068 & 0.0343 & 0.1942 & 0.039 & 0.590 \\
\hline & $\mathrm{CV}$ & & & 0.0279 & 0.1867 & 0.103 & 0.1797 & 0.028 & 0.176 & 0.111 & 0.2447 & 0.108 & 0.437 \\
\hline
\end{tabular}


Table A-50. 1994 CNG Dodge Caravan: CNG Tests at Lab 2 Round 1

\begin{tabular}{|c|c|c|c|c|c|c|c|c|c|c|c|c|c|}
\hline Decal ID & Date & Odometer & Fuel & MPG & $\mathrm{CH}_{3} \mathrm{CHO}$ & $\mathrm{CH}_{4}$ & $\mathrm{CO}$ & $\mathrm{CO}_{2}$ & $\mathrm{HCHO}$ & NMHC & $\mathrm{NO}_{\mathrm{x}}$ & THC & Evap HC \\
\hline DC301CM & $6 / 12 / 95$ & 12373 & CNG & 18.4 & 0.00037 & 0.1402 & 0.2488 & 372.83 & 0.00499 & 0.0338 & 0.3662 & 0.174 & 0.5085 \\
\hline DC302CM & $6 / 8 / 95$ & 12618 & CNG & 17.91 & 0.00044 & 0.1711 & 0.3058 & 382.59 & 0.0062 & 0.036 & 0.4156 & 0.2071 & 0.2863 \\
\hline DC303CM & $6 / 6 / 95$ & 14282 & CNG & 18.25 & 0.00035 & 0.4413 & 0.2565 & 374.51 & 0.00782 & 0.0847 & 0.916 & 0.526 & 0.3931 \\
\hline DC306CM & $8 / 7 / 95$ & 4567 & CNG & 17.07 & 0.0002 & 0.0687 & 0.4745 & 402.42 & 0.00388 & 0.0117 & 0.0231 & 0.0804 & 0.1661 \\
\hline DC307CM & $5 / 25 / 95$ & 6279 & CNG & 17.33 & 0.00051 & 0.0925 & 0.367 & 396.11 & 0.00511 & 0.019 & 0.0402 & 0.1116 & 0.0537 \\
\hline DC309CM & $8 / 4 / 95$ & 4342 & CNG & 16.98 & 0.00032 & 0.1103 & 0.4371 & 403.98 & 0.00179 & 0.0201 & 0.0337 & 0.1303 & 0.0518 \\
\hline DC310CM & $7 / 3 / 96$ & 3817 & CNG & 16.97 & 0.00048 & 0.1159 & 0.4821 & 387.48 & 0.00277 & 0.0097 & 0.0175 & 0.1254 & 0.0438 \\
\hline DC311CM & $12 / 8 / 95$ & 4613 & CNG & 16.86 & 0.00024 & 0.1422 & 0.1941 & 390.24 & 0.00238 & 0.0065 & 0.257 & 0.1601 & 0.0763 \\
\hline DC313CM & $8 / 14 / 95$ & 4380 & CNG & 17.16 & 0.00016 & 0.0906 & 0.3843 & 400.44 & 0.0032 & 0.0122 & 0.0494 & 0.1028 & 0.7008 \\
\hline DC314CM & $6 / 19 / 95$ & 5052 & CNG & 17.65 & 0.00039 & 0.0853 & 0.3413 & 389.14 & 0.00588 & 0.0098 & 0.0587 & 0.0951 & 0.0474 \\
\hline DC317CM & $7 / 21 / 96$ & 4969 & CNG & 17.35 & 0.00039 & 0.0918 & 0.2962 & 378.82 & 0.00247 & 0.0125 & 0.153 & 0.1045 & 0.1419 \\
\hline DC318CM & $7 / 14 / 95$ & 4736 & CNG & 17.37 & 0.00016 & 0.1283 & 0.4597 & 395.39 & 0.00264 & 0.0177 & 0.0612 & 0.146 & 0.7374 \\
\hline \begin{tabular}{|l|} 
DC320CM \\
\end{tabular} & $7 / 5 / 95$ & 4855 & CNG & 17.58 & 0.00017 & 0.1742 & 0.485 & 390.09 & 0.00334 & 0.0169 & 0.0408 & 0.1911 & 0.8388 \\
\hline & COINT & & & 13 & 13 & & & & & & & & \\
\hline & AVG & & & $\frac{13}{17.452}$ & $\frac{13}{0.00032}$ & $\frac{13}{0.1425}$ & $\frac{13}{0.364}$ & $\frac{13}{38954}$ & $\frac{13}{0.004}$ & $\frac{13}{0.0224}$ & $\frac{13}{0.1871}$ & $\frac{13}{0.1657}$ & $\frac{13}{0.3112}$ \\
\hline & STD DEV & & & 0.489 & 0.00012 & 0.0955 & 0.0991 & 10.18 & 0.0018 & 0.0207 & 0.2574 & 0.1149 & 0.294 \\
\hline & $\mathrm{CV}$ & & & 0.028 & 0.3849 & 0.6705 & 0.2723 & 0.0261 & 0.4493 & 0.9272 & 1.3757 & 0.6933 & 0.9448 \\
\hline
\end{tabular}

Table A-51. 1994 Standard Dodge Caravan: RFG Tests at Lab 2 Round 1

\begin{tabular}{|c|c|c|c|c|c|c|c|c|c|c|c|c|c|}
\hline Decal ID & Date & Odometer & Fuel & MPG & $\mathrm{CH}_{3} \mathrm{CHO}$ & $\mathrm{CH}_{4}$ & $\mathrm{CO}$ & $\mathrm{CO}_{2}$ & $\mathrm{HCHO}$ & $\mathrm{NMHC}$ & $\mathrm{NO}_{x}$ & $\mathrm{THC}$ & Evap HC \\
\hline DC321GMC & $7 / 1 / 96$ & 17617 & RFG & 18.37 & 0.00092 & 0.0281 & 1.6061 & 479.14 & 0.00378 & 0.1548 & 0.2917 & 0.1771 & 0.1794 \\
\hline DC322GMC & $7 / 6 / 96$ & 18415 & RFG & 18.8 & 0.00086 & 0.0242 & 1.6466 & 467.57 & 0.0033 & 0.1468 & 0.3391 & 0.1661 & 0.4018 \\
\hline DC323GMC & $7 / 15 / 96$ & 16366 & RFG & 18.72 & 0.00109 & 0.0284 & 1.6123 & 469.82 & 0.00385 & 0.1632 & 0.2603 & 0.1858 & 0.383 \\
\hline DC324GMC & $7 / 18 / 96$ & 15527 & RFG & 19.12 & 0.00087 & 0.0312 & 1.6844 & 459.71 & 0.00257 & 0.1324 & 0.2983 & 0.1572 & 0.3701 \\
\hline DC325GMC & $7 / 23 / 96$ & 20696 & $\mathrm{RFG}$ & 18.91 & 0.00082 & 0.0278 & 1.1659 & 466.32 & 0.00362 & 0.1423 & 0.3074 & 0.1644 & 0.3129 \\
\hline \multirow[t]{5}{*}{ DC326GMC } & $7 / 28 / 96$ & 18704 & RFG & 19.09 & 0.00085 & 0.0263 & 1.5939 & 460.74 & 0.00369 & 0.1441 & 0.2821 & 0.1651 & 0.2917 \\
\hline & & & & & & & & & & & & & \\
\hline & AVG & & & $\frac{6}{18835}$ & $\frac{6}{0009}$ & $\frac{6}{00277}$ & $\frac{6}{15515}$ & $\frac{6}{46722}$ & $\frac{6}{00035}$ & $\frac{6}{01473}$ & $\frac{6}{2965}$ & $\frac{6}{1693}$ & $\frac{6}{3232}$ \\
\hline & STD DEV & & & 0.2766 & 0.0001 & 0.0023 & 0.1918 & 7.0448 & 0.00048 & 0.0106 & 0.0264 & 0.0103 & 0.0821 \\
\hline & $\mathrm{CV}$ & & & 0.0147 & 0.1085 & 0.0842 & 0.1236 & 0.015 & 0.1383 & 0.0723 & 0.0889 & 0.0609 & 0.2542 \\
\hline
\end{tabular}

shaded areas mark outliers or a data point removed to balance a FFV data set

$\dagger$ - missing data

$\ddagger$ - instrument problems caused loss of data

* - evaporative test not required for re-tests resulting from a regulated emissions component being out of EPA standards

- - first tests on CNG vehicles did not include evaporative 


\section{Appendix B: Speciated Compounds}




\begin{tabular}{|c|c|c|c|}
\hline $\begin{array}{l}\text { Compound } \\
\text { Number }\end{array}$ & $\begin{array}{l}\text { Compound } \\
\text { Name }\end{array}$ & $\begin{array}{l}\text { CAS } \\
\text { Number }\end{array}$ & Formula \\
\hline & TMETHANE & 74828 & $\mathrm{CH} 4$ \\
\hline & ETHYLENE & 74851 & $\mathrm{C} 2 \mathrm{H} 4$ \\
\hline 3 & ETHANE & 74840 & $\mathrm{C} 2 \mathrm{H} 6$ \\
\hline 4 & ACETYLENE & 74862 & $\mathrm{C} 2 \mathrm{H} 2$ \\
\hline 5 & PROPANE & 74986 & $\mathrm{C} 3 \mathrm{H} 8$ \\
\hline 6 & PROPYLENE & 115071 & $\mathrm{C} 3 \mathrm{H} 6$ \\
\hline 7 & PROPADIENE & 463490 & $\mathrm{C} 3 \mathrm{H} 4$ \\
\hline 8 & METHYLACETYLENE & 74997 & $\mathrm{C} 3 \mathrm{H} 4$ \\
\hline 9 & ISO-BUTANE & 75285 & $\mathrm{C} 4 \mathrm{H} 10$ \\
\hline 11 & 1-BUTENE & 106989 & $\mathrm{C} 4 \mathrm{H} 8$ \\
\hline 12 & ISO-BUTYLENE & 115117 & $\mathrm{C} 4 \mathrm{H} 8$ \\
\hline 13 & 1,3-BUTADIENE & 106990 & $\mathrm{C} 4 \mathrm{H} 6$ \\
\hline 14 & N-BUTANE & 106978 & $\mathrm{C} 4 \mathrm{H} 10$ \\
\hline 15 & 2,2-DIMETHYLPROPANE & 463821 & $\mathrm{C} 5 \mathrm{H} 12$ \\
\hline 16 & TRANS-2-BUTENE & 624646 & $\mathrm{C} 4 \mathrm{H} 8$ \\
\hline 17 & 1-BUTEN-3-YNE & 689974 & $\mathrm{C} 4 \mathrm{H} 4$ \\
\hline 18 & 1-BUTYNE & 107006 & $\mathrm{C} 4 \mathrm{H} 6$ \\
\hline 19 & CIS-2-BUTENE & 590181 & $\mathrm{C} 4 \mathrm{H} 8$ \\
\hline 20 & ${ }^{* * *}$ UNKNOWN ${ }^{* * *}$ & & $\mathrm{C} 4 \mathrm{H} 8$ \\
\hline 21 & 1,3-BUTADIYNE & 460128 & $\mathrm{C} 4 \mathrm{H} 2$ \\
\hline 22 & 3-METHYL-1-BUTENE & 563451 & $\mathrm{C} 5 \mathrm{H} 10$ \\
\hline 23 & ISO-PENTANE & 78784 & $\mathrm{C} 5 \mathrm{H} 12$ \\
\hline 24 & 1,4-PENTADIENE & 591935 & $\mathrm{C} 5 \mathrm{H} 8$ \\
\hline 25 & 2-BUTYNE & 503173 & $\mathrm{C} 4 \mathrm{H} 6$ \\
\hline 26 & 1-PENTENE & 109671 & $\mathrm{C} 5 \mathrm{H} 10$ \\
\hline 27 & $\mathrm{C} 5 \mathrm{H} 8$ & & $\mathrm{C} 5 \mathrm{H} 8$ \\
\hline 28 & 2-METHYL-1-BUTEN-3-YNE & 78808 & $\mathrm{C} 5 \mathrm{H} 6$ \\
\hline 29 & 2-METHYL-1-BUTENE & 563462 & $\mathrm{C} 5 \mathrm{H} 10$ \\
\hline 30 & N-PENTANE & 109660 & $\mathrm{C} 5 \mathrm{H} 12$ \\
\hline 31 & ISOPRENE & 78795 & $\mathrm{C} 5 \mathrm{H} 8$ \\
\hline 32 & TRANS-2-PENTENE & 646048 & $\mathrm{C} 5 \mathrm{H} 10$ \\
\hline 33 & 3,3-DIMETHYL-1-BUTENE & 558372 & $\mathrm{C} 6 \mathrm{H} 12$ \\
\hline 34 & CIS-2-PENTENE & 627203 & $\mathrm{C} 5 \mathrm{H} 10$ \\
\hline 35 & 2-METHYL-2-BUTENE & 513359 & $\mathrm{C} 5 \mathrm{H} 10$ \\
\hline 36 & TRANS-1,3-PENTADIENE & 2004708 & $\mathrm{C} 5 \mathrm{H} 8$ \\
\hline 37 & CYCLOPENTADIENE & 542927 & $\mathrm{C} 5 \mathrm{H} 6$ \\
\hline 38 & 2,2-DIMETHYLBUTANE & 75832 & $\mathrm{C} 6 \mathrm{H} 14$ \\
\hline 39 & CIS-1,3-PENTADIENE & 1574410 & $\mathrm{C} 5 \mathrm{H} 8$ \\
\hline 40 & $\mathrm{C} 5 \mathrm{H} 8$ & & $\mathrm{C} 5 \mathrm{H} 8$ \\
\hline 42 & CYCLOPENTENE & 142290 & $\mathrm{C} 5 \mathrm{H} 8$ \\
\hline 44 & 4-METHYL-1-PENTENE & 691372 & $\mathrm{C} 6 \mathrm{H} 12$ \\
\hline 45 & 3-METHYL-1-PENTENE & 760203 & $\mathrm{C} 6 \mathrm{H} 12$ \\
\hline 45.501 & ${ }^{* \star *}$ UNKNOWN ${ }^{\star * \star *}$ & & \\
\hline 46 & CYCLOPENTANE & 287923 & $\mathrm{C} 5 \mathrm{H} 10$ \\
\hline 48 & 2,3-DIMETHYLBUTANE & 79298 & $\mathrm{C} 6 \mathrm{H} 14$ \\
\hline 49 & 4-METHYL-CIS-2-PENTENE & 691383 & $\mathrm{C} 6 \mathrm{H} 12$ \\
\hline 51 & 2-METHYLPENTANE & 107835 & $\mathrm{C} 6 \mathrm{H} 14$ \\
\hline 52 & 4-METHYL-TRANS-2-PENTENE & 674760 & $\mathrm{C} 6 \mathrm{H} 12$ \\
\hline 53 & C5H6 & & $\mathrm{C} 5 \mathrm{H} 6$ \\
\hline 54 & $\mathrm{C} 5 \mathrm{H} 8$ & & $\mathrm{C} 5 \mathrm{H} 8$ \\
\hline 55 & ${ }^{* * *}$ UNKNOWN ${ }^{* \star *}$ & & $\mathrm{C} 6 \mathrm{H} 12$ \\
\hline 57 & ${ }^{* * *}$ UNKNOWN ${ }^{* * *}$ & & $\mathrm{C} 6 \mathrm{H} 12$ \\
\hline 58 & 3-METHYLPENTANE & 96140 & $\mathrm{C} 6 \mathrm{H} 14$ \\
\hline 59 & 2-METHYL-1-PENTENE & 763291 & $\mathrm{C} 6 \mathrm{H} 12$ \\
\hline 60 & 1-HEXENE & 592416 & $\mathrm{C} 6 \mathrm{H} 12$ \\
\hline 62 & 2-ETHYL-1-BUTENE & 760214 & $\mathrm{C} 6 \mathrm{H} 12$ \\
\hline 63 & N-HEXANE & 110543 & $\mathrm{C} 6 \mathrm{H} 14$ \\
\hline 64 & CIS-3-HEXENE & 7642093 & $\mathrm{C} 6 \mathrm{H} 12$ \\
\hline 64.501 & TRANS-3-HEXENE & 13269528 & $\mathrm{C} 6 \mathrm{H} 12$ \\
\hline 65 & TRANS-2-HEXENE & 405045 & $\mathrm{C} 6 \mathrm{H} 12$ \\
\hline 66 & 2-METHYL-2-PENTENE & 625274 & $\mathrm{C} 6 \mathrm{H} 12$ \\
\hline 66.501 & 3-METHYLCYCLOPENTENE & 1120623 & $\mathrm{C} 6 \mathrm{H} 10$ \\
\hline 67 & CIS-3-METHYL-2-PENTENE & 922623 & $\mathrm{C} 6 \mathrm{H} 12$ \\
\hline 68 & 4-METHYLCYCLOPENTENE & 1759815 & $\mathrm{C} 6 \mathrm{H} 10$ \\
\hline 69 & CIS-2-HEXENE & 7688213 & $\mathrm{C} 6 \mathrm{H} 12$ \\
\hline 70 & $\mathrm{C} 6 \mathrm{H} 10$ & & $\mathrm{C} 6 \mathrm{H} 10$ \\
\hline 72 & TRANS-3-METHYL-2-PENTENE & 616126 & $\mathrm{C} 6 \mathrm{H} 12$ \\
\hline 72.501 & 2,2-DIMETHYLPENTANE & 590352 & $\mathrm{C} 7 \mathrm{H} 16$ \\
\hline 73 & METHYLCYCLOPENTANE & 96377 & $\mathrm{C} 6 \mathrm{H} 12$ \\
\hline 76 & 2,4-DIMETHYLPENTANE & 108087 & $\mathrm{C} 7 \mathrm{H} 16$ \\
\hline 76.501 & 2,3-DIMETHYL-2-BUTENE & 563791 & $\mathrm{C} 6 \mathrm{H} 12$ \\
\hline 76.502 & ${ }^{\star \star *}$ UNKNOWN & & \\
\hline
\end{tabular}

\begin{tabular}{|c|c|c|c|}
\hline $\begin{array}{l}\text { Compound } \\
\text { Number }\end{array}$ & $\begin{array}{l}\text { Compound } \\
\text { Name }\end{array}$ & $\begin{array}{l}\text { CAS } \\
\text { Number }\end{array}$ & Formula \\
\hline & 2,2,3-TRIMETHYLBUTANE & 464062 & $\mathrm{C} 7 \mathrm{H} 16$ \\
\hline 78 & $\mathrm{C} 6 \mathrm{H} 8$ & & $\mathrm{C} 6 \mathrm{H} 8$ \\
\hline 79 & $\mathrm{C} 7 \mathrm{H} 12$ & & $\mathrm{C} 7 \mathrm{H} 12$ \\
\hline 79.501 & *** UNKNOWN *** & & \\
\hline 80 & 2,4-DIMETHYL-1-PENTENE & 2213323 & $\mathrm{C} 7 \mathrm{H} 12$ \\
\hline 80.501 & ${ }^{\star \star \star}$ UNKNOWN & & \\
\hline 81 & 1-METHYLCYCLOPENTENE & 693890 & $\mathrm{C} 6 \mathrm{H} 10$ \\
\hline 82 & BENZENE & 71432 & $\mathrm{C} 6 \mathrm{H} 6$ \\
\hline 83 & 4,4-DIMETHYL-2-PENTENE & 26232984 & $\mathrm{C} 7 \mathrm{H} 14$ \\
\hline 84 & 3,3-DIMETHYLPENTANE & 562492 & $\mathrm{C} 7 \mathrm{H} 16$ \\
\hline 84.501 & ${ }^{* * *}$ UNKNOWN & & \\
\hline 85 & TRANS-2-METHYL-3-HEXENE & 692240 & $\mathrm{C} 7 \mathrm{H} 14$ \\
\hline 86 & CYCLOHEXANE & 110827 & $\mathrm{C} 6 \mathrm{H} 12$ \\
\hline 88 & $\mathrm{C} 7 \mathrm{H} 14$ & & $\mathrm{C} 7 \mathrm{H} 14$ \\
\hline 89 & 4-METHYL-1-HEXENE & 3769231 & $\mathrm{C} 7 \mathrm{H} 14$ \\
\hline 91 & TRANS-4-METHYL-2-HEXENE & 3683225 & $\mathrm{C} 7 \mathrm{H} 14$ \\
\hline 92 & 2-METHYLHEXANE & 591764 & $\mathrm{C} 7 \mathrm{H} 16$ \\
\hline 93 & 2,3-DIMETHYLPENTANE & 565593 & $\mathrm{C} 7 \mathrm{H} 16$ \\
\hline 94 & ${ }^{* * *}$ UNKNOWN & & $\mathrm{C} 7 \mathrm{H} 14$ \\
\hline 95 & 1,1-DIMETHYLCYCLOPENTANE & 1638262 & $\mathrm{C} 7 \mathrm{H} 14$ \\
\hline 96 & 3-METHYLHEXANE & 58934 & $\mathrm{C} 7 \mathrm{H} 16$ \\
\hline 96.501 & CYCLOHEXENE & 110838 & $\mathrm{C} 6 \mathrm{H} 10$ \\
\hline 97 & TRANS-5-METHYL-2-HEXENE & 7385822 & $\mathrm{C} 7 \mathrm{H} 14$ \\
\hline 97.501 & ${ }^{\star * \star}$ UNKNOWN ${ }^{\star \star \star *}$ & & \\
\hline 98 & CIS-1,3-DIMETHYLCYCLOPENTANE & 2532583 & $\mathrm{C} 7 \mathrm{H} 14$ \\
\hline 99 & TRANS-1,3-DIMETHYLCYCLOPENTANE & 1759586 & $\mathrm{C} 7 \mathrm{H} 14$ \\
\hline 100 & TRANS-1,2-DIMETHYLCYCLOPENTANE & 822504 & $\mathrm{C} 7 \mathrm{H} 14$ \\
\hline 101 & 3,4-DIMETHYL-TRANS-2-PENTENE & 4914925 & $\mathrm{C} 7 \mathrm{H} 14$ \\
\hline 102 & ISO-OCTANE & 540841 & $\mathrm{C} 8 \mathrm{H} 18$ \\
\hline 103 & 3-METHYL-TRANS-3-HEXENE & 3899363 & $\mathrm{C} 7 \mathrm{H} 14$ \\
\hline 104 & TRANS-3-HEPTENE & 14686147 & $\mathrm{C} 7 \mathrm{H} 14$ \\
\hline 105 & N-HEPTANE & 142825 & $\mathrm{C} 7 \mathrm{H} 16$ \\
\hline 106 & CIS-3-METHYL-3-HEXENE & 491489 & $\mathrm{C} 7 \mathrm{H} 14$ \\
\hline 108 & TRANS-2-HEPTENE & 14686136 & $\mathrm{C} 7 \mathrm{H} 14$ \\
\hline 109 & 3-ETHYL-2-PENTENE & 816795 & $\mathrm{C} 7 \mathrm{H} 14$ \\
\hline 109.501 & $\mathrm{C} 7 \mathrm{H} 12$ & & $\mathrm{C} 7 \mathrm{H} 12$ \\
\hline 110 & 2-METHYL-2-HEXENE & 2738194 & $\mathrm{C} 7 \mathrm{H} 14$ \\
\hline 111 & 1,5-DIMETHYLCYCLOPENTENE & 16491159 & $\mathrm{C} 7 \mathrm{H} 12$ \\
\hline 111.5 & CIS-2-HEPTENE & 6443921 & $\mathrm{C} 7 \mathrm{H} 14$ \\
\hline 111.501 & 2,3-DIMETHYL-2-PENTENE & 10574375 & $\mathrm{C} 7 \mathrm{H} 14$ \\
\hline 111.502 & 3-ETHYL CYCLOPENTENE & 694359 & $\mathrm{C} 7 \mathrm{H} 14$ \\
\hline 112 & 4-ETHYL CYCLOPENTENE & & $\mathrm{C} 7 \mathrm{H} 12$ \\
\hline 112.5 & 2,2-DIMETHYLHEXANE & 590738 & $\mathrm{C} 8 \mathrm{H} 18$ \\
\hline 112.501 & 1-CIS-2-DIMETHYLCYCLOPENTANE & 1192183 & $\mathrm{C} 7 \mathrm{H} 14$ \\
\hline 113 & METYHLCYCLOHEXANE & 108872 & $\mathrm{C} 7 \mathrm{H} 14$ \\
\hline 114 & 1,1,3-TRIMETHYLCYCLOPENTANE & & $\mathrm{C} 8 \mathrm{H} 16$ \\
\hline 115 & $\mathrm{C} 8 \mathrm{H} 14$ & & $\mathrm{C} 8 \mathrm{H} 14$ \\
\hline 116 & $\mathrm{C} 8 \mathrm{H} 14$ & & $\mathrm{C} 8 \mathrm{H} 14$ \\
\hline 118 & 2,5-DIMETHYLHEXANE & 592132 & $\mathrm{C} 8 \mathrm{H} 18$ \\
\hline 119 & 2,4-DIMETHYLHEXANE & 589435 & $\mathrm{C} 8 \mathrm{H} 18$ \\
\hline 119.501 & 2,2,3-TRIMETHYLPENTANE & 564023 & $\mathrm{C} 8 \mathrm{H} 18$ \\
\hline 119.502 & 3-METHYLCYCLOHEXENE & 591480 & $\mathrm{C} 7 \mathrm{H} 12$ \\
\hline 119.503 & 4-METHYLCYCLOHEXENE & 591479 & $\mathrm{C} 7 \mathrm{H} 12$ \\
\hline 120 & 1,2,4-TRIMETHYLCYCLOPENTANE & 16883480 & $\mathrm{C} 8 \mathrm{H} 16$ \\
\hline 120.501 & 3,3-DIMETHYLHEXANE & 563166 & $\mathrm{C} 8 \mathrm{H} 18$ \\
\hline 121 & $\mathrm{C} 8 \mathrm{H} 16$ & & $\mathrm{C} 8 \mathrm{H} 16$ \\
\hline 122 & $\mathrm{C} 8 \mathrm{H} 14$ & & $\mathrm{C} 8 \mathrm{H} 14$ \\
\hline 123 & C,T,C-1,2,3-TRIMETHYLCYCLOPENTANE & 15890401 & $\mathrm{C} 8 \mathrm{H} 16$ \\
\hline 124 & 2,3,4-TRIMETHYLPENTANE & 565753 & $\mathrm{C} 8 \mathrm{H} 18$ \\
\hline 125 & 1-ETHYLCYCLOPENTENE & 2146385 & $\mathrm{C} 7 \mathrm{H} 12$ \\
\hline 125.502 & 2,3,3-TRIMETHYLPENTANE & 560214 & $\mathrm{C} 8 \mathrm{H} 18$ \\
\hline 126 & TOLUENE & 108883 & $\mathrm{C} 7 \mathrm{H} 8$ \\
\hline 127 & 2,3-DIMETHYLHEXANE & 584941 & $\mathrm{C} 8 \mathrm{H} 18$ \\
\hline 127.501 & $\mathrm{C} 8 \mathrm{H} 14$ & & $\mathrm{C} 8 \mathrm{H} 14$ \\
\hline 128 & 2-METHYLHEPTANE & 592278 & $\mathrm{C} 8 \mathrm{H} 18$ \\
\hline 129 & 4-METHYLHEPTANE & 589537 & $\mathrm{C} 8 \mathrm{H} 18$ \\
\hline 130 & 3,4-DIMETHYLHEXANE & 583482 & $\mathrm{C} 8 \mathrm{H} 18$ \\
\hline 131 & 3-METHYLHEPTANE & 589811 & $\mathrm{C} 8 \mathrm{H} 18$ \\
\hline 131.501 & 3-ETHYLHEXANE & 619998 & $\mathrm{C} 8 \mathrm{H} 18$ \\
\hline 132 & 1,2,4-TRIMETHYLCYCLOPENTANE & & $\mathrm{C} 8 \mathrm{H} 16$ \\
\hline 133 & TRANS-1,4-DIMETHYLCYCLOHEXANE & 2207047 & $\mathrm{C} 8 \mathrm{H} 16$ \\
\hline 134 & 1,3-DIMETHYLCYCLOHEXANE & & $\mathrm{C} 8 \mathrm{H} 16$ \\
\hline
\end{tabular}


Compound Compound

Number Name 135 2,2,5-TRIMETHYLHEXANE

136 1-OCTENE

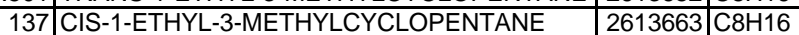

$138 \mathrm{C} 8 \mathrm{H} 16$

$139 \mathrm{C} 8 \mathrm{H} 16$

$140 \mathrm{C} 8 \mathrm{H} 16$

141 N-OCTANE

$142 \mathrm{C} 8 \mathrm{H} 16$

142.501 TRANS-1,2-DIMETHYLCYCLOHEXANE

143 1,1,2-TRIMETHYLCYCLOPENTANE

143.501 1,2,3-TRIMETHYLCYCLOPENTANE

$144 \mathrm{C} 8 \mathrm{H} 16$

145 2-OCTENE

146 ISOPROPYLCYCLOPENTANE

$147^{* \star *}$ UNKNOWN ***

\begin{tabular}{l|l}
148 & $2,3,5-T R I M E T H Y L H E X A N E$
\end{tabular}

$149 \mathrm{C} 8 \mathrm{H} 14$

160 2,4-DIMETHYLHEPTANE

$161 \mathrm{C} 8 \mathrm{H} 14$

162 2,6-DIMETHYLHEPTANE

163 n-PROPYLCYCLOPENTANE

165 2,5-DIMETHYLHEPTANE

165.501 3,5-DIMETHYLHEPTANE

$165.502 \mathrm{C} 9 \mathrm{H} 18$

166 1,1,4-TRIMETHYLCYCLOHEXANE

$167 \mathrm{C} 9 \mathrm{H} 18$

$167.501-\mathrm{C} 9 \mathrm{H} 18$

\begin{tabular}{ll}
167.502 & $\mathrm{C} 9 \mathrm{H} 16$ \\
\hline 167.503 & $\mathrm{CgH} 18$
\end{tabular}

$167.503 \mathrm{C} 9 \mathrm{H} 18$

168 ETHYLBENZENE

169 2,3-DIMETHYLHEPTANE

170 3,4-DIMETHYLHEPTANE

171 M\&P-XYLENE

174 3-METHYLOCTANE

$176 \mathrm{C} 9 \mathrm{H} 18$

$177 \mathrm{C} 10 \mathrm{H} 22$

177.501 STYRENE

178 1-NONENE

178.501 2-NONENE

179 O-XYLENE

180 4-NONENE

$182 \mathrm{C} 9 \mathrm{H} 18$

187 N-NONANE

$188 \mathrm{C} 9 \mathrm{H} 18$

$190 \mathrm{C9H} 18$

$193 \mathrm{C} 9 \mathrm{H} 18$

$194 \mathrm{C} 9 \mathrm{H} 18$

195 ISOPROPYLBENZENE

$196 \mathrm{C} 10 \mathrm{H} 22 ?$

$197 \mathrm{C} 10 \mathrm{H} 22 ?$

$197.501 \mathrm{C} 10 \mathrm{H} 22 ?$

198 n-BUTYLCYCLOPENTANE

$199 \mathrm{C} 10 \mathrm{H} 22$ ?

$200 \mathrm{C} 10 \mathrm{H} 22$

$201 \mathrm{C} 9 \mathrm{H} 18$

$202 \mathrm{C} 10 \mathrm{H} 22$ ?

$202.501^{\star \star \star}$ UNKNOWN $^{\text {***}}$

$203 \mathrm{C} 10 \mathrm{H} 20$

204 N-PROPYLBENZENE

206 1-METHYL-3-ETHYLBENZENE

207 1-METHYL-4-ETHYLBENZENE

209 1,3,5-TRIMETHYLBENZENE

$210 \mathrm{C} 10 \mathrm{H} 22$

$211 \mathrm{C} 10 \mathrm{H} 20$

$212 \mathrm{C} 10 \mathrm{H} 22$

$212.501 \mathrm{C} 10 \mathrm{H} 20$

213 1-METHYL-2-ETHYLBENZENE

$214 \mathrm{C} 10 \mathrm{H} 20$

$215 \mathrm{C} 10 \mathrm{H} 20$

$216 \mathrm{C} 10 \mathrm{H} 20$

217 o-METHYLSTYRENE
CAS

Number Formula

3522949 C9H20

\begin{tabular}{|l|l|}
2613652 & $\mathrm{C} 8 \mathrm{H} 16$ \\
\hline
\end{tabular}

\begin{tabular}{l|l}
\hline & $\mathrm{C} 8 \mathrm{H} 16$ \\
\hline & $\mathrm{C} 8 \mathrm{H} 16$ \\
\hline
\end{tabular}

$111659 \mathrm{C} 8 \mathrm{H} 18$

$\mathrm{C} 8 \mathrm{H} 16$

$2613696 \mathrm{C} 8 \mathrm{H} 16$

$\mathrm{C} 8 \mathrm{H} 16$

$3875512 \mathrm{C} 8 \mathrm{H} 16$

$\mathrm{C} 8 \mathrm{H} 16$

\begin{tabular}{l|l}
1069530 & $\mathrm{C} 9 \mathrm{H} 20$ \\
\hline
\end{tabular}

\begin{tabular}{l|l}
2213232 & $\mathrm{C} 9 \mathrm{H} 20$ \\
\hline
\end{tabular}

$1072055 \mathrm{C} 9 \mathrm{H} 20$

$2040962 \mathrm{C} 8 \mathrm{H} 16$

$2216300 \mathrm{C9H} 20$

$926829 \mathrm{C} 9 \mathrm{H} 20$

\begin{tabular}{ll}
$\mathrm{C} 9 \mathrm{H} 18$ \\
\hline
\end{tabular}

$\mathrm{C} 9 \mathrm{H} 18$

$\mathrm{C} 9 \mathrm{H} 18$

$\mathrm{C} 9 \mathrm{H} 18$

$\mathrm{C} 9 \mathrm{H} 16$

$\mathrm{C} 9 \mathrm{H} 18$

$100414 \mathrm{C} 8 \mathrm{H} 10$

$3074713 \mathrm{C} 9 \mathrm{H} 20$

$922281 \mathrm{C} 9 \mathrm{H} 20$

\begin{tabular}{l|l}
\hline 2216333 & $\mathrm{C} 8 \mathrm{H} 10$ \\
\hline
\end{tabular}

$\mathrm{C} 9 \mathrm{H} 18$

$\mathrm{C} 10 \mathrm{H} 22$

$100425 \mathrm{C} 8 \mathrm{H} 8$

$124118 \mathrm{C} 9 \mathrm{H} 18$ $\mathrm{C} 9 \mathrm{H} 18$

$95476 \mathrm{C} 8 \mathrm{H} 10$

$2198234 \mathrm{C9H} 18$

$111842 \mathrm{C} 9 \mathrm{H} 20$

$\mathrm{C} 9 \mathrm{H} 18$

$\mathrm{C} 9 \mathrm{H} 18$

$\mathrm{C} 9 \mathrm{H} 18$

$\mathrm{C} 9 \mathrm{H} 18$

$98828 \mathrm{C} 9 \mathrm{H} 12$

$\mathrm{C} 10 \mathrm{H} 22$

$\mathrm{C} 10 \mathrm{H} 22$

$\mathrm{C} 10 \mathrm{H} 22$

$\mathrm{C} 9 \mathrm{H} 18$

$\mathrm{C} 10 \mathrm{H} 22$

$\mathrm{C} 10 \mathrm{H} 22$

$\mathrm{C} 9 \mathrm{H} 18$

$\mathrm{C} 10 \mathrm{H} 22$

$\mathrm{C} 10 \mathrm{H} 22$

$\mathrm{C} 10 \mathrm{H} 20$

$620144 \mathrm{C} 9 \mathrm{H} 12$

$622968 \mathrm{C} 9 \mathrm{H} 12$

$\mathrm{C} 10 \mathrm{H} 22$

$\mathrm{C} 10 \mathrm{H} 20$

$\mathrm{C} 10 \mathrm{H} 22$

$\mathrm{C} 10 \mathrm{H} 20$

$611143 \mathrm{C} 9 \mathrm{H} 12$

$\mathrm{C} 10 \mathrm{H} 20$

$\mathrm{C} 10 \mathrm{H} 20$

$\mathrm{C} 10 \mathrm{H} 20$

\begin{tabular}{ll}
100801 & $\mathrm{C} 9 \mathrm{H} 10$ \\
\hline
\end{tabular}
$4259001 \mathrm{C} 8 \mathrm{H} 16$

$103651 \mathrm{C} 9 \mathrm{H} 12$

$108678 \mathrm{C} 9 \mathrm{H} 12$
Compound Compound

Number Name

218 1,2,4-TRIMETHYLBENZENE

218.501 m-METHYLSTYRENE

219 N-DECANE

$219.5 \mathrm{C} 10 \mathrm{H} 2 \mathrm{O}$

$219.501 \mathrm{C} 10 \mathrm{H} 20$

$219.502^{\star * \star}$ UNKNOWN $^{\star \star \star}$

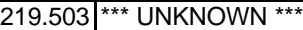

220 2-METHYLPROPYLBENZENE

221 1-METHYLPROPYLBENZENE

$222 \mathrm{C} 11 \mathrm{H} 24$

222.501 1-METHYL-3-ISOPROPYLBENZENE

$222.502 \mathrm{C} 11 \mathrm{H} 24$

222.503 p-METHYLSTYRENE

223 1,2,3-TRIMETHYLBENZENE

$224 \mathrm{C} 11 \mathrm{H} 24$

$224.501 \mathrm{C} 10 \mathrm{H} 2 \mathrm{O}$

224.502 C11H24

225 2,3-DIHYDROINDENE(INDAN)

$225.501 \mathrm{C} 10 \mathrm{H} 12$

$226 \mathrm{C} 10 \mathrm{H} 20$

227 1,3-DIETHYLBENZENE

229 1-METHYL-3-n-PROPYLBENZENE

229.501 1-METHYL-4-n-PROPYLBENZENE 230 1,2-DIETHYLBENZENE

230.501 n-BUTYLBENZENE

230.502 C11H24

$231 \mathrm{C} 11 \mathrm{H} 24$

231.501 1,4-DIETHYLBENZENE

$232 \mathrm{C} 11 \mathrm{H} 24$

232.501 1,3-DIMETHYL-5-ETHYLBENZENE 233 1-METHYL-2-n-PROPYLBENZENE

$233.501 \mathrm{C} 11 \mathrm{H} 24$

234 1,4-DIMETHYL-2-ETHYLBENZENE

235 1,3-DIMETHYL-4-ETHYLBENZENE

236 1,2-DIMETHYL-4-ETHYLBENZENE

236.501 o-ETHYLSTYRENE

237 1,3-DIMETHYL-2-ETHYLBENZENE

$237.501 \mathrm{~m}-\mathrm{ETHYLSTYRENE}$

$238 \mathrm{C} 10 \mathrm{H} 12$

$239 \mathrm{C} 11 \mathrm{H} 22$

240 n-UNDECANE

$240.501 \mathrm{C} 10 \mathrm{H} 12$

$241 \mathrm{C} 11 \mathrm{H} 16$

$241.501 \mathrm{C} 11 \mathrm{H} 16$

242 1,2-DIMETHYL-3-ETHYLBENZENE

$243 \mathrm{C} 11 \mathrm{H} 14$

$243.501 \mathrm{C} 12 \mathrm{H} 26$

245 1,2,4,5-TETRAMETHYLBENZENE

246 1,2,3,5-TETRAMETHYLBENZENE

$247 \mathrm{C} 12 \mathrm{H} 26$

$247.5011^{\star \star * *}$ UNKNOWN ${ }^{\text {***}}$

$249 \mathrm{C} 11 \mathrm{H} 16$

$250 \mathrm{C} 11 \mathrm{H} 16$

$252 \mathrm{C} 11 \mathrm{H} 16$

$255 \mathrm{C} 10 \mathrm{H} 12$

$256 \mathrm{C} 11 \mathrm{H} 16$

257 1-METHYL-1H-INDENE

$258 \mathrm{C} 10 \mathrm{H} 12$

$259 \mathrm{C} 11 \mathrm{H} 16$

$260 \mathrm{C} 11 \mathrm{H} 16$

$261 \mathrm{C} 11 \mathrm{H} 16$

$262 \mathrm{C} 10 \mathrm{H} 12$

$263 \mathrm{C} 11 \mathrm{H} 16$

$263.5011^{\star * \star}$ UNKNOWN ***

$265 \mathrm{C} 11 \mathrm{H} 14$

$267^{\star * \star}$ UNKNOWN $^{* \star \star}$

268 NAPHTHALENE

$268.501 \mathrm{C} 11 \mathrm{H} 14$

269 n-DODECANE

330 MTBE

340 METHANOL

341 ETHANOL
CAS

Number Formula

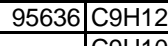

$\mathrm{C} 9 \mathrm{H} 10$

$124185 \mathrm{C} 10 \mathrm{H} 22$

$\mathrm{C} 10 \mathrm{H} 20$

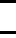

$538932 \mathrm{C} 10 \mathrm{H} 14$

$135988 \mathrm{C} 10 \mathrm{H} 14$

$\mathrm{C} 11 \mathrm{H} 24$

$535773 \mathrm{C} 10 \mathrm{H} 14$

$\mathrm{C} 11 \mathrm{H} 24$
$\mathrm{C} 9 \mathrm{H} 10$

$576738 \mathrm{C} 10 \mathrm{H} 14$

$\mathrm{C} 11 \mathrm{H} 24$

$\mathrm{C} 10 \mathrm{H} 20$

$\mathrm{C} 11 \mathrm{H} 24$

$496117 \mathrm{C} 9 \mathrm{H} 10$

$\mathrm{C} 10 \mathrm{H} 12$

$141935 \mathrm{C} 10 \mathrm{H} 14^{14}$

\begin{tabular}{l|l}
1074437 & $\mathrm{C} 10 \mathrm{H} 14$ \\
\hline
\end{tabular}

$1074551 \mathrm{C} 10 \mathrm{H} 14$

$135013 \mathrm{C} 10 \mathrm{H} 14$

$104518 \mathrm{C} 10 \mathrm{H} 14$

$\mathrm{C} 11 \mathrm{H} 24$

$\mathrm{C} 11 \mathrm{H} 24$

105055 C10H14

$\mathrm{C} 11 \mathrm{H} 24$

$\mathrm{C} 10 \mathrm{H} 14$

1074175 C10H14

$\mathrm{C} 11 \mathrm{H} 24$

$1758889 \mathrm{C} 10 \mathrm{H} 14$

$874419 \mathrm{C} 10 \mathrm{H} 14$

$934805 \mathrm{C} 10 \mathrm{H} 14$

2870044

$\mathrm{C} 10 \mathrm{H} 14$

$\mathrm{C} 10 \mathrm{H} 12$

$\mathrm{C} 10 \mathrm{H} 12$

$\mathrm{C} 11 \mathrm{H} 22$

$1120214 \mathrm{C} 11 \mathrm{H} 24$

$\mathrm{C} 10 \mathrm{H} 12$

$\mathrm{C} 11 \mathrm{H} 16$

$\mathrm{C} 11 \mathrm{H} 16$

$\mathrm{C} 10 \mathrm{H} 14$

$\mathrm{C} 11 \mathrm{H} 14$

$\mathrm{C} 12 \mathrm{H} 26$

$95932 \mathrm{C} 10 \mathrm{H} 14$

$527537 \mathrm{C} 10 \mathrm{H} 14$

$\mathrm{C} 12 \mathrm{H} 26$

$\mathrm{C} 11 \mathrm{H} 16$

$\mathrm{C} 11 \mathrm{H} 16$

$\mathrm{C} 11 \mathrm{H} 16$

$\mathrm{C} 10 \mathrm{H} 12$

\begin{tabular}{l|l}
5161046 & $\mathrm{C} 11 \mathrm{H} 16$
\end{tabular}

$767599 \mathrm{C} 10 \mathrm{H} 10$

$\mathrm{C} 10 \mathrm{H} 12$

$\mathrm{C} 11 \mathrm{H} 16$

$\mathrm{C} 11 \mathrm{H} 16$

$\mathrm{C} 11 \mathrm{H} 16$

$\mathrm{C} 10 \mathrm{H} 12$

$\mathrm{C} 11 \mathrm{H} 16$

C11H14

$\mathrm{C} 11 \mathrm{H} 16$

$91203 \mathrm{C} 10 \mathrm{H} 8$

$\mathrm{C} 11 \mathrm{H} 14$

$112403 \mathrm{C} 12 \mathrm{H} 26$

$1634044 \mathrm{C} 5 \mathrm{H} 12 \mathrm{O}$

$67561 \mathrm{CH} 4 \mathrm{O}$

108101 C $2 \mathrm{H} 6 \mathrm{O}$ 


\section{Appendix C: Speciated Data Sets}

C-1 
Table C-1. 1995 FFV Dodge Intrepid: M85 Tests at Lab 1

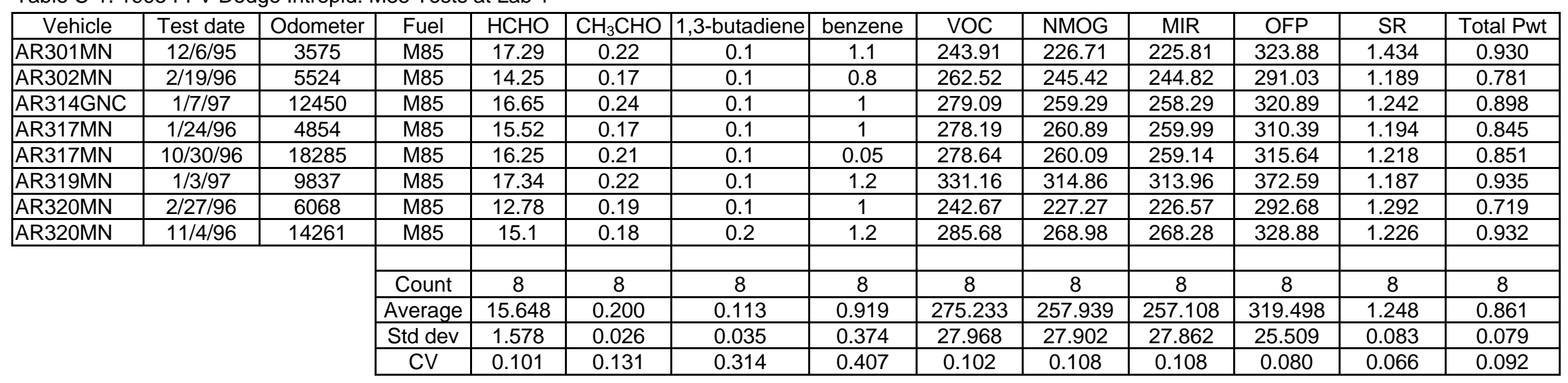

Table C-2. 1995 FFV Dodge Intrepid: RFG Tests at Lab 1

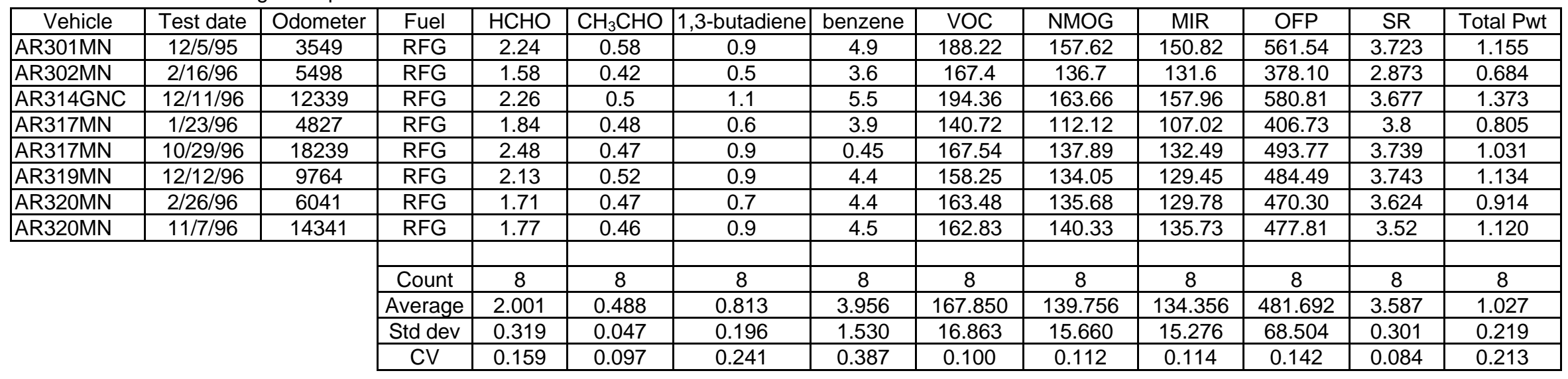

Table C-3. 1995 Standard Dodge Intrepid: RFG Tests at Lab 1

\begin{tabular}{|c|c|c|c|c|c|c|c|c|c|c|c|c|c|}
\hline Vehicle & Test date & Odometer & Fuel & $\mathrm{HCHO}$ & $\mathrm{CH}_{3} \mathrm{CHO}$ & 1,3-butadiene & benzene & VOC & NMOG & MIR & OFP & SR & Total Pwt \\
\hline AR304GNC & $8 / 6 / 96$ & 14546 & RFG & 1.96 & 0.51 & 0.75 & 0.375 & 136.61 & 114.26 & 110.36 & 410.78 & 3.724 & 0.855 \\
\hline AR305GNC & $6 / 21 / 95$ & 3906 & RFG & 1.88 & 0.3 & 0.6 & 3.9 & 138.58 & 111.28 & 106.98 & 375.32 & 3.508 & 0.806 \\
\hline AR305GNC & $9 / 26 / 96$ & 15883 & RFG & 2.29 & 0.52 & 0.9 & 4.3 & 150.51 & 122.41 & 118.11 & 448.18 & 3.795 & 1.139 \\
\hline DT308GNC & $11 / 21 / 95$ & 5021 & RFG & 1.35 & 0.37 & 0.6 & 3.3 & 123.22 & 103.02 & 99.32 & 350.82 & 3.532 & 0.764 \\
\hline DT308GNC & 9/3/96 & 13177 & RFG & 1.68 & 0.44 & 0.6 & 3.5 & 126.72 & 106.42 & 103.22 & 383.46 & 3.715 & 0.786 \\
\hline & & & Count & 7 & 7 & 7 & 7 & 7 & 7 & 7 & 7 & 7 & 7 \\
\hline & & & & 0.174 & 0.193 & 0.179 & 0.408 & 0.093 & 0.082 & 0.083 & 0.105 & 0.038 & 0.162 \\
\hline
\end{tabular}


Table C-4. 1993 FFV Dodge Spirit: M85 Tests at Lab 1

\begin{tabular}{|c|c|c|c|c|c|c|c|c|c|c|c|c|c|}
\hline Vehicle & Test date & Odomete & Fuel & $\mathrm{HCHO}$ & $\mathrm{CH} 3 \mathrm{CHO}$ & 1-3_but & benz & VOC & NMOG & MIR & OFP & SR & Total Pwt \\
\hline AR206MS & $11 / 21 / 94$ & 6735 & M85 & 9.28 & 0.17 & 0.1 & 1.3 & 187.85 & 177.25 & 176.9 & 221.52 & 1.252 & 0.567 \\
\hline DT219MS & $6 / 13 / 94$ & 17116 & M85 & 13.67 & 0.32 & 0.1 & 1.5 & 206.69 & 190.69 & 189.59 & 273.49 & 1.443 & 0.776 \\
\hline DT219MS & $6 / 22 / 95$ & 29679 & M85 & 17.29 & 0.23 & 0.1 & 1.4 & 233.02 & 217.02 & 216.02 & 323.53 & 1.498 & 0.939 \\
\hline DT221MS & $5 / 3 / 94$ & 11588 & M85 & 12.54 & 0.2 & 0.1 & 0.9 & 167.64 & 156.24 & 155.94 & 228.29 & 1.464 & 0.705 \\
\hline DT221MS & $3 / 16 / 95$ & 22320 & M85 & 12.69 & 0.2 & 0.1 & 1.1 & 231.69 & 220.59 & 219.39 & 280.98 & 1.281 & 0.718 \\
\hline DT226MSC & $6 / 2 / 94$ & 15299 & M85 & 18.74 & 0.39 & 0.1 & 0.05 & 199.67 & 188.42 & 187.67 & 254.63 & 1.372 & 0.967 \\
\hline & & & Count & 6 & 6 & 6 & 6 & 6 & 6 & 6 & 6 & 6 & 6 \\
\hline & & & Average & 14.035 & 0.252 & 0.100 & 1.042 & 204.427 & 191.702 & 190.918 & 263.740 & 1.385 & 0.779 \\
\hline & & & Std dev & 3.450 & 0.085 & 1.67E-09 & 0.531 & 25.364 & 24.305 & 23.971 & 37.655 & 0.101 & 0.152 \\
\hline & & & $\mathrm{CV}$ & 0.246 & 0.338 & 1.67E-08 & 0.510 & 0.124 & 0.127 & 0.126 & 0.143 & 0.073 & 0.195 \\
\hline
\end{tabular}

Table C-5. 1993 FFV Dodge Spirit: RFG Tests at Lab 1

\begin{tabular}{|c|c|c|c|c|c|c|c|c|c|c|c|c|c|}
\hline Vehicle & Test date & Odometer & Fuel & $\mathrm{HCHO}$ & $\mathrm{CH}_{3} \mathrm{CHO}$ & 1,3-butadiene & benzene & VOC & NMOG & MIR & OFP & $\mathrm{SR}$ & Total Pwt \\
\hline AR206MS & $11 / 22 / 94$ & 6769 & RFG & 1.23 & 0.39 & 0.8 & 4.7 & 110.22 & 94.52 & 91.72 & 364.76 & 3.977 & 1.001 \\
\hline DT219MS & $6 / 1 / 94$ & 16919 & RFG & 1.55 & 0.54 & 0.9 & 5 & 164.59 & 133.79 & 130.39 & 452.94 & 3.474 & 1.126 \\
\hline DT219MS & $6 / 20 / 95$ & 29653 & RFG & 2.01 & 0.45 & 0.9 & 4.8 & 233.02 & 217.02 & 216.02 & 323.53 & 1.498 & 1.140 \\
\hline DT221MS & $4 / 28 / 94$ & 11500 & RFG & 1.41 & 0.46 & 0.6 & 3.6 & 124.27 & 102.27 & 99.57 & 355.74 & 3.573 & 0.776 \\
\hline DT221MS & $3 / 13 / 95$ & 22279 & RFG & 1.29 & 0.39 & 0.7 & 3.9 & 231.69 & 220.59 & 219.39 & 280.98 & 1.281 & 0.879 \\
\hline DT226MSC & $6 / 1 / 94$ & 15257 & RFG & 2.63 & 0.7 & 0.9 & 4.4 & 172.53 & 142.63 & 138.63 & 505.82 & 3.649 & 1.159 \\
\hline & & & Count & & 6 & 0 & 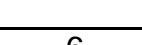 & $e_{0}$ & $c$ & 8 & 0 & 0 & 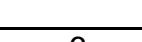 \\
\hline & & & Average & 1.687 & 0.488 & $\frac{0}{0800}$ & $\frac{0}{4.400}$ & $\frac{0}{172720}$ & $\frac{0}{15180}$ & $\frac{0}{14929}$ & $\frac{0}{38063}$ & $\begin{array}{c}0 \\
2909\end{array}$ & $\frac{0}{1013}$ \\
\hline & & & Std dev & 0.540 & 0.118 & 0.126 & 0.548 & 51.833 & 55.006 & 55.900 & 83.622 & 1.191 & 0.157 \\
\hline & & & $\mathrm{CV}$ & 0.320 & 0.241 & 0.158 & 0.124 & 0.300 & 0.362 & 0.374 & 0.220 & 0.409 & 0.155 \\
\hline
\end{tabular}

Table C-6. 1993 Standard Dodge Spirit: RFG Tests at Lab 1

\begin{tabular}{|c|c|c|c|c|c|c|c|c|c|c|c|c|c|}
\hline Vehicle & Test date & Odometer & Fuel & $\mathrm{HCHO}$ & $\mathrm{CH}_{3} \mathrm{CHO}$ & 1,3-butadiene & benzene & VOC & NMOG & MIR & OFP & SR & Total Pwt \\
\hline DT214GSC & $5 / 9 / 94$ & 10632 & RFG & 1.39 & 0.43 & 0.3 & 0.1 & 59.23 & 51.18 & 49.98 & 165.09 & 3.304 & 0.370 \\
\hline DT214GSC & $8 / 10 / 95$ & 32278 & RFG & 1.86 & 0.33 & 0.4 & 2 & 91.29 & 78.89 & 75.39 & 261.09 & 3.463 & 0.548 \\
\hline DT221GSC & $4 / 22 / 94$ & 8994 & RFG & 1.23 & 0.4 & 0.3 & 2.6 & 75.43 & 63.53 & 62.03 & 193.43 & 3.118 & 0.438 \\
\hline DT221GSC & $8 / 16 / 95$ & 23507 & RFG & 1.47 & 0.32 & 0.3 & 3.7 & 112.09 & 90.49 & 86.59 & 265.74 & 3.069 & 0.481 \\
\hline DT225GSC & $5 / 18 / 94$ & 13037 & RFG & 1.34 & 0.34 & 0.4 & 3.2 & 92.78 & 76.88 & 75.08 & 223.5 & 2.977 & 0.560 \\
\hline DT225GSC & $5 / 15 / 95$ & 25452 & RFG & 1.29 & 0.31 & 0.5 & 3.1 & 104.7 & 86.4 & 83.2 & 265.45 & 3.191 & 0.655 \\
\hline & & & & & & & & & & & & & \\
\hline & & & Count & 6 & 6 & 6 & 6 & 6 & 6 & 6 & 6 & 6 & 6 \\
\hline & & & Average & 1.430 & 0.355 & 0.367 & 2.450 & 89.253 & 74.562 & 72.045 & 229.05 & 3.187 & 0.509 \\
\hline & & & Std dev & 0.226 & 0.048 & 0.082 & 1.288 & 19.335 & 14.740 & 13.737 & 42.634 & 0.175 & 0.100 \\
\hline & & & CV & 0.158 & 0.137 & 0.223 & 0.526 & 0.217 & 0.198 & 0.191 & 0.186 & 0.055 & 0.198 \\
\hline
\end{tabular}


Table C-7. 1993 FFV Dodge Spirit: M85 Tests at Lab 3

\begin{tabular}{|l|c|c|c|c|c|c|c|c|c|c|c|c|c|}
\hline \multicolumn{1}{|c|}{ Vehicle } & Test date & Odometer & Fuel & HCHO & CH3CHO & $1-3$ but & benz & VOC & NMOG & MIR & OFP & SR & Total Pwt \\
\hline DV205MS & $10 / 18 / 95$ & 20922 & M85 & 11.5 & 0.5 & 0.2 & 1.9 & 255.1 & 234.6 & 233.23 & 340.83 & 1.461 & 0.79 \\
\hline DV206MS & $12 / 5 / 95$ & 15864 & M85 & 9.7 & 0.3 & 0.2 & 1.6 & 263.87 & 248.97 & 247.29 & 344.97 & 1.395 & 0.697 \\
\hline DV207MS & $10 / 3 / 95$ & 26750 & $M 85$ & 12.1 & 0.3 & 0.1 & 2 & 336.97 & 316.77 & 315.14 & 424.44 & 1.347 & 0.719 \\
\hline DV242MS & $2 / 8 / 95$ & 8746 & $M 85$ & 6.9 & 0.1 & 0.1 & 1 & 179.7 & 166.3 & 165.03 & 234.85 & 1.423 & 0.448 \\
\hline DV242MS & $2 / 27 / 96$ & 11346 & $M 85$ & 9 & 0.2 & 0.288 & 1.86 & 306.59 & 286.219 & 283.461 & 370.28 & 1.306 & 0.759 \\
\hline DV248MS & $11 / 7 / 95$ & 18349 & $M 85$ & 9.4 & 0.3 & 0.2 & 2.2 & 263.59 & 243.09 & 241.61 & 326.30 & 1.351 & 0.701 \\
\hline DV249MS & $2 / 2 / 95$ & 13241 & $M 85$ & 7.3 & 0.2 & 0.1 & 1.5 & 201.72 & 185.42 & 184.7 & 263.41 & 1.426 & 0.482 \\
\hline DV249MS & $11 / 28 / 95$ & 20873 & M85 & 11.9 & 0.3 & 0.2 & 1.5 & 277.98 & 259.08 & 257.31 & 356.22 & 1.384 & 0.795 \\
\hline
\end{tabular}

Table C-8. 1993 FFV Dodge Spirit: RFG Tests at Lab 3

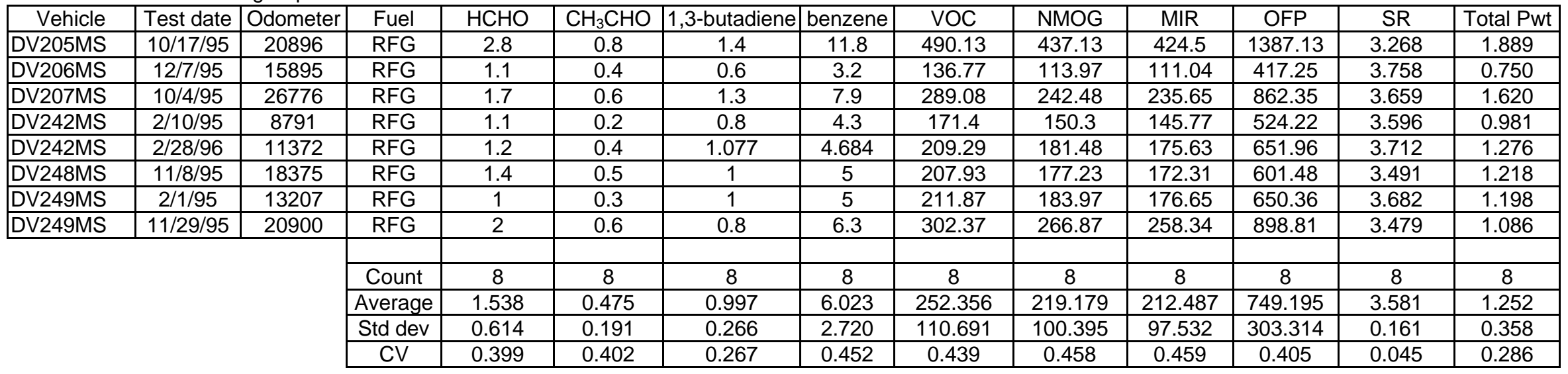

Table C-9. 1993 Standard Dodge Spirit: RFG Tests at Lab 3

\begin{tabular}{|c|c|c|c|c|c|c|c|c|c|c|c|c|c|}
\hline Vehicle & Test & Odometer & Fuel & $\mathrm{HCHO}$ & $\mathrm{CH}_{3} \mathrm{CHO}$ & 1,3-butadiene & benzene & VOC & NMOG & MIR & OFP & SR & Total Pwt \\
\hline DV212GSC & $2 / 23 / 95$ & 9467 & RFG & 0.7 & 0.1 & 0.3 & 1.8 & 86.27 & 74.77 & 72.54 & 223.95 & 3.087 & 0.387 \\
\hline DV212GSC & $1 / 31 / 96$ & 13560 & RFG & 1 & 0.3 & 0.192 & 2.758 & 108.76 & 88.761 & 85.711 & 270.98 & 3.162 & 0.323 \\
\hline DV213GSC & $10 / 6 / 95$ & 34397 & RFG & 1.6 & 0.4 & 0.3 & 2.6 & 109.68 & 97.08 & 95.06 & 296.41 & 3.118 & 0.455 \\
\hline DV225GSC & $10 / 11 / 95$ & 30953 & RFG & 1.1 & 0.5 & 0.2 & 2.3 & 113.02 & 100.42 & 98.89 & 291.70 & 2.950 & 0.324 \\
\hline DV226GSC & $2 / 15 / 95$ & 9051 & RFG & 0.5 & 0.1 & 0.2 & 2.3 & 86.94 & 75.44 & 74.12 & 246.22 & 3.322 & 0.293 \\
\hline DV226GSC & $2 / 20 / 96$ & 13090 & RFG & 0.9 & 0.2 & 0.236 & 1.786 & 84.25 & 73.031 & 71.069 & 221.50 & 3.117 & 0.333 \\
\hline & & & Std dev & 0.329 & 0.139 & 0.046 & 0.379 & 12.381 & 10.922 & 10.925 & 31.440 & 0.126 & 0.056 \\
\hline & & & $\mathrm{CV}$ & 0.342 & 0.505 & 0.202 & 0.173 & 0.128 & 0.130 & 0.134 & 0.123 & 0.040 & 0.164 \\
\hline
\end{tabular}


Table C-10. 1994/95 FFV Ford Taurus: E85 Tests at Lab 1

\begin{tabular}{|l|c|c|c|c|c|c|c|c|c|c|c|c|c|}
\hline Vehicle & Test_dat & Odometer & Fuel & $\mathrm{HCHO}$ & $\mathrm{CH}_{3} \mathrm{CHO}$ & 1,3 -butadiene & benzene & VOC & NMOG & MIR & OFP & SR & Total Pwt \\
\hline AR317ET & $11 / 11 / 96$ & 8211 & E85 & 2 & 10.25 & 0.2 & 1.1 & 195.94 & 166.34 & 165.84 & 372.92 & 2.249 & 0.407 \\
\hline AR318ET & $5 / 15 / 95$ & 3077 & E85 & 2.09 & 9.34 & 0.1 & 1 & 148.03 & 129.23 & 128.63 & 271.91 & 2.114 & 0.301 \\
\hline AR318ET & $10 / 16 / 96$ & 11104 & E85 & 2.26 & 9.71 & 0.2 & 1.3 & 220.86 & 199.36 & 198.46 & 426.05 & 2.147 & 0.421 \\
\hline AR320ET & $11 / 15 / 96$ & 9713 & E85 & 1.73 & 9.24 & 0.1 & 1.1 & 190.99 & 163.39 & 162.79 & 356.21 & 2.188 & 0.287 \\
\hline AR325ET & $9 / 13 / 95$ & 3406 & E85 & 2.26 & 7.83 & 0.2 & 1 & 149.59 & 125.09 & 124.59 & 288.84 & 2.318 & 0.397 \\
\hline AR325ET & $8 / 29 / 96$ & 15178 & E85 & 2.55 & 13.2 & 0.2 & 0.1 & 243.82 & 215.52 & 214.37 & 473.36 & 2.209 & 0.426 \\
\hline AR326ET & $10 / 6 / 95$ & 17016 & E85 & 2.81 & 8.83 & 0.2 & 1 & 177.54 & 145.34 & 144.54 & 343.14 & 2.374 & 0.430 \\
\hline AR334ET & $10 / 17 / 95$ & 9133 & E85 & 2.08 & 10.43 & 0.2 & 1.5 & 264.91 & 231.51 & 230.21 & 488.22 & 2.121 & 0.424 \\
\hline
\end{tabular}

Table C-11. 1994/95 FFV Ford Taurus: RFG Tests at Lab 1

\begin{tabular}{|c|c|c|c|c|c|c|c|c|c|c|c|c|c|}
\hline Vehicle & Test & Odometer & Fuel & $\mathrm{HCHO}$ & $\mathrm{CH}_{3} \mathrm{CHO}$ & 1,3 -butadiene & benzene & VOC & NMOG & MIR & OFP & SR & Total Pwt \\
\hline AR317ET & $11 / 20 / 96$ & 8355 & RFG & 1.1 & 0.28 & 0.6 & 2.6 & 95.63 & 83.53 & 80.93 & 300.19 & 3.709 & 0.731 \\
\hline AR318ET & $5 / 12 / 95$ & 3051 & RFG & 1.06 & 0.22 & 0.5 & 2.6 & 88.78 & 80.38 & 77.28 & 271.96 & 3.519 & 0.629 \\
\hline AR318ET & $10 / 10 / 96$ & 11042 & RFG & 1.24 & 0.31 & 0.6 & 3.5 & 120.09 & 107.59 & 103.99 & 370.17 & 3.56 & 0.765 \\
\hline AR320ET & $11 / 12 / 96$ & 9645 & RFG & 0.95 & 0.19 & 0.6 & 2.9 & 104.52 & 92.02 & 89.12 & 316.62 & 3.553 & 0.732 \\
\hline AR325ET & $9 / 14 / 95$ & 3432 & RFG & 1.31 & 0.29 & 0.5 & 2.4 & 87.9 & 77.4 & 74.8 & 271.16 & 3.625 & 0.635 \\
\hline AR325ET & $8 / 14 / 96$ & 15012 & RFG & 1.4 & 0.38 & 0.55 & 3.4 & 119.04 & 105.59 & 101.99 & 369.74 & 3.632 & 0.719 \\
\hline AR326ET & $10 / 5 / 95$ & 16990 & RFG & 2.23 & 0.34 & 0.6 & 2.9 & 124.07 & 108.97 & 105.17 & 362.43 & 3.446 & 0.792 \\
\hline AR334ET & $10 / 13 / 95$ & 9107 & RFG & 1.11 & 0.19 & 0.4 & 2.6 & 94.2 & 82.9 & 79.6 & 282.23 & 3.546 & 0.531 \\
\hline & & & & & & & & & & & & & \\
\hline
\end{tabular}

Table C-12. 1995 Standard Ford Taurus: RFG Tests at Lab 1

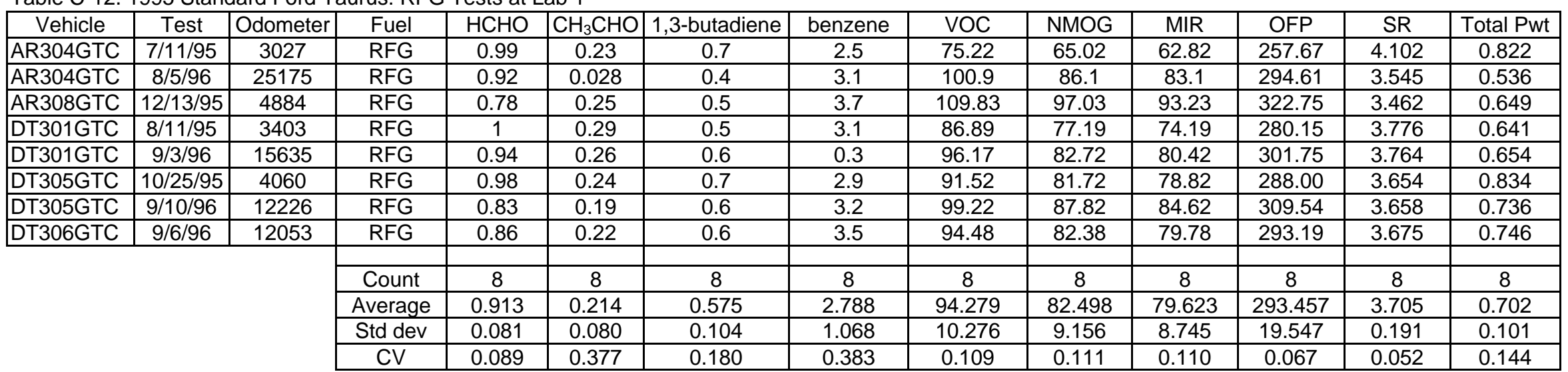


Table C-13. 1992/94 CNG Dodge B250 Van: CNG Tests at Lab 1

\begin{tabular}{|c|c|c|c|c|c|c|c|c|c|c|c|c|c|}
\hline Vehicle & Test & Odometer & Fuel & $\mathrm{HCHO}$ & $\mathrm{CH}_{3} \mathrm{CHO}$ & 1,3-butadiene & benzene & VOC & NMOG & MIR & OFP & SR & Total Pwt \\
\hline $\mathrm{OH} 301 \mathrm{CR}$ & 8/2/95 & 5508 & CNG & 1.860 & 0.150 & 0 & 0.1 & 384.51 & 19.11 & 19.01 & 40.361 & 2.123 & 0.090 \\
\hline $\mathrm{OH} 301 \mathrm{CR}$ & $1 / 15 / 97$ & 13434 & CNG & 2.120 & 0.160 & 0 & 0 & 321.38 & 22.48 & 22.48 & 47.237 & 2.101 & 0.099 \\
\hline $\mathrm{OH} 305 \mathrm{CR}$ & $12 / 10 / 96$ & 11503 & CNG & 2.540 & 0.210 & 0 & 0 & 488.07 & 30.17 & 30.17 & 69.66 & 2.31 & 0.119 \\
\hline $\mathrm{OH} 305 \mathrm{CR}$ & $12 / 2 / 96$ & 11457 & CNG & 2.320 & 0.150 & 0 & 0.2 & 329.15 & 24.05 & 24.05 & 60.726 & 2.525 & 0.114 \\
\hline Average & & & & 2.430 & 0.180 & 0 & 0.1 & 408.61 & 27.11 & 27.11 & 65.193 & 2.4175 & 0.116 \\
\hline OH307CR & $12 / 10 / 96$ & 9014 & CNG & 1.440 & 0.160 & 0 & 0 & 224.7 & 16.3 & 16.3 & 33.54 & 2.058 & 0.068 \\
\hline $\mathrm{OH} 308 \mathrm{CR}$ & $1 / 28 / 97$ & 12246 & CNG & 1.540 & 0.110 & 0 & 0.1 & 328.65 & 24.75 & 24.75 & 39.683 & 1.6034 & 0.075 \\
\hline & & & Count & 5 & 5 & & 5 & 5 & 5 & 5 & 5 & 5 & 5 \\
\hline & & & Average & 1.878 & 0.152 & & 0.060 & 333.570 & 21.950 & 21.930 & 45.203 & 2.061 & 0.089 \\
\hline & & & Std dev & 0.409 & 0.026 & & 0.055 & 71.154 & 4.322 & 4.339 & 12.183 & 0.292 & 0.019 \\
\hline & & & CV & 0.218 & 0.170 & & 0.913 & 0.213 & 0.197 & 0.198 & 0.270 & 0.142 & 0.217 \\
\hline
\end{tabular}

Table C-14. 1992 Standard Dodge B250 Van: RFG Tests at Lab 1

\begin{tabular}{|c|c|c|c|c|c|c|c|c|c|c|c|c|c|}
\hline Vehicle & Test & Odometer & Fuel & $\mathrm{HCHO}$ & $\mathrm{CH}_{3} \mathrm{CHO}$ & 1,3-butadiene & benzene & VOC & NMOG & MIR & OFP & SR & Total Pwt \\
\hline AR301GRC & $8 / 15 / 95$ & 36218 & RFG & 6.120 & 1.110 & 2.0 & 12.4 & 385.63 & 313.93 & 300.43 & 1177.30 & 3.9187 & 2.662 \\
\hline AR301GRC & $8 / 28 / 97$ & 60261 & RFG & 4.900 & 1.100 & 2.0 & 14.7 & 455.00 & 367.50 & 353.00 & 1207.66 & 3.421 & 2.675 \\
\hline DT303GRC & $9 / 21 / 95$ & 34217 & RFG & 5.660 & 0.950 & 1.9 & 11.0 & 351.21 & 280.81 & 270.81 & 1063.27 & 3.926 & 2.498 \\
\hline DT303GRC & $1 / 31 / 97$ & 51772 & RFG & 5.920 & 1.340 & 2.6 & 17.0 & 520.28 & 429.68 & 414.28 & 1642.58 & 3.965 & 3.393 \\
\hline DT303GRC & $1 / 24 / 97$ & 51733 & RFG & 7.130 & 1.550 & 2.4 & 18.1 & 492.86 & 410.86 & 396.86 & 1556.16 & 3.921 & 3.283 \\
\hline Average & & & & 6.525 & 1.445 & 2.5 & 17.55 & 506.57 & 420.27 & 405.57 & 1599.37 & 3.943 & 3.338 \\
\hline DT304GRC & $10 / 10 / 97$ & 40152 & RFG & 5.500 & 1.230 & 2.1 & 15.1 & 466.93 & 389.93 & 372.33 & 1478.97 & 3.972 & 2.816 \\
\hline & & & Count & 5 & 5 & 5 & 5 & 5 & 5 & 5 & 5 & 5 & 5 \\
\hline & & & Average & 5.741 & 1.167 & 2.100 & 14.15 & 433.07 & 354.49 & 340.43 & 1305.31 & 3.836 & 2.798 \\
\hline & & & Std dev & 0.619 & 0.184 & 0.235 & 2.537 & 63.209 & 56.626 & 54.465 & 224.238 & 0.233 & 0.322 \\
\hline & & & $\mathrm{CV}$ & 0.108 & 0.158 & 0.112 & 0.179 & 0.146 & 0.160 & 0.160 & 0.172 & 0.061 & 0.115 \\
\hline
\end{tabular}


Table C-15. 1992/94 CNG Dodge B250 Van: CNG Tests at Lab 3

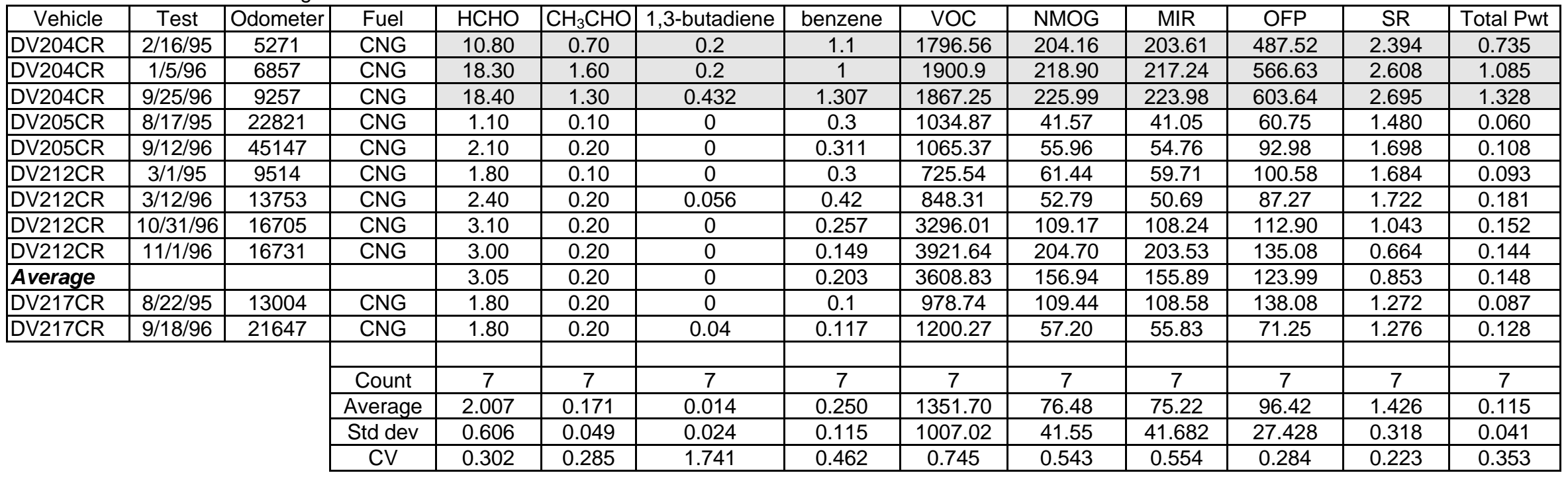

Table C-16. 1992 Standard Dodge B250 Van: RFG Tests at Lab 3

\begin{tabular}{|c|c|c|c|c|c|c|c|c|c|c|c|c|c|}
\hline Vehicle & Test & Odometer & Fuel & $\mathrm{HCHO}$ & $\mathrm{CH}_{3} \mathrm{CHO}$ & 1,3-butadiene & benzene & VOC & NMOG & MIR & OFP & SR & Total Pwt \\
\hline DV209GRC & $9 / 24 / 96$ & 15482 & RFG & 0.161 & 0.008 & 2.103 & 12.302 & 354.083 & 297.728 & 289.33 & 1158.44 & 4.004 & 2.641 \\
\hline DV209GRC & 9/26/96 & 15508 & RFG & 0.1702 & 0.008 & 1.589 & 12.373 & 351.19 & 299.999 & 292.04 & 1135.27 & 3.887 & 2.138 \\
\hline \begin{tabular}{|l|} 
Average \\
\end{tabular} & & & & 0.1656 & 0.008 & 1.846 & 12.338 & 352.637 & 298.864 & 290.68 & 1146.85 & 3.946 & 2.390 \\
\hline DV214GRC & $4 / 27 / 95$ & 7287 & RFG & 0.1058 & 0.0048 & 2.00 & 9.50 & 345.12 & 299.42 & 290.45 & 1164.62 & 4.010 & 2.396 \\
\hline DV214GRC & 9/17/96 & 10361 & RFG & 0.1886 & 0.0096 & 2.231 & 13.087 & 399.445 & 345.673 & 336.86 & 1340.67 & 3.980 & 2.822 \\
\hline DV215GRC & $8 / 24 / 95$ & 11392 & RFG & 0.1288 & 0.0056 & 1.80 & 10.30 & 375.69 & 319.59 & 309.58 & 1270.01 & 4.102 & 2.243 \\
\hline DV215GRC & $10 / 15 / 96$ & 17452 & RFG & 0.1932 & 0.0088 & 1.743 & 9.326 & 349.045 & 295.312 & 286.96 & 1181.32 & 4.117 & 2.225 \\
\hline & & & Count & 9 & 9 & 9 & 9 & 9 & 9 & 9 & 9 & 9 & 9 \\
\hline & & & Average & 0.159 & 0.008 & 1.985 & 11.179 & 367.971 & 308.723 & 300.022 & 1208.927 & 4.031 & 2.488 \\
\hline & & & Std dev & 0.029 & 0.002 & 0.195 & 1.416 & 27.051 & 21.203 & 21.301 & 81.864 & 0.096 & 0.229 \\
\hline & & & CV & 0.184 & 0.245 & 0.098 & 0.127 & 0.074 & 0.069 & 0.071 & 0.068 & 0.024 & 0.092 \\
\hline
\end{tabular}


Appendix D:

Emissions Data Compilation, Editing, and Reduction and

the Analysis of Variance Approach to Statistical

Treatment of Emissions Data 
Raw data files of the emissions tests from each laboratory were submitted electronically and then loaded into the Alternative Fuels Data Center at NREL. Before any data analysis was conducted, checks and edits were undertaken to ensure data quality. In particular, the data were reviewed for the presence of outliers. To begin this review process, the data sets were sorted by vehicle type, test fuel, and test round. At the first level of data quality checks, the replicate test results were evaluated. An initial set of replicate tests was conducted on some vehicles to provide information about test repeatability. Additional replicated tests were performed on vehicles that exceeded the EPA emissions certification standards. A comparison of the replicate results helped to identify some individual test results as outliers. These results were then eliminated from further consideration (although, as described below, the established outlier detection procedure involved more than these replicate test results).

The four-stage procedure outlined below was used to identify and eliminate outliers in the exhaust emissions test results, and to compile the final data sets for statistical analysis. No evaporative emissions results were removed from the data sets because of the high level of variability in typical evaporative emissions.

1. Stage One (Replicate Analysis)—For each emissions constituent (e.g., $\mathrm{NO}_{\mathrm{x}}$ ), all pairs of replicated test results were first considered. The absolute value of the difference between each pair was computed, and the mean and standard deviation of all such differences were also computed. Individual differences outside a bound equal to the mean plus three standard deviations were flagged as excessive. The two test results from each of the flagged pairs were then reviewed, and the one result in each pair furthest from the overall mean was designated as an outlier and eliminated. For all other pairs (those not flagged as excessive), the two test results were simply averaged to produce a single result. In this manner, the overall data set was reduced to a single value per vehicle type/fuel/test round for each emissions constituent.

2. Stage Two (Among-Vehicle Data Quality Checks)—Having a single set of values for each vehicle type/fuel/test round, it was then necessary to compare the results for each combination of the three (e.g., Dodge Spirit, M85, round 1). Consequently, for every vehicle type/fuel/test round combination, the mean and the standard deviation of each emissions constituent were computed. Individual vehicle values outside a bound of the mean plus or minus three standard deviations were designated as outliers and removed from further consideration.

3. Stage Three (Checks Among Emissions Constituents, or Total Vehicle Viability)-Depending on the emissions constituent in question, the application of the edits performed in Stage Two left a number of "holes" in the data. In some cases, the process resulted in multiple holes (more than one emissions constituent missing) for a given test. Because each hole is the result of an emissions test value being designated as an outlier, tests (for a given fuel/test round combination) having two or more holes on major emissions constituents $\left(\mathrm{HC}, \mathrm{NO}_{\mathrm{x}}\right.$, and $\left.\mathrm{CO}\right)$ were deemed to be "not viable" and were completely eliminated from further consideration.

4. Stage Four (Data Reduction for Multiple Rounds) - Finally, for purposes of this particular report, only the results on vehicles tested in all rounds (for a particular model/fuel combination) were retained for data analysis purposes (Note: some vehicles were not tested in all rounds for a number of reasons. For example, some failed the pre-test maintenance checks and were returned to the agencies, and some were retired from service by GSA before all rounds of testing could be completed).

Analysis of variance (ANOVA) was the principal statistical technique used to analyze the emissions data presented in this report. Whereas the t-test-one of the most frequently applied statistical procedures - is used to assess the significance of differences in pairs of mean values, ANOVA facilitates simultaneous assessment of multiple differences among a collection of two or more means (see, for example, Table D-1). 
Table D-1. Example Table of Mean Values

\begin{tabular}{|l|l|l|l|}
\cline { 2 - 4 } \multicolumn{1}{c|}{} & Round 1 & Round 2 & Round 3 \\
\hline Fuel 1 & -11 & -12 & -13 \\
\hline Fuel 2 & -21 & -22 & -23 \\
\hline
\end{tabular}

Note: See below for explanation of "fuel" and "round." _ stands for the mean value of some emissions constituent of interest (e.g., CO). ${ }_{-11^{-}{ }_{2} 3}$ is an example of one possible difference in mean values.

ANOVA is even more useful in that it allows the total variation in a set of data (as measured by the sum of squared deviations from a mean value) to be subdivided into the portions that are attributable to various experimental or observational factors. In this manner, the contributions of various factors to the observed variability in some test result, laboratory response, or property of interest, can be identified and quantified, along with the effects of such factors interacting among themselves.

In the context of the emissions testing program discussed in this report, the experimental factors assumed to generate differences in test results are: (1) fuel (alternative fuel versus gasoline); (2) round (a proxy for mileage); (3) laboratory (three different laboratories chosen through competitive bidding and employing the same test procedures; one of the three at high altitude); and (4) vehicle model (Dodge Caravan, Chevy Lumina, etc.). In addition, differences among individual vehicles of the same model contribute to the total variation in emissions test results, with random sampling resulting in such differences. Although other factors may affect variability in emissions, these are not explicitly controlled in the test program. Contributions to the total variation from these factors cannot be determined.

The arithmetic computations of analysis of variance, which are explained in textbooks on statistical methods, are usually summarized in a tabular form like the one shown in Table D-2. The first column in the table identifies the experimental factors, or sources of variation, while the second lists the corresponding numbers associated with a quantity called the "degrees of freedom." Typically, the degrees of freedom associated with a particular factor consist of the number of "levels" of that factor minus one (or in the case of the category labeled "Total," the overall number of observations or test results minus one). 
Table D-2. General Form of an ANOVA Table

\begin{tabular}{|l|l|l|l|l|l|}
\hline Source & $\begin{array}{l}\text { Degrees of } \\
\text { Freedom }\end{array}$ & $\begin{array}{l}\text { Sums of } \\
\text { Squares }\end{array}$ & $\begin{array}{l}\text { Mean } \\
\text { Squares }\end{array}$ & F-Value & $\begin{array}{l}\text { Significance } \\
\text { Level }\end{array}$ \\
\hline Total & $\mathrm{n}-1$ & $*$ & & & \\
\hline Factor A & $\mathrm{a}-1$ & $*$ & $*$ & $*$ & $*$ \\
\hline Factor B & $\mathrm{b}-1$ & $*$ & $*$ & $*$ & $*$ \\
\hline$\ldots$. & $\ldots$ & $*$ & $*$ & $*$ & $*$ \\
\hline Factor Z & $\mathrm{z}-1$ & $*$ & $*$ & $*$ & $*$ \\
\hline Remainder $^{1}$ & $(\mathrm{n}-1)-(\mathrm{a}-1)-(\mathrm{b}-1)-\ldots-(\mathrm{z}-1)$ & $*$ & $*$ & & \\
\hline
\end{tabular}

*Values to be computed.

"In many cases, "Remainder" is denoted as "Error," which, depending on the context of the analysis, can be either experimental error or sampling error.

Note: $\mathrm{n}$ is the total number of observations; $\mathrm{a}$ is the number of levels of Factor $\mathrm{A}, \mathrm{b}$ is the number of levels of Factor B, etc.

The third column lists a series of intermediate calculations, referred to as "sums of squares," which are associated with the respective factors or sources of variation. "Sums of squares" is abbreviated wording for "sum of squared deviations from the mean," which is the basic calculation needed for computing a statistical variance. The sums of squares associated with the different factors in Table D-2 below the "Total" line must, of necessity, add up to the sum of squares shown on the "Total" line (this is the additive property of ANOVA).

The fourth column in Table D-2 lists a series of numbers referred to as the "mean squares." The mean squares associated with the respective factors or sources of variation are computed by dividing the corresponding sum of squares by the corresponding degrees of freedom. It is these mean squares that are actual variances.

The fifth column in the table contains a series of numbers under the heading of "F-Value." These numbers are determined by taking ratios of the mean squares associated with various factors. The numbers in this column are referred to as F-values because they adhere to a special probability distribution called the F-distribution.

The sixth and final column in the table lists probability values that can be used to assess the size of the corresponding F-values (or ratios of "mean squares"). These are often referred to as "Significance Levels."

Typical ANOVA tables based on some of the data presented in this report is shown in Tables D-3 and D-4.

Once the experimental factors, or sources of variation, have been accurately identified, the calculations necessary to complete an ANOVA table are relatively straightforward. Software products such as JMP, available from SAS Institute, make it possible to avoid the algebraic tedium that would otherwise be required to compute all the numbers. Interpreting the results is quite a different matter. To make an appropriate interpretation, we must consider the population of units to which statistical inferences are to be drawn. In addition, we must determine which factors are to be regarded as "fixed" and which are "random."

Table D-3. ANOVA in CO Measurements Obtained in Emissions Tests on Flexible-Fuel Dodge Intrepids

\begin{tabular}{|l|l|l|l|l|l|}
\hline Source & $\begin{array}{l}\text { Degrees of } \\
\text { Freedom }\end{array}$ & $\begin{array}{l}\text { Sums of } \\
\text { Squares }\end{array}$ & $\begin{array}{l}\text { Mean } \\
\text { Squares }\end{array}$ & F-Value & $\begin{array}{l}\text { Significance } \\
\text { Level }^{4}\end{array}$ \\
\hline Total & 59 & 1.5431 & & & \\
\hline Rounds & 1 & 0.2926 & 0.2926 & 10.1715 & 0.0066 \\
\hline Fuels & 1 & 0.0150 & 0.0150 & 1.1894 & 0.2939 \\
\hline
\end{tabular}




\begin{tabular}{|l|l|l|l|l|l|}
\hline Round x Fuel $^{1}$ & 1 & 0.0023 & 0.0023 & 0.2306 & 0.6385 \\
\hline \multicolumn{1}{|c|}{ Vehicles $^{2}$} & 14 & 0.5149 & 0.0368 & 1.1669 & 0.3941 \\
\hline Vehicle x Round $^{2}$ & 14 & 0.4027 & 0.0288 & 2.9077 & 0.0275 \\
\hline Vehicle x Fuel & 14 & 0.1771 & 0.0127 & 1.2783 & 0.3261 \\
\hline Error & 14 & 0.1385 & 0.0099 & & \\
\hline
\end{tabular}

Factor interaction terms

${ }^{4}$ Values of .05 or less would ordinarily indicate significant differences. For example, the significance level of 0.0066 associated with the F-value for "Rounds" indicates that the same average value of $\mathrm{CO}$ was not obtained in both test rounds.

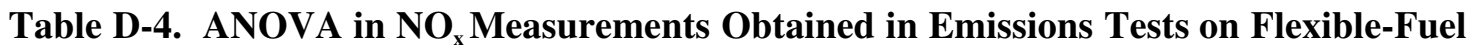
Dodge Spirits

\begin{tabular}{|l|l|l|l|l|l|}
\hline Source & $\begin{array}{l}\text { Degrees of } \\
\text { Freedom }\end{array}$ & $\begin{array}{l}\text { Sums of } \\
\text { Squares }\end{array}$ & $\begin{array}{l}\text { Mean } \\
\text { Squares }\end{array}$ & F-Value & $\begin{array}{l}\text { Significance } \\
\text { Level }^{4}\end{array}$ \\
\hline Total & 83 & 1.2592 & & & \\
\hline Rounds & 1 & 0.0074 & 0.0074 & 0.4901 & 0.4920 \\
\hline Fuels & 1 & 0.0031 & 0.0031 & 0.2444 & 0.6264 \\
\hline Round x Fuel & 1 & 0.0500 & 0.0500 & 17.5905 & 0.0004 \\
\hline Vehicles $^{1}$ & 20 & 0.5851 & 0.0293 & 1.1708 & 0.3381 \\
\hline Vehicle x Round $^{2}$ & 20 & 0.3032 & 0.0152 & 5.3304 & 0.0002 \\
\hline Vehicle x Fuel $^{2}$ & 20 & 0.2534 & 0.0127 & 4.4551 & 0.0008 \\
\hline Error & 20 & 0.0569 & 0.0028 & & \\
\hline
\end{tabular}

${ }_{1,2,3}$ Factor interaction terms

${ }^{4}$ Values of .05 or less would ordinarily indicate significant differences. For example, the significance level of 0.0004 associated with the F-value for the "Round $x$ Fuel" interaction indicates that the difference in the average values of $\mathrm{NO}_{\mathrm{x}}$ for the two fuels was not the same from one test round to the next.

Fixed factors are those whose range of values, or levels, are completely encompassed by the specific population units included in the investigation. In the context of the this emissions testing study, "fuel" is a fixed experimental factor because there is not interest in, nor rationale for, drawing conclusions about fuels other than those being specifically studied. A random factor, on the other hand, is one about which conclusions can be extended to a larger collection of units than the ones specifically included in the investigation. In this context, "vehicle" is a random factor because individual vehicles were randomly selected from a larger collection, or population, and projecting the results of the testing program to that larger population is desirable. The determination of fixed and random factors governs the way the F-values are computed (that is, the choice of numerator and denominator in the ratio of mean squares; the denominator always represents an "error" term against which the numerator is compared) and directly affects interpretation of the results. The bigger the F-value, the more likely at least one difference among the means being compared is statistically significant.

ANOVA's statistical procedure is constructed on certain mathematical assumptions. The first assumption - that effects of the various experimental factors are additive-has already been mentioned (in the sense that the individual sums of squares add up to the total). The second assumption is that all experimental errors are random, independent, and follow a normal (Gaussian, or bell-shaped) distribution. Violating either of these assumptions will negate the interpretability of the results.

Statistical software packages such as JMP provide many other capabilities that extend and build on the information derived from the basic ANOVA. In particular, it is possible to estimate the actual components of variance attributable to each experimental factor, and to adjust mean values for unequal numbers of observations using a least squares approach. The details of these techniques are beyond the scope of this discussion. 


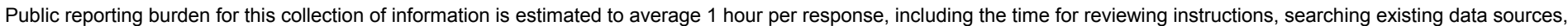

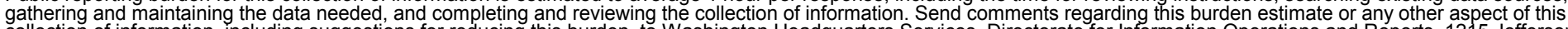

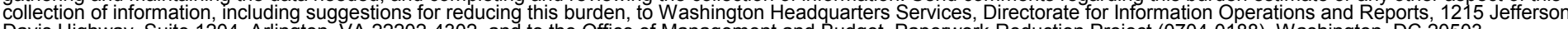
Davis Highway, Suite 1204, Arlington, VA 22202-4302, and to the Office of Management and Budget, Paperwork Reduction Project (0704-0188), Washington, DC 20503.

\begin{tabular}{|l|l|l} 
1. AGENCY USE ONLY (Leave blank) & $\begin{array}{l}\text { 2. REPORT DATE } \\
\text { September } 1999\end{array}$ & $\begin{array}{l}\text { 3. REPORT TYPE AND DATES COVERED } \\
\text { Technical report }\end{array}$ \\
\hline
\end{tabular}

\section{TITLE AND SUBTITLE}

Light-Duty Alternative Fuel Vehicles: Federal Test Procedure Emissions Results

6. AUTHOR(S)

Kenneth Kelly, Leslie Eudy, and Timothy Coburn

7. PERFORMING ORGANIZATION NAME(S) AND ADDRESS(ES)

National Renewable Energy Laboratory

1617 Cole Blvd.

Golden, CO 80401

9. SPONSORING/MONITORING AGENCY NAME(S) AND ADDRESS(ES)

U.S. Department of Energy

1000 Independence Avenue, SW

Washington, D.C. 20585

\section{SUPPLEMENTARY NOTES}

\section{2a. DISTRIBUTION/AVAILABILITY STATEMENT}

National Technical Information Service

U.S. Department of Commerce

5285 Port Royal Road

Springfield, VA 22161
5. FUNDING NUMBERS

(C)

(TA) FU905010

8. PERFORMING ORGANIZATION REPORT NUMBER

NREL/TP-540-25818

10. SPONSORING/MONITORING AGENCY REPORT NUMBER

2b. DISTRIBUTION CODE

UC-1504

\section{ABSTRACT (Maximum 200 words)}

In support of the U.S. Department of Energy's development and deployment of alternative fuels for environmental and national security reasons, NREL has managed a series of light-duty vehicle emissions tests on alternative fuel vehicles (AFVs). The purpose of this report is to give a detailed evaluation of the final emissions test results on vehicles tested on methanol, ethanol, and compressed natural gas.

\section{SUBJECT TERMS}

15. NUMBER OF PAGES

Alternative fuel vehicles (AFVs), emissions, emissions testing, methanol, ethanol, and compressed natural gas

\begin{tabular}{l|l}
$\begin{array}{l}\text { 17. SECURITY CLASSIFICATION } \\
\text { OF REPORT }\end{array}$ & $\begin{array}{l}\text { 18. SECURITY CLASSIFICATION } \\
\text { OF THIS PAGE } \\
\text { Unclassified }\end{array}$ \\
\hline
\end{tabular}

19. SECURITY CLASSIFICATION
OF ABSTRACT
Unclassified

20. LIMITATION OF ABSTRACT UL

NSN 7540-01-280-5500

Standard Form 298 (Rev. 2-89) Prescribed by ANSI Std. Z39-18 